\title{
Risk attitude, risk perceptions and risk management strategies: an empirical analysis of Syrian wheat-cotton and pistachio farmers
}

\author{
Dissertation \\ to obtain the $\mathrm{Ph}$. $\mathrm{D}$. degree \\ in the International Ph. D. Program for Agricultural Sciences in \\ Göttingen (IPAG) \\ at the Faculty of Agricultural Sciences, \\ Georg-August-University Göttingen, Germany
}

presented by

Mohamad Isam Nabil Almadani

born in Algeria

from Homs, Syria

Göttingen, March 2014 
D7

1. Name of supervisor: Prof. Dr. Ludwig Theuvsen

2. Name of co-supervisor: Prof. Dr. Jörg Michael Greef

Date of dissertation: May the $22^{\text {nd }}, 2014$ 
DEDICATED TO THE SOUL OF MY FATHER AND THE SYRIAN REVOLUTION MARTYRS 
FOR MY MOTHER MAY ALLAH GRANT HER LONG LIFE 
FOR MY LOVE, DR. HANADI ALJABI AND

MY LOVELY DAUGHTERS: HANIN AND MARIAM 
FOR MY SISTERS RIM AND FAHEMAH MY BROTHERS JAMAL AND ABDULRAHIM MAJZOB 


\section{Acknowledgments}

First of all I am indebted for the success in my research to Our Merciful "ALLAH” Who always gives me the ability to do my work.

I would like to express my deep gratitude to my supervisor Prof. Dr. Ludwig Theuvsen, the Chair of Management in Agribusiness at Göttingen University for his patient supervision, guidance, kindness, and encouragement throughout the entire period of my study. I never forget his word "I am optimistic". I am optimistic that you are able to collect the required data, I am optimistic that you will build the appropriate model and statistical analysis, I am optimistic that you are able to submit your thesis in the deadline.

I am grateful to my second supervisor Prof. Dr. Jörg Michael Greef at Julius KühnInstitut (JKI), Braunschweig, who provided me an acceptance letter to achieve my $\mathrm{PhD}$ in Germany.

I am greatly indebted to my best friend Dr. Walid Soufan, who advised me to achieve my PhD study in Göttingen, and patiently support me during my first days in Germany.

I would like to show my thankfulness to many people in the department of agricultural economics and rural development-Göttingen University, for their advice, encouragement and support, which was invaluable for the successful completion of this work. I would like to thank my third examiner, Prof. Dr. Stephan v.Cramon-Taubadel, the Chair of Agricultural Policy and Prof. Dr. Bernhard Brümmer, the Chair of Agricultural Market Analysis at Göttingen University for agreeing to be the examiner in my final disputation. Gratitude to Prof. Dr. Elke Pawelzik, the Chair of Plant Product for many supports for me and my wife during our scientific life in Göttingen.

I would also like to thank all my colleagues in the department of Management in Agribusiness at Göttingen University, for their support and encouragement during my doctoral studies as well for creating such friendly atmosphere. In the following, some of them who have made this work possible are gratefully acknowledged. First, I would like to thank Dr. Christian Schaper for his closer supervision and encouragement throughout the entire period of my study. I would like to thank my colleagues Dr. Maike Kayser, Martina Reichmann, Maria Näther, Janina Müller and Tuba Pekkirbizli. 
I would like to thank Dr. Hamad Muhketer and his brothers from Al Hasakah-Syria for their invaluable help with collecting data from wheat-cotton area. I would like to show my thankfulness to Mr. Abo Jasin, Mr. Awoad and Mr. Abdulkarim Barakat who guided me through the research areas. A lot of thanks also for Mr. Abo Farag Muhketer for the kind hospitality in his house in Al Hasakah - Syria.

Thankfulness to my friends in Göttingen who helped me during the thesis reviewing procedure, Dr. Mudawi Mukhtar Elobeid, Dr. Salamah Alwahsh and Dr. Nizar Aouni.

Finally, I am grateful to all relatives and friends who pray for me to achieve my $\mathrm{PhD}$. 


\section{Table of contents}

\section{ACKNOWLEDGMENTS}

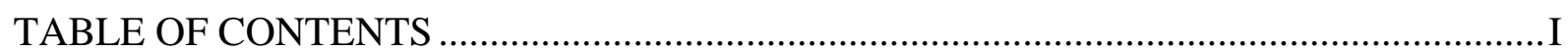

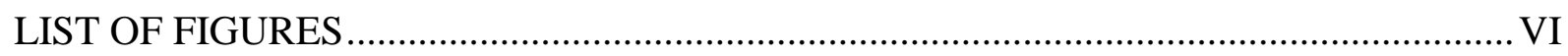

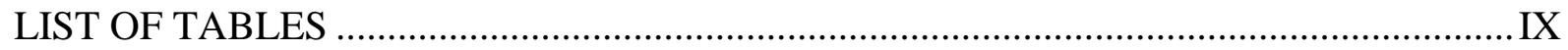

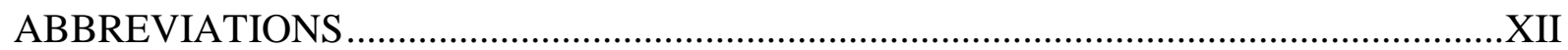

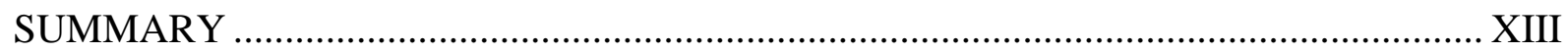

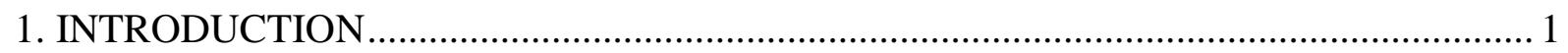

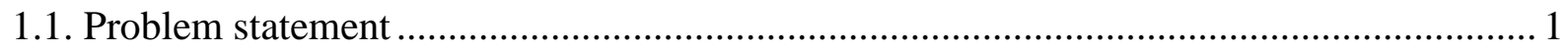

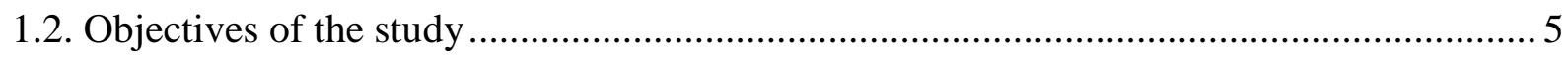

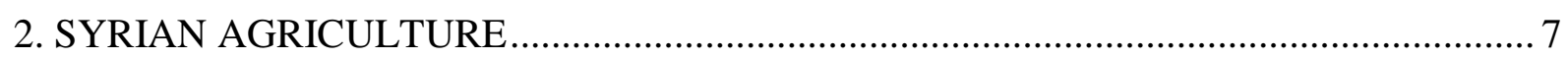

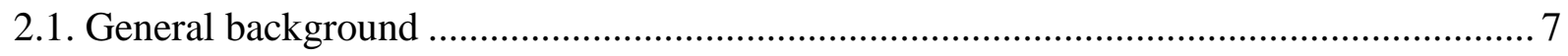

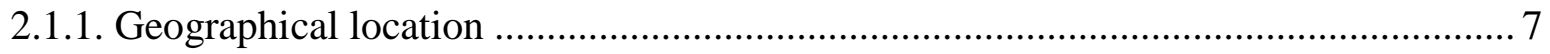

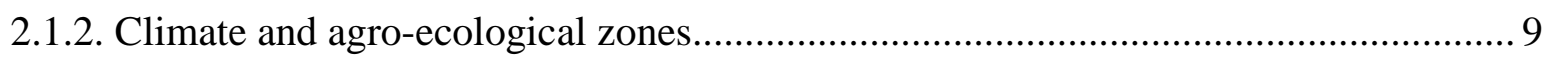

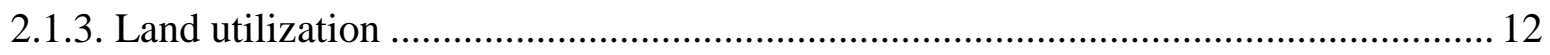

2.2 Role of the agricultural sector in the Syrian economy ................................................. 14

2.3 Policies affecting agricultural production in Syria...................................................... 19

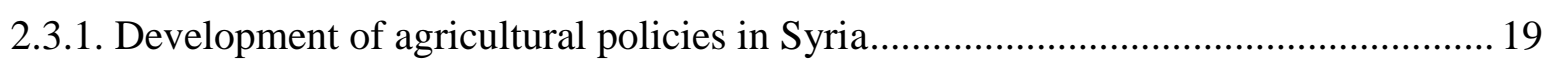

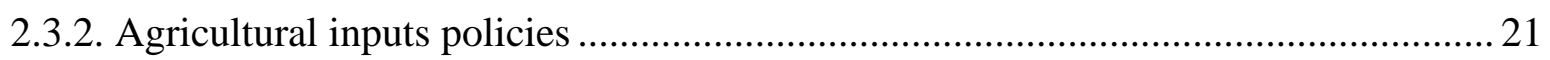

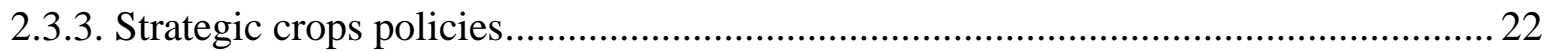




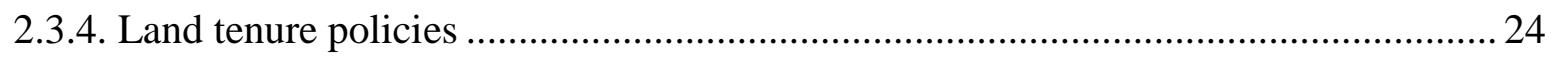

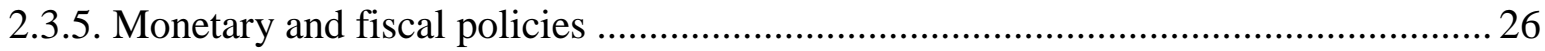

2.3.5.1. Exchange rate (ER) and currency policies .................................................... 26

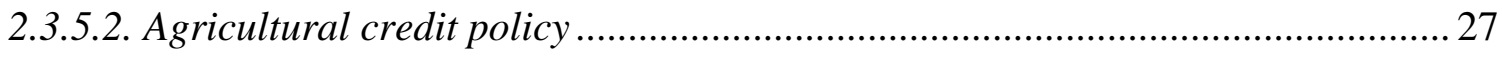

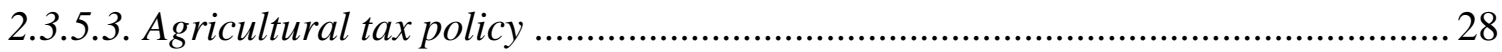

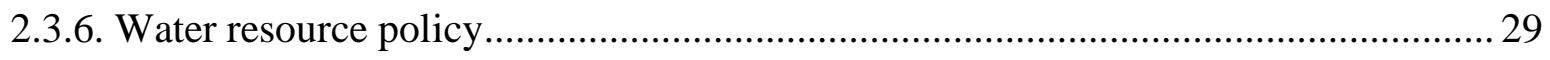

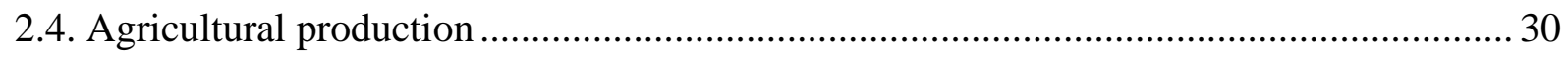

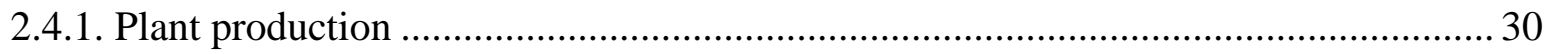

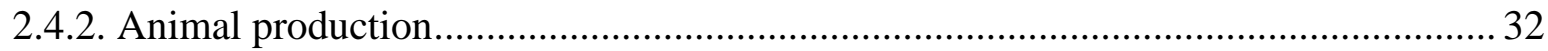

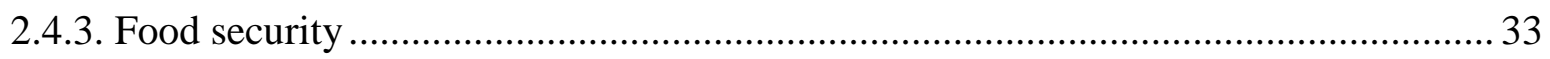

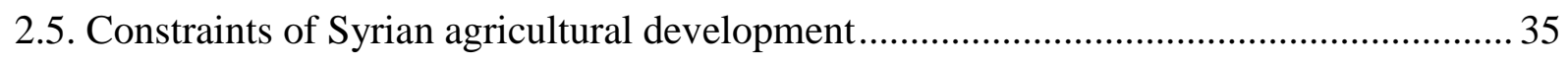

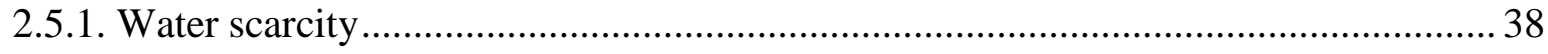

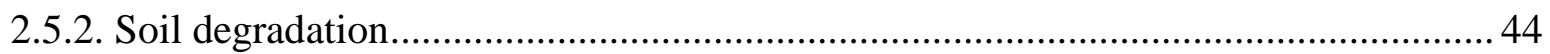

2.5.2.1. Wind Erosion ............................................................................................... 45

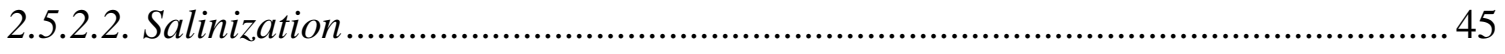

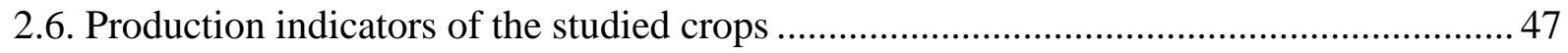

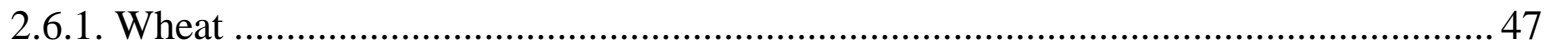

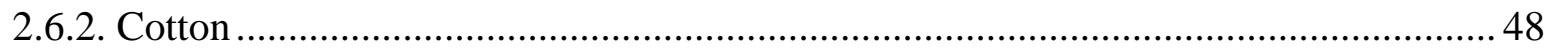

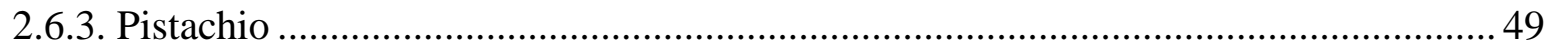

3. GENERAL APPROACHES TO AGRICULTURAL RISK MANAGEMENT .................. 51

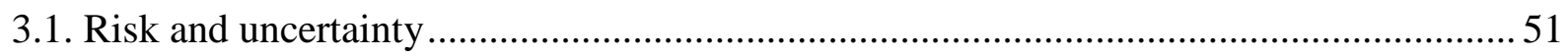


3.2. Risk sources in agriculture

3.2.1. Farmers perceptions of risk sources 54

3.3. Risk management in agriculture. 55

3.3.1. Risk management process 55

3.3.2. Risk management strategy 59

3.3.3. Farmers’ preferences of risk management strategies 60

3.4. Risk attitude.

3.5. Determinants of farmers' attitudes and perceptions 65

4. EMPIRICAL ANALYSIS BY QUESTIONNAIRES ON WHEAT-COTTON AND PISTACHIO FARMS

4.1. Conceptual framework

4.2. Research methodology 72

4.2.1. Questionnaire design 72

4.2.2. Study location. .75

4.2.3. Sampling... .76

4.2.4. Data limitation 77

4.3. Data analysis 78

4.3.1. Factor analysis .79

4.3.2. Multiple regression analysis 80

5. RESULTS AND DISCUSSION

5.1. Socio-economic characteristics of the interviewed farmers. .82 


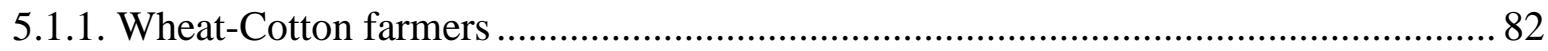

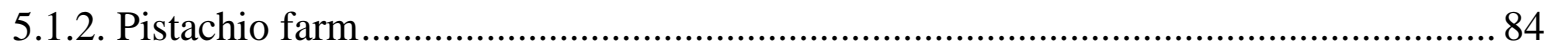

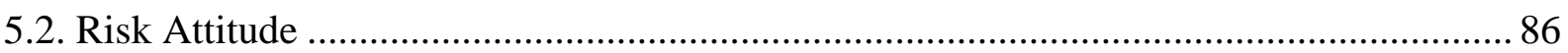

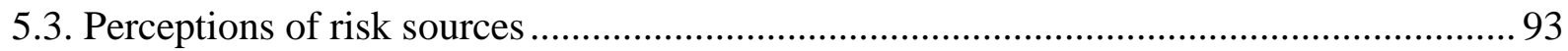

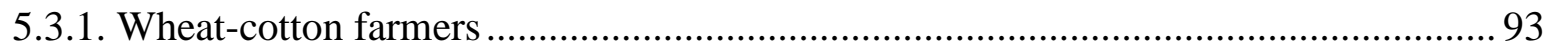

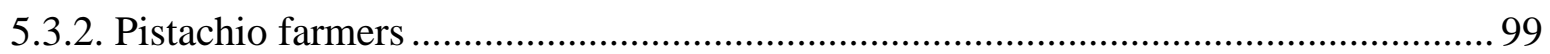

5.4. Perceptions of risk management strategies ............................................................. 103

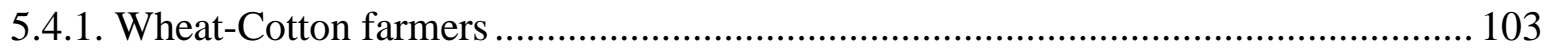

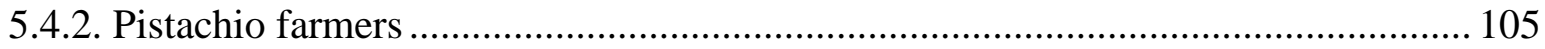

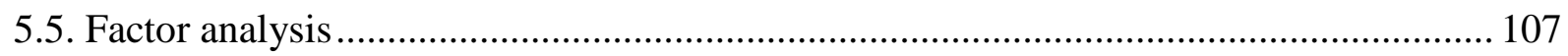

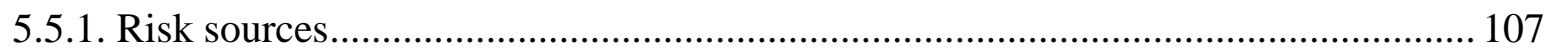

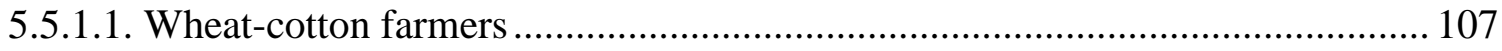

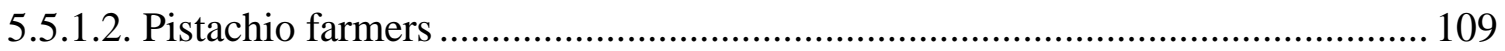

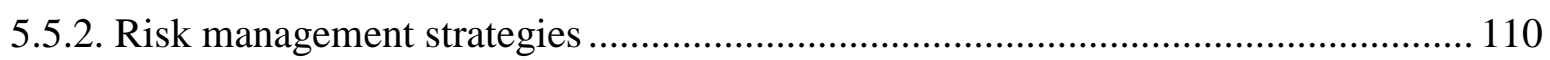

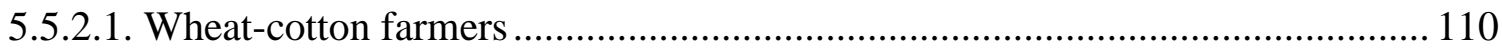

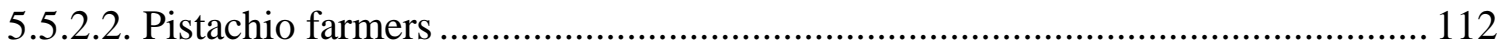

5.6. Determinants of attitudes and perceptions based on socio-economic characteristics ..... 113

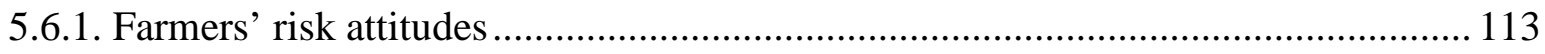

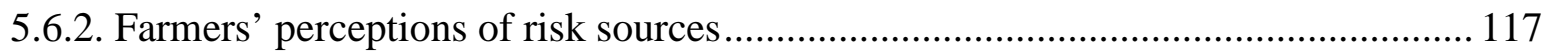

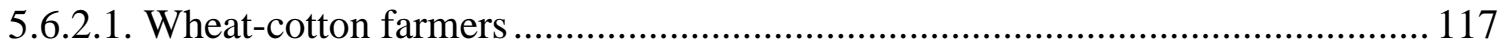

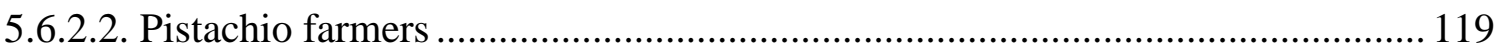


5.6.3. Farmers’ perceptions of risk management strategies 122

5.6.3.1. Wheat-cotton farmers 122

5.6.3.2. Pistachio farmers 125

5.7. Contribution of subjective information to resultant attitudes and perceptions 127

5.7.1. Wheat-cotton farmers 127

5.7.2. Pistachio farmers 131

6. CONCLUSIONS AND IMPLICATIONS 133

7. BIBLIOGRAPHY 138

APPENDIX 


\section{List of figures}

Figure 2.1: Map of Syria 8

Figure 2.2: Syrian map with agro-ecological zones 10

Figure 2.3: Average of annual rainfall and distribution of the total and the cultivable land by agro-ecological zones, 2002-2011.

Figure 2.4: Cultivable area including crop regions in Syria 12

Figure 2.5: Development of rainfall average mm/year, rain-fed and irrigated yields tons/ha of field crops and vegetables in Syria, 1996-2011. 39

Figure 2.6: Surface irrigation technique used in wheat-cotton farms in Al Hasakah - Syria... 42

Figure 2.7: Salt accumulation after water evaporation form irrigation furrows 46

Figure 3.1: An outline of risk management process. 56

Figure 3.2: Risk mapping concept..... .57

Figure 3.3: Risk attitude spectrum 62

Figure 3.4: Representation of a risky choice by a decision-tree 63

Figure 3.5: The triple strand of influences on perceptions and risk attitudes 68

Figure 4.1: Van Raaij’s model of economic-psychological relationships 70

Figure 4.2: Conceptual framework of the study 72

Figure 4.3: Example of risk source item and choice options in the questionnaire .73

Figure 4.4: Example of risk management statement and choice potions in the questionnaire. 73

Figure 4.5: Example of self-assessment scale's statement and choice options in the questionnaire 74 
Figure 4.6: Development of cultivated area (ha) and production (tons) for wheat and cotton in Al Hasakah compared to the other Syrian governorates, 2005-2011 .75

Figure 4.7: Development of Pistachio cultivated area (ha) and production (tons) for in Hamah and Idlib compared to the other Syrian governorates, 2005-2011 76

Figure 4.8: Map of Syria and the selected study areas .77

Figure 4.9: The assumed regressions related to the conventional approaches 81

Figure 4.10: The assumed regressions related to the multidirectional approaches .81

Figure 5.1: Distribution the Syrian wheat-cotton and pistachio farmers' by risk attitude categories, ( $\mathrm{n}=103$ and 105, respectively). 93

Figure 5.2: Risk sources with low incident rates and low expected damages for Syrian wheatcotton farmers, $(n=103)$...... 94

Figure 5.3: Risk sources with low incident rates and high expected damages for Syrian wheatcotton farmers, $(n=103)$....... .95

Figure 5.4: Risk sources with high incident rates and low expected damages for Syrian wheatcotton farmers, $(\mathrm{n}=103)$ 96

Figure 5.5: Risk source with high incident rates and high expected damages for Syrian wheatcotton farmers, $(n=103)$

Figure 5.6: Development of rainfall average and production of wheat and cotton in Syria, 2005-2011 98

Figure 5.7: Risk map of wheat-cotton farming in Syria..... 99

Figure 5.8: Risk sources with low incident rates and low expected damages for Syrian pistachio farmers, $(n=105)$ 100

Figure 5.9: Risk sources with low incident rates and high expected damages for Syrian pistachio farmers, $(n=105)$ 100 
Figure 5.10: Risk sources with high incident rates and low expected damages for Syrian pistachio farmers, $(\mathrm{n}=105)$.... 101

Figure 5.11: Risk sources with high incident rates and high expected damages, for Syrian pistachio farmers, $(\mathrm{n}=105)$ 102

Figure 5.12: Risk map of pistachio farming in Syria 103

Figure 5.13: Attitudes toward risk management strategies of Syrian wheat-cotton farmers, $(n=103)$ 105

Figure 5.14: Attitudes toward risk management strategies of Syrian pistachio farmers, ( $\mathrm{n}=105)$ 106 


\section{List of tables}

Table 2.1: Land utilization of Syria, 2000-2011

Table 2.2: GDP of Syria 1995-2011 by sectors at constant prices ${ }^{*}$ 15

Table 2.3: Contribution of agro-industries to some selected indicators and contribution of its subsectors at current prices, 2001-2009 16

Table 2.4: Value of total and agricultural exports, imports and balance of trade of Syria in selected years

Table 2.5: Population and employment statistics of Syria in selected years 19

Table 2.6: Contribution of strategic crops to both cultivated and crop land, and development of their state prices, 2002-2011 24

Table 2.7: Exchange rate developments of selected items by SYP per USD, 1990-2000 27

Table 2.8: Interest rate of the ACB loans (\%) in 2012 28

Table 2.9: Harvested area, yield and production of plant production groups in Syria, 20052011 32

Table 2.10: Enumeration of livestock categories and their production in Syria, 2005-2011... 33

Table 2.11: $\mathrm{SSR}^{*}$ and $\mathrm{IDR}^{* *}$ of main agricultural products in Syria, 2001-2010 34

Table 2.12: Availability of selected agricultural products in Syria, 2000-2008 (kg/person/year) 35

Table 2.13: Irrigated land according to irrigation system and sources ('000 ha), and number of wells ('000) in Syria, 2000-2011.

Table 2.14: Comparison in area and production of wheat, cotton and pistachio between Syria and world. 48

Table 5.1: Socio-economic characteristics of the Syrian wheat-cotton farmers, $(n=103)$ 84 
Table 5.2: Socio-economic characteristics of the Syrian pistachio farmers, $(n=105)$ 86

Table 5.3: Statements of risk attitude scale, and related CISC and coefficient alpha for the Syrian wheat-cotton and pistachio farmers, (n=103 and 105, respectively)

Table 5.4: Refinement procedure of self-assessment scale's statements, the Syrian wheatcotton farmers' responses $(n=103)$.

Table 5.5: Refinement procedure of self-assessment scale’s statements, the Syrian pistachio farmers' responses, $(n=105)$.

Table 5.6: Responses of the Syrian wheat-cotton and pistachio farmers about refined statements of self-assessment scale, ( $\mathrm{n}=103$ and 105, respectively)......

Table 5.7: Varimax rotated factor loadings of relevant risk sources for Syrian wheat-cotton farmers, $(n=103)$ 108

Table 5.8: Varimax rotated factor loadings of relevant risk sources for Syrian pistachio farmers, $(n=105)$

Table 5.9: Varimax rotated factor loadings of risk management strategies for Syrian wheatcotton farmers, $(\mathrm{n}=103)$

Table 5.10: Varimax rotated factor loadings of risk management strategies for Syrian pistachio farmers, $(n=103)$

Table 5.11: Results of multiple regressions for farmers' risk attitude scale against socioeconomic variables of wheat-cotton farmers $(n=103)$ and pistachio farmers $(n=105)^{a}$

Table 5.12: Results of multiple regressions for risk source factors against socio-economic variables of wheat-cotton farmers $(n=103)^{a}$

Table 5.13: Results of multiple regressions for risk source factors against socio-economic variables of pistachio farmers $(n=105)^{a}$

Table 5.14: Results of multiple regressions for risk management strategy factors against socio-economic variables of wheat-cotton farmers $(n=103)^{a}$ 
Table 5.15: Results of multiple regressions for risk management strategy factors against socio-economic variables of pistachio farmers $(n=105)^{a}$

126

Table 5.16: Results of multiple regressions for farmers' risk attitude scale, risk source factors and risk management strategy factors of wheat-cotton farmers $(n=103)^{a}$ 130

Table 5.17: Results of multiple regressions for farmers' risk attitude scale, risk source factors and risk management strategy factors of pistachio farmers $(n=105)^{a}$ 132 


\section{Abbreviations}

ACB

APSF

${ }^{\circ} \mathrm{C}$

CISC

$\mathrm{dS} / \mathrm{m}$

EC

ER

EU

FAO

FYP

GAFTA

GDP

GESM

ha

IDR

$\mathrm{Kg}$

$\mathrm{Km}$

MAAR

$\mathrm{mm}$

NAPC

$R_{a d j}^{2}$

RA

RMS

RS

SADB

S-E

SSR

SYP

USD

VIF

WTO
Agricultural Cooperative Bank

Agricultural Production Supporting Fund

Degrees Celsius

Corrected Item-Scale Correlation

deciSiemen per meter

Electrical conductivity

Exchange rate

European Union

Food and Agriculture Organization of the United Nations

Five Year Plan

Great Arab Free Trade Area

Gross Domestic Product

The General Establishment for seed Multiplication

Hectare

Import dependency ratio

Kilogram

Kilometer

Syrian Ministry of Agriculture and Agrarian Reform

millimeter

National Agricultural Policy Center

Adjusted R Squared

Farmers' risk attitude

Risk management strategies

Risk sources

Syrian Agricultural Database

Socio-economic

Self-Sufficiency Ratios

Syrian pound

United States Dollars

Variance Inflation Factor

World Trade Organization 


\section{Summary}

The agricultural sector is characterized by higher exposure to a variety of risks compared to the other economic sectors. Agricultural risks include production, market, credit, technological, institutional and human resource risks. Moreover, the agricultural risk environment is changing with high frequency and severity due to climate change and market liberalization. Insecurity about water and food supply has rapidly increased corresponding to the change in agricultural risk environment, and this requires a continuous improvement of risk management instruments for sustainable economic development. If the changeable risks are excluded from the agricultural and rural development analysis, then policy recommendations would be misleading. Additionally, policy decisions about the suggested improvements and intervention measures might be inappropriate. In such a context, a comprehensive and continuous monitoring of how farmers perceive risks in their own ways is paramount for policy makers to develop appropriate risk management strategies. Moreover, it is useful for the developers of risk management programs to have information about the factors that differentiate farmers' attitudes and perceptions. Against this background, it is the objective of the thesis to provide empirical insights into various issues of risk management in Syrian agriculture. Syria is an emerging economy in which agriculture still plays an important role and where at the same time climate change as well as changing agricultural policies, for instance market liberalization, put farmers under severe pressure.

Based on survey data of 103 wheat-cotton and 105 pistachio farms in Syria, this thesis studies survey data relating to farmers' risk attitudes and farmers' perceptions of risk and risk management. Furthermore, it analyzes, using multiple regression analysis, whether related socio-economic characteristics and farmers' subjective beliefs relate to these attitudes and perceptions. Results show that wheat-cotton farmers are more likely risk-averse than pistachio farmers who could better be described as risk-neutral farmers. Rainfall shortage and fuel price increase are the most important risk sources that threaten both wheat-cotton and pistachio cultivation. Moreover, risks of 'farm business effectiveness decline' and 'farm insolvency' are highly perceived by wheat-cotton farmers compared with pistachio farmers. Despite their risk-averse nature, wheat-cotton farmers are less desired toward the adoption of management tools which would help to mitigate risk. 'Farming as a secondary occupation' and 'faming forsaking' are acceptable by almost half of interviewed wheat-cotton farmers. On the contrary, pistachio producers seem to be more satisfied with their farm income, thus they do 
not find the necessity to supplemented it with or replace it by non-farm income. The geographical location, education level and information resources have a considerable exploratory power for wheat-cotton farmers' risk attitude and perceptions of risk and risk management. Socio-economic variables such off-farm work, farm land, availability of family labour and wells ownership had a considerable relationship with such perceptions.

Our findings, also, provide new evidences on the relationships between subjective beliefs and both risk attitudes and perceptions, particularly for wheat-cotton samples. These evidences provide policy makers a wide prospect in order to optimize risk management strategies. 


\section{INTRODUCTION}

\subsection{Problem statement}

The agricultural sector is characterized by higher exposure to a variety of risks compared to the other economic sectors. Agricultural risks include production, market, credit, technological, institutional and human resource risks. Moreover, the agricultural risk environment is changing with high frequency and severity. The changes in agricultural risk environment can be divided into two main groups; climate change and market liberalization. Farmers operate in an external farm environment that is becoming more and more uncertain. Climate change or natural disasters particularly droughts directly cause highly variable agricultural production outcomes and food supply and threaten food security. Natural disasters are exacerbated by agricultural market liberalization that affects input and output prices. These changes threaten millions of those who depend on agriculture for their livelihoods and food particularly in resource-poor areas. Furthermore, these changes disrupt the social and economic development and increase the government spending on relief and compensation (Singh el al. 2005; Gallego et al. 2007; McIntyre et al. 2009).

The frequency and severity of agricultural risk environment particularly in last few decades has increased on account of widespread climate variability and changes. For instance, the duration and intensity of droughts have generally increased. According to FAO (2013), while regional droughts have occurred in the past, the spatial extent of current droughts is broadly consistent with expected changes in the hydrologic cycle under warming.

Droughts threaten many regions over the world; Sub-Saharan Africa, the Middle-East and North Africa, South-Eastern Europe, Central Asia, Australia, Brazil, India, USA and China. Regarding the multi-year droughts between 2002 and 2010 in Australia, the total Australia wheat yield in 2006 dropped by 46\% below the 1960-2010 yield trend level between. Furthermore, the Australian economic loss (mostly agricultural) reached 2.34 billion dollars during 2002-2003 droughts. Russia suffered in 2010 the worst drought among the last 38 years, which was very intensive and caused severe environmental and economic injuries (FAO 2013; UNISDR 2011). Natural disaster caused forest fires in southern Spain increased by 63\% compared to the previous decade (1991-1995) (UNISDR 2011). Furthermore, in 2005 drought led to $40 \%$ loss of cereal production, which reached $€ 2500$ million for the nonirrigated crop and pasture losses (Sepulcre-Canto et al. 2012). In Africa, 8 million hectares (ha) of crops in Mozambique were damaged since 1990 by droughts. Similarly, Southern 
Africa was supplied of for food and non-food assistance with the cost of $\$ 950$ million in ten countries during drought between 1991 and 1992 (UNISDR 2011). The horn of Africa has been affected by droughts almost every year for the past 12 years. Recent years have included the most dreadful droughts in the Horn and severe droughts in 2009 and 2011 in Kenya. Available crop data for 2009 indicate that Kenya's agriculture was the most severely affected, with wheat yields dropping by 45\% compared to 2010's good crop season. Additionally, 70\% of the Kenyan population was dependent on food aid during 2007-2009 droughts (UNISDR 2011; FAO 2013). Ten of US states were directly affected by the 2011-2012 droughts in USA. The extreme US great grain belt drought in 2012 persisted into spring in 2013. Drought in large parts of the USA also pushed up world food prices, exerting pressure on the cost of living and affecting food security (FAO 2013).

Countries that are already subjected to water stress such as those in the Middle East and North Africa will suffer from water limitation over the next years. In such countries climate change is likely to experience additional declines in agricultural production, which will negatively impact rural incomes and food security (Breisinger et al. 2010). In the rainfed Euphrates and Tigris drainage basins, the prolonged drought episode between 2007 and 2010, which was represented by a very low precipitation, generated a steep decline in agricultural productivity. Drought periods in the Middle East region recurred in an irregular and non-uniform manner, with the highest severity, magnitude, and duration over the last decade. Consequently, vast arid and semi-arid zones of the Middle East which rely on fragile systems of rain-fed and irrigated cultivation could be threatened (Kaniewski et al. 2012).

Price risks resulting from agricultural market liberalization and lifting of subsidies exacerbate the climate change disasters and give rise to devastating consequences for local farm incomes. Many new risks can be emerged by increasingly integrated global markets such as distinguishing comparative from competitive advantage (Kaplinsky 2000). In agricultural production trade, large and typically multinational companies are present in all or at least all critical stages of the commodity chain. In the case of agricultural market liberalization, the risk arises owing to small producers, and even some large producers particularly in developing countries will find themselves as the weakest link in the chain (Burch et al. 2006 as cited in FAO 2003a). Due to their small relative size of their market contribution, developing countries cannot influence world market prices. This makes such countries, at individual and national level, as price-risk takers which are severely affected by dramatic or unexpected changes in world market prices (FAO 2003a). 
Insecurity about water and food supply has rapidly increased corresponding to the change in agricultural risk environment, and this requires a continuous improvement of risk management instruments for sustainable economic development. If the changeable risks are excluded from the agricultural and rural development analysis, then policy recommendations would be misleading. Additionally, policy decisions about the suggested improvements and intervention measures might be inappropriate (Cowell and Schokkaert 2001; Legesse and Drake 2005). In such a context, a comprehensive and continuous monitoring of how farmers perceive risks in their own ways is very paramount for policy makers to develop appropriate risk management strategies. Slovic (2001, p. 18) illustrated that "new perspectives and new approaches are needed to manage risks effectively in our society".

Investigation of the farmers' attitudes, their perceptions of risk sources and their preferences of risk management tools is critical to incorporate appropriate responses into development strategies. Supposed that farmers are risk-averse in a region, this means that they accept a lower average income for lower uncertainty. For this reason, the development procedure of risk management strategies should consider such an attitude more than concentrate on average or expected income. Furthermore, identifying farmers' perceptions of the importance of risks which they are facing helps policy makers to address the most appropriate strategies that are acceptable by the targeted farmers' community.

Moreover, it is useful for the developers of risk management programs to have information about the factors that differentiated farmers' attitudes and perceptions. Such knowledge is an essential precondition for devising perfect risk-reducing tools. So far, the continuous and up to date information about farmers' risk attitudes and perceptions and their underlying determinants are still inadequate, particularly in developing countries. Although much theoretical researches on risk in agriculture and their management have been done, (Anderson et al. 1977; Roumasset et al. 1979; Barry 1984; Huirne et al. 1997; Hardaker et al. 1997; Williams and Schroder 1999; Guehlstorf 2004; Berg and Kramer 2008; Craven et al. 2011), useful and up to date empirical insight for policy makers, risk management strategies’ developers and advisors of farmers' risk attitudes and perceptions is generally limited particularly in developing countries. Sjöberg (1998, p. 751) indicated that "risk perception is studied largely because it is believed that perceived risk is a clue to policy demands as perceived risk has consequences for action”.

Related researches started in USA in 1985 (Patrick et al. 1985; Boggess et al. 1985; Shapiro and Brorsen 1988; Wilson et al. 1988; Patrick and Musser 1997). These studies 
investigated farmers' perceptions of risk and risk management application, and described such attitudes and perceptions based on farmers' socio-economic profile. Similar studies in Europe have been achieved by Pålsson (1996) who explained Swedish farmers’ risk attitudes based on farm and farmers characteristics. Similar has been done by Meuwissen et al. (2001) with an empirical study of Dutch livestock farmers. In developing countries, where risk management tools are still insufficient to deal with the increased agricultural risks, the required studies are quite limited. This study is the first report, to our knowledge, of a comprehensive determination of farmers' risk attitudes and perceptions of risk and risk management strategies in the Middle East and North Africa region.

In general, preliminary studies focusing on decision making analysis under uncertainty were taking into account the predominance of farmers being risk-averse (Binswanger 1980). The recent empirical literatures have provided deeper understanding of farmers' levels of risk attitudes and perceptions based on their socio-demographic characteristics as it was done in the mentioned U. S. studies. Wilson et al. (1993) tried to explain farmers' preferences of risk management strategies based on their perceptions of risk sources. Most of these studies revealed that the classification of farmers' risk attitudes and perceptions based on socioeconomic variables was not possible (Boggess et al. 1985; Wilson et al. 1988). Patrick and Musser (1997) found that farm location, farm type and the related institutional structures were likely to influence farmers' perceptions of risk sources and responses to risk. This study will build upon the previous experimental evidence to explore whether such classification is also not possible. Furthermore, it seeks to explain risk attitudes and perceptions based on farmers' subjective beliefs of attitudes and perceptions themselves using multidirectional linkage between socio-economic variables, risk attitudes, risk source perceptions and risk management strategies.

Syrian agriculture is considered as a representative case study in this thesis; since the risks of climate change and agricultural liberalization are accomplished fact in the Syrian agriculture. Moreover, it represents a typical example for many dry areas and those regions which are characterized by Mediterranean climate (e.g. Australia). Breisinger et al. (2011, p. 1) demonstrated that “Syria is an important case study given the country's location in a region that is consistently projected to be amongst the hardest hit by climate change. In addition, both global and local impacts matter for Syria's future development, given its status as a net food- and energy-importing country for many commodities”. 
Droughts in Syria have frequently occurred during the past 50 years. Throughout the fifty years, from 1961 to 2009, Syria suffered through a quarter century's worth of drought (Breisinger et al. 2011). Due to the recent severe, frequent droughts in Syria 2000-2009, the total rain-fed area has declined from 1.12 to 0.98 million ha (Erian et al. 2013). Although these general directions of drought impacts in Syria are well known, the potential size of drought impacts in terms of GDP loss and changes in poverty are not understood (Breisinger et al. 2011). This dark picture becomes more tragedy by the recent increase of agricultural liberalization, particularly fuel prices, and market liberalization and transition from a planned to an open economy. In Syria, there are no permanent and actual systems adopted to deal with agricultural risk, the only way applied to help Syrian farmers in case of emergencies is reschedule or respite the credits they got. Also, the only agricultural insurance system used in Syria is the livestock funds (Cafiero, 2007). Because of the potentially serious agro-economic nature of Syrian agriculture, the National Agricultural Policy Center in Syria (NAPC) recommended in the last annual report (2010) to give risks, particularly drought, more concern and superiority among the scientific research in the country.

To be more comprehensive, our study carries out on two different types of agricultural production, wheat-cotton and pistachio. Wheat and cotton are characterized by high level of governmental interventions and subsidy throughout all production chains compared with the pistachio cultivation.

\subsection{Objectives of the study}

The study does not attempt to determine optimal risk management strategies. However, it attempts to provide the policy makers, strategies' developers and advisors with empirical insights about farmers' risk attitudes and perceptions, in order to be a useful reference for the consequent procedure of risk management development. Therefore, the study specifies two main objectives:

1- Examine farmers' attitudes toward risks, their perceptions of risk sources and preferences of risk management strategies.

2- Examine the factors that cause the resultant attitudes and perceptions.

The first study objective provides the required information about the following questions: 
A- What are the level of acceptance and rejection of take risks among the interviewed wheat-cotton and pistachio farmers?

B- What are the most important sources of risk as perceived by the studied farmers?

C- What are the most acceptable risk management strategies which the targeted farmers prefer?

The second study objective explores the principal determinants of variations in the observed attitudes and perceptions under two sub-objectives:

A- Investigate whether objective information represented by farmers' socio-economic variables could influence their risk attitudes and perceptions. In another word, is the classification of farmers' risk attitudes, perceptions of risk sources and perceptions of risk management strategies based on their socio-economic profiles possible?

B- Explore whether the subjective information related to farmers' risk and their perceptions of risk sources and risk management strategies could influence the attitudes and perceptions themselves. This sub-objective provides the required information about the following question: Do farmers' risk attitudes, perceptions of risk sources and perceptions of risk management strategies have an exploratory power to explain (1) their risk attitudes, (2) their perceptions of risk sources and (3) their perceptions of risk management strategies? 


\section{SYRIAN AGRICULTURE}

\subsection{General background}

\subsubsection{Geographical location}

Syria is a Middle Eastern country, home to some of the oldest continuously inhabited cities in the world, located on the east coast of the Mediterranean Sea between latitudes $32^{\circ} 19^{\prime}$ and $37^{\circ} 30^{\prime} \mathrm{N}$ and longitude $35^{\circ} 45^{\prime}$ and $42^{\circ} \mathrm{E}$. It occupies a strategic geopolitical region that has functioned as a crossroad between Asia, Africa, and Europe. As shown in Figure 2.1, Syria borders Turkey to the north, Iraq to the east and southeast, Lebanon to the west, Jordan to the south and the Golan Heights region on Syria's far southwestern edge, which Israel has occupied it since 1967 (MSEA 2003). Syrian’s geographical structure can be divided into four distinct natural regions, the coastal region, the mountainous region, the interior region and AlBadia.

The western coastal region occupies a narrow plain between the mountains and the short expanse of Mediterranean coastline, 193 kilometers $(\mathrm{km})$. The coastal plain is characterized by intense agricultural development because of its highly fertile soil and the Mediterranean climate, which is known for its high rate of relative humidity, heavy rainfall in winter and moderate temperatures in summer. In parallel to the coastal plain in the east, the mountains extend from north to south, with annual average rainfall exceeding 1000 millimeter (mm) and the climate in summer is moderate. The interior region, east of the highlands, includes the interior plains with two long flat river basins; the Euphrates River and its branches and Orontes River in the northwestern and east of this region, respectively. The plains of these two basins contribute to the highest rate of cultivation in the interior region. The Al-Badia in the south eastern side of the country, bordering Jordan and Iraq, consists of steppe or desert plateau with low elevation mountain ranges, and occasional oases where the annual average rainfall is very low (NAPC 2007; IFAD 2012; Frenken 2009; FDR 2005). 
Figure 2.1: Map of Syria

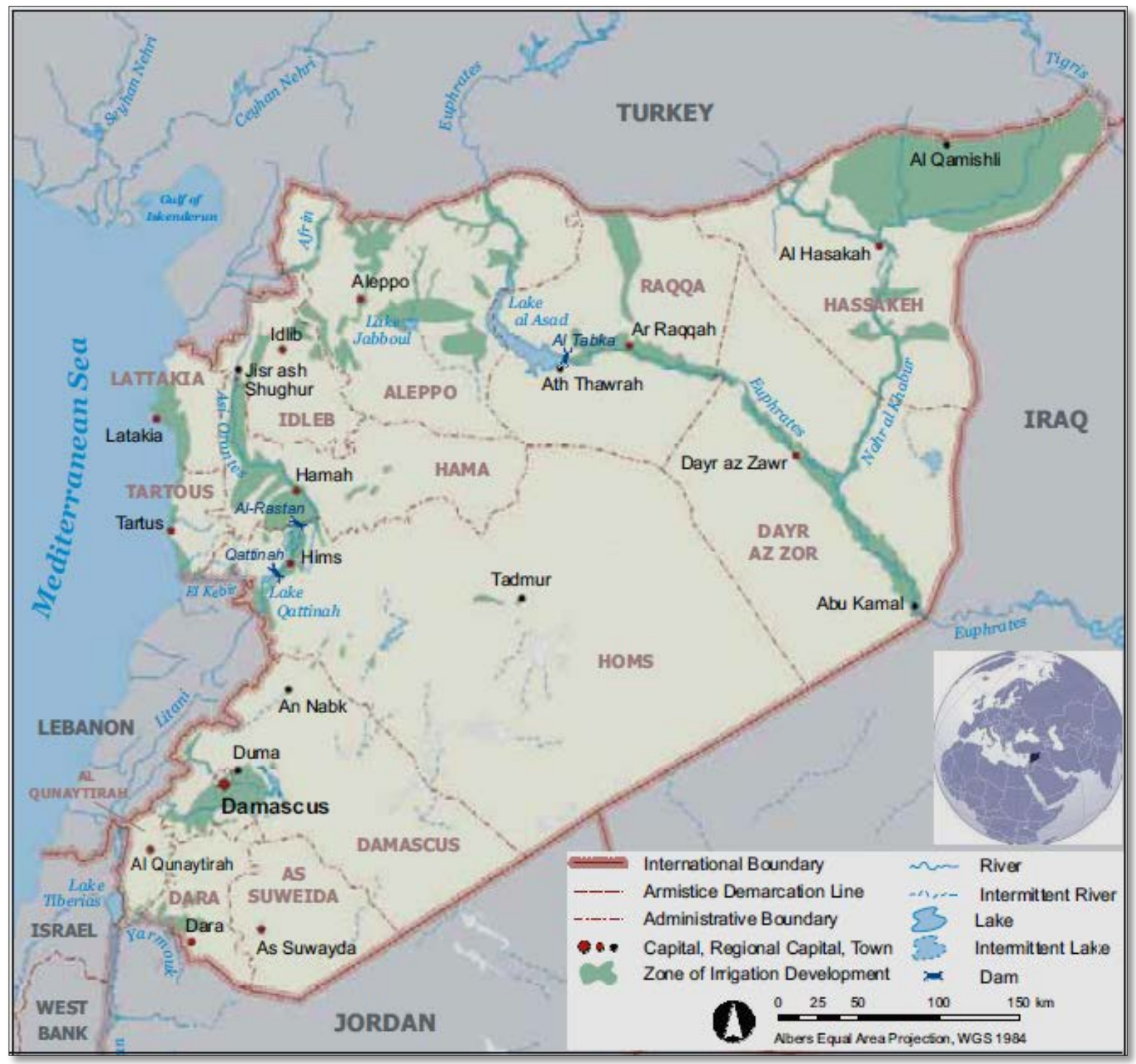

Source: Frenken 2009

For administrative purposes, Syria is divided into five regions, namely Eastern, Northern, Central, Coastal and Southern region, and each region is divided into governorates. Totally, Syria comprises 14 governorates, 61 districts and 6309 villages (MEDSTAT II 2009).

The eastern region, the widest region in Syria, includes the governorates of $\mathrm{Al}$ Hasakah, Ar Raqqah and Deir ez-Zur in the northeast of Syria, constituting $41 \%$ of the total area of Syria. Cultivable land covers one-third of this region while, steppes and pastures represent about $44 \%$. The majority of field crops are concentrated in the eastern region particularly irrigated wheat. Farm sizes in this region are the largest in the country. 
The northern region forms $13.3 \%$ of the total area including Aleppo and Idlib. Cultivable land represents a high portion about $64 \%$ of the region. This region contributes to about half of Syrian production of lentil, chickpeas and olive and nearly $70 \%$ of pistachio.

The Central region extends on Homs and Hamah governorates, forming $27.6 \%$ of the total area. Steppes and pastures cover about $60 \%$ of this region while cultivable land forms only $16 \%$. It produces mainly sugar beets, dried onion, potato, almonds and pistachio.

The coastal region includes Latakia and Tartus governorates. It is the smallest region in Syria with $2.3 \%$ of the total area, even though it contributes significantly to the national agricultural production, with most of citrus and closely half of tobacco, tomato and olive production, and approximately 95\% of the Syrian greenhouse agriculture.

The southern region covers the southeast governorates: Damascus the capital; Reef Demashq (Damascus countryside), Daraa, As Suwayda and Al Qunaiterah. It forms 15.81\% of the total area, out of which $27 \%$ is cultivated. Its agriculture is marked by a wide diversification of field crops, vegetables and trees such as cereals, legumes, tomato, apricots, apples and grapes (SIA 2011; SADB 2013; Frenken 2009).

\subsubsection{Climate and agro-ecological zones}

Syrian's climate is classified as Mediterranean with continental characteristics; rainy cold winters (from November to end February) and drought hot summers (from May to August), with relatively short spring and autumn seasons (March and April, September and October, respectively) (Edwards-Jones 2001). The rainy season starts in September over the coastal and north-east areas, and spreads out by October to cover most of the country. Precipitation reaches its maximum during December and January. For almost the whole country; the rainy season ends in mid-April except for the coastal and mountains regions where this season may last until the end of June. Precipitation trends decrease from west to east and from north to south (Jamal et al. 2007). Recently, drought is one of the main critical crises in the Syrian agricultural sector due to the notable decline of annual average rainfall which affected the agricultural production especially the rain-fed crops and the groundwater table for the irrigated ones (NAPC 2007).

The continent and sea effects are apparent on temperature, the average temperature range of coastal and mountains region, where humidity is usually high, $10-18{ }^{\circ} \mathrm{C}$ in the winter and $20-24^{\circ} \mathrm{C}$ in the summer. The maximum difference in daily temperature can be as high as $13^{\circ} \mathrm{C}$, whereas, in interior and Al-Badia regions, where the relative humidity is usually low 
due to less pronounced sea-effects, the average temperature range is $7-15^{\circ} \mathrm{C}$ in winter and 25 $30^{\circ} \mathrm{C}$ in summer. The maximum difference in daily temperature is $32^{\circ} \mathrm{C}$ (Jamal et al. 2007; Frenken 2009).

Agro-ecological zone is a land unit characterized by the major climate indicators measured over the length of the related period (Breisinger et al. 2011). Syria encompasses a high diversity of agro-ecological conditions, and a wide range of annual precipitation ranging from about $1500 \mathrm{~mm}$ in the west of the country to less than $100 \mathrm{~mm}$ in the southeast. For this reason, the Syrian Ministry of Agriculture and Agrarian Reform (MAAR) has divided the country into five agro-ecological zones (agricultural stability zones). These regions were mainly defined by annual rainfall amount and the temporal distribution of rainfall and secondary by terrain and soil characteristics as in Figure 2.2.

Figure 2.2: Syrian map with agro-ecological zones

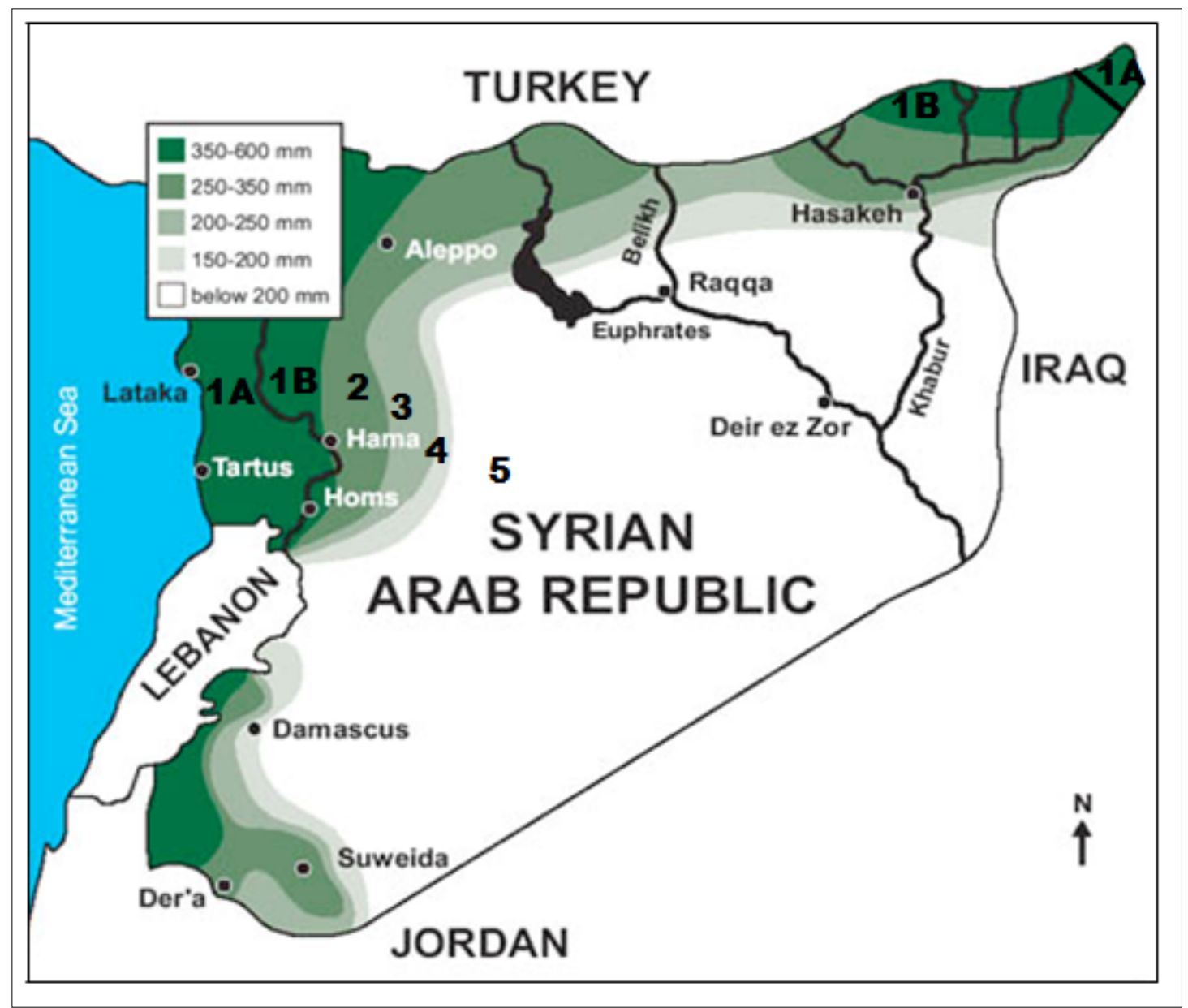

Source: Adapted from FAO 2003b and Breisinger et al. 2011

Zone 1: it is characterized by the highest precipitation's range all over the country (Figure 2.3) with an annual average rainfall of over $350 \mathrm{~mm}$. it is the superior agricultural production area, about half of agricultural contribution in GDP is produced in this zone. It is 
divided into two sub-zones: (1A) with an annual average rainfall of over $600 \mathrm{~mm}$ where rainfed crops can be grown successfully, and (1B) with an annual average rainfall between 350 to $600 \mathrm{~mm}$, and not less than $300 \mathrm{~mm}$ during two-thirds of the observed years, where it is possible to grow two successful crops every three years. Cultivated species in zone 1 depend on altitude; low altitude contains greenhouse crops, mostly vegetables. Citrus, olive, grapes, wheat, lentil and chickpea are the major productions in mid-altitude area while, apples, pears, cherries, wheat, lentil and chickpea have the majority in high altitude.

Zone 2: it covers the greatest share of the cultivable land (30.1\%) with an annual rainfall of 250 to $350 \mathrm{~mm}$, but not less than $250 \mathrm{~mm}$ for two-thirds of the observed years. Growing two barley crops every three years is possible. The major crop in the deep soil lands is wheat, although legumes and summer crops are also planted. Barley and cumin occupy the majority in the shallow soil land. Some fruit trees, especially pistachio, almonds and olives can be also cultivated in this zone.

Zone 3: it forms the lowest share of total land (7.1\%) with an average rainfall exceeding $250 \mathrm{~mm}$ annually and not less than $250 \mathrm{~mm}$ for a half of the observed years. The major crop is barley, although legumes and wheat could be cultivated, where it is possible to grow one to two crops every three years. Agricultural production in this area is highly vulnerable because of its extreme dependency on precarious weather conditions.

Zone 4: it stretches between the arable zones and the desert one with an annual rainfall between 200 and $250 \mathrm{~mm}$ and not less than $200 \mathrm{~mm}$ during half of the observed years. This zone is suitable for barley cultivation as well as permanent grazing where sheep husbandry represents the main practice for households there.

Zone 5: it is characterized as desert and steppe zone covering the widest portion of the total land and the least one of the cultivable land (Figure 2.3). Only the irrigated agriculture is permitted in some areas in this zone, where the rivers are adjacent (IFAD 2001; Masri 2006; Breisinger et al. 2011). 
Figure 2.3: Average of annual rainfall and distribution of the total and the cultivable land by agro-ecological zones, 2002-2011

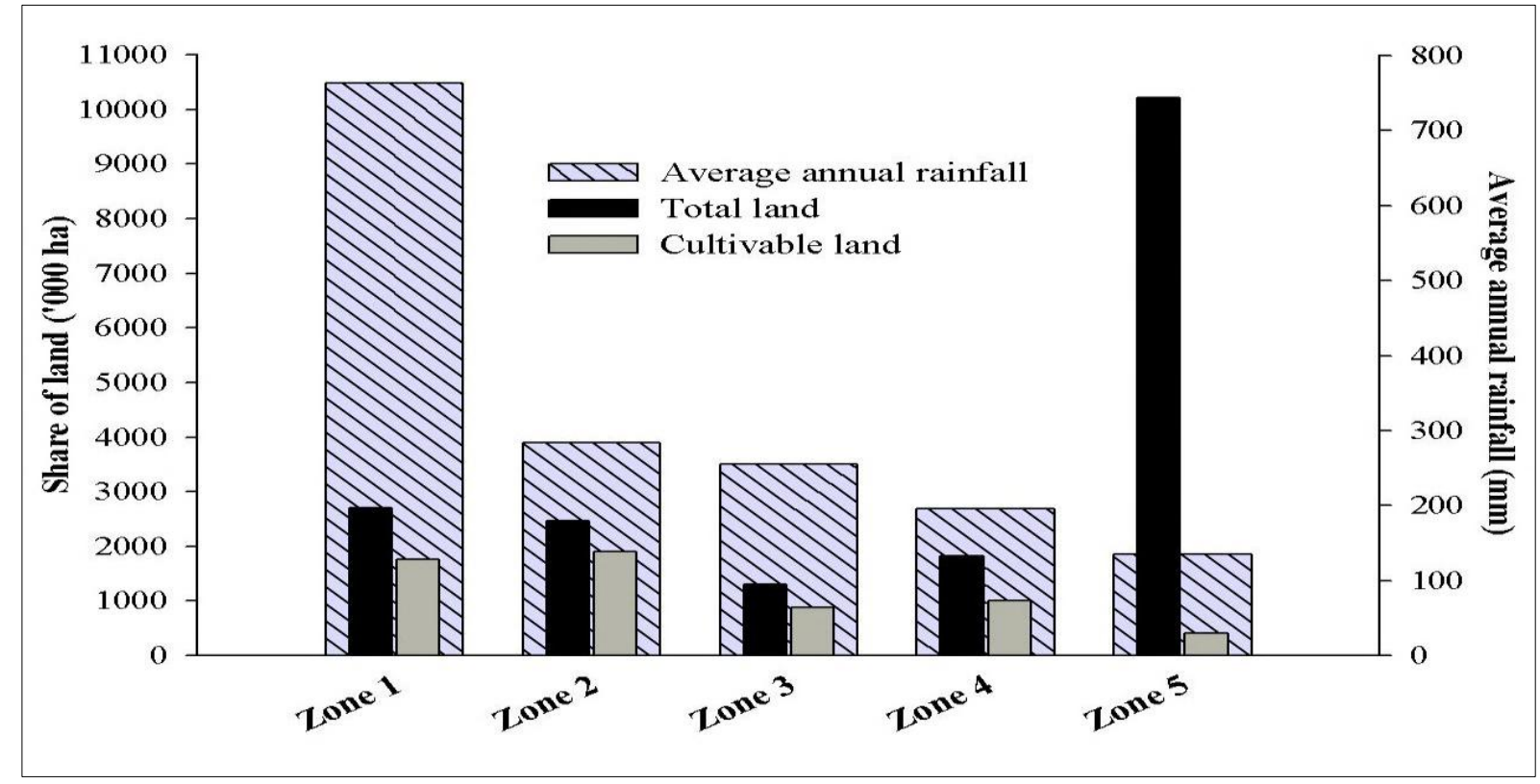

Source: SADB 2013

\subsubsection{Land utilization}

Syria is a middle-sized country with a total land area of $185,180 \mathrm{~km}^{2}$ divided into cultivable lands, uncultivable lands, forests, steppes and pastures (Alhasan and Alnoaimi 2004). Syrian cultivable area is part of the Fertile Crescent (Figure 2.4), extending from the plains of Al-Khabour and the Euphrates rivers in the north-eastern, to northern plains then through the south along the coastal plains (TID 2011).

Figure 2.4: Cultivable area including crop regions in Syria

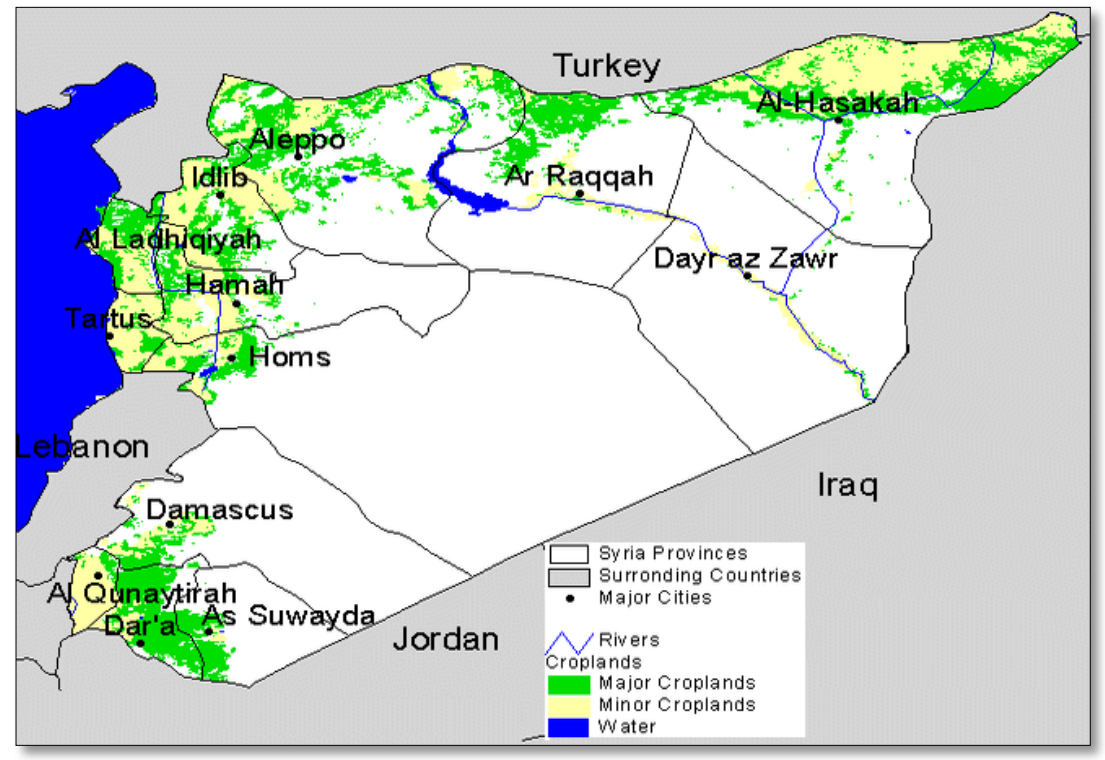

Source: FAS 2002 
Cultivable land is comprised of planted, fallow and un-invested land. The planted land covers both irrigated and rain-fed agriculture. Uncultivable land incorporates sandy and rocky lands, buildings, roads, public places, rivers and lakes. The major portion of Syrian land is covered with steppes and pastures (44.28 of the total land in 2011) (Table 2.1). This portion is only suitable for extensive small ruminants (sheep) production system due to its poor soils, and low-average rainfall that varies from 200 to $50 \mathrm{~mm}$ /year as well as governmental banning of rain-fed and irrigated cropping (IFAD 2012).

Table 2.1: Land utilization of Syria, 2000-2011

\begin{tabular}{|c|c|c|c|c|c|c|c|c|c|}
\hline \multirow{3}{*}{ Year } & \multicolumn{6}{|c|}{ Cultivable land } & \multirow{3}{*}{$\begin{array}{c}\text { Un- } \\
\text { cultivable } \\
\text { land }\end{array}$} & \multirow{3}{*}{$\begin{array}{c}\text { Steppe } \\
\text { and } \\
\text { pasture }\end{array}$} & \multirow{3}{*}{ Forest } \\
\hline & \multirow{2}{*}{ Total } & \multicolumn{3}{|c|}{ Planted } & \multirow{2}{*}{ Fallow } & \multirow{2}{*}{$\begin{array}{c}\text { Un- } \\
\text { Invested }\end{array}$} & & & \\
\hline & & Total & Irrigated & Rain-fed & & & & & \\
\hline \multirow[t]{2}{*}{2000} & 5,905 & 4,547 & 1,211 & 3,336 & 806 & 553 & 3,697 & 8,359 & 557 \\
\hline & 31.89 & 76.99 & 26.63 & 73.37 & 13.65 & 9.36 & 19.96 & 45.14 & 3.01 \\
\hline \multirow[t]{2}{*}{2001} & 5,988 & 4,549 & 1,267 & 3,282 & 901 & 538 & 3,690 & 8,273 & 566 \\
\hline & 32.34 & 75.97 & 27.85 & 72.15 & 15.05 & 8.98 & 19.93 & 44.68 & 3.06 \\
\hline \multirow[t]{2}{*}{2002} & 5,911 & 4,591 & 1,333 & 3,258 & 830 & 490 & 3,694 & 8,338 & 575 \\
\hline & 31.92 & 77.67 & 29.03 & 70.97 & 14.04 & 8.29 & 19.95 & 45.03 & 3.11 \\
\hline \multirow[t]{2}{*}{2003} & 5,863 & 4,661 & 1,361 & 3,300 & 817 & 385 & 3,730 & 8,335 & 590 \\
\hline & 31.66 & 79.50 & 29.20 & 70.80 & 13.94 & 6.56 & 20.14 & 45.01 & 3.19 \\
\hline \multirow[t]{2}{*}{2004} & 5,910 & 4,729 & 1,439 & 3,290 & 796 & 384 & 3,736 & 8,279 & 593 \\
\hline & 31.91 & 80.03 & 30.43 & 69.57 & 13.47 & 6.50 & 20.18 & 44.71 & 3.20 \\
\hline \multirow[t]{2}{*}{2005} & 5,933 & 4,873 & 1,426 & 3,447 & 690 & 371 & 3,721 & 8,266 & 598 \\
\hline & 32.04 & 82.13 & 29.26 & 70.74 & 11.63 & 6.25 & 20.09 & 44.64 & 3.23 \\
\hline \multirow[t]{2}{*}{2006} & 5,950 & 4,743 & 1,402 & 3,340 & 845 & 362 & 3,677 & 8,290 & 601 \\
\hline & 32.13 & 79.71 & 29.57 & 70.43 & 14.20 & 6.09 & 19.86 & 44.77 & 3.25 \\
\hline \multirow[t]{2}{*}{2007} & 6,039 & 4,719 & 1,396 & 3,323 & 963 & 357 & 3,689 & 8,214 & 576 \\
\hline & 32.61 & 78.15 & 29.59 & 70.41 & 15.94 & 5.91 & 19.92 & 44.36 & 3.11 \\
\hline \multirow[t]{2}{*}{2008} & 6,024 & 4,611 & 1,356 & 3,254 & 1,056 & 357 & 3,683 & 8,232 & 579 \\
\hline & 32.53 & 76.54 & 29.42 & 70.58 & 17.52 & 5.93 & 19.89 & 44.45 & 3.13 \\
\hline \multirow[t]{2}{*}{2009} & 6,012 & 4,339 & 1,238 & 3,101 & 1,325 & 348 & 3,681 & 8,244 & 581 \\
\hline & 32.47 & 72.17 & 28.54 & 71.46 & 22.05 & 5.79 & 19.88 & 44.52 & 3.14 \\
\hline \multirow[t]{2}{*}{2010} & 6,045 & 4,794 & 1,341 & 3,453 & 903 & 348 & 3,679 & 8,212 & 583 \\
\hline & 32.64 & 79.30 & 27.97 & 72.03 & 14.93 & 5.76 & 19.87 & 44.35 & 3.15 \\
\hline \multirow[t]{2}{*}{2011} & 6,068 & 4,579 & 1,399 & 3,180 & 1,136 & 352 & 3,666 & 8,199 & 585 \\
\hline & 32.77 & 75.47 & 30.56 & 69.44 & 18.73 & 5.80 & 19.80 & 44.28 & 3.16 \\
\hline
\end{tabular}

Source: MAAR 2009 and 2011

Unit: ‘000ha

Forests in Syria are Mediterranean forests, which are concentrated only in the coastal mountains with a low ratio (3.16 of the total land in 2011) (MAAR 2011). Similar to most the developing countries, land available for agriculture is limited, and not optimally exploited. According to different official Syrian sources, cultivable land is estimated to be around 6 million ha that forms only one-third of the total land, out of which 4.5-4.9 million ha are 
under cultivation. The irrigated area ranges between 1.2 and 1.4 million ha, which is about $29 \%$ of the planted land. Table 2.1 indicates an upward trend in the contribution of irrigated, fallow and forest lands and downward trend in the share of rain-fed and un-invested lands. The un-invested share of the total cultivable land has been declined from $9.36 \%$ in 2000 to about 6\% in 2011 regarding the expansion of land reclamation projects and support modern irrigation schemes. Recently, fallow land was doubled because of the 2006-2008 frequent droughts which enhanced irrigated agriculture to the detriment of rain-fed one.

\subsection{Role of the agricultural sector in the Syrian economy}

Syria is located in the region of origin for major agricultural species such as wheat, barley, lentil, vetch and sheep, where agriculture is the oldest practise, around 10000 years ago (Pannell and Nordblom 1998). Syria is similar to most of the developing countries that its economic development is based on agriculture. Over recent decades, agriculture has been the mainstay of the Syrian economy, and it was the largest productive sector. It contributes to multiple economic and social aspects comprising, apart from the basic agricultural production and food security, the overall growth, manufacturing and trading, services and employment (Sarris 2003; SIA 2007; Altinbilek 2004).

During 1950s and 1960s, the agricultural sector was absolutely predominated sector in the Syrian economy with an estimated contribution to the Gross Domestic Product (GDP) between 40 and 30\% (IFAD 2001). In 1970s, agriculture continued to be the largest sector contributing to the GDP, even though, the mining and export of crude oil emerged as an effective sector in GDP. During the 1980s and 1990s, contributions of agriculture and related processing activities to GDP fluctuated between $25 \%$ and $32 \%$ depending on the precipitations and the level of oil production and prices (SADB 2013). In 1998, agriculture contribution in GDP was positively influenced by the high precipitation $(541 \mathrm{~mm})$. It accounted for the highest share in GDP in the last two decades with 32.4\% (Table 2.2). In contrast, the extended drought in 1999 reduced the real per capita GDP by $4.4 \%$ compared to the previous year. This highlights the importance of agriculture in the overall economy (Sarris 2001). During 2000-2006, the contribution of the agricultural sector in GDP ranked second after mining and manufacturing with a moderate dissimilarity. Agriculture accounted for somewhat stable shares ranged between $23 \%$ and $26 \%$. This contribution has suddenly dropped from $24.1 \%$ in 2006 to $19.7 \%$ in 2007, and it continues with a dramatic decrease to reach a unique level roughly $16 \%$ in 2010 with a growth rate for $-4.87 \%$ during $2006-2010$, in comparison to 4.56\% during 2000-2006 (CBS 2011). This serious decline most likely resulted 
from the unique drought period 2006-2008, especially 2008 which is considered as the driest year in 38 years. Oil played an important position in the Syrian economy since the 1990s, after that, oil output declined, and Syria has become a net importer of oil and petroleum products, which means that agriculture and other economic sectors will have to increasingly contribute to the growth. In fact, this does not appear to be the case for agriculture (ICARDA 2008; Bennett and Marston 2008).

Table 2.2: GDP of Syria 1995-2011 by sectors at constant prices ${ }^{*}$

\begin{tabular}{|c|c|c|c|c|c|c|}
\hline Year & Agriculture & $\begin{array}{c}\text { Mining } \\
\text { and } \\
\text { manufacture }\end{array}$ & $\begin{array}{l}\text { Wholesale } \\
\text { and } \\
\text { retail trade }\end{array}$ & $\begin{array}{c}\text { Transport } \\
\text { and } \\
\text { communication }\end{array}$ & $\begin{array}{c}\text { Government } \\
\text { services }\end{array}$ & Others $^{* *}$ \\
\hline \multirow[t]{2}{*}{1995} & 161,024 & 78,864 & 148,650 & 66,357 & 53,097 & 62,983 \\
\hline & 28.2 & 13.8 & 26.0 & 11.6 & 9.3 & 11.1 \\
\hline \multirow[t]{2}{*}{1996} & 184,426 & 84,529 & 135,738 & 70,959 & 54,768 & 66,216 \\
\hline & 30.9 & 14.2 & 22.8 & 11.9 & 9.2 & 11.0 \\
\hline \multirow[t]{2}{*}{1997} & 178,549 & 85,291 & 131,543 & 80,587 & 57,037 & 71,347 \\
\hline & 29.5 & 14.1 & 21.8 & 13.3 & 9.4 & 11.9 \\
\hline \multirow[t]{2}{*}{1998} & 219,138 & 115,801 & 136,138 & 78,323 & 55,213 & 71,275 \\
\hline & 32.4 & 17.1 & 20.1 & 11.6 & 8.2 & 10.6 \\
\hline \multirow[t]{2}{*}{1999} & 183,189 & 120,561 & 139,328 & 86,373 & 55,176 & 77,769 \\
\hline & 27.7 & 18.2 & 21.0 & 13.0 & 8.3 & 11.8 \\
\hline \multirow[t]{2}{*}{2000} & 223,749 & 272,514 & 134,453 & 113,851 & 76,392 & 83,663 \\
\hline & 24.7 & 30.1 & 14.9 & 12.6 & 8.4 & 9.3 \\
\hline \multirow[t]{2}{*}{2001} & 247,726 & 277,960 & 148,245 & 124,985 & 82,692 & 93,690 \\
\hline & 25.4 & 28.5 & 15.2 & 12.8 & 8.5 & 9.6 \\
\hline \multirow[t]{2}{*}{2002} & 261,008 & 264,984 & 168,492 & 132,530 & 89,225 & 96,487 \\
\hline & 25.8 & 26.2 & 16.6 & 13.1 & 8.8 & 9.5 \\
\hline \multirow[t]{2}{*}{2003} & 254,078 & 248,905 & 163,857 & 147,419 & 98,387 & 106,062 \\
\hline & 24.9 & 24.4 & 16.1 & 14.5 & 9.7 & 10.4 \\
\hline \multirow[t]{2}{*}{2004} & 246,270 & 295,369 & 194,632 & 114,484 & 117,658 & 120,614 \\
\hline & 22.6 & 27.1 & 17.9 & 10.5 & 10.8 & 11.1 \\
\hline \multirow[t]{2}{*}{2005} & 265,504 & 286,529 & 233,945 & 125,464 & 120,803 & 124,469 \\
\hline & 23.0 & 24.8 & 20.2 & 10.8 & 10.4 & 10.8 \\
\hline \multirow[t]{2}{*}{2006} & 292,457 & 288,140 & 222,230 & 136,902 & 128,699 & 146,654 \\
\hline & 24.1 & 23.7 & 18.3 & 11.3 & 10.6 & 12.0 \\
\hline \multirow[t]{2}{*}{2007} & 252,856 & 299,061 & 249,817 & 152,564 & 165,836 & 163,901 \\
\hline & 19.7 & 23.3 & 19.5 & 11.9 & 12.9 & 12.7 \\
\hline \multirow[t]{2}{*}{2008} & 234,872 & 310,654 & 289,807 & 167,247 & 167,391 & 171,544 \\
\hline & 17.5 & 23.2 & 21.6 & 12.5 & 12.5 & 12.7 \\
\hline \multirow[t]{2}{*}{2009} & 265,048 & 321,505 & 294,887 & 174,988 & 187,676 & 176,728 \\
\hline & 18.7 & 22.6 & 20.8 & 12.3 & 13.2 & 12.4 \\
\hline \multirow[t]{2}{*}{2010} & 239,527 & 362,244 & 297,427 & 190,778 & 206,887 & 183,912 \\
\hline & 16.2 & 24.5 & 20.1 & 12.9 & 14.0 & 12.3 \\
\hline
\end{tabular}

Source: CBS 2011

Unit: Million Syrian Pound (SYP), bold indicates the share percentage in GDP

*GDP 1995-1999 at constant 1995 prices

*GDP 2000-2011 at constant 2000 prices

** Others: Building and Construction, Social and Personal Services and Finance and insurance. 
Syrian agriculture is a major source of raw materials for agro-industry including food products and beverages, tobacco, textiles, wooden and paper products. It includes a wide variety of industrial crops including cotton, sugar beet, tobacco, cumin, aniseeds, sesame, black cumin, soybean, oily sunflower, peanuts, sunflower, Indian millet and lupines (NAPC 2007). In 2011, these industrial crops accounted for $9 \%$ of the total crops area and $37 \%$ of crop production (MAAR 2011). Syrian household consumption expenditure related to food processing constitutes the largest share of total food consumption preceding that for meat, fruits, vegetables, and cereals (Breisinger et al. 2011). Agro-industries are the major contributor to the Net Domestic Product of the Transformation Industries (NDPTI), as shown in Table 2.3, particularly after the exemption of agro-industrial production taxes. Table 2.3 points out that, textiles almost come first in Syrian agro-industry sector, particularly cotton clothes. Food products and beverages especially olive oil come at the second place (Maletta 2003; NAPC 2010a).

Table 2.3: Contribution of agro-industries to some selected indicators and contribution of its subsectors at current prices, 2001-2009

\begin{tabular}{|c|c|c|c|c|c|c|c|c|c|}
\hline \multirow[b]{2}{*}{ Year } & \multirow[b]{2}{*}{$\begin{array}{c}\text { Total } \\
\text { AINDP }\end{array}$} & \multicolumn{3}{|c|}{ Contribution of agro-industry (\%) } & \multicolumn{5}{|c|}{$\begin{array}{l}\text { Contribution of agro industrial sub-sectors to } \\
\text { total }{ }^{\mathrm{d}} \text { AINDP (\%) }\end{array}$} \\
\hline & & Total ${ }^{\mathrm{a}} \mathrm{NDP}$ & Total ${ }^{\mathrm{b}}$ INDP & Total ${ }^{\mathrm{C}} \mathrm{NDPTI}$ & Textiles & $\begin{array}{l}\text { Food stuff } \\
\text { and } \\
\text { beverages }\end{array}$ & Wooden & $\begin{array}{l}\text { Paper } \\
\text { products }\end{array}$ & Tobacco \\
\hline 2001 & 44,557 & 4.8 & 15.7 & 59.5 & 47.8 & 38.9 & 8.2 & 4.5 & 0.6 \\
\hline 2002 & 42,178 & 4.3 & 14.9 & 58.6 & 50.0 & 37.8 & 8.1 & 3.3 & 0.8 \\
\hline 2003 & 50,221 & 4.9 & 17.8 & 64.9 & 43.6 & 45.0 & 7.2 & 3.3 & 0.9 \\
\hline 2004 & 50,316 & 4.1 & 14.4 & 48.1 & 42.8 & 47.4 & 5.6 & 3.4 & 0.8 \\
\hline 2005 & 74,587 & 4.3 & 15.2 & 61.1 & 45.5 & 38.9 & 9.9 & 5.3 & 0.4 \\
\hline 2005 & 70,221 & 5.2 & 12.7 & 59.1 & 49.7 & 32.4 & 11.6 & 5.6 & 0.7 \\
\hline 2007 & 73,377 & 3.8 & 12.1 & 62.7 & 44.6 & 41.2 & 8.4 & 5.1 & 0.7 \\
\hline 2008 & 80,891 & 3.4 & 10.5 & 60.3 & 46.6 & 38.6 & 9.4 & 4.8 & 0.6 \\
\hline 2009 & 94,016 & 3.9 & 14.9 & 60.4 & 40.5 & 46.0 & 8.5 & 4.5 & 0.5 \\
\hline
\end{tabular}

Source: CBS 2010

* Unit: million SYP

a Net Domestic Product

${ }^{\mathrm{b}}$ Industrial Net Domestic Product

${ }^{\mathrm{c}}$ Net Domestic Product of the Transformation Industries

${ }^{\mathrm{d}}$ Agro-Industrial Net Domestic Product

These processed products play an important role in foreign trade as foreign currency suppliers by the export. It witnessed a remarkable growth from $18 \%$ of the total Syrian exports in 1990 to about 30\% in 1998 (see Table 2.4) due to new governmental regulations such as the abolition of taxes for agricultural products export. This enhanced the import of new technologies and machineries required for agro-industry. Consequently, export of fruits climbed by two and half times, and vegetables by one and half time in that period (Madani 2005). However, as all agriculture-based sectors, Syrian’s agricultural export is also affected 
by drought. In 1998, when the average rainfall was $541 \mathrm{~mm}$, agricultural export counted the highest share in total Syrian exports with $32.2 \%$. After that, it is sharply declined to $16.7 \%$ in 2000 due to the rainless season 1999-2000 with $371 \mathrm{~mm}$, and $6.6 \%$ in the deserted season of 2008 with $349 \mathrm{~mm}$ with the total discontinuity of exports of the main food products such as wheat (NAPC 2009).

Table 2.4: Value of total and agricultural exports, imports and balance of trade of Syria in selected years

\begin{tabular}{|c|c|c|c|c|c|c|c|c|c|c|}
\hline \multirow{3}{*}{ Year } & \multicolumn{4}{|c|}{ Export } & \multicolumn{4}{|c|}{ Import } & \multicolumn{2}{|c|}{ Balance of trade } \\
\hline & \multirow[b]{2}{*}{ Total } & \multicolumn{3}{|c|}{ Agriculture } & \multirow[b]{2}{*}{ Total } & \multicolumn{3}{|c|}{ Agriculture } & \multirow[b]{2}{*}{ Total } & \multirow[b]{2}{*}{ Agriculture } \\
\hline & & Total & $\begin{array}{l}\text { \%Agro- } \\
\text { industrial }\end{array}$ & $\begin{array}{c}\% \\
\text { Raw }\end{array}$ & & Total & $\begin{array}{l}\text { \%Agro- } \\
\text { industrial }\end{array}$ & $\begin{array}{c}\% \\
\text { Raw }\end{array}$ & & \\
\hline 1990 & 3,189 & $\begin{array}{c}574 \\
(18.0 \%)\end{array}$ & 8.4 & 91.6 & 4,231 & $\begin{array}{c}714 \\
(19.9 \%)\end{array}$ & 60.2 & 39.8 & -942 & -141 \\
\hline 1996 & 3,962 & $\begin{array}{c}894 \\
(22.6 \%)\end{array}$ & 9.6 & 90.4 & 4,705 & $\begin{array}{c}820 \\
(17.4 \%)\end{array}$ & 61.6 & 38.4 & -743 & 74 \\
\hline 1997 & 3,609 & $\begin{array}{c}942 \\
(26.1 \%)\end{array}$ & 9.7 & 90.3 & 4,434 & $\begin{array}{c}817 \\
(18.4 \%)\end{array}$ & 63.0 & 37 & -825 & 125 \\
\hline 1998 & 2,890 & $\begin{array}{c}931 \\
(32.2 \%)\end{array}$ & 10.2 & 89.8 & 3,895 & $\begin{array}{c}789 \\
(20.3 \%)\end{array}$ & 62.6 & 37.4 & $-1,005$ & 142 \\
\hline 1999 & 3,471 & $\begin{array}{c}794 \\
(22.9 \%)\end{array}$ & 10.3 & 89.7 & 3,823 & $\begin{array}{c}881 \\
(23.0 \%)\end{array}$ & 60.8 & 39.2 & -352 & -87 \\
\hline 2000 & 4,700 & $\begin{array}{c}786 \\
(16.7 \%)\end{array}$ & 10.8 & 89.2 & 4,033 & $\begin{array}{c}835 \\
(20.7 \%)\end{array}$ & 54.5 & 45.5 & 667 & -49 \\
\hline 2001 & 5,287 & $\begin{array}{c}823 \\
(15.6 \%)\end{array}$ & 15.7 & 84.3 & 4,747 & $\begin{array}{c}878 \\
(18.5 \%)\end{array}$ & 58.4 & 41.6 & 540 & -55 \\
\hline 2002 & 6,556 & $\begin{array}{c}1,333 \\
(20.3 \%)\end{array}$ & 12.6 & 87.4 & 5,070 & $\begin{array}{c}1,034 \\
(20.4 \%)\end{array}$ & 64.1 & 35.9 & 1,486 & 299 \\
\hline 2003 & 5,762 & $\begin{array}{c}1,137 \\
(19.7 \%)\end{array}$ & 19.9 & 80.1 & 5,092 & $\begin{array}{c}1,086 \\
(21.3 \%)\end{array}$ & 61.6 & 38.4 & 670 & 51 \\
\hline 2004 & 7,115 & $\begin{array}{c}1,066 \\
(15.0 \%)\end{array}$ & 23.2 & 76.8 & 7,996 & $\begin{array}{c}1,330 \\
(16.6 \%)\end{array}$ & 66.3 & 33.7 & -881 & -264 \\
\hline 2005 & 8,486 & $\begin{array}{c}1,132 \\
(13.3 \%)\end{array}$ & 33.5 & 66.5 & 10,047 & $\begin{array}{c}1,443 \\
(14.4 \%)\end{array}$ & 63.8 & 36.2 & $-1,561$ & -311 \\
\hline 2006 & 10,100 & $\begin{array}{c}1,222 \\
(12.1 \%)\end{array}$ & 27.8 & 72.2 & 10,626 & $\begin{array}{c}1,284 \\
(12.1 \%)\end{array}$ & 66.2 & 33.8 & -526 & -62 \\
\hline 2007 & 11,581 & $\begin{array}{c}1,386 \\
(12.0 \%)\end{array}$ & 30.3 & 69.7 & 13,691 & $\begin{array}{c}1,911 \\
(14.0 \%)\end{array}$ & 68.1 & 31.9 & $-2,110$ & -525 \\
\hline 2008 & 15,231 & $\begin{array}{c}1,002 \\
(6.6 \%)\end{array}$ & 36.5 & 63.5 & 17,994 & $\begin{array}{c}2,030 \\
(11.3 \%)\end{array}$ & 57.0 & 43.0 & $-2,763$ & $-1,028$ \\
\hline 2009 & 10,477 & $\begin{array}{c}2,202 \\
(21.0 \%)\end{array}$ & 48.8 & 51.2 & 15,258 & $\begin{array}{c}2,777 \\
(18.2 \%)\end{array}$ & 58.2 & 41.8 & $-4,781$ & -575 \\
\hline
\end{tabular}

Source: CBS 2011 and SADB 2013

Unit: Million USD

Despite the gradual increasing of the share of agro-industrial products in the Syrian agricultural exports over the years, raw material accounted for the majority; it comprised initially live animals then raw cotton, vegetables and fruits (SADB 2013). Table 2.4 also shows that the growth of the Syrian agricultural exports was slower than that of imports. This 
leads to agricultural trade balance deficit that registered its higher rate in deserted year 2008 with 1,028 United States Dollar (USD) million. Syrian agricultural imports consist of the cereals and processed food products. The main agricultural imports in 2008 were cereals with $38 \%$ of total Syrian agricultural imports. Rice, which is not locally produced, was ranked first before maize which is very necessary for poultry. They are followed by fodder and dairy products (11\%), sugar and sugar confectionery (8\%), coffee, tea, mate and spices (5\%) (NAPC 2009).

In 2009, Syrian’s major agricultural export destinations were Arab countries (52.5\%) and the European Union (EU) (30.2\%) while, major import destinations were Asian countries (31.2\%) and the EU (23.6\%) (CBS 2010).

In terms of agricultural labour, the population of the country in 2010 was estimated at 23.695 million inhabitants distributed to 3.900 million families while, the actual number of Syrians who were living in Syria amounted to 20.397 million inhabitants. This leaves an estimated 3.298 million Syrians (14\% of the registered population) living abroad in 2010 due to migration or birth abroad, a colossal share by international standards. Syria's population growth is one of the highest in the world for both urban and rural population. It accounted 2.45\% in 2010 (CBS 2011). According to the database of FAO's global water information system (AQUASTAT) in 2011, the population density is estimated at 112.1 inhabitants per square kilometre $\left(\mathrm{km}^{2}\right)$ (FAO 2011). However, 60\% of the Syrian population are located in $13 \%$ of the total area which are Damascus, Aleppo and the first agro-ecological zone area. The highest population density exceeds 2000 inhabitants $/ \mathrm{km}^{2}$ in Damascus, and more than 350 inhabitants $/ \mathrm{km}^{2}$ in both Aleppo and the first agro-ecological zone area. Conversely, zone 5, which makes up the majority of Syria's surface area (55\%), has the lowest population density with less than 5 inhabitants/km² (CBS 2011; Breisinger et al. 2011).

In general, half of total Syrian population live in rural areas and are involved in various agricultural activities. Nearby 700 thousand agricultural holdings are counted all over the country in 2009 (MEDSTAT II 2009). However, the share of agricultural employment has dramatically decreased from 32.6\% of the total Syrian employment in 1982 to $16.8 \%$ in 2008. This is due to the development of the other economic sectors especially services, which accounted for $26.5 \%$ of the total employment. On the other hand, severe droughts and water scarcity caused a notable relapse for agricultural investment from 15.7 to $7.8 \%$ of the total investment between 2000 and 2008. This explains the limited job opportunities in the agricultural sector (CBS 2009; NAPC 2010a). Table 2.5 shows the fluctuated shares on 
agricultural employment, which indicate that agriculture in Syria is mostly a source of parttime employment especially for poor families who contribute for a large share of seasonally agricultural workers (Sarris 2001).

Table 2.5: Population and employment statistics of Syria in selected years

\begin{tabular}{|c|c|c|c|c|c|c|}
\hline \multirow[b]{2}{*}{ Year } & \multicolumn{3}{|c|}{ Population } & \multicolumn{3}{|c|}{ Employment } \\
\hline & Total & Rural & Urban & Total & Agriculture & $\begin{array}{c}\text { Non- } \\
\text { agriculture }\end{array}$ \\
\hline \multirow[t]{2}{*}{1982} & 9,548 & 5,039 & 4,509 & 2,128 & 694 & 1,434 \\
\hline & & 52.8 & 47.2 & & 32.6 & 67.4 \\
\hline \multirow[t]{2}{*}{1987} & 11,267 & 5824 & 5,443 & 2,740 & 849 & 1,891 \\
\hline & & 51.7 & 48.3 & & 31.0 & 69.0 \\
\hline \multirow[t]{2}{*}{1992} & 13,063 & 6,617 & 6,446 & 3,498 & 1,033 & 2,465 \\
\hline & & 50.7 & 49.3 & & 29.5 & 70.5 \\
\hline \multirow[t]{2}{*}{1997} & 14,856 & 7,311 & 7,545 & 4,064 & 978 & 3,086 \\
\hline & & 49.2 & 50.8 & & 24.1 & 75.9 \\
\hline \multirow[t]{2}{*}{2000} & 16,320 & 8,177 & 8,143 & 4,937 & 1,430 & 3,507 \\
\hline & & 50.1 & 49.9 & & 29.0 & 71.0 \\
\hline \multirow[t]{2}{*}{2001} & 16,720 & 8,344 & 8,376 & 5,275 & 1,473 & 3,802 \\
\hline & & 49.9 & 50.1 & & 27.9 & 72.1 \\
\hline \multirow[t]{2}{*}{2002} & 17,130 & 8,531 & 8,599 & 5,459 & 1,462 & 3,997 \\
\hline & & 49.8 & 50.2 & & 16.8 & 73.2 \\
\hline \multirow[t]{2}{*}{2003} & 17,550 & 8,744 & 8,806 & 4,821 & 1,462 & 3,359 \\
\hline & & 49.8 & 50.5 & & 30.3 & 69.7 \\
\hline \multirow[t]{2}{*}{2004} & 18,138 & 8,433 & 9,705 & 4,302 & 734 & 3,568 \\
\hline & & 46.5 & 53.5 & & 17.1 & 82.9 \\
\hline \multirow[t]{2}{*}{2005} & 18,356 & 8,536 & 9,820 & 4,680 & 940 & 3,740 \\
\hline & & 46.5 & 53.5 & & 20.1 & 79.9 \\
\hline \multirow[t]{2}{*}{2006} & 18,941 & 8,808 & 10,133 & 4,860 & 952 & 3,908 \\
\hline & & 46.5 & 53.5 & & 19.6 & 80.4 \\
\hline \multirow[t]{2}{*}{2007} & 19,405 & 8,915 & 10,490 & 4,946 & 947 & 3,999 \\
\hline & & 45.9 & 54.1 & & 19.1 & 80.9 \\
\hline \multirow[t]{2}{*}{2008} & 19,644 & 9,133 & 10,511 & 4,848 & 814 & 4,034 \\
\hline & & 46.5 & 53.5 & & 16.8 & 83.2 \\
\hline
\end{tabular}

Source: CBS, different statistical abstracts

Unit: thousand people

\subsection{Policies affecting agricultural production in Syria}

\subsubsection{Development of agricultural policies in Syria}

Socialism was the driving paradigm in Syria from the late of 1950s with centrally planned economic system. State organizations and agencies closely dominated all of the planning, production and marketing activities while, the private sector played a very limited role in the economy under strictly controlled policies and regulations by the state. The design of agricultural policy was influenced considerably by a closed economy mind-set. The majority of the Syrian agricultural production (98\%) is privately produced, based on a large 
number of relatively small farm units (Westlake 2001). Even though, the state monopolised marketing and processing most of the agricultural productions as well as agricultural inputs with stiffness to apply the state crop plans at the farm level (Sarris 2003; Parthasarathy 2003a). Self-sufficiency of major food staples formed the priority of agricultural policy's goals in that period (Sarris 2001).

It is accurate that the Syrian government had ensured high levels of overall selfsufficiency by a large-scale exploitation of natural resources for agricultural production and extreme government intervention. The self-sufficiency purpose led to serious distortions such as exhaustion of natural resources and heavy burden on the state budget (NAPC 2010a). From the late of 1980's, there was a growing awareness that a new economic development strategy is needed due to mitigation for the aforementioned distortions, and the international considerations followed by the cold war. The new economic strategies aimed to integrate with the world economy by continuous efforts towards signing an Association Agreement with the EU, and regional trade agreements, and joining the World Trade Organization (WTO) (Sarris 2001; 2003; NAPC 2010a). Therefore, Syrian government tended toward phase out of centrally planned mechanisms and gradually switched to indicative planning procedures. This gradual abolition of centrally planned economic system was to prevent the sharp decline of agricultural output, which the countries of Central and Eastern Europe and the former Soviet Union had suffered from when they suddenly abolished the central plan (Wehrheim 2003).

The gradual changing towards indicative planning procedures is coincided with more liberal agricultural policies represented by considerable reduction of state rigidities in crop planning, foreign trade and price controls. In addition, private sector has been allowed to be involved in the production, marketing and processing activities while keeping the state role in terms of controlling resources distribution, partial provision of inputs and marketing and processing of main crops (Wehrheim 2003; Parthasarathy 2003a; NAPC 2007). The gradual move towards indicative planning by the 6th Five-Year Plan (FYP) from 1986 to 1990 was characterized by the involvement of all related parties in the preparation and endorsement of the annual agricultural plan. The plan preparation starts with the issuance by the MAAR of the indicative figures, which include interim quantitative production targets, under the general quantitative production targets set for individual crops in the FYP. In addition, it includes the recommended crop rotations to be adopted by agro-ecological zones for both irrigated and rain-fed farms. These indicative figures are discussed and reviewed at all administrative levels, down to the village, and eventually agreed upon by all concerned parties to provide the MAAR by feedback. The final agricultural plan is submitted by the Monitoring Committee 
chaired by the Minister of Agriculture before the endorsement by the Prime Minister's Office (NAPC 2007).

Since the 10th FYP from 2006 to 2010, Syrian government adopted social market economy system which affords both agriculture and agro-industries more open environment that enables both sectors to integrate with the world economy. As a consequence export and import restrictions were eliminated for countries of Great Arab Free Trade Area (GAFTA) and expand bilateral trade agreements with Turkey and the EU. This creates numerous free trade zones, and enabled Syria to be accepted as an observer in the WTO in 05.04.2010 (NAPC 2010a). Recently, self-sufficiency of vital food staples is still a major agricultural policy's goals. At the same time, the aforementioned policy reform procedures aim to promote the integration of the agricultural sector into the economy through expanding agricultural trade to play a more important role in achieving food security. Given the production conditions, Syria's agriculture competitiveness on international standards is indeed substantial for some agricultural products, particularly Mediterranean ones. Policy objective is to remove related constraints in order to increase the economic and social benefits from agricultural production (Wehrheim 2003; NAPC 2010a).

\subsubsection{Agricultural inputs policies}

The Syrian agricultural inputs policy was characterized by the state supplying agricultural inputs, directly by public sector establishments with support prices or as subsidized in-kind loans. The state subsidy of production inputs contributed to the considerable growth rates of the agricultural production by use of improved seeds and fertilizers. Thus, it enhanced farmer profit of crops that cost of inputs accounts for a significant portion of the cost of production such as wheat and cotton. On the other hand, the cost of agricultural production price subsidies constituted a tremendous burden to the state budget, e.g., the estimated losses of price subsidies for wheat, cotton and sugar beet amounted to about 4.5\% of GDP in 1999 (Sarris 2001). Since the early 1990’s, the agricultural inputs policy was gradually shifted towards reduction of state supporting of most inputs and enabling private sector participation in producing, importing, and marketing inputs. This orientation aimed to release the pressure on the state budget and to cope with the international changes. These conversions terminated by a wide liberalisation of inputs in 2009 with sharp increasing of input prices. The fertilisers varieties increased by 76 to $160 \%$; also fuel price recorded a sudden increase in 2008 with $180 \%$ comparing to 2007. Even though, the fuel price is still 
lower than in neighboring countries and it is subsidized for agriculture as well as other economic sectors (Sarris 2001; NAPC 2009; NAPC 2010a).

In order to compensate the increase of the agricultural input prices, the Syrian government relies on specific payments (special compensation program) instead of extensive support, namely support policies. To implement the agricultural inputs policies, Agricultural Production Supporting Fund (APSF) was established, in 2008, to support farmers with direct payments depending on cropped acres of supported crops. In the agricultural season 20092010, APSF provided farmers who implemented the production plan designed by MAAR with cash payments in SYP. Cotton farmers are supplied by 8,000/ha plus 3000/season, maize 10,000/ha, potatoes 6,000/ha, field tomatoes 5,000/ha, greenhouse tomatoes 1,000/house, apples 10,000/ha, olives 5,000/ha and citrus 14,000/ha (NAPC 2010a). Furthermore, a portion of the subsidies are allocated to treat contagious diseases that threaten agricultural production and livestock by providing compulsory control free of charge, but standard treatment materials are not subsidized (NAPC 2009). The General Establishment for Seed Multiplication (GESM) supplies about one third of the improved seeds of limited crops, wheat, cotton, sugar beet, potatoes, barley, lentils and chickpeas with a price equal to the cost (Cafiero 2003).

For food staples subsidies, the government has adopted a programme to subsidize wheat flour bread, sugar and rice. Consumers pay half prices for the bread at state-subsidized bakeries comparing to that at private bakeries. In addition, ration cards are used to provide consumers with subsidized sugar and rice, 0.5 kilogram $(\mathrm{kg})$ of rice and $1 \mathrm{~kg}$ of sugar/ person/month, with a price 50\% lower than the market price (NAPC 2010a).

\subsubsection{Strategic crops policies}

From the agricultural policy viewpoint, crops in Syria are classified into strategic crops and other crops. The former are cotton, wheat, barley, sugar beet, tobacco, lentil and chickpea were characterized by an intensive system of state interventions due to their high importance in the Syrian agriculture. They account for almost $90 \%$ of the total Syrian crops, and $75 \%$ of the planted area, consuming $89 \%$ of the total water supply and with a significant role in food security, agro-industry, employment and water supply consuming as shown in Table 2.6 (Westlake 2003; IFAD 2009). After the recent inputs liberalization, state support has been restricted on supplying of improved seeds for strategic crops by the GESM. It has improved and marketed all required quantities of cotton and sugar beet seeds, 35-50\% of wheat seeds and only $1 \%$ of barley seeds. Therefore, the remaining quantities of wheat and barley seeds 
and all lentils and chickpeas seeds demand are supplied by farmers or the private sector. General Organization for Tobacco supplies all of tobacco seeds demand (NAPC 2010a).

Prices of strategic crops are affected directly by government pricing policy where the state monitors fixed prices based on unit costs of production, with the objective of ensuring that farmers are able to cover the costs and make some profits (NAPC 2007). State prices for wheat, barley, cotton, tobacco and sugar beet are determined according to the actual cost plus a profit margin of $25 \%$ of the total cost. The price of sugar beet is determined according to its degree of sweetness. The General Organization for Sugar calculates the price per tonne of beet specified with the sucrose content of $16 \%$. The price's formula is adjusted by a fixed SYP premium or discount for every percentage point of beet's sucrose content is above or below $16 \%$, respectively, whereas cotton pricing considers the delivery time and quality, the early delivering the best price (Westlake 2003). A specific subsidy for cotton farmers is supposed be state with SYP 8,000/ha plus SYP 3,000/season (NAPC 2009). As a result of international price increase and liberalization of fuel and fertilizer prices, the prices of the strategic crops have started to rise since 2005. The evolution of these prices from 1999 to 2008 is presented in Table 2.6.

Despite considerable liberalisation in recent years, the Syrian government still heavily intervenes in the marketing of most of the strategic agricultural products. From this point of view, strategic crops can be divided into two subsectors. Cotton, sugar beet, and tobacco, which farmers have to sell all produced quantities at the determined price to public sector agencies. This maintains the governmental status of the monopoly of purchasing and processing of these crops. However, this is not the case for wheat and barley since farmers have the possibility to sell their production to private purchasers in the high-production years. Lentil and chickpea farmers can sell their production to public sector agencies at state price or to private purchasers at market prices (Sarris 2001; Westlake 2001; Sadiddin and Atiya 2009). The year 2006 was the latest year for purchasing barley, lentil and chickpea by public sector agencies (MAAR 2011). From 2010, lentil and chickpea prices have been subjected to supply and demand without state intervention on the floor price (NAPC 2010a).

The annual plan is the core element of the national planning system. It guides farmers towards a systematic land use that is governmentally perceived as the best option to meet the national objectives. Given most irrigated areas face severe water constraints, land use is highly restricted by water aspects, particularly for summer crops which tend to substantially consume more water than winter crops. Consequently, the upper limit to the land percentage 
that will be planted in summer should be set. Cotton as a summer crop occupies the highest share of total available irrigated land. Therefore, cotton license policy sets a limit to the expansion of cotton area. This license is changeable due to the annual availability of irrigation water, and changes in the expected world cotton price. To accomplish the annual plan purposes; license policy controls, as well, the cultivated area of the following items: maize, potatoes, olives, citrus, apples, grapes, pistachios, figs, cherries. Licenses policy for the mentioned crops is limited to farms with over one hectare (Westlake 2001).

Table 2.6: Contribution of strategic crops to both cultivated and crop land, and development of their state prices, 2002-2011

\begin{tabular}{|c|c|c|c|c|c|c|c|c|c|c|}
\hline \multirow{2}{*}{ Year } & \multicolumn{2}{|c|}{$\begin{array}{l}\text { \% Contribution to } \\
\text { strategic crops }\end{array}$} & \multicolumn{8}{|c|}{ Development of the state prices (SYP/kg) } \\
\hline & $\begin{array}{c}\text { Cultivate } \\
\text { d land }\end{array}$ & $\begin{array}{l}\text { Crop } \\
\text { land }\end{array}$ & $\begin{array}{l}\text { Wheat } \\
\text { durum }\end{array}$ & $\begin{array}{l}\text { Wheat } \\
\text { soft }\end{array}$ & Cotton & Barley & $\begin{array}{c}\text { Sugar } \\
\text { beet }\end{array}$ & Tobacco & Lentil & Chickpea \\
\hline 2002 & 62.4 & 87.3 & 11.8 & 10.8 & 30.75 & 7.5 & 2.25 & 80.98 & 17.0 & 17.85 \\
\hline 2003 & 64.6 & 89.3 & 11.8 & 10.8 & 30.75 & 7.5 & 2.25 & 69.42 & 17.0 & 17.85 \\
\hline 2004 & 65.4 & 89.6 & 11.8 & 10.8 & 30.75 & 7.5 & 2.25 & 80.98 & 17.0 & 17.85 \\
\hline 2005 & 67.2 & 90.2 & 11.8 & 10.8 & 30.75 & 7.5 & 2.25 & 80.98 & 20.0 & 17.85 \\
\hline 2006 & 63.9 & 89.9 & 11.8 & 10.8 & 30.75 & 9.0 & 2.70 & 93.50 & 20.0 & 25.00 \\
\hline 2007 & 61.6 & 89.0 & 11.8 & 10.8 & 30.75 & 9.0 & 2.70 & 134.59 & 23.0 & 25.00 \\
\hline 2008 & 59.1 & 87.8 & 17.0 & 16.5 & 41.00 & 15.0 & 3.75 & 110.55 & 24.0 & 25.00 \\
\hline 2009 & 54.6 & 87.8 & 20.0 & 19.5 & 42.00 & 16.0 & 3.75 & 127.00 & 24.0 & 25.00 \\
\hline 2010 & 62.1 & 90.0 & 20.5 & 20.0 & 42.00 & 16.0 & 4.50 & 123.00 & - & - \\
\hline 2011 & 56.7 & 88.4 & 21.5 & 21.0 & 42.00 & 17.0 & 4.50 & 123.00 & - & - \\
\hline
\end{tabular}

Non-strategic crops, fruit and vegetables as well as livestock and other related products are freely traded by the private sector, at all levels of the market chain. Price monitoring and controlling exist at the wholesale and retail level for most food products (Sarris 2001).

\subsubsection{Land tenure policies}

The current land tenure system in Syria is based on socialism paradigm. Land tenure legislation was issued in 1958, Agricultural Relations Law (No. 134) and the Agrarian Reform Law (No. 161). According to these laws, the maximum ownership is determined by 80 ha of irrigated land or 300 ha of rain-fed land per owner. In addition, the owner can also keep a maximum 40 ha of irrigated land or 160 ha of rain-fed land to his family, distributed as 10 ha of irrigated land or 40 ha of rain-fed land to his wife and each of his children (Persons 1959; Keilany 1980). This law was followed by some modifications which increased the acres of irrigated lands by wells and rain-fed land in zones 4 and 5. Consequently, 22\% of cultivable land was expropriated by the state in early 1960's to distribute to 150,000 households representing $27 \%$ of the rural population. Lots were distributed per household by 
maximum 8 ha of irrigated land or 30 ha of rain-fed land. In family case, the parts were divided by 3 parts for parents and one part per child or 1.25 parts for single man and one part for single woman. Since, one part equals 0.8 ha of irrigated land or one ha of rain-fed land (Garzouzi 1963; Keilany 1980; Forni 2003; personal communication with Agricultural advisory center in Al Hasakah 2009). The rest of expropriated hectares are invested by state farmers or rented to private farmers. Hectares ceiling established by land reform is specified by ownership. Therefore, there is no legal obstacle to operate a larger scale farms by renting from private or state land (Forni 2003).

Land reform farms are a complicated form of ownership. Land reform beneficiaries consider themselves as the real owners of such farms with their right of renting and inheritance. However, in the state point of view, land reform farms are classified under the term of state land, and the farmers only have usufructuary rights, not wholly private property rights. Laws of 1958 stated the right of land reform beneficiary to apply for private ownership twenty years after getting the land and payment quarter of the land price by annual dues. This point is an open issue due to the political, social and ethnic aspects and absence of possessing and inheritance mechanisms (Sarris 2001; Forni 2003). There are many cases in which the householder is dead, and his/her successors operate the farm without getting the final private ownership, particularly in north-eastern of Syria where the Kurdish people are concentrated (personal communication with wheat-cotton farmers in Al Hasakah.2010). Consequently, the common classification of land ownership in Syria comprises state land, land reform and private land. Land reform farms officially belong to the state, and at the same time it is privately operated. Therefore, we can say that the state land accounted for about half of all cultivated land, but the agricultural production is almost totally privately based. State land also includes state farms, forests, pastures, which used by herders under traditional rights of access, public purpose land, and uncultivable land. Private land includes mainly cultivated land ingrained or irrigated conditions, which are operated by individuals or companies (Sarris and Corsi 2003; NAPC 2010a).

This complicated land tenure system affects the tenure system in Syria by existing of multiple tenure systems. In such overlapping systems, the households operate three farms with different ownerships at the same time; private farm, land reform farm and another as a squatter. Conversely, we distinguish the absentee holders who obtained some hectares by land reform, but do not cultivate them either due to their occupation by another job or due to the far distance between their homes and the location of the obtained farm (NAPC 2002; Forni 2003). The lengthy land reform policy compound with population growth, inheritance system 
constitutes a big pressure on land and enhances the fragmentation of agricultural holdings. This structure restrains the efficient utilisation of land resources and mechanisation (NAPC 2010a). Agricultural production carried out by a large number of small farm holdings since approximately two-thirds of all holdings accounted an area of 2 ha and below (CBS 2010). This holding size varies among regions, where the smallest holding size prevails in the coastal plain with an average of 1.3 ha/holding with intense land resource use. However, the largest holdings concentrated in the eastern region with average 27.8 ha/holding in Ar Raqqa and 18.2 ha/holding in Al Hasakah with many fallow lands due to absentee holders (Wattenbach 2006).

\subsubsection{Monetary and fiscal policies}

\subsubsection{Exchange rate (ER) and currency policies}

Syria's ER policy is considered as one of the most important macroeconomic policies affecting the development of the agricultural sector. It compensates for the policy effects of other economic sectors. Syria had implemented a multiple ER systems. In another word, ER applied for imports of agricultural inputs were different from those for import and export of agricultural commodities. Furthermore, holding or exchanging foreign currency has been tightly regulated for decades and it was considered a crime punishable with prison (Maletta 2003; Wehrheim 2003). From the early 1990’s, a substantial progress reform of the foreign ER has been gradually taking place by the unification of various ER and a devaluation of all exchange rates to be closer to the prevailing market ER. This reform progress was terminated in 2002 by unified ER system instead of multiple ones. In addition, Syrians are allowed to retain foreign currency or to exchange with Commercial Bank of Syria at market rates. This permission is confined only to personal purposes, mostly tourism and remittance, at a rate that is closely to the prevailing rate at the black market (Sarris 2001; Maletta 2003; Wehrheim 2003).

The unification of the ER which is relevant for agricultural production started in 1992 since, the ER at which pesticides had to be imported was increased from SYP 11.25 to USD 40. In 1994, the same happened for that of fertilizers from SYP 11.25 to USD 43 (Table 2.7). An adjustment of similar magnitude followed with respect to the ER at which was imported. Finally, in 2000 all agricultural related ER were imported from the old value of SYP11.25 to approximately USD 46 (Sarris 2003). In the progress of justification the multiple ER closer to the real one which reflects the actual ER for the SYP, in 2003, ER was abridged in two prices. 
The first one is specified with the transactions of the state and public sector, which reached SYP 50/one USD. The second one is related to persons and private sector transactions determined by international ER, which was ranked between SYP 53.33 and 53.75/one USD at that time. In 2007, the ER decreased to be less than SYP 50/1 USD (NAPC 2007).

Table 2.7: Exchange rate developments of selected items by SYP per USD, 1990-2000

\begin{tabular}{lccccccccccc}
\hline Exchange rate & 1990 & 1991 & 1992 & 1993 & 1994 & 1995 & 1996 & 1997 & 1998 & 1999 & 2000 \\
\hline Official & 11.25 & 11.25 & 11.25 & 11.25 & 11.25 & 11.25 & 11.25 & 11.25 & 11.25 & 11.25 & 46.50 \\
Fertilizers & 11.25 & 11.25 & 11.25 & 11.25 & 43.00 & 43.00 & 43.00 & 45.00 & 46.50 & 46.50 & 46.60 \\
Pesticides & 11.25 & 11.25 & 40.00 & 40.00 & 43.00 & 43.00 & 43.00 & 45.50 & 46.50 & 46.50 & 46.70 \\
Agro- Exports & 11.25 & 11.25 & 11.25 & 11.25 & 11.25 & 11.25 & 11.25 & 11.25 & 11.25 & 11.25 & 46.80 \\
Agro-Imports & 11.25 & 11.25 & 11.25 & 11.25 & 11.25 & 11.25 & 11.25 & 11.25 & 11.25 & 11.25 & 46.90 \\
Black Market & 46.45 & 45.84 & 50.48 & 49.67 & 51.20 & 50.00 & 51.00 & 51.00 & 51.00 & 51.00 & 51.00 \\
\hline
\end{tabular}

Source: Sarris 2003

Foreign currency revenues from agricultural trade have been restricted in the 1990s. Syrian exporters were obliged to abdicate $25 \%$ of foreign currency earnings from exports, and substitute it by SYP at the locally prevailing ER in 1990's (SYP11.25/ one USD), which was far below the respective international ER. On the import side, the importer had to prove that the owned foreign currency needed for imports was earned from exports. In addition, customs duty applied for importing some of food staples such as wheat, sugar, rice, etc. calculated at locally prevailing ER in 1990's (SYP11.25/ one USD). While, the foreign currency required for imports can be obtained from Commercial Bank at international ER in that period (SYP 50/one USD) (Sarris 2003). Government Decree No. 1184 dated of 19.09.2002 has been unified the ER of customs duty applied for agricultural imports with the international one. Additionally, commercial bank share of foreign currency revenues was reduced to only $10 \%$ of total exports revenue which was substituted by SYP at national ER. This legislation excepts public and private exporters of vegetables, fruits and table eggs which are allowed to keep all of their export proceeds in foreign currency (NAPC 2010a).

\subsubsection{Agricultural credit policy}

Agricultural Cooperative Bank (ACB) is the only official organisation that financed agricultural activities for public, cooperative, and private agents in Syria. It provides short, medium and long-term loans dependent on the purpose of use. Short-term loans are supplied in-kind, seeds and fertilizers, and in-cash to finance farm operations. The largest share of macro elements fertilizers are sold by ACB stores either directly to farmers or through in-kind seasonal loans according to the permitted quantities stipulated in crop licenses (Parthasarathy 2003b). Medium-term loans are specialised to finance land reclamation, irrigation equipment, 
greenhouses, animal purchase, poultry farm equipment, fence and terrace construction and banana plantations. Long-term loans are intended for land improvement, storage facilities and cold storage units, forestation projects and fruit trees. Short-term loans do not exceed 300 days, and they are due by the first of August for winter crops and the first of December for summer ones whereas medium and long term loans are given for maximum 5 and 10 years, respectively (NAPC 2007).

Interest rate of ACB loans are governmentally fixed neither market-driven nor updated macro-economic situations (Parthasarathy 2003b). It varies for each loan according to the beneficiaries (Table 2.8). In order to mitigate drought consequences, ACB fully or partially reschedules the repayments of short-term loans depending on the extent of damage. If damage is more than $30 \%$ of the debtors' average annual yield, $50 \%$ of the sum due is rescheduled whereas the total sum is rescheduled when the damage is more than $60 \%$. The deferment applies to the principal, but interest must continue to be paid. The repayment in equal instalments is allowed over three, and sometimes for five years as it took place in 2002, 20072009 period and 2012. When repayment capacity is affected by drought, there is no possibility to loans rescheduling for medium and long-term loans (Parthasarathy 2003b; NAPC 2010b; MAAR 2013).

Table 2.8: Interest rate of the ACB loans (\%) in 2012

\begin{tabular}{lccc}
\hline Loan type & Public sector & Cooperatives & $\begin{array}{c}\text { Individuals and } \\
\text { joint sector }\end{array}$ \\
\hline Short-term & 3.50 & 9.00 & 10.00 \\
Medium-term & 3.50 & 10.00 & 11.00 \\
Long-term & 3.50 & 11.00 & 12.00 \\
Delay interest & 0.25 & 14.00 & 14.00 \\
\hline
\end{tabular}

Source: SANA 2012

In some cases, farmers are not able to obtain agricultural loans from ACB because of their overdue installments to the ACB, or in order to finance illegal activates such as establishing well without licence or cultivating cotton over licensed area. In such cases, traders, exporters' agents or owners of cold storage units can be considered as unofficial financier for agricultural producers by a simple contract which includes the price and the way of payment such as direct advances ahead of the season or by an agreement on a lump sum to be paid to the farmer for the entire output (NAPC 2002).

\subsubsection{Agricultural tax policy}

As in many other countries, the agricultural sector benefits from various preferential tax treatments with the aim of subsidizing agricultural production and supplying food staples 
at reasonable prices. Most notably, tax exemptions have been introduced for farm income, all production and consumption cooperatives, agricultural investments, agricultural labour housing, warehouses of agricultural products and barns. Symbolic tax is imposed on farm animals, which are taxed annually per head at the following rates, sheep and goat SYP 2.25, camels SYP 4, cattle SYP 7 and pigs SYP 11 (Wehrheim 2003; NAPC 2007). Tax applied on agro-industry products ranged between 10 and 12\%. Then it was exempted in 1999 for textile industry, and for all agro-industry products by 2001 (Sarris 2003).

On the export side, agricultural exports were governed by tax ranges between 9.5 and $12 \%$ of the production value. However, since early 1990's gradual exemptions from these export taxes has occurred. These exemptions started for exports of dry and frozen vegetables of superior quality, followed by all fruits and vegetable, olive oil in 1996, cotton in 2000 and finally in 2001 Government Decree No.15 exempted all agricultural commodities from the export tax. Furthermore, the Syrian government has abolished the income taxes of all agricultural export revenues (1\% of all earnings from exports plus a tax on foreign currency earnings of one-tenth SYP/USD) which were valid until 2001 (Wehrheim 2003; NAPC 2010). The custom tariff schedule has been recently modified to reduce the import tariff of agricultural inputs to the minimum level. Under the policy of domestic production protection, import tariff of products similar to the locally produced ones that cover the local demand was raised to the maximum level (NAPC 2010a). The same was done for luxury products such as Caviar 100\% (Syrian customs 2013).

\subsubsection{Water resource policy}

Syrian water resources are very limited in comparison with the country needs, since last estimations show that the water balance for Syria is almost negative with a considerable deficit. Under these facts, there is a growing preoccupation for sustainable irrigation water policies aimed to climb the efficiency of water use in agriculture and to preserve water resources by reducing future consumption (Varela-Ortega and Sagardoy 2003). Of major importance in this context is the adoption of modern irrigation techniques which are crucial for the country's development of irrigated agriculture. The related authorities such as MAAR and the Ministry of Irrigation are actively encouraging irrigation modernization policies such as:

- Government Decree No. 26 dated in May 2005, which adopted establishment of the Directorate of National Project for Irrigation Modernization to supervise the 
modernization of irrigation schemes in all irrigated areas for a decade starting from 2006 (Munlahasan 2007).

- Presidential Decree No. 91 dated in September 2005, which adopted establishment a fund for financing the national plan of modern irrigation with a capital of SYP 52.2 Billion. It concerns farmers who want to adopt new irrigation techniques as long-term loans without any interest, and it gives the priority for beneficiaries located in the water-deficit basins. These loans have to be repaid within 10 years after a grace period of two years. It is also worth mentioning that the fund contributes to $50 \%$ of the modern irrigation cost, in addition to ACB commission (7\% of the credit value), but if the beneficiary pays $40 \%$ of the cost in cash, the fund covers the rest (Munlahasan 2007; NAPC 2010b).

- Government Decree No. 122 dated in January 2008, which obligates the application of modern irrigation techniques for both licensed wells and compressed public irrigation canals.

- Licenses cover unlicensed wells in case of construction of modern irrigation schemes (NAPC 2010a).

In the context of sustainable use of groundwater aquifers, several procedures were taken by the government. They include banning of well drilling, limitation of well deepening licenses and installation of flow meters in wells, and banning pumping system installation in water channels in water-deficit basins. Additionally, the annual state plan tended to minimize the percentage of the land planted by summer crops, and outlawed the pumping system installation in water-deficit basins (Westlake 2001; Varela-Ortega and Sagardoy 2003). Concerning to public irrigation scheme fees, the government determines these fees by SYP 600/ha for winter crops and SYP 3500 /ha for summer ones (NAPC 2007).

\subsection{Agricultural production}

\subsubsection{Plant production}

Plant production in Syria can be divided into three groups: field crops, vegetables and fruits. Field crops contribute to the majority of Syrian plant production in terms of area and production. They include cereals, legumes, grazing crops and industrial crops. According to Syrian Agricultural Database (SADB) 2013, Table 2.9 highlights some indicators including area, yield and production related to plant production for both rain-fed and irrigated areas 
from 2005 to 2011. Irrigated agriculture contributes to three-quarters of the total agricultural production, although it accounts on average about $30 \%$ of the planted area in the mentioned period. In general, the cropped area considerably decreased from 4,967 thousand ha in 2005 to 4,646 thousand ha in 2011 due to the droughts prevailing from 2006-2008. This degradation was for both irrigated and rain-fed lands comparing with considerable rising for fallow lands. On average, cropped area was composed of about $79 \%$ field crops, $4 \%$ vegetables and $17 \%$ fruit trees. We notice an increasing trend for vegetables and fruit trees areas with the exception of that related to rain-fed vegetables while, irrigated and rain-fed areas, which related to field crops, were characterized by a decreasing trend. The general upward trend for vegetables and fruits area in comparison with that for field crops can be explained by the farmers' preferences. Farmers switched to vegetable and fruits cultivation due to their high returns by new export markets to eliminate the drought effects, but this switching is still limited due to the restriction of the agricultural plan supposed by the government (NAPC 2010a).

Yield and productivity maximisation by vertical expansions are essential factors in agriculture, particularly in the case of limited availability of land resources such as Syria. The 10th FYP from 2006 to 2010 went awry to increase agricultural yield for both irrigated and rain-fed cultivation (NAPC 2010a). Apparently, yield of rain-fed agriculture dramatically decreased in detected period with the exception of fruit trees yield which is characterized by putting in an additional number of fruitful trees over years and the facility of modern irrigated utilisation as a supplemental irrigation system in rain-fed trees lands. Indeed, rain-fed land which contributes to the majority of cultivated land is characterized by very low productivity, much lower than that of irrigated land. That means a high loss of agricultural production compared with that if the supplemental irrigation is enabled. It is worth mentioning that, similar to yield of rain-fed agriculture, yield in irrigated areas have varied considerably from year to year particularly for field crops (Pannell and Nordblom 1998). Given that irrigated production is more controlled than rain-fed production, the logical expectation is the variability of irrigated yields would be smaller than that of rain-fed ones. In fact, this does not appear to be the case in Syria. This is substantially regarding the agricultural plan and land license policy which is strictly applied in field crops areas. It obligates the farmer to cultivate certain acres and supply him by inputs on the basis of these acres. Since the farmer has a limited opportunity to manipulate the licensed area, he may compensate this, in order to achieve his production goals by varying amounts of actual applied inputs, and consequence yields (Sarris 2001). 
Most of the Syrian agricultural production comes from field crops. However, similar to the crop's area and yield, the production of field crops decreased from $62 \%$ to $56 \%$ of the total Syrian agricultural production between 2005 and 2011, in comparison with notable increasing of fruit trees production from $18 \%$ to $24 \%$ of the total agricultural production over the same period. Under the expanding of drought threat, the contribution of irrigated production increases comparing with that of rain-fed, to reach about $80 \%$ of the total agricultural production in 2011.

Table 2.9: Harvested area, yield and production of plant production groups in Syria, 20052011

\begin{tabular}{|c|c|c|c|c|c|c|c|c|c|c|}
\hline Category & Plant & $\begin{array}{c}\text { Water } \\
\text { supply }\end{array}$ & 2005 & 2006 & 2007 & 2008 & 2009 & 2010 & 2011 & $\begin{array}{l}\text { Growth } \\
\text { rate }\end{array}$ \\
\hline \multirow{6}{*}{$\begin{array}{c}\text { Area } \\
\text { (‘000ha) }\end{array}$} & Crops & Irrigated & 1,276 & 1,236 & 1,217 & 1,185 & 1,048 & 1,132 & 1,183 & -1.14 \\
\hline & & Rain-fed & 2,639 & 2,503 & 2,457 & 2,369 & 2,216 & 2,550 & 2,228 & -2.78 \\
\hline & Vegetables & Irrigated & 109 & 101 & 125 & 120 & 128 & 124 & 127 & 2.58 \\
\hline & & Rain-fed & 80 & 84 & 87 & 86 & 76 & 81 & 76 & -0.85 \\
\hline & Fruits & Irrigated & 144 & 151 & 155 & 167 & 169 & 174 & 187 & 4.45 \\
\hline & & Rain-fed & 719 & 743 & 770 & 777 & 804 & 814 & 845 & 2.73 \\
\hline \multirow{6}{*}{$\begin{array}{l}\text { Yield } \\
\text { Kg/ha }\end{array}$} & Crops & Irrigated & 5,150 & 5,400 & 5,260 & 4,080 & 5,280 & 4,540 & 5,800 & 2 \\
\hline & & Rain-fed & 830 & 1,100 & 720 & 180 & 700 & 610 & 620 & -4.75 \\
\hline & Vegetables & Irrigated & 21,950 & 22,280 & 21,580 & 20,660 & 22,150 & 20,970 & 22,140 & 0.14 \\
\hline & & Rain-fed & 4,050 & 2,840 & 1,950 & 1,420 & 2,140 & 1,750 & 1,680 & -13.64 \\
\hline & Fruits & Irrigated & 9,953 & 10,981 & 10,826 & 10,693 & 11,510 & 10,265 & 10,537 & 0.95 \\
\hline & & Rain-fed & 1,614 & 2,304 & 1,147 & 1585 & 1,627 & 1,751 & 1,765 & 1.5 \\
\hline \multirow{6}{*}{$\begin{array}{c}\text { Production } \\
\text { ('000t) }\end{array}$} & Crops & Irrigated & 6,569 & 6,671 & 6,394 & 4,839 & 5,538 & 5,140 & 6,859 & 0.72 \\
\hline & & Rain-fed & 2,192 & 2,753 & 1,769 & 421 & 1,561 & 1,559 & 1,381 & -7.41 \\
\hline & Vegetables & Irrigated & 2,390 & 2,261 & 2,704 & 2,472 & 2,827 & 2,594 & 2,802 & 2.69 \\
\hline & & Rain-fed & 325 & 238 & 170 & 122 & 162 & 142 & 128 & -14.9 \\
\hline & Fruits & Irrigated & 1,435 & 1,658 & 1,674 & 1,789 & 1,947 & 1,783 & 1,968 & 5.41 \\
\hline & & Rain-fed & 1,160 & 1,713 & 883 & 1232 & 1,307 & 1,425 & 1,491 & 4.27 \\
\hline
\end{tabular}

Source: SADB 2013

\subsubsection{Animal production}

Livestock and its products considerably contribute to food security, income generation and employment in Syria. They made up on average 36\% of agricultural GDP over the 20002011, at 2000 Fixed Market Prices (SADB 2013). Table 2.10 shows that livestock number and its production witnessed considerable growth from 2005 to 2011 except fish. Fish production in Syria is limited due to the short of coastal line. The fish stock is estimated at 0.9 tonnes (t) per square mile, which is very low as compared to that of other countries. Additionally, the 
internal lakes and rivers used for fishing or fish farming are very limited, and they are sharply affected by recent droughts (NAPC 2010a).

Since the feed of Syrian sheep depends on open grassing system more than other livestock, which subjected to stockyard one, sheep number and its productivity are slightly affected by the degradation of natural pastures capabilities as drought consequence. Even though, Syrian Awassi sheep are still first source of red meat for human consumption in Syria with on average share of $95 \%$ of the red meat and $40 \%$ of the total meat production between 2005 and 2011. Furthermore, it plays an important position as export-oriented commodity with remarkable share of the total agricultural exports value reached 16.1\% in 2005 (Atiya 2007; NAPC 2010a).

Table 2.10: Enumeration of livestock categories and their production in Syria, 2005-2011

\begin{tabular}{llcccccccc}
\hline Livestock & \multicolumn{1}{c}{ Item } & 2005 & 2006 & 2007 & 2008 & 2009 & 2010 & 2011 & Growth rate \\
\hline \multirow{2}{*}{ Dairy cows } & No. ('000 head) & 561 & 597 & 630 & 607 & 605 & 518 & 611 & 1.43 \\
& Milk ('000t) & 1,506 & 1,616 & 1,706 & 1,609 & 1,600 & 1,453 & 1,702 & 2.06 \\
\hline \multirow{2}{*}{ Cattle } & No. ('000 head) & 1,083 & 1,121 & 1,168 & 1,109 & 1,085 & 1,010 & 1,112 & 0.44 \\
& Meat ('000t) & 55 & 60 & 66 & 64 & 63 & 62 & 71 & 4.35 \\
\hline \multirow{5}{*}{ Sheep } & No. ('000 head) & 19,651 & 21,380 & 22,865 & 19,237 & 18,336 & 15,511 & 18,071 & -1.39 \\
& Milk ('000t) & 766 & 824 & 874 & 713 & 706 & 644 & 706 & -1.35 \\
& Meat ('000t) & 180 & 187 & 205 & 185 & 190 & 153 & 172 & -0.75 \\
& Wool (t) & 21,678 & 24,434 & 24,633 & 20,258 & 21,856 & 18,670 & 21,069 & -0.47 \\
\hline \multirow{5}{*}{ Goats } & No. ('000 head) & 1,296 & 1,420 & 1,561 & 1,579 & 1,508 & 2,057 & 2,294 & 9.98 \\
& Milk ('000t) & 81 & 91 & 97 & 99 & 97 & 139 & 145 & 10.19 \\
& Meat ('000t) & 7 & 7 & 8 & 8 & 8 & 13 & 14 & 12.25 \\
Poultry & Hair (t) & 1,107 & 1,113 & 1,162 & 1,205 & 1,176 & 1,690 & 1,929 & 9.7 \\
& No. ('000 hen) & 23,795 & 30,946 & 26,095 & 23,143 & 24,489 & 25,401 & 26,203 & 1.62 \\
& Egg (Million) & 3,104 & 3,781 & 3,428 & 3,028 & 3,249 & 3,266 & 3,457 & 1.81 \\
\hline Fish & Meat ('000t) & 163 & 175 & 175 & 180 & 184 & 191 & 180 & 1.67 \\
\hline
\end{tabular}

Source: MAAR 2011 and SADB 2013

\subsubsection{Food security}

Over successive FYPs, the most consistent objective of agricultural policy in Syria is the achievement of food security. It can be defined as World Food Summit adopted in 1996: "Food security, at the individual, household, national, regional and global levels [is achieved] when all people, at all times, have physical and economic access to sufficient, safe and nutritious food to meet their dietary needs and food preferences for an active and healthy life" (FAO 2003a). According to this definition, food security depends on food self-sufficiency. This means the ability to produce and/or buy or import food, which has particular relevance in Syria and all Middle East and North African regions. By the commencement of liberalization policy in Syria, the concept of self-reliance has been gradually substituting the concept of 
self-sufficiency. It relies on enhanced exports of products that enjoy a comparative advantage to generate foreign exchange revenues. Consequently, it helps the country to finance food imports, and food purchases at household level (Sarris 2001; Breisinger et al. 2010; Breisinger et al. 2011).

Table 2.11: SSR $^{*}$ and IDR $^{* *}$ of main agricultural products in Syria, 2001-2010

\begin{tabular}{|c|c|c|c|c|c|c|c|c|c|c|c|}
\hline Agro-product & Item & 2001 & 2002 & 2003 & 2004 & 2005 & 2006 & 2007 & 2008 & 2009 & 2010 \\
\hline \multirow{2}{*}{ Wheat } & SSR & 100.3 & 113.1 & 108.9 & 114 & 113.8 & 98.7 & 131 & 93.7 & 69 & 73.5 \\
\hline & IDR & 0.5 & 1.8 & 5.9 & 3.6 & 4.6 & 3.1 & 1.5 & 13.6 & 31 & 27.2 \\
\hline \multirow{2}{*}{ Rice } & SSR & 0 & 0 & 0 & 0 & 0 & 0 & 0 & 0 & 0 & 0 \\
\hline & IDR & 100 & 100 & 100 & 100 & 100 & 100 & 100 & 100 & 100 & 100 \\
\hline \multirow{2}{*}{ Legumes } & SSR & 112 & 114.5 & 134.5 & 168.1 & 157.5 & 152.8 & 145.8 & 210.9 & 97.4 & 116.6 \\
\hline & IDR & 3.8 & 3.7 & 2.2 & 6.6 & 3.7 & 3.6 & 9.2 & 20.3 & 8.3 & 13.5 \\
\hline \multirow{2}{*}{ Cotton fibre } & SSR & 212.3 & 1081 & 181.8 & 146.3 & 177.6 & 145.5 & 121.5 & 117.3 & 76.8 & 295.2 \\
\hline & IDR & 0.2 & 0 & 0 & 0 & 0 & 0 & 0 & 0 & 23.2 & 1.6 \\
\hline \multirow{2}{*}{ Vegetables } & SSR & 110.3 & 108.6 & 107.6 & 107.2 & 109.7 & 109.2 & 123.7 & 130.4 & 138.7 & 130.5 \\
\hline & IDR & 2 & 2.7 & 3 & 4.4 & 5.4 & 2.1 & 7 & 17.9 & 8.7 & 8.9 \\
\hline \multirow{2}{*}{ Fruit } & SSR & 106.0 & 105.2 & 104.6 & 103.3 & 108.5 & 112.7 & 115.3 & 107.4 & 116.1 & 112.1 \\
\hline & IDR & 0 & 0 & 0.2 & 0 & 0.1 & 0 & 0.2 & 1 & 1 & 1.3 \\
\hline \multirow{2}{*}{ Citrus } & SSR & 104.8 & 102.8 & 102.7 & 101.1 & 104.6 & 106.3 & 106.1 & 103.9 & 126.8 & 132.9 \\
\hline & IDR & 0.9 & 1.2 & 1.9 & 2.2 & 2.6 & 2.5 & 2.7 & 4.6 & 4.5 & 4.0 \\
\hline \multirow{2}{*}{ Raw milk } & SSR & 100.1 & 100.8 & 100 & 100 & 100 & 100.2 & 100 & 100 & 100 & 100 \\
\hline & IDR & 0.6 & 0 & 0 & 0 & 0 & 0 & 0 & 0 & 0 & 0 \\
\hline \multirow{2}{*}{ Red meat } & SSR & 102 & 156.3 & 113 & 122 & 126.2 & 100 & 99.3 & 127.5 & 97.9 & 105.7 \\
\hline & IDR & 0.4 & 0.4 & 3.6 & 3.3 & 2.2 & 0 & 0.7 & 3.6 & 13.2 & 15.1 \\
\hline \multirow{2}{*}{ Poultry meat } & SSR & 100 & 100 & 100 & 100 & 100 & 99.4 & 100.9 & 116.6 & 101 & 101.7 \\
\hline & IDR & 0 & 0 & 0 & 0 & 0 & 0.6 & 0 & 0 & 0.4 & 2.8 \\
\hline \multirow{2}{*}{ Fish } & SSR & 87.5 & 55.6 & 55.2 & 55.8 & 59.6 & 48.6 & 45 & 44.4 & 29.3 & 31.4 \\
\hline & IDR & 12.5 & 44.4 & 44.8 & 44.2 & 40.4 & 51.4 & 55.0 & 55.6 & 70.7 & 68.6 \\
\hline \multirow[b]{2}{*}{ Eggs } & SSR & 100.6 & 100.3 & 103.2 & 101.2 & 100.7 & 100.8 & 100 & 100 & 100 & 100 \\
\hline & IDR & 0 & 0 & 0 & 0 & 0 & 0 & 0 & 0 & 0 & 0 \\
\hline
\end{tabular}

Source: MAAR 2011

* SSR=Production / (Production+Imports-Exports) *100

** IDR=Imports / (Production+Imports-Exports) *100

Various indicators can be used to measure food security such as domestic per capita food production, self-sufficiency ratios (SSRs) and the ratio of total exports to food imports, which commonly used to investigate whether a country is food secure (FAO 2003a; Breisinger et al. 2010; Yu et al. 2010). Syrian government's orientation toward intensifying food security integrated with the agricultural trade's growing to influence the SSR, and the import dependency ratio (IDR). SSR illustrates the magnitude of production in relation to domestic utilization, while, IDR tells us the amount of the available domestic food supply has been imported, and the quantity that domestically produced (FAO 2001). As a result, selfsufficiency has been achieved in a variety of products (Table 2.11) such as legumes, cotton, vegetables, fruits, raw milk, eggs, red and poultry meat. However, domestic production of 
crops for sugar, rice, fish, vegetable oils (with the exception of olive oil), dairy products (cheese, butter and dried milk) and maize used for poultry feed.

Despite the attained SSR for main agricultural products, and the recent steady climb of Syria's food security, the achieved food security levels remain much lower than in neighboring Turkey and the international average (Breisinger and Diao 2008). In such context, for many food commodities, the per capita domestic apparent consumption is declined by population growth, which is apparently growing faster than increasing of Aggregate Availability for consumption (Production + Imports - Exports). Table 2.12 shows an adverse impact on the per capita availability of cereals, fruits, vegetables, red meat and eggs during 2000-2008. In general, the per capita consumption of food cereals in Syria is estimated on average $219 \mathrm{~kg} / \mathrm{capita} /$ year during 2006-2008, it is higher than that of the world average, which reached $127 \mathrm{~kg}$ for the same period. Conversely, the Syrian consumption of red meat is much lower than that of the world average consumption. It accounted 9 kg/capita/year between 2006 and 2008 compared with 24 for the average world consumption in mentioned years (NAPC 2010a).

Table 2.12: Availability of selected agricultural products in Syria, 2000-2008 (kg/person/year)

\begin{tabular}{lcccccccccc}
\hline Agro-Product & 2000 & 2001 & 2002 & 2003 & 2004 & 2005 & 2006 & 2007 & 2008 & Growth rate \\
\hline Cereals & 191 & 298 & 249 & 265 & 230 & 236 & 244 & 250 & 162 & -2.04 \\
Fruits & 170 & 143 & 181 & 173 & 157 & 144 & 126 & 126 & 139 & -2.49 \\
Vegetables & 113 & 116 & 153 & 132 & 122 & 112 & 106 & 97 & 100 & -1.52 \\
Red meat & 14 & 13 & 7 & 10 & 10 & 9 & 9 & 8 & 10 & -4.12 \\
Poultry meat & 7 & 8 & 9 & 11 & 11 & 10 & 9 & 8 & 8 & 1.68 \\
Milk & 103 & 98 & 105 & 111 & 118 & 142 & 122 & 116 & 111 & 0.94 \\
Eggs $^{*}$ & 153 & 159 & 193 & 190 & 217 & 169 & 160 & 155 & 152 & -0.08 \\
\hline
\end{tabular}

Source: NAPC 2007 and 2010a

${ }^{*}$ : One egg/person/year

\subsection{Constraints of Syrian agricultural development}

Various intervention projects and policies are embraced throughout all Syrian FYPs targeting multiple objectives: ensure food security, generate new job opportunities and close the gaps of regional disparities in the country (CEDARE 2009). However, successive interventions have not adequately been able to care for the series of constraints and risks that still constitute prominent obstacles to achieving the prospective goals of agricultural improvement. Constraints aggravation minimizes the role of agriculture in the Syrian economic and turns the agriculture to in an ugly environment for labour force and domestic and foreign investments (NAPC 2007). According to the annual Syrian investment report, 
2011, the achieved agricultural projects decreased from 24 to 9 projects between 2007 and 2011. In that direction, the total achieved projects in that period reached 82 agricultural projects compared with 108 for transport and 539 industrial projects.

The last report about The State of Food and Agriculture in Syria (NAPC 2010a), as well as, FAO Agricultural Policy and Economic Development Series (Fiorillo and Vercuei 2003) confronted many challenges affecting the sustainable development of the agricultural sector. These challenges engrave Syrian agriculture by low and variable yields, and thus low and vulnerable net revenues at the farm level since, farm income is strongly dependent on the cash flow earned by the crop production (Pannell and Nordblom 1998; Westlake 2001). The severity of each constraint varied considerably from year to year and from agricultural production system to another. The pervasive and persistent problems of the Syrian agriculture can be summarized by:

1- The limitation of natural and agricultural resources and its impress by climate change:

- Frequent drought waves, as a climate change phenomenon, resulted in a scarcity of water resources. In addition, the allocation of river's water with neighboring countries exacerbates the water scarcity problem. These evidences are exaggerated by the slow adoption of advanced irrigation technologies because of the lack of credits as well as the administrative obstacles. Other risks, which appear to be increasing, perhaps due to climate change, are the increasing frequency of unpredictable cold spells and dust storms.

- Agricultural land constraints include the scarcity of agricultural land, soil degradation, expansion of buildings and constructions and fragmentation of agricultural holdings, which restrain the horizontal expansion and the introduction of mechanization. Serious actions to restrain the impact of these constraints are limited.

- The continuous degradation and desertification of natural pastures in Al-Badia, which are imputed by the intense tillage, overgrazing, and droughts, which negatively affect the availability of fodder and sheep population.

2- Institutional constraints: the Syrian agriculture is stamped by inveterate administrative constraints such as:

- Lack of coordination between the numerous institutions responsible for the agricultural sector management. 
- The incoherence applied agricultural policies and their disability to comply with the development of the agricultural environment related aspects such as the development of agricultural production, the considerations of environmental impact and course resources utilization. The developments of the international relations of Syria and integration with world markets for products which are important to Syrian agricultural trade imply the necessity to reconsider the current agricultural policies.

- The limitation of the government budget allocated for the establishment of an adequate agricultural infrastructure.

- The absence of permanent instruments and security fund to deal with unfair agricultural cases such as droughts and disasters. Only some urgent practices can be provided such as rescheduling loans and exempted from deferral mulcts, license of illegal wells and providing free batch of fodder (NAPC 2010b).

3- Constraints of human resources, which are subject to:

- Low productivity of agricultural labour by Western standards (Pannell and Nordblom 1998).

- Low agricultural labour's income compared with that of other economic sectors, which induces a continuous emigration from rural to urban areas. This emigration exacerbates due to the relatively high population growth and the increasing of drought threat.

- Low educational status among farmers. According to Central Bureau of Statistics in Syria (CBS) 2004, more than 75\% of them are holders of education level less than or equal to elementary (Alhasan and Alnoaimi 2004).

4- The augmentation of agricultural input prices due to the domestic inputs liberalisation policy, particularly fuel price, coincides with international increasing of agricultural input prices which put the agri-business under the risk of instable income.

5- Marketing constraints represented by lack of farmers' experience in agricultural post farm operations, weak concomitance between development of domestic agricultural production and international marketing specifications, and the discrepancy between domestic and international quality standards. These restrictions generate marketing bottlenecks and inefficient utilization of both available production capacities and value-added agriculture.

In what follows, water scarcity and land degradation will be explained in more details. 


\subsubsection{Water scarcity}

Syria belongs to one of the poorest areas in the world in terms of water resources, Middle East and North Africa which stretch within the arid and semi-arid areas. Water is becoming progressively scarce as future demand is coming close or even surpassing available resources. For instance, Middle East region covers $4.9 \%$ of the total area of the world and contains $4.4 \%$ of its population, however, its water resources forms only about $1.1 \%$ of the total renewable water resources of the world (Varela-Ortega and Sagardoy 2003; Frenken 2009; AOAD 2011). Water availability is expressed in cubic metres per inhabitant per year. The total available water resources are lower than the cut-off point of $500 \mathrm{~m}^{3}$, considered being the threshold for absolute water scarcity, which is the case for Israel, Jordan and Palestine. The limit of $1000 \mathrm{~m}^{3}$ indicates chronic scarcity while, less than $1600 \mathrm{~m}^{3}$ is termed as water stress. Water availability is around $10000 \mathrm{~m}^{3}$ or more reflects real water-rich countries such as northern Europe and Canada. Syrian water availability estimated by 1791 $\mathrm{m}^{3} /$ inhabitant in 1995, it sharply reduced to reach $880 \mathrm{~m}^{3}$ in the period between 2005 and 2010. This number is expected to worsen in the future which might drop to $760 \mathrm{~m}^{3}$ in 2020 (Altinbilek 2004; Frenken 2009). In such a context, Syria is still subjected to water deficit. In 2001, MAAR estimations showed that total renewable water resources amounted to 16.058 $\mathrm{km}^{3} /$ year. Whereas, the total water withdrawal reached $19.162 \mathrm{~km}^{3} /$ year with a deficit of $3.104 \mathrm{~km}^{3}$ in the same year (Varela-Ortega and Sagardoy 2001). This deficit increased to 3.5 $\mathrm{km}^{3}$ in 2009 (NAPC 2010a).

Mentioned water scarcity indicators are mostly a result of frequent drought waves since rainwater composes about $44 \%$ of the total renewable water resources in Syria. Drought is the most substantial climate disaster in the country, not only by its frequency, but also by the prolonged periods of low rainfall that occur in different zones at the same time which tend to exacerbate the impacts. About half of recent fifty years are distressed by drought, with an average prolong by four and a half years per decade, particularly in 1970s were drought lasted for 10 consecutive years covering four out of the five agro-ecological zones in Syria (Breisinger et al. 2011; Frenken 2009). The International Disaster Database of the Center for Research on Epidemiology of Disasters (CRED 2009) classified the drought in 1999 which stretched till 2001 and drought in 2008 which started in 2006, among the top 10 natural disasters in Syria since 1990.

From an agricultural perspective, both rain-fed and irrigated agricultural productions are hardly hit by droughts (Figure 2.5). It straightforwardly threatens rain-fed agricultural 
activities, which account the majority of cultivated area, resulted by yield reduction or, in extreme cases, by complete loss of the harvest. For example, the droughts of 1999-2001 and 2006-2008 led to complete filed crop failure in zones 3, 4 and 5 (SADB 2013). Drought effects also lengthen to irrigated agricultural production by lessening ground water supplies and exclusion of some rivers and springs. Precipitations times strongly influence cereals yield, when rain starts late in the season (late of November), much of the seeding is done in dry soil, which threatens seed germination. In addition, stopping rainfall on late April coinciding with high temperatures, threaten the operation of grains fill out. Consequently, cereal yields will be low even though high rain-fall such was the case of 2009 in Syria (ICARDA 2009).

Figure 2.5: Development of rainfall average mm/year, rain-fed and irrigated yields tons/ha of field crops and vegetables in Syria, 1996-2011.

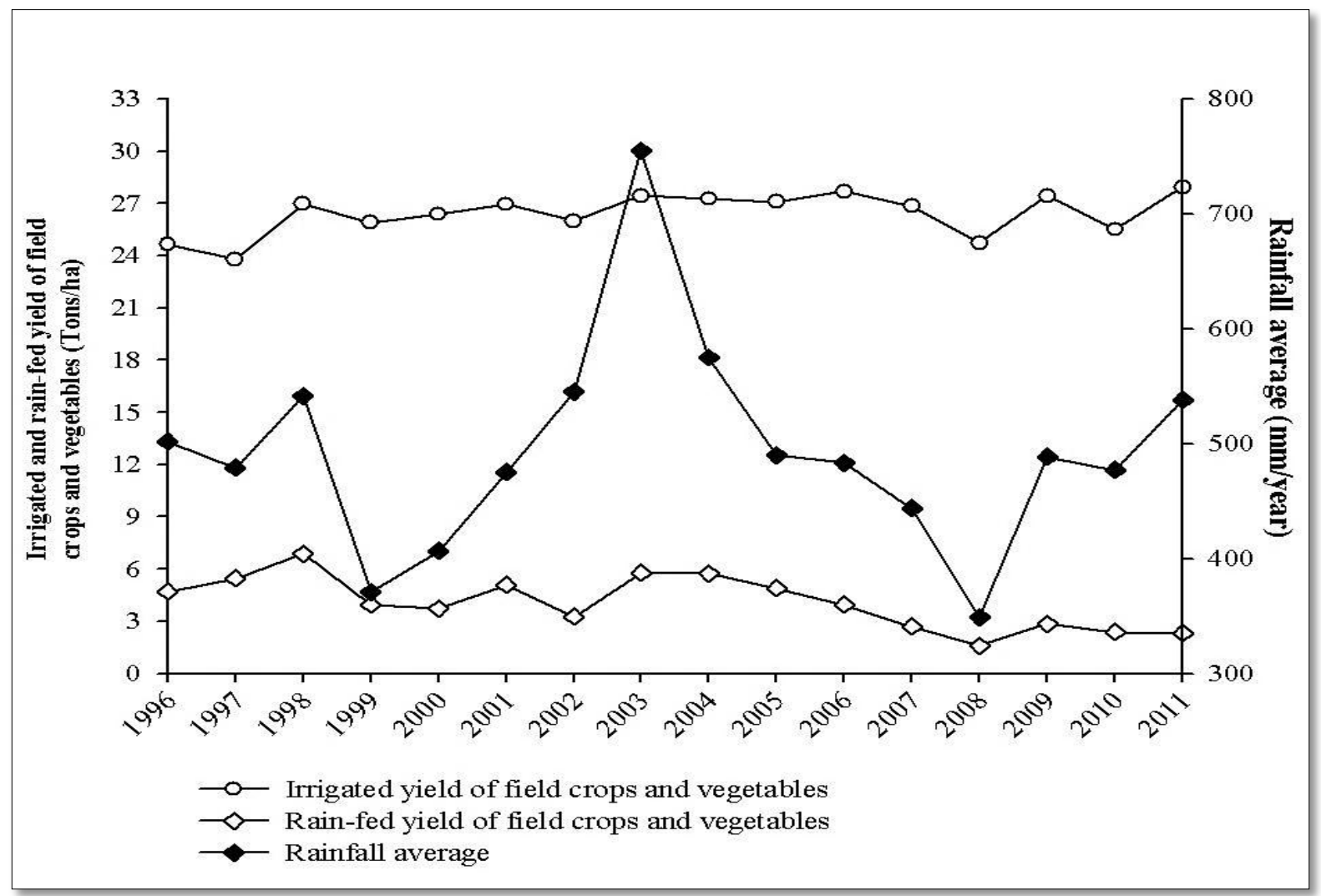

Source: SADB 2013

Recent severe droughts over 2006-2008 have negatively impacted the performance of the Syrian agriculture and as a consequence the livelihood of the rural population all over the country. Almost 1.3 million inhabitants of the eastern region have been affected by this disaster, out of which 803 thousand have lost their livelihoods and faced extreme hardship. Therefore, the government has established an emergency support covering food aid, and farming inputs and animal fodder. The recent droughts did not confine to have only smallscale farmers and herders. They also affected non-farm households by higher food prices, 
since food- and agriculture-related commodities makes up about $50 \%$ of household consumption expenditure. In addition, drought impacts exceed the agricultural sector to other economic sectors and consequent implications on poverty GDP lost, particularly in the case of longer-lasting nationwide drought occurrence (NAPC 2010a; Breisinger et al. 2011).

Diminishing water quantities received from the shared rivers with neighboring countries is still situation of chronic water scarcity. Despite the contribution of all 16 rivers in the country amounts nearly $26 \%$ of the total renewable water resources, they provide the majority of national water withdrawal. The restriction related aspect that the three largest rivers in the country, Euphrates, Orontes and Al-Khabour are externally spring. The renewable surface water resources from the externally coming rivers are estimated by 17.335 $\mathrm{km}^{3}$ /year, of which $15.750 \mathrm{~km}^{3}$ entering annually with the Euphrates, as unilaterally submitted by Turkey. The Euphrates is the largest river in the country, which runs through Syria for 680 $\mathrm{km}$ and has an average flow of $564 \mathrm{~m}^{3} /$ second. In drought season 1999, the Euphrates Basin accounted for about 50\% of total water withdrawal in the country (Salman and Mualla 2003; Frenken 2009). As the population increases, the demand for agricultural products increases and hence the number of water supply projects in the Euphrates. Problems of water quantity resulted in disputes between the riparian nations of the Euphrates Basin: Turkey, Syria and Iraq. Turkey, as the spring country, is considered itself in a strategically strong position that grants it to enjoy its abundant water. Also, Iraq is reliant upon the Euphrates, in spite of uses the Tigris River as well as an alternative source of water. In southeast Turkey, a number of large irrigation projects have been planned to utilize the waters of the Euphrates River (Beaumont 1996; Höhendinger 2006).

It started in 1973, when Turkey constructed the Keban Dam with a capacity of $31 \mathrm{~km}^{3}$. In 1977, Turkey announced plans for South-eastern Anatolia Project, which included 22 dams and 19 hydropower installations on the Euphrates-Tigris. The most two famous dams on the Euphrates River were Karakaya in 1987 and Ataturk in 1992 with a capacity of 9.58 and 48.7 $\mathrm{km}^{3}$ respectively (Frenken 2009). By these projects, the flow of the Euphrates into Syria was substantially reduced. This has already led to complaints from the downstream countries, Syria and Iraq (Beaumont 1996).

To obviate water fallow reduction, Syria, which heavily depends on the Euphrates water, constructed Al Tabqah, which completed in 1973 and filled in 1975 with a capacity of $11.2 \mathrm{~km}^{3}$ (Frenken 2009). The filling of Keban and Al Tabqah dams caused a sharp decrease in the quantity of water entering Iraq, which fell by $25 \%$, causing tension between the 
Euphrates riparian countries, which came dangerously close to a military confrontation between Syria and Iraq (El-Fadel et al. 2002; Akanda et al. 2007). Some efforts were put forth to reduce tensions when the Syrian Arab Republic agreed to take only $40 \%$ of the river's water, leaving the remainder for Iraq. In that direction in 1976, Turkey started to release $450 \mathrm{~m}^{3} / \mathrm{s}$ from the Euphrates downstream (Kaya 1998).

On 13th January 1990, the flow of the Euphrates was stopped for one month for purely technical reasons to fill the Ataturk Dam's reservoir. Turkey claimed that, a month before the filling process got started, it has notified Syria, and the flow was increased to $768 \mathrm{~m}^{3} / \mathrm{second}$. During the filling process, only $60 \mathrm{~m}^{3} /$ second could be released to Syria from catchments downstream from the dam. This created tension and caused a mounting crisis among the basin countries, Syrian and Iraqi media portrayed it as a belligerent act, accused Turkey of not informing them about the shutting off the river flow, Iraq even threatened to bomb the Euphrates dams. Turkey had kept its word after the dam became operational. It returned to previous sharing of water release agreements, even though, the tensions were never completely resolved as downstream demands have increased in the meantime (Kaya 1998; Altinbilek 2004; Akanda et al. 2007).

In connection with ground water, Syria has valuable renewable groundwater resources estimated at $4.8 \mathrm{~km}^{3} /$ year, representing $30 \%$ of the total renewable water resources of the country (Frenken 2009). The Syrian ground water resources are subject to overexploitation since five from all seven main hydrographic basins in Syria are in severe deficit. The tremendous water deficit can be detected in Al-Khabour-Tigris Basin in the deep northeastern with a defect percentage about 50\% during 2006-2008 drought seasons (NAPC 2010a). The extreme exhaustion of groundwater is mostly due to the expansion of the irrigated area coinciding with rapid population growth, and at the same time to compensate the recent decreasing of precipitation (Varela-Ortega and Sagardoy 2003). Concerning the case of the poorest basin (Al-Khabour-Tigris Basin), the groundwater-irrigated area in the basin, where cotton and wheat are intensively cultivated, drastically increased from 88 to 330 thousand ha during the period 1989 to 1994. This increasing was a result of government supported prices for cotton and wheat coupled with subsidized pumping fuel costs have proved to be strong motivations for farmers to construct more wells (FAO 2005).

The number of wells in the basin area has dramatically increased; about one-third of these wells are illegal (Salman and Mualla 2003). Consequently, a severe groundwater overexploitation finishes up by evident negative impacts represented by drying of Al-Khabour 
River and all springs recharge it (FAO 2005) in addition to unstable change in the soil profile texture which recently caused several collapses in some areas of the basin (Galli et al. 2010).

The misused utilization of irrigated water also aggravates the groundwater exhaustion, since the agricultural sector depletes between 85 and $90 \%$ of the total water use in the country. Traditional surface irrigation is the prevailing irrigation system in Syria covering on average 83\% of the total irrigated area from 2000 to 2011 (Table 2.13). This predominant technique used in surface irrigation is summarized, as shown in Figure 2.6, by collecting water in reservoirs, and then it follows throughout the field by furrows which required overpumping of ground water. Thus, irrigation field efficiency is reported to be below $60 \%$. Furthermore, surface irrigation method implies a huge water loss between 10 and $60 \%$ of the water from evaporation and seepage. In 2003, the agricultural sector withdrew 14,669 million $\mathrm{m}^{3}$ to irrigate 1,361 ha, which means an average of $10,777 \mathrm{~m}^{3} /$ ha in that year and the average consumption of the irrigated hectares in the Euphrates Basin reached 16,750 $\mathrm{m}^{3} /$ year. Sometimes, traditional surface irrigation leads to over-irrigation by $47 \%$ more supplemental irrigation than the recommended application rate. These huge quantities necessitate a reconsideration of the current irrigation methods, and signify the insistence of shifting to modern water saving irrigation systems and prevent additional wells establishing (VarelaOrtega and Sagardoy 2003; Frenken 2009; ICARDA 2011).

Figure 2.6: Surface irrigation technique used in wheat-cotton farms in Al Hasakah - Syria

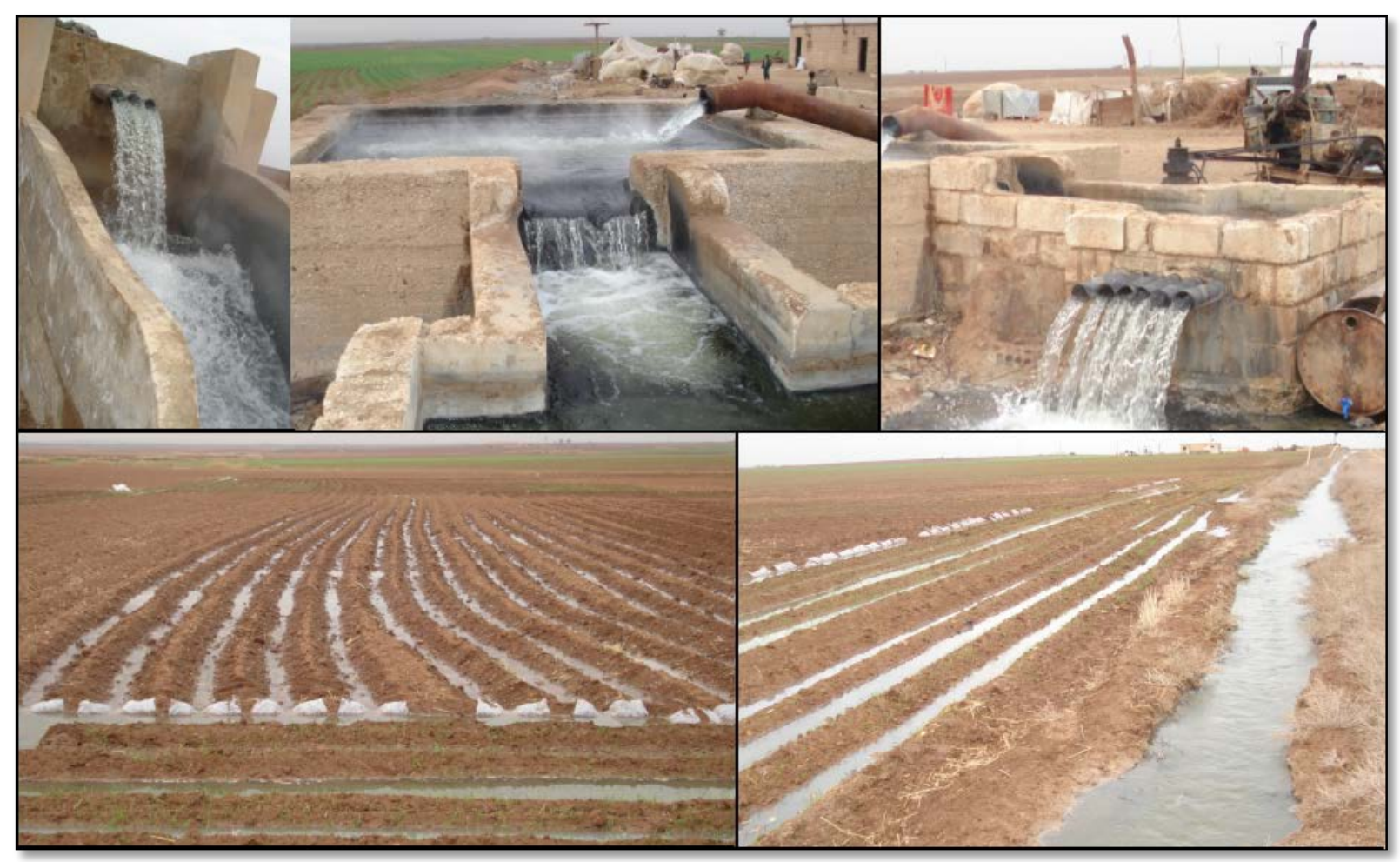

Source: Own photo during collecting data, 2010 
As it is shown in Table 2.13, the modern irrigation area increased from 81 thousand ha in 2000 to 314 thousand ha in 2011. This increasing was for both sprinkler and dropping (localized) irrigation. Between 2000 and 2006, bulk of the increase in irrigated areas has come from construction of new wells. The number of new wells has increased by about 19 and 95\% for licensed and non-licensed wells respectively in that period. After that, a slight decreasing in the irrigated area can be noticed due to the drought spells during 2006-2009. Same decrease can be found in terms of irrigated land by wells because of the synchronous raising of fuel prices, which is the main energy source for irrigation and machinery. Conversely, irrigated lands by rivers, lakes and springs, where water follow by gravity is possible without pumping, were noticeably raised.

Table 2.13: Irrigated land according to irrigation system and sources (' 000 ha), and number of wells ('000) in Syria, 2000-2011.

\begin{tabular}{|c|c|c|c|c|c|c|c|c|}
\hline \multirow[b]{2}{*}{ Year } & \multicolumn{4}{|c|}{ Irrigated area by system } & \multicolumn{2}{|c|}{ Irrigated area by source } & \multicolumn{2}{|c|}{ Number of wells } \\
\hline & Total & Surface & Sprinkle & Dropping & $\begin{array}{l}\text { Rivers, lakes } \\
\text { and springs }\end{array}$ & Wells & Licensed & $\begin{array}{c}\text { Non } \\
\text { licensed }\end{array}$ \\
\hline 2000 & 1,211 & 1,130 & 66 & 15 & 513 & 698 & 74 & 64 \\
\hline 2001 & 1,267 & 1,111 & 112 & 44 & 513 & 754 & 70 & 97 \\
\hline 2002 & 1,333 & 1,118 & 139 & 76 & 515 & 818 & 73 & 102 \\
\hline 2003 & 1,361 & 1,176 & 133 & 52 & 506 & 855 & 81 & 103 \\
\hline 2004 & 1,439 & 1,251 & 130 & 57 & 574 & 865 & 86 & 106 \\
\hline 2005 & 1,426 & 1,182 & 160 & 84 & 561 & 865 & 86 & 116 \\
\hline 2006 & 1,402 & 1,166 & 163 & 73 & 551 & 851 & 88 & 125 \\
\hline 2007 & 1,396 & 1,152 & 164 & 80 & 583 & 813 & 91 & 122 \\
\hline 2008 & 1,356 & 1,101 & 162 & 92 & 595 & 761 & 92 & 131 \\
\hline 2009 & 1,238 & 956 & 179 & 103 & 583 & 655 & 90 & 129 \\
\hline 2010 & 1,341 & 1,043 & 187 & 111 & 614 & 727 & 99 & 131 \\
\hline 2011 & 1,399 & 1,085 & 191 & 123 & 647 & 752 & 103 & 128 \\
\hline
\end{tabular}

Source: SADB 2013 and MAAR 2007, 2009, 2011 and 2013

In the context of irrigation constraints, the seasonal distribution of the available water does not coincide with the Syrian irrigation requirements. As it is known, the typical lowwater season in all basins occurs from July to December, and reaching its lowest level in August and September when water's need climaxes to irrigate winter crops (Akanda et al. 2007).

Non-conventional water resources in Syria are represented by waste water. They doubled from about 300 million $\mathrm{m}^{3}$ in 1993 to about 550 million $\mathrm{m}^{3}$ in 2003 which are totally reused. While, reused agricultural drainage water in 2004 accounted for 2,246 million $\mathrm{m}^{3}$ in 2004. The production of desalinated water in Syria is marginal. It is less than 3 million $\mathrm{m}^{3}$ /year (Frenken 2009). 
With regard to water quality, ground and surface water quality is affected by various pollutants coming from agricultural, industrial and municipal wastewater, e.g. sewage, chemicals, nitrates, leather industry and oil refineries waste. Also, the quality of groundwater has drastically deteriorated by over-pumping and subsequent salinization as well as leaching of fertilizers and pesticides, particularly in drought years (NAPC 2007).

Water pollution indicators were detected near almost all water basins in Syria such as, high concentrations of biochemical oxygen demand, suspended solids, ammonia, nitrates and chrome, particularly in Orientes and Barada (near Damascus) basins. Crops grown in some areas of Damascus countryside showed high levels of lead, cadmium, chromium, and arsenic. High concentrations of arsenic, many times above the permitted threshold, have been found in vegetables irrigated from Quaik River near Aleppo. High percentage of saltiness was discovered in Al-Badia Basin (NAPC 2002).

The orientation towards the use of wastewater to reward water shortage leads to the prevalence of water diseases. This harm raised by using untreated wastewater in irrigation under the absence of the infrastructure needed to wastewater treatment and disposal. In 1996, there were 900 thousands cases of waterborne diseases caused by water contamination in Syria. Animals were attacked by several diseases, such as tapeworm and pulmonary tuberculosis, resulting from the use of untreated wastewater for fodder crop irrigation. High concentration of Coli forum bacteria was detected in the groundwater of Barad and Coast basins which refer to the leaching of sewage water to aquifer (NAPC 2002 and Frenken 2009).

\subsubsection{Soil degradation}

Apart from agricultural land fragmentation, inadequate distribution of holdings, efficiency of land resource utilization and mechanizing of agricultural land, land degradation and dwindling of soil fertility, are actual natural depressions in Syria.

In Syria, around a quarter of the total land suffers from some degree of degradation and deteriorated fertility (NAPC 2007). Soil degradation processes in Syria come mostly from water erosion in mountain regions, wind erosion in the steppe area and salinization in irrigated areas in addition to a modest effect by chemical degradation and urban sprawl (Ilaiwi 2001; NAPC 2002; Edwards-Jones 2003; NAPC 2007). In the following section, the two main types of soil degradation affecting agricultural practices in Syria (wind erosion and salinization) will be discussed. 


\subsubsection{Wind Erosion}

Wind erosion caused about $75 \%$ of the total soil degradation all over the country. It is considered as the most the serious form of soil degradation in Syria (NAPC 2007).

Syrian steppe, or Al-Badia covers 10 million ha or 55\% of the country's land area, the soils of the steppe in Syria are Aridisols, which are characterized by an aridic soil moisture regime under the prevailing annual average of the rainfall drops below $250 \mathrm{~mm}$, weak structural stability and light texture. In other words, $50 \%$ of the soils of Syria are extremely accessible to erosion (Ilaiwi 2001; IFAD 2012).

As a result of the critical expansion of the mechanized cultivation of the rain-fed barley in the Syrian steppe between 1985 and 1990 from 218 to 552 thousand ha over zone 5, (SADB 2013) severe environmental consequences have occurred. These consequences are represented by destruction of the shrubby cover which has the major role in protecting the soil over the years as the natural vegetation cover, subsequently, leaving the soil particles as a subject to the wind's action (Ilaiwi 2001). Gavin the minimum wind speed, required to transport soil particles, is about 5 meter/second, the wind speed in Al-Badia reaches its summit around September as dust storms with 27 meter/second. Thus, official estimations of up to 12 ton/ha/year in Al-Badia, and 570 thousand tonnes of soil/day for the whole country are lost by wind erosion follow by transformation of many areas barren and unusable, which is called desert expenditure (ICARDA pers. comm.; ERM 1998 as cited in Edwards-Jones 2003).

Recently, frequency, duration and intensity of dust storms have remarkably increased, and got worse particularly in the eastern part of the country (IFAD 2012). Out of time, cultivation was governmentally prohibited in the steppe since 1995. Therefore, rain-fed agriculture in the Syrian steppe has suddenly diminished from 268 to 26 thousand ha between 1995 and 1996, then it reached 5 thousand ha in 2000 (SADB 2013).

\subsubsection{Salinization}

Salinization is the major land degradation sort in the irrigated agriculture. EdwardsJones (2003) pointed out that 125 thousand ha are under the weight of a disparate degree of salinization, of which 90 ha suffered from high salinity with electrical conductivity (EC) higher than 16 deciSiemen per meter (dS/m), 25 ha with medium salinity (EC: 8-16 dS/m) and 10 ha with low salinity (EC: 4-8 dS/m). The most affected areas by salinization include 
the Euphrates and Al-Khabour valleys, which are the largest irrigated areas in Syria. AlKhabour Valley spreads over the southeast of Aleppo, and the extreme east of the country.

Soil with high salinity is concentrated in The Euphrates Valley, the largest irrigated area in Syria with high intense cultivation of strategic and industrial crops. The extensive irrigation in the Euphrates Valley began during the fourth millennium BC. The soil salinization was first started with remarkably accelerated process in the late 1940s when cotton was introduced into the area as a large-scale irrigated agriculture with the possibility of using diesel driven pumps (Ilaiwi 2001).

The wastefulness of irrigation water by surface irrigation accompanied with the lack of effective drainage systems led to a rise in the groundwater level and consequently salt accumulation within the root layers by evapotranspiration. In such arid areas, the scarcity of rainwater needed to dissolve the salts generated by the soil exacerbates salinization impacts. The detected ECe values of wells water ranged between 2.6 and $7 \mathrm{dS} / \mathrm{m}$ in Al-Khabour valley (Yigezu et al. 2011) and between 7 and $10 \mathrm{dS} / \mathrm{m}$ in the south of the Euphrates valley. Indeed, surface irrigation system, which mostly requires water storage in uncovered reservoirs, leaving the stocked water as a subject to intense evaporation, which tends to concentrate the salt concentration of the stored water. Therefore, many large areas became out of agricultural use. It has been estimated by 3,000 to 5,000 ha of the irrigated lands that have been abandoned every year, due to extreme salinization (Ilaiwi 2001; Edwards-Jones 2003).

Figure 2.7: Salt accumulation after water evaporation form irrigation furrows

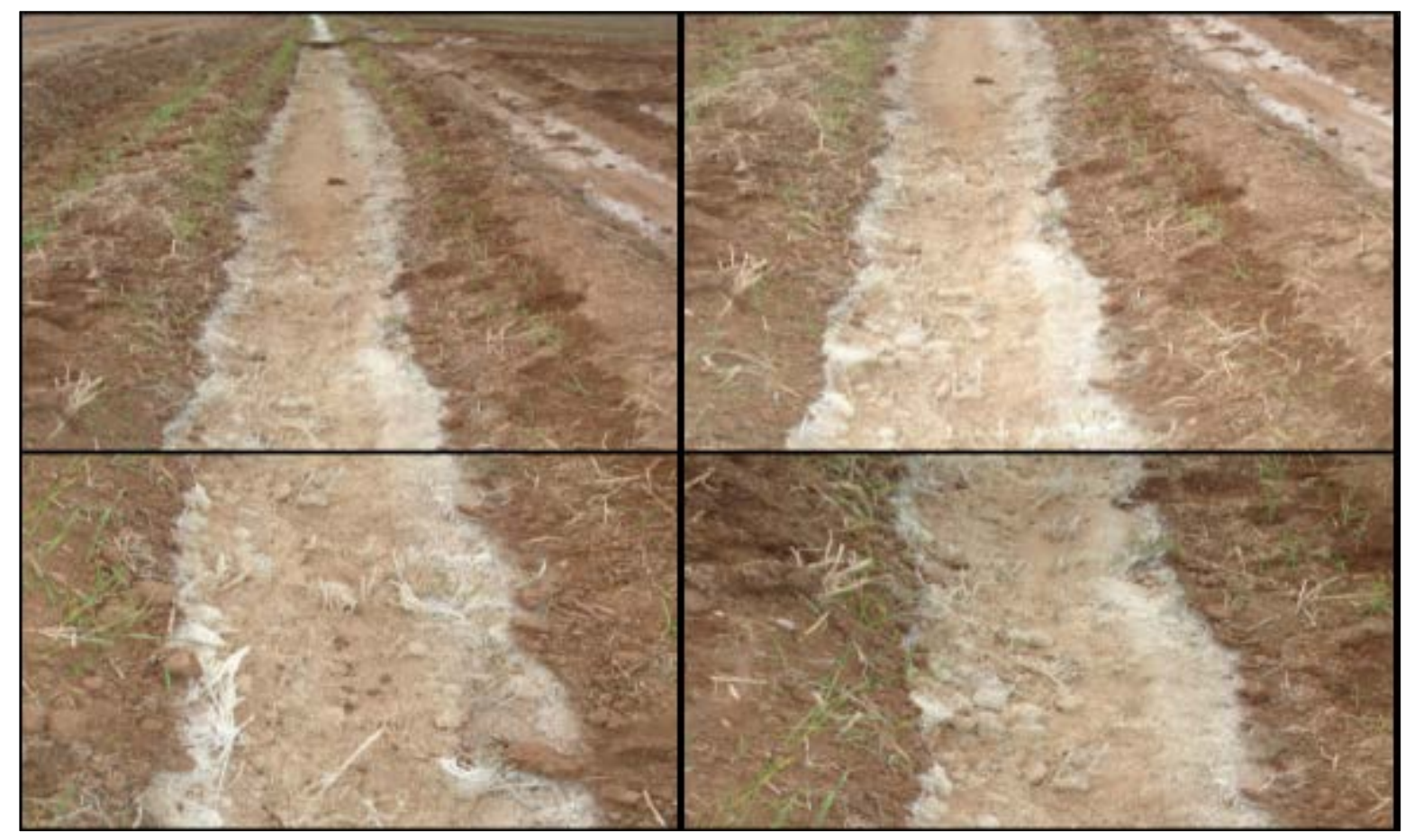

Source: Own photo during collecting data, 2010 


\subsection{Production indicators of the studied crops}

\subsubsection{Wheat}

Wheat is one of the most important strategic crops for Syrian food security because wheat grains involve in Syrians daily diet, providing a major source of essential nutrients such as carbohydrates, proteins, fibers, vitamins and minerals (Sadiddin and Atiya 2009). In Syria, $60 \%$ of the wheat grown is hard durum wheat (Triticum durum), while the remaining $40 \%$ is being soft bread wheat (Triticum aestivum L.) (Sadiddin and Atiya 2009). The main food products produced from wheat are flour, bread, macaroni, noodles and biscuits and the consumption per capita is on average $230 \mathrm{~kg} /$ person. In addition to food, wheat is utilized in animal feed, seed as well as waste (NAPC 2007).

Botanically, wheat plants are annual grasses and belong to the monocot family Poaceae. They are members of the subfamily Pooideae and the tribus Triticeae (Belitz et al. 2009). Winter wheat is the only cultivation type in Syrian moderate climate (Sadiddin and Atiya 2009). The winter type requires a vernalization by low temperatures; it is sown in autumn and matures in early summer. The optimum growing temperature is about $25^{\circ} \mathrm{C}$, with minimum and maximum growth temperatures of $3^{\circ}-4^{\circ} \mathrm{C}$ and $30^{\circ}-32^{\circ} \mathrm{C}$, respectively (Curtis et al. 2002).

Syria achieves self-sufficient in wheat production. Winter wheat occupies around 57\% of the total cereal area and $78 \%$ of the cereal production in Syria, while in the term of crop area and production, it accounts for $47 \%$ and 51\%, respectively (NAPC 2007). Wheat grows on irrigated as well as rain-fed land, and durum wheat is the predominant wheat in rain-fed area (Sadiddin and Atiya 2009). The irrigated wheat is accounting about $50 \%$ of all irrigated land, $60 \%$ of the irrigated land devoted to annual crops, and $70 \%$ of the irrigated land devoted to the strategic crops (Sadiddin and Atiya 2009).

Regarding the period of our study in Syria during 2009 -2011, the cultivated area of wheat winter wheat, either durum or soft type averaged 1,519,174 ha. Irrigated and rain-fed wheat occupied around $47 \%$ and $52.45 \%$ of the total wheat area as an average. Soft bread wheat was the majority planted wheat with $60 \%$ of the total area either in irrigated or rain-fed area. Regarding the wheat yield and production, they were 2.35 tons/ha and 3,547,732 ha as an average, respectively. The hard durum wheat produced $56 \%$ of the total wheat production. The yield of irrigated wheat was accounted for $63.3 \%$ and with $36.7 \%$ for rain-fed wheat. Both soft and hard wheat had approximately the same average yield with $50 \%$ of the total 
wheat yield. The highest wheat production during the former period is achieved by irrigated wheat which represented $80 \%$ of the total production (SADB 2013).

The comparisons in wheat area and production between Syria and world during 20092011 are given in Table 2.14. The average total world wheat production in the same period is 220,649,810 ha; with an average yield of nearly 3 tons/ha (FAOSTAT 2014). The consumption of wheat as food accounts for $53 \%$ in the developed countries, and close to $85 \%$ in the developing countries (Dencic et al. 2011). China is the largest wheat-growing area in the world, followed closely by USA and the Russian Federation. Extensive wheat growing regions occur in India, Australia, Canada, Pakistan, Argentina and some countries of the EU (FAOSTAT 2014). Syria was the 28th largest wheat producer in the world during 2009-2011 (FAOSTAT 2014).

Table 2.14: Comparison in area and production of wheat, cotton and pistachio between Syria and world

\begin{tabular}{lccccc}
\hline Crops & Crops/tress & Country & 2009 & 2010 & 2011 \\
\hline \multirow{4}{*}{ Area (ha) } & Wheat & Syria & $1,437,375$ & $1,599,108$ & $1,521,038$ \\
& & World & $224,647,490.00$ & $216,989,747.02$ & $220,312,194.47$ \\
& Cotton & Syria & 163,712 & 172,414 & 175,147 \\
& & World & $29,990,000$ & $29,760,000$ & $31,250,000$ \\
& Pistachio & Syria & 56,117 & 56,167 & 60,956 \\
& & World & 463,919 & 471,142 & 483,215 \\
\hline \multirow{3}{*}{ Wheat } & Syria & $3,701,784$ & $3,083,082$ & $3,858,331$ \\
& & World & $687,455,660.00$ & $649,521,158.02$ & $699,490,445.60$ \\
(tons) & Cotton & Syria & 652,058 & 472,485 & 671,668 \\
& & World & $20,871,388$ & $23,557,970$ & $25,947,260$ \\
& \multirow{2}{*}{ Pistachio } & Syria & 61,484 & 57,471 & 5,561 \\
& & World & 817,410 & 947,197 & 936,740 \\
\hline
\end{tabular}

Source: SADB 2013; FAOSTAT 2014 for wheat world data; USDA 2011 for cotton world data

\subsubsection{Cotton}

Cotton is one of central component of the economy in Syria. In addition, cotton is the source of more than one-half of Syria's foreign exchange, and the industry generates a significant part of the government's revenues (NAPC 2007). It was documented by economic resources (Sadiddin and Atiya 2009; Fiorillo and Vercueil 2003) that more than 20\% of the labour force depends, partially or totally, on the cotton sector, in which represents about 7\% (half a million people) from the Syrian population. It ranks first in terms of production value among Syrian agro-industrial crop, i.e. sugar beet and tobacco, and it is third exported item in overall exports, following petroleum and sheep (Maldonado 2009; Sadiddin and Atiya 2009). Only $30 \%$ of output of cotton fiber is utilized by domestic spinners, whereas the majority portion of cotton (70\%) is being exported (Fiorillo and Vercueil 2003; Westlake 2001).The 
fiber is most often spun into yarn or thread and used to make a soft, breathable textile. The Syrian governmental goal is to increase production of cotton yarn and textiles and to increase exports of these products in lieu of cotton lint. The cotton lint has multiple uses such as production of mattresses, pillows, baby diapers, and other sanitary products, yarn, textiles (Maldonado 2009). Additionally, cotton seed is used for planting and production of the cotton-seed oil and cake (Fiorillo and Vercueil 2003).

Botanically, cotton (Gossypium hirsutum L.), also known as upland cotton, belongs to the Malvaceae family and is one of the most important and earliest domesticated plants in Syria (Acton 2012). It is an irrigated summer crop which is sown in April and harvested from September until the end of the year (Maldonado 2009; Fiorillo and Vercueil 2003). Therefore, it is generally grown in the northern regions of Syria where the water resources are available. It occupies about $20 \%$ of the country's irrigated area, consuming 3-4 billions of cubic meters of water which corresponds to about 25\% of domestic annual available water (NAPC 2006; Sadiddin and Atiya 2009). The Syrian cotton fiber is medium staple length, which is the most common length produced worldwide. It is mainly used for cotton yarn, textiles, and garments (Fiorillo and Vercueil 2003).

Regarding the studying period between 2009 and 2011, the total cultivated area of cotton averaged 170,424 ha. Regarding the cotton yield and production, they were 4 tons/ha and 170,424 ha as an average, respectively (CADP 2013).

Recently, Syria occupied the tenth place in the world in terms of annual average production, with a share of $1.6 \%$ of the total production and the second place in terms of yield per hectare (Sadiddin and Atiya 2009). Table 2.14 represents the comparisons in cotton area and production between Syria and world during 2009-2011.

\subsubsection{Pistachio}

The pistachio tree considers one of the most important fruit trees in Syria. It has the potential for profit and the generation of hard currency by the exported pistachio to Arab and European countries (Al-Shareef 2007). The pistachio nuts have valuable nutritional value because they are high in unsaturated fatty acids ( 80\%) and low in saturated fatty acids. In addition, they are good sources of proteins, dietary fibers, vitamins, mineral and antioxidant photochemical (e.g., carotenoids, phenolic compound). Moreover, they are lower in calories and fat content and higher in protein and potassium compared with other tree nuts and peanut. Besides the nutrient value, they have health attributes since recent studies have shown that a 
diet that incorporates pistachio nuts can reduce the risk of heart disease, the total cholesterol and the plasma malondialdehyde (Kashaninejas 2011).

Pistachios are consumed as fresh, dried and roasted nuts with or without flavoring. They are also an essential ingredient in dessert, baked goods, candies, and ice cream. Additionally, they can be added to many foods to improve nutrition, color and flavor (Kashaninejas 2011). They are considered a 'luxury' good for Syrian people (Al-Shareef 2007).

Pistachio vera L. is economically the most important cultivated species grown in Syria over centuries and belongs to Anacariaceae family. The pistachio tree is a moderately sized deciduous (3 to $8 \mathrm{~m}$ ) and dioecious tree. Both male and female trees are required to produce nuts. The native range of pistachio is characterized by long, hot, dry summers and moderately cool or cold winters (Kashaninejas 2011). This is because pistachio needs comparatively cold winter temperatures in order to break bud dormancy. The tree is resistant to cold and wind but is sensitive to very extreme climate conditions, such as extreme drought, prolonged frost and excessive dampness and high humidity. It is planted in arid and drought areas alongside figs, olives or vines. Pistachio needs almost 10 years to start an early fruit period and 20 years to enter full production period. It subjects to alternate bearing phenomena, in the bearing year the production is very good, and in the alternative year the production is limited. The harvesting season extends from mid-July to mid-November (Al-Shareef 2007).

Regarding the investigated period of our study in Syria during 2009-2011, the cultivated area of pistachio trees was 57,747 ha with 6,596,000 trees. The rain-fed pistachio trees were predominant with around $88.6 \%$ of the total pistachio area as an average. Regarding the pistachio yield and production, they were $8.57 \mathrm{~kg} /$ tree and 41,505 tons from 6,803 fruiting trees, respectively SADB 2013).Syria ranked fifth in the world in terms of pistachio production, which accounts for $13 \%$ of the global total after Iran, USA, Turkey and China (FAOSTAT 2014). The Syrian pistachio land accounted for $5 \%$ of the world productive area of pistachio (Al-Shareef 2007). Table 2.14 represents the comparisons in pistachio area and production between Syria and world during 2009-2011. 


\section{GENERAL APPROACHES TO AGRICULTURAL RISK MANAGEMENT}

\subsection{Risk and uncertainty}

Risk is an integral part of various aspects of life. It is a broad subject which accompanies such as personal circumstances (health, pensions, insurance, investments etc.), society (terrorism, economic performance, food safety etc.), and business (corporate governance, strategy, business continuity etc.) (Hillson and Murray-Webster 2004). Despite strivings to make our plans with great prudence and anticipation, risk is still existent (Williams and Schroder 1999; Nguyen 2007). In general, welfare is commonly affected by risk items with the probability of unexpected loss (Harwood et al. 1999; Dallas 2006). For risk term, as for any subject, it is difficult to reach agreement on definitions. Eminent economist and Nobel Prize winner, Joseph Stiglitz, said: "Risk is like love: we all know what it is, but we don't know how to define it” (Nguyen 2007, p. 2). In the literature, there are huge variations of underlying concepts that define risk. However, most of the risk definitions agree that any decision-making framework is based on two terms: risk and uncertainty. The main key distinction between risk and uncertainty arises from consideration of the consequences. Hardaker et al. (1997) illustrated that the uncertainty can be defined as imperfect knowledge and risk as uncertain consequences. Thus, uncertainty without consequence means no risk.

\subsection{Risk sources in agriculture}

The sources of risk that affect agricultural production are numerous and diverse. They comprise a wide scope of independent events which are linked to each other.

Some of these events are restricted to agricultural business, and others are related to the individuals who operate the farm business (Miller et al. 2004; Aimin 2010). In general, farming is involved in natural, economic, political and institutional environments which create many types of risks (Pingali 2001; Hanson et al. 2004). As can be seen in most of related literature, the categorization of risk sources varies depending on the study objectives. However, the simplest classification of risk in agriculture was introduced by Hardaker et al. (1997), who distinguished two main risk sources; business risks, which are directly associated with the variability of farm profitability, and financial risks, which directly affect net cash flows to farmers' equity. Business risks include the following sub-risks: production, market, 
human and institutional risks, while financial risks are related to the way that farms are financed. This simple classification was adopted by Baquet et al. (1997), Kay and Edwards (1999) and Huirne et al. (2000).

Risk sources in agriculture reflect each other. Thus, this issue must be considered carefully when building a whole farm plan. The institutional risk could lead to a change in subsidized prices, and it affects market risk. Likewise, institutional and human resources risks have an impact on production risk. Risks of all categories have an effect on net farm income; consequently they linked to the financial risk category (Pellegrino 1999; European Commission 2001).

\section{$\underline{\text { Production risk }}$}

It is called yield risk which distinguishes agricultural production (plant and livestock) from other business sectors. It is the essence of risk in agriculture which concern losses arising from the unpredictable nature such as biological, ecological, and technological changes. Farming is affected by production risk which is often related to weather phenomena including flood, insufficient rainfall, frost, overheating, hail, windstorms, diseases and insects. Given that the agricultural production are more sensitive about the environment effects, timing of some climate aspects are very important. The precipitation at the seed time is luck, but at harvesting is ordeal (Musser 1998; Harwood et al. 1999; Huirne et al. 2000). Losses caused by production risk could be covered by some mechanisms such as insurance, while its negative impact is prolonged by the interruption of normal farm activity that often follows specific catastrophes such as flood and fire. Development and adoption of new techniques and production methods are considered as one of production risk. New crop varieties, chemicals, crop rotations, models of machines may cause losses while they are proving their appropriateness and effectiveness in different agricultural systems (Miller et al. 2004).

\section{Market risk}

Market or price risk is associated with the changes of input and output prices arising from unpredictable competitive markets, particularly when these changes occur after the production plan has been taken (Hardaker et al. 1997; Harwood et al. 1999).

The price changes result from different sources, such as world market prices, interest rates, supply and demand variations, quality requirements, shipping problems, change of consumer behavior and policy development. The governmental interventions in the 
agricultural market as well as subsidy policy lead to considerable price variability. Trade liberalization is translated by a wide world price risk for the objective commodities (Anderson 1997). The expected damage resulted by market risk aggravate developing countries because of the limited access to futures and options markets which provide information needed for agricultural operation management (Heidelbach 2007). Furthermore, price peaks can endanger food security, whereas low prices threaten farm profitability and farm family incomes.

\section{$\underline{\text { Human resource risk }}$}

Farm operators may themselves be a source of risk in the farm business since the health, the continuing ability to work and the death of the farm owner or the divorce status in the farm family may threaten farming continuity. Consideration of human resources risk is an important issue in risk management procedure, particularly in the case of big size farms and more complex technology. Furthermore, the rapid growth of rural population worldwide accompanied with a shallow skilled rural labour may cause severe losses to production and/or substantially increase costs (Musser 1998; Harwood et al. 1999).

\section{$\underline{\text { Institutional risk }}$}

This type of risks represents the negative impact of changes in policies and legislation on agricultural business. It embodies the political risk by the national governmental interventions in the agricultural sector such as regulations restricting the use of pesticides in horticulture, and use of drugs for disease prevention and treatment in animal husbandry sector. Also, it includes regulations which result in increasing market liberalization and decreasing subsidy levels. Legislation which control land and water use, as well as area licenses, might affect farm profitability. The agricultural output prices are also subjected to foreign trade agreements. Furthermore, agricultural business is indirectly affected by policies and regulations which are not specific to the agricultural sector, such as monetary and fiscal policies, occupational health, patent rights, genetic engineering and environmental regulations (Hardaker et al. 1997; Musser 1998; Huirne et al. 2000).

\section{Financial risk}

Financial risk is related to farm capital and farming finance (Harwood et al. 1999). It is reflected in the variability of the net cash flows which can lead to insufficient liquidity and 
loss of equity. Consequently, farmers are unable to meet preceding claims on their operations (e.g., debt servicing commitments) with cash generated by the farm business. (Martin 1996). Musser (1998) suggested three dimensions of financial risk, i.e. interest rate, liquidity, and solvency. The fluctuations in interest rates are ranked as a crucial risk source in agriculture since bank loans are often the main financial supplier, due to farmers' capital scarcity needed to agricultural investments. Furthermore, the loans’ period and repayment deadlines are not always corresponded with the farming cycle (Nguyen 2007).

\subsubsection{Farmers perceptions of risk sources}

In fact, farmers' risk realization varies substantially, and scholars repeatedly addressed farmers' preferences of risk variations. According to previous empirical studies, there is no agreement about the risks that have a priority for farmers.

Boggess et al. (1985) indicated that rainfall variability, pests and diseases, and crop price variability were the primary risk sources for crop farmers in northern Florida and southern Alabama. While, prices, diseases and weather variability were ranked as most important risk sources for livestock producers in the same study sites.

Patrick et al. (1985) concluded that the weather variability, input costs and output prices were the three most important risk sources for both crop and livestock operators in 12 American states. On the other hand, the participants who were discovered by Knutson et al. (1998) in Texas and Kansas, listed price as well as yield variability, and input costs as particularly high. Severe drought and meat price variability caused the greatest worries for cattle farmers in Texas and Nebraska, who were studied by Hall et al. (2003).

The results obtained by Martin (1996) revealed that market risk was ranked as a crucial source of risk by all interviewed farmers in New Zealand, The human risk related to accidents or health problems was perceived moderately. Price and production risks were identified as the most important sources of risk in dairy farming, which was studied by Meuwissen et al. (2001) in the Netherlands.

Agricultural policy followed by the changes in output costs and economic situation were the most relevant risk sources which threaten the agricultural production in Cukurova region of Turkey (Akcaoz and Ozkan 2005). South African sugarcane farmers, studied by Nicol et al. (2007), perceived land institutional risks that were represented by reform regulations and labour legislation as highly relevant risk sources. Production risks represented by coffee berry disease and coffee wilt diseases and market risks such as output and input 
prices were the most relevant risks which were perceived by Ethiopian coffee farmers (Ejigie 2005).

Schaper et al. (2010) demonstrated a wide range of risk perceptions among dairy farmers in five European countries. Increasing feed prices, increasing land rents and reduced land availability had the priority among the German dairy farmers. Farmers in France, Ireland and the Netherlands perceive institutional risks highest. Whereas, Swiss farmers gave production risks a higher importance than institutional and market risks.

The unexpected variability of input and output prices, and diseases and pests that affect plants and animals were classified as the most harmful injurious risk sources that threaten the smallholder farmers in Thailand (Aditto 2011).

\subsection{Risk management in agriculture}

\subsubsection{Risk management process}

Risk management process includes much more than dealing with risky events after they occurred. It involves the identification of risky events in the organization in advance given the likelihood and consequences of such events to react in an appropriate way (Merna and Al-Thani 2008). Risk management is a complex process which can be summarized in five consecutive steps (Figure 3.1): establish the context, risk identification, risk analysis, risk assessment and risk management (Hardaker et.al 1997; Noell and Odening 1997; Waters 2011).

\section{Establish the context}

Defining the context is the first step in the risk management process. It starts by identifying the relationship between the farm and its environment, taking into account the strengths, weaknesses, opportunities and threats related to the farm. Furthermore, the setting of the division of responsibility for various types of decision making among people in the farm is s very essential element in the context establishment. The basic risk management instruments through which risks will be managed must be determined in this stage. Given the impossibility to deal with every risk all at once, some priority setting must be built in this stage by start with risks which are expected to be more dangerous. A successful context establishment highly ensures the efficiency of subsequent risk management steps. The 
modification of these basic risk management strategies is possible throughout the remaining stages based on the suggestions of monitor and review part (Hardaker et al. 1997).

Figure 3.1: An outline of risk management process

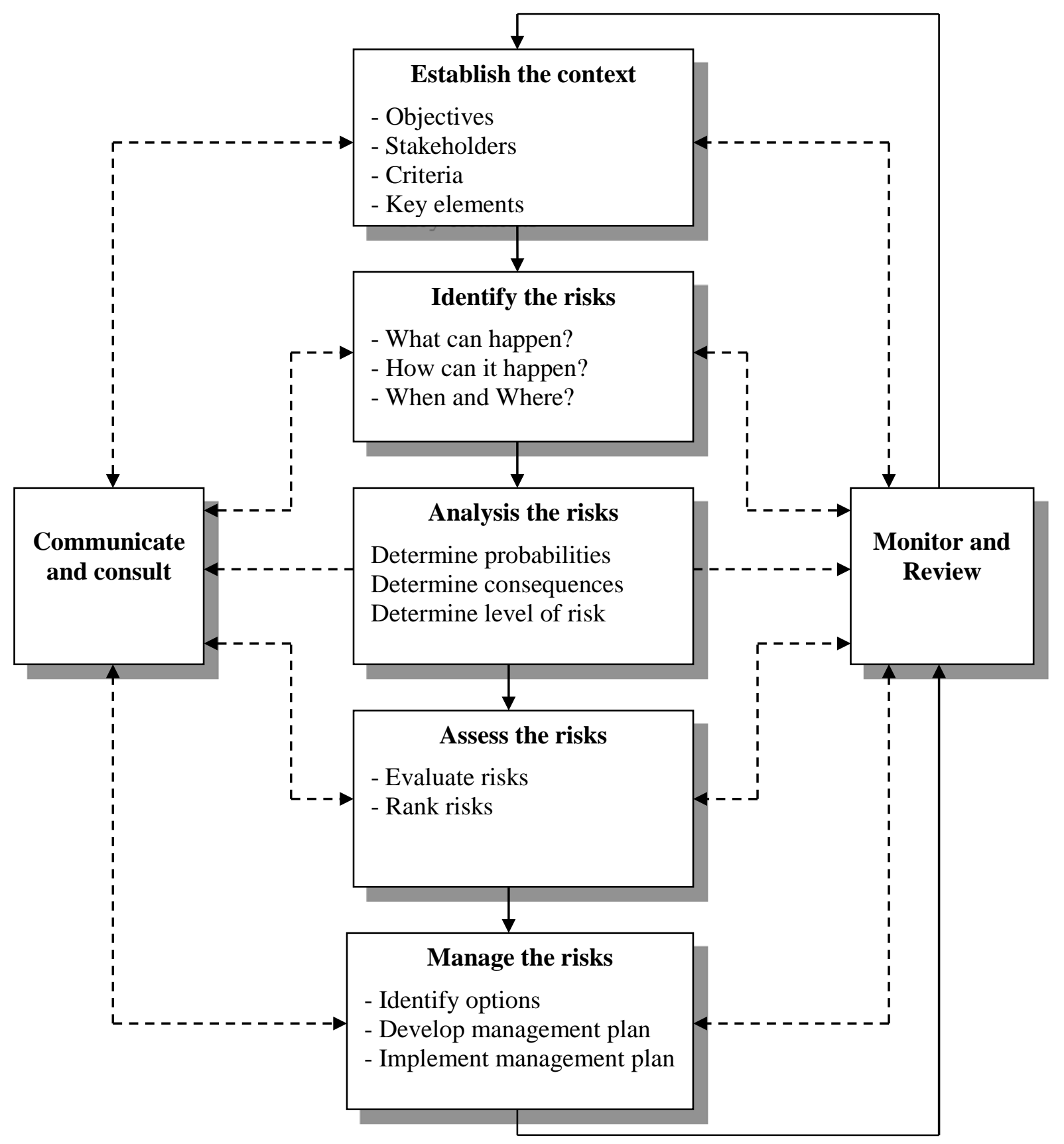

Source: Adapted from the Australian/New Zealand Standards (2004). AS/NZS 4360:2004

\section{$\underline{\text { Risk identification }}$}

Risks in agriculture are obviously endless. Thus, the aim of the risk identification step is to filter those events that are predicted to have a notable effect on the attainment of the 
farm's performance by answering the following questions: What might happen, why and how might it happen, and finally how the organization might be affected (Hardaker et al. 1997).

\section{$\underline{\text { Risk analysis }}$}

Risk analysis seeks to estimate the chance of risk occurrence, and assess the magnitude of negative consequences. Thus, it will be able to classify risks into low/high probability/impact (Hardaker et al. 1997).

Merna and Al-Thani (2008) introduced various qualitative and quantitative instruments for analyzing risks such as checklists, risk map and simulations. Balance sheet, profit-or-loss statements (Bahrs 2002 as cited in Schaper et al. 2010), as well as methods based on Value-atrisk or Extreme-Value theories, were also illustrated to perform risk analysis step (Crouhy et al. 2006).

Among them, the risk map is a standard tool used to assess risks (Figure 3.2). It is simply a graphical representation of risks on a two-dimensional graph where each risk can be placed once to clarify the levels of frequency and severity of consequences for each risk identified in the second step. Iso-risk curves drawn on the graph help to distinguish relevant risks which need treatment priorities, and less relevant risk can be distinguished by the risk map (Merna and Al-Thani 2008).

Figure 3.2: Risk mapping concept

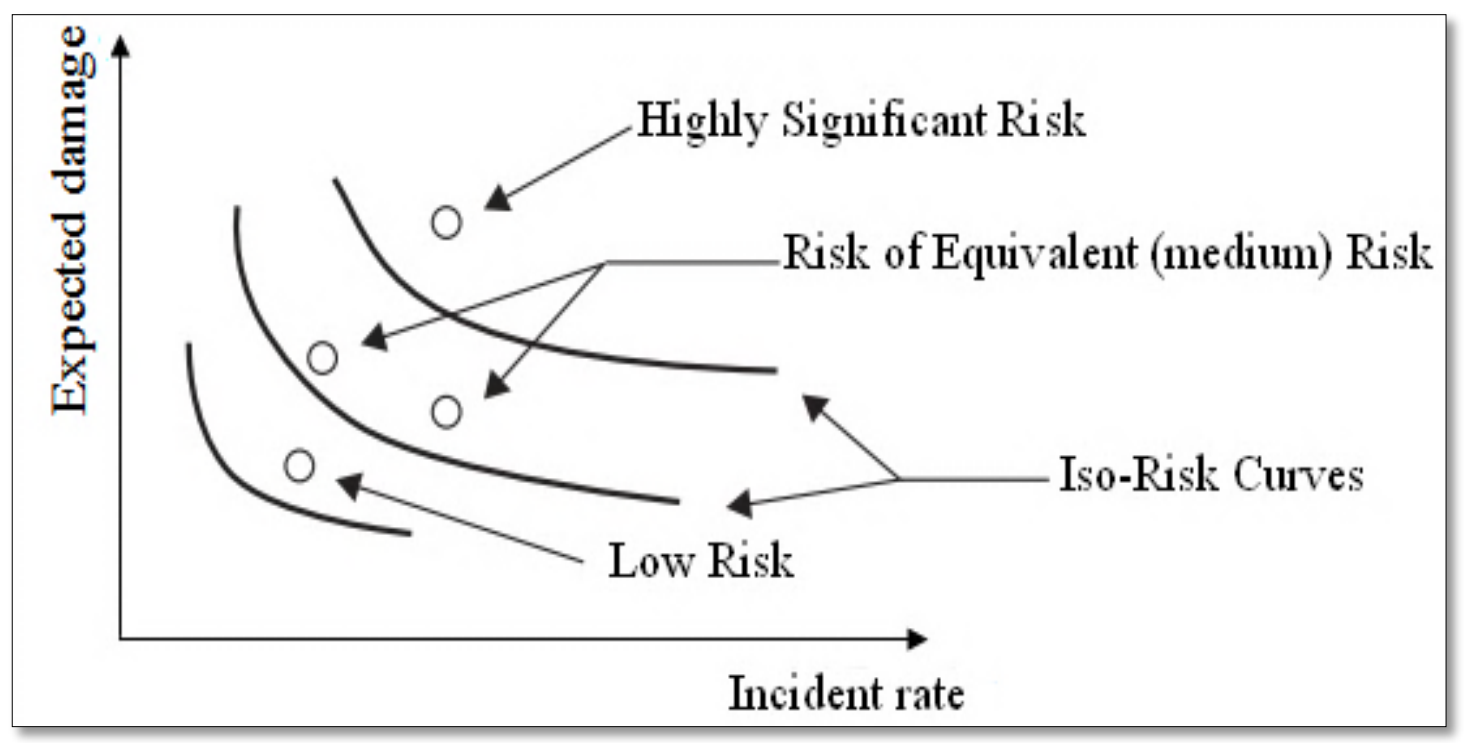

Source: Adapted from Merna and Al-Thani 2008 


\section{$\underline{\text { Risk assessment }}$}

Risk assessment is concerned with decision making based on the outcome of the risk analysis step. The decision making has to include two aspects: First, which risks need treatment and treatment priorities? Second, identification of those risks for which current risk management practices are not appropriate, so that further strategies must be developed. These two steps can be achieved by comparing the outcomes from events recognized during the analysis process with risk evaluation criteria which were considered when the context was established. Furthermore, farmers might postpone the decision when further analysis is required (Hardaker et al. 1997).

\section{$\underline{\text { Risk management }}$}

It follows the risk assessment to identify the range of treatment options such as ignorance, acceptance, reduction, avoidance and transfer of risks. After that, it proceeds in selecting and implementing appropriate options to deal with risks. These options can be applied either individually or in combination based on the target risk, and the extent of any additional benefits or opportunities created by the treatment (Hardaker et al. 1997). Nguyen (2007, p. 21) illustrated that "the successful implementation of the risk management plan requires an effective management system which specifies the methods chosen, assigns responsibilities and individual accountabilities for actions, and monitors them against specified criteria”. In the subsequent section (3.3.2) further details of risk management strategies in agriculture are reviewed.

\section{Monitoring and review}

The risks and the steps of the risk management process, which have been planned and implemented, require frequent monitoring. Risks and knowledge of risks are likely to change over time, so new risks may arise, and new outcomes associated with the new risks have to be analyzed. Consequently, it is important to monitor the outcomes of the implemented decisions to identify the insufficient ones, and improve further appropriate management practices.

Monitoring and review based on communication and information exchange are necessary to certain that the risk management plan is working, and to identify aspects where further decisions need to be made (Hardaker et al. 1997). Perfect information access is very essential in such a step. 


\subsubsection{Risk management strategy}

The conventional identification of risk management strategies refers to the applied measures to remove or minimize the effect of factors that threaten the agricultural production. Merna and Al-Thani (2008) demonstrated that the aim of risk management strategy implementation is to optimize opportunity-risk portfolio taking into account farm objectives and operator's attitudes toward risk. Therefore, calculating the risk return trade-off is an influential target in designing risk management strategies (Kobzar 2006). Generally, risk management finds the combination of activities which are most preferred by the operator and are congruous with his/her financial situation in order to achieve the desired level of income and an acceptable level of risk.

The large numbers of potential practices that can be used to manage risk have been classified in several ways in the literatures. Barry and Fraser (1976), Sonka and Patrick (1984), Patrick et al. (1985), Patrick and Ullerich (1996) and Martin (1996), organized such practices into production, marketing, and financial risk management strategies. Production strategies include purchasing and renewing machinery, storing outputs, employment plant protection programs and diversification. Marketing strategies can be summarized by collecting information about market and price trends, managing sales over different time periods and forward contracts. Financial strategies reflect practices such as off-farm work and/or investment to supplement farm income, reducing debt levels, machinery leasing and increasing cash assets.

Schaper et al. (2010) assembled another type in the classification of risk management strategies for in the German dairy farms as following: risk avoidance, risk reduction, risk transfer and risk acceptance. Risk avoidance strategies include practices that reduce the farm's exposure to risks by excluding some of farm activities which are characterized by high related risk level. Risk reduction strategies mean mitigating risk by reducing the concomitant occurrence probability and limiting the extent of possible downside consequences (Hardaker et al. 1997). Diversification of farm activities is the commonly used strategy under the risk reduction category. Risk transfer strategy is identified simply as transferring the consequences of risk incidences to other (e.g., agricultural insurance mechanisms). When all of the mentioned risk management strategies are impossible to be implemented, risk acceptance will be the last opportunity for farmers. Furthermore, risk acceptance strategies are employed when risks have not been identified, no appropriate risk management strategy is available or such a strategy is too expensive (Schaper et al. 2010). 
Hardaker et al. (1997) and Huirne et al. (2000) introduced two types of risk management strategies: (1) On-farm measures and (2) risk-sharing with others. On-farm risk management strategies include collecting information, selecting products with low-risk exposure, choosing less risky technologies, diversification, and holding sufficient liquidity while risk-sharing strategies include contract marketing and future trading, participation in mutual funds, and insurance.

\subsubsection{Farmers' preferences of risk management strategies}

Given that farmers are generally risk-averse, they tend to manage risks that threaten their sources and income. However, risk management strategies adopted by farmers are usually in accordance with their personal preferences and with the risks which are more relevant in their farm business.

According to (Brorsen 1995), The Australian farmers were more concerned with loan repayment schedules as a price risk management strategy. Based on the study of grain, swine, and fed-cattle farmers in Iowa State, Edelman et al. (1990) indicated that the use of hedging was the preferred risk management strategy to mitigate risk associated with grain sales. The survey results which were founded by Harwood et al. (1999) revealed a wide variation of risk management strategies' preferences among the respondents, for example reliance on government farm programs, farm diversification, crop insurance and forward contracts related to inputs. Similarly, a range of production, marketing, and financial risk management strategies was used by the New Zealand farmers who were interviewed by Martin (1996). Meuwissen et al. (2001) demonstrated that producing at lowest possible costs and the buying of business and personal insurances were perceived as the most relevant among Dutch livestock farmers. The use of future and option market was perceived as the least relevant to manage risks.

Both production strategies, represented by growing more than one crop and more than one variety, and market strategies, such as gathering market information and spreading sales, were the most preferred risk management strategies among Turkish farmers in Cukurova region (Akcaoz and Ozkan 2005). Similarly, the Ethiopian coffee farmers perceived crop diversification, diversifying crop varieties, and use of drought tolerant varieties of coffee as the most appropriate risk management strategies Ejigie (2005).

Schaper et al. (2010) observed that the German dairy farmers strongly relied on risk acceptance strategies such as increase growth in output of milk production, decrease costs of 
milk production and growth of the dairy business. Indeed, the cooperation with other milk producers to collaboratively buy inputs, as risk reduction strategies, was accepted by $83 \%$ of the interviewed farmers, whereas, all farmers had fire insurance. For the other EU countries which were included in the empirical study, increasing specialization and the growth of dairy operations were the most important strategies. French and Irish dairy farmers mostly preferred the intensification of dairy production to mitigate production costs, whereas farmers in Germany, the Netherlands and Switzerland did not agree with that strategy.

Purchase of farm machinery to replace labour and storing feed and/or seed reserves and holding cash and off-farm work were perceived at high relevance by smallholder farmers in Thailand (Aditto 2011).

\subsection{Risk attitude}

Hillson and Murray-Webster (2004, p. 4) illustrated that, "if risk is defined as an uncertainty that could have a positive or negative effect on one or more objectives, and attitude is defined as chosen state of mind, mental view or disposition with regard to a fact or state, then combining the two gives a working definition of risk attitude as chosen state of mind with regard to those uncertainties that could have a positive or negative effect on objectives, or more simply chosen response to perception of significant uncertainty”.

People have different attitudes toward risks, and each perceives the same risk source differently. When a number of people should make a decision about the same uncertain situation, different preferred attitudes will be elicited depending on how individuals or groups perceive the uncertainty. Consequently, different behaviors will be exhibited; for example, a situation is regarded as too risky by one person but it is less risky or acceptable by others (Hillson and Murray-Webster 2004). In fact, the varieties of possible attitudes toward risk which can be displayed by individuals or groups are infinite; since risk attitudes steps on a continuous spectrum (Figure 3.3). However, scholars have been seeking to border the unlimited risk attitudes by useful headlines as risk-averse, risk-seeking and risk-neutral which represent a working definition of risk attitude (Murray-Webster and Hillson 2008).

Risk-averse people can be defined as those who are highly uncomfortable with the uncertain outcome; this may guide them to sacrifice expected profit to avoid risk. They are willing to accept a lower average income to avoid or reduce threats (Murray-Webster and Hillson 2008). Furthermore, Kahneman and Tversky (2009) elucidated that risk-averse 
individuals would value a protective action which keep the probability of injury at the zero level.

Figure 3.3: Risk attitude spectrum

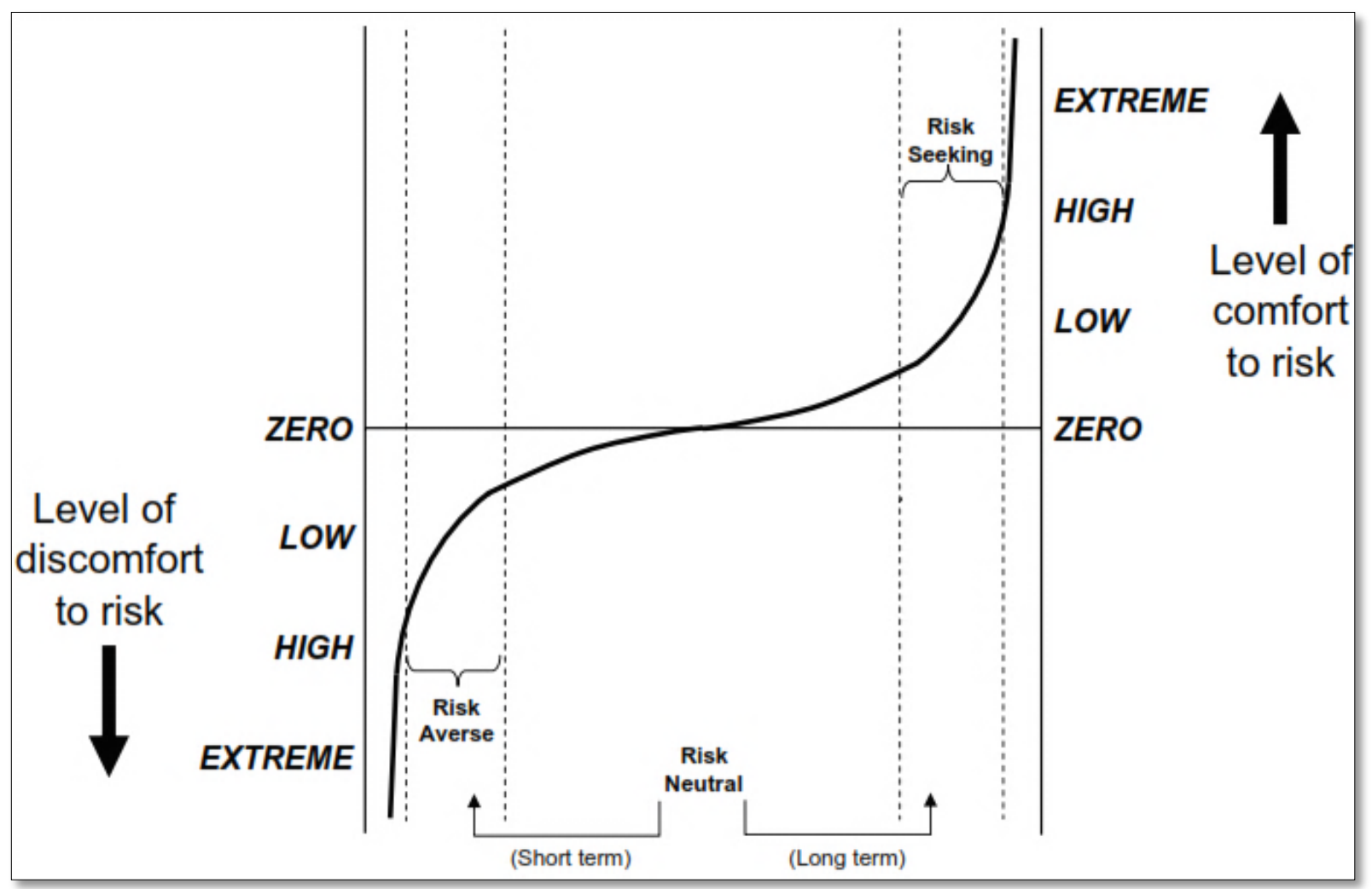

Source: adopted from Hillson and Murray-Webster 2007

In contrast, risk seekers are quite interested with uncertainties, and they do not have a desire to avoid or reduce threats. They perceive risk as a profitable chance. Thus, they seek to pursue the venture and accept losses to take their chances (Murray-Webster and Hillson 2008). Tversky and Fox (1995) indicated that risk-seeking is presented when the risky event is preferred to a sure outcome with equal or greater expected value.

Between the two extremes attitudes, there are still other individuals named as riskneutral. They are uncomfortable with uncertainty in the long term; therefore, they are able to take whatever necessary short-term activates to gain a certain long-term outcome. Risk neutrality is exhibited when the decision maker are able to eliminate the threat (Gustafsson, 2000; Murray-Webster and Hillson 2008). In another word, risk neutral individuals are seemed unconcerned with risk when deciding between investments. Thus, they are disinterested to the risk involved in the investment and are only concerned about the predicted outcome (Nguyen 2007). 
Risk-taking action means that people take chances depending on their understanding of such chances. The effectiveness of risk-taking action are determined by the individuals' embrace of results which the situation could drive away differently from their expectations (Murray-Webster and Hillson 2008). Regarding the decision-tree diagram (Figure 3.4), the avoidance of low outcome (3) which is involved in the risky action, the risk-averse decision maker may decide to take the sure outcome (1), even though the high expected outcome (2) might yield by the risky actions.

Figure 3.4: Representation of a risky choice by a decision-tree

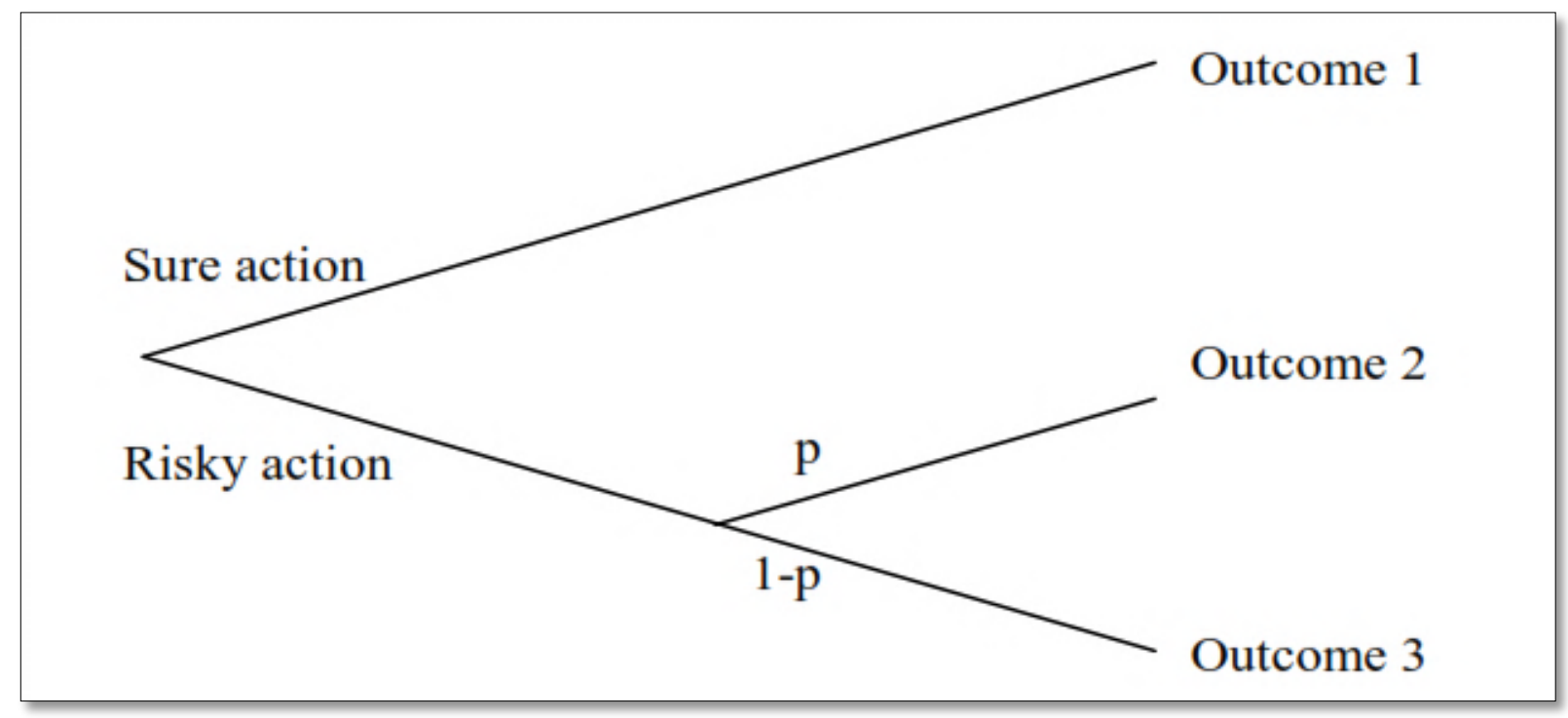

Source: Parton and Pandey 1991, as cited in Wegener 1994

Several methods have been used to extract farmers' risk attitudes using different theories and elicitation techniques. Both expected utility theory and prospect theory are widely used in risk attitude researches (Anderson et al. 1977; Dillon 1979; Kahneman and Tversky 1979; Bell and Raiffa 1988; Tversky and Kahneman 1992; Hardaker et al. 1997). Additionally, three common elicitation techniques are also employed to investigate farmers' risk attitudes as included in Gómez-Limón et al. (2003). They are: (1) Direct elicitation of utility functions (Francisco and Anderson 1972; Young 1979; Hamal and Anderson 1982; Ramaratnam et al. 1986); (2) experimental methods (Binswanger 1980); (3) observed economic behavior methods (Chavas and Holt 1990 and 1996; Pope and Just 1991; Lence 2000).

These theories, however, have some restrictions because of their assumptions' violations or the discrepancy between the hypotheses and the results (Kahneman and Tversky 1979; Robison 1982; Machina 1987; Schoemaker 1991). Likewise, the elicitation techniques could require time and cost to implement practically such as the case of experimental methods 
and the possibility for aggregate data to influence risk attitude e. g. observed economic behavior method (Young 1979; La Rovere 1997; Gómez-Limón et al. 2003).

To avoid the restrictions related the previous methods used to assess risk attitude, Musser and Musser (1984) suggested employing psychological measurement scales in such assessments. Ranking procedure can be structured by identifying a scale of statements that represent the respondent's attitudes toward an underlying variable (risk attitude). Such a scale can be applied to a large number of farmers through less costly and time-consuming media forms than personal interviews (Bard and Barry 2000).

Wide variation of statements can be underlined in risk attitude scales. The selfassessment scale, using Likert-type scales, is a commonly used scale for risk attitude. It consists of a series of risk attitude related statements which directly reflect farmers' attitudes toward risk by two directions: (1) By asking the farmer about his/her willingness to take risks such as 'I am willing to take a number of risks to achieve my goals', or (2) by measuring farmer' risk attitude in relative to others through statements such as 'I am willing to take more risks than my colleagues with respect to production risk'. After that, farmers' risk attitudes can be easily calculated by the sum of the scores for the individual statements. This scale is broadly used in the literature (Schurle and Tierney 1990; Kastens and Featherstone 1996; Patrick and Ullerich 1996; Patrick and Musser 1997; Meuwissen et al. 2001; Xu et al. 2005; Schaper et al. 2010). Eckman et al. (1996) inserted statements of willingness to take risk, risk premiums, and the extent of the agreement with the group of risk sources.

Bard and Barry (2000) developed another type of risk attitude scale that indirectly investigates farmers' risk attitudes. They suggested that the socio-economic factors and life experiences influence the attitude toward risk, thus true risk attitude is rarely apparent. For this reason, risk attitude must usually be measured indirectly (Bard and Barry 2000). Based on the theory supposing that the adopted risk management practices are influenced by the farmers’ risk attitudes, Bard and Barry (2000) developed a risk attitude scale which consists of 25 risk management strategy' statements. This scale assumes that if the farmers are more desired to implement the given risk management strategies, this means that farmers are concerned with a decline their exposure to risk, consequently the farmers are risk-averse, and vice versa. Such a scale was also adapted by Lagerkvist (2005), Bardhan et al. (2006) and Roslan et al. 2012.

Despite the existence of farmer risk-seeking and risk neutral, the tremendous number of methods and empirical analyses revealed that farmers are generally risk-averse. Farmers 
are concerned with adoption of risk management strategies in order to minimize threat effects. Moreover, for the most of agricultural operators, small and certain gain is more preferred than a large uncertain gain (Dillon and Scandizzo 1978; Young 1979; Binswanger 1980; Bond and Wonder 1980; McLeay et al. 1996; Anderson and Hazell 1997; Meuwissen et al. 2001; Hall et al. 2003; Aditto 2011). On the other hand, $\mathrm{Xu}$ et al. (2005) demonstrated that about $75 \%$ of American corn and soybean farmers in 1993 and 1994 were willing to take a number of risks to be successful. Furthermore, about $60 \%$ of those farmers regarded themselves as more willing to take a few more risks than others at the same period. Paddy farmers in Ketara, Malaysia were classified as risk-seeking farmers (Roslan et al. 2012).

\subsection{Determinants of farmers' attitudes and perceptions}

There is, however, disagreement among previous studies about the consolidated determinants, which inevitably influence farmers' risk attitudes, perceptions of risk sources and perceptions of risk management strategies. There are numerous variations of factors which can affect farmers' risk attitude and perceptions. Also, a wide range of researches has been carried out in order to investigate how risk attitudes and perceptions vary from farmer to farmer and from farm type to another. It is worth mentioning that most of these researches rely on farm and farmers' socio-economic characteristics to such variation. However, the classification of attitudes and perceptions, which was based on farmers' socio-economic profile, was impossible in most of the previous studies (Patrick et al. 1985; Boggess et al. 1985; Wilson et al. 1988; Gunjal and Legault 1995; Patrick and Musser 1997; Meuwissen et al. 2001; Aditto 2011). Wilson et al. (1993, p. 99) pointed out that "results illustrate the highly complex and individualistic nature of risk perceptions and the selection of management tools”.

Regarding to farmers’ risk attitudes, Bardsley and Harris (1987) found that the wealth and income indicators played a significant role to form the Australian farmers' attitudes toward risk. Conversely, Pålsson (1996) discovered that the Swedish farmers’ risk attitudes were constant with respect to the wealth indicators. Gender, age, experience and education level of the farm householders are found as important aspects to explain their attitudes toward risk (Pålsson 1996; Gómez-Limón et al. 2003; Olarinde et al. 2010; Aditto 2011; Menapace et al. 2013). The education level is a catalyzer factor which increases farmers' willingness to take risks (Moscardi and Janvry 1977; Binswanger 1980; Anosike and Coughenour 1990; Binici 2001; Aditto 2011; Roslan et al. 2012). 
In addition to the socio-economic factors' importance to explain farmers' perceptions of risk sources, such perceptions can change over time. Patrick and Musser (1997) demonstrated that crop price and yield variability were the most important sources of risk in the first stage of the study in 1991 while human resources risk and the environmental regulations recorded the highest score in 1993. Furthermore, the production program plays an essential role in constituting farmers' risk perceptions. Harwood et al. (1999) found that the cereal producers (wheat, corn, and soybean) were worried mostly about the yield and the price risks, whereas institutional risk was ranked first for the livestock farmers. Comparable results were reported by Ali and Kapoor (2008). They revealed that Indian fruit producers were more concerned about input prices than vegetables producers, although the fallen ground water levels and seasonality were perceived as the most important sources of risk in production of fruits and vegetables in India. Flaten and his team (2005) compared perceptions of risk sources among conventional and organic dairy farmers in Norway. They found that the institutional and market risks were ranked as the main risk sources threatening the organic dairy production, whereas the operating cost variability and animal welfare policy were perceived as having high relevance for the conventional dairy farmers. Lien et al. (2006) revealed significant differences between full-time and part-time crop and dairy farmers in Norway. Full-time crop' farmers perceived risks of consumer preferences' changes and human resources risks at a higher relevance than part-time farmers. Similarly, full-time dairy farmers were more concerned about animal welfare policy and production diseases than parttime farmers.

Regarding to the farmers' preferences of risk management strategies, the scholars showed an extensive range of factors affecting such preferences. In Indiana (Shapiro and Brorsen 1988), it was displayed that the use of hedging was positively related to farm size. Contrary to expectations, education was found to be inversely related to hedging. Farmers' risk attitudes have no influence on selecting such a strategy. Makus’ working (1990) on farm willingness to adopt 'futures and options marketing program', reported that employing of forward contracts, value of gross sales, education level above bachelor degree and membership in a marketing club positively and significantly influenced the adoption of such a program (Makus et al. 1990). Similarly, the total years of formal education, marketing seminar participation, farm size and crop occupation, input intensity and the use of crop insurance had the greatest positive impact on the adoption of forward pricing techniques among Kansas farms (Goodwin and Schroeder 1994). Meuwissen's study (2001) revealed that Dutch dairy farmers were more concerned about price risks, while pig and mixed farmers 
more likely perceived production risks as very important. Furthermore, insurance was less relevant for mixed farmers compared with those in dairy and pig farms (Meuwissen et al. 2001). Ritchie et al. (2004) found that risk reduction by adjusting planted areas corresponding to the forecasted seasonal climate led to significant gains in gross margin returns for irrigated cotton farmers in Australia. However, the adoption of such a strategy was strongly influenced by farmers' risk attitudes. Price risk management was an important practice among Australian cotton operators studied by Ada et al. (2006). However, demographic, agronomic, biophysical factors as well as farmers' personality played a critical role in accepting price risk management instruments.

In fact, risk realization varies substantially from farmer to farmer. This variation is attributed to many personal aspects for instance, farmers' goals, intents, experience and attitudes toward risk. Both business environment and the available instruments to cope with risks are also determining farmers’ risk perceptions. A number of researchers (Renn 1992; Slovic 1992; Slovic 2001) illustrated that the general perception of risk was a mixture of many considerations like uncertainty, equity, controllability, fear and catastrophic future. This mixture is translated as a complex and qualitative perception by individuals. Legesse and Drake (2005) suggested that an extensive framework which includes psychometric paradigm, cultural theories of risk and farm structure model, should be followed, in order to provide comprehensive insights into factors determining risk perceptions. Psychometric paradigm includes aspects such as farmers' attitudes, psychological and personal characteristics, and cognitive sources. A cultural theory is fundamentally a social theory which is considered as the most eloquent framework to investigate the relationships among human beings, as well as societal relationships. Farm structure theoretical model is concerned with the farm operation items, such as the size of the farming operation, which may influence such perceptions (Legesse and Drake 2005).

Murray-Webster and Hillson (2008) introduced a triple strand that influences perceptions and risk attitudes (Figure 3.5). This triple strand summarizes the factors that influence perceptions and attitudes under three headings: Conscious, subconscious and affective factors. Conscious factors represent the visible and measurable characteristics of the situation in which the decision is being made. Six typical conscious factors were suggested, for instance the familiarity, which investigates whether the individuals do something like before or in an adverse manner. Subconscious factors include mental short-cuts made to facilitate decision-making (heuristics); hence they provide mechanisms for making sense of complex or uncertain situations, and other sources of cognitive bias. Affective factors 
represent the responses based on instinctive emotion or deep underlying feelings rather than rational assessments, such as fear, desire, love, hate, joy and sadness (Murray-Webster and Hillson 2008).

Figure 3.5: The triple strand of influences on perceptions and risk attitudes

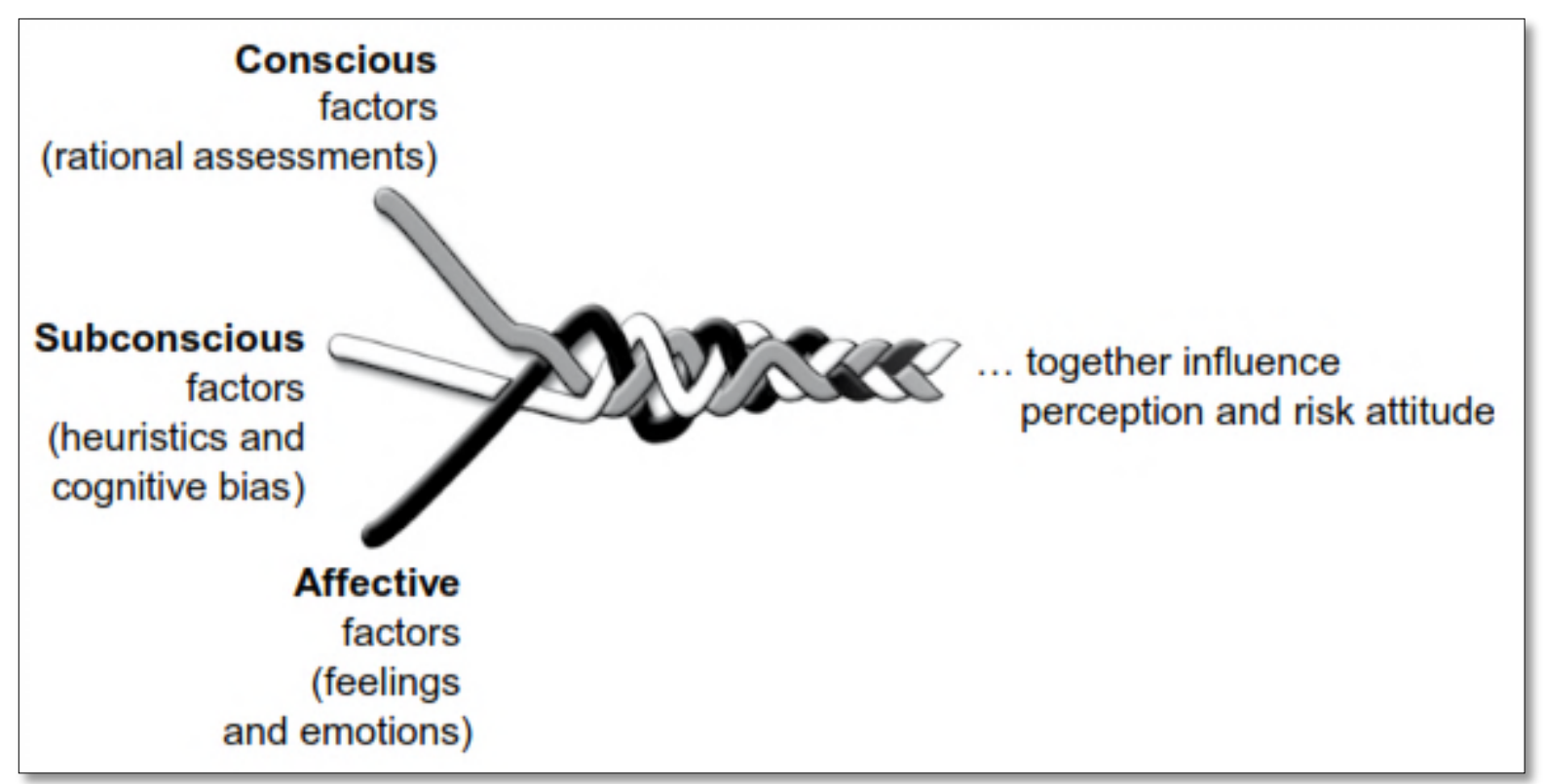

Source: Murray-Webster and Hillson 2008 


\section{EMPIRICAL ANALYSIS BY QUESTIONNAIRES ON WHEAT- COTTON AND PISTACHIO FARMS}

\subsection{Conceptual framework}

In order to investigate the determinants of farmers' attitudes and perceptions, Van Raaij's model (1981) of the decision-making environment represents an appropriate and complementary design for defining these determinants (Figure 4.1). The Van Raaij's model of Economic-psychological relationships produces insights regarding the decision-making process. The general macroeconomic environment GE refers to a recession, upswing, general and economic state policy and ecological conditions. Economic environment E includes the objective economic conditions such as financial, labour, and market conditions. Simply, E/P refers to the business environment as perceived by firms' entrepreneurs. The casual link $\mathrm{GE} \rightarrow \mathrm{E} \rightarrow \mathrm{E} / \mathrm{P}$ implies the influence that the general macroeconomic environment and the business environment have on the preferences of firms' entrepreneurs. Furthermore, E/P is influenced by personal characteristics $\mathrm{P}$. The economic behavior $\mathrm{B}$ refers to the economic choices followed by persons and agents which can be influenced by personal and business characteristics $\mathrm{P}$, as well as the perceived economic environment $\mathrm{E} / \mathrm{P}$ in such relationship $\mathrm{P} \rightarrow \mathrm{E} / \mathrm{P} \rightarrow \mathrm{B}$.

Applying the concept of framing on studies of attitudes and perceptions in farm business is possible. Farmers decide to select appropriate risk management tools based on the expectation to reduce losses and costs rather than calculating means, variances and probabilities belonging to this decision (Wilson et al. 1993). Economic behavior B is revealed in farmers' choices which are applied to cope with the perceived risks as risk management strategies. E/P represents farmers' perceptions of their farm's business environment within the general macroeconomic environment. Risks included in this farm business environment such as the comprehension of climate and market conditions, the expected price developments and the related political structure are evaluated to yield farmers' risk attitudes. Furthermore, the way that farmers differentiate the importance of different environment's risk sources is generated as a perception of risk sources. Personal factors $\mathrm{P}$ are supposed to affect both E/P and $\mathrm{B}$. These factors include objective information related to personal characteristics of the farmer (education, age, occupation, etc.) as well as farm characteristics (geographical location, tenure size, farm type, etc.). These characteristics can be sorted under socioeconomic characteristics. Other indicators of personality such as goals, aspirations, and 
cognitive and lifestyle seem to be significant personal factors which contribute to the perceptions (Van Raaij 1981; Wilson et al. 1993).

Based on the Van Raaij's model, relationships of $P \rightarrow E / P$ and $P \rightarrow B$ were commonly tracked by previous related studies (Boggess et al. 1985; Patrick et al. 1985; Wilson et al. 1988; Patrick and Musser 1997; Aditto et al. 2012), to draw a systematic classification of attitudes and perceptions based on socio-economic factors.

Figure 4.1: Van Raaij’s model of economic-psychological relationships

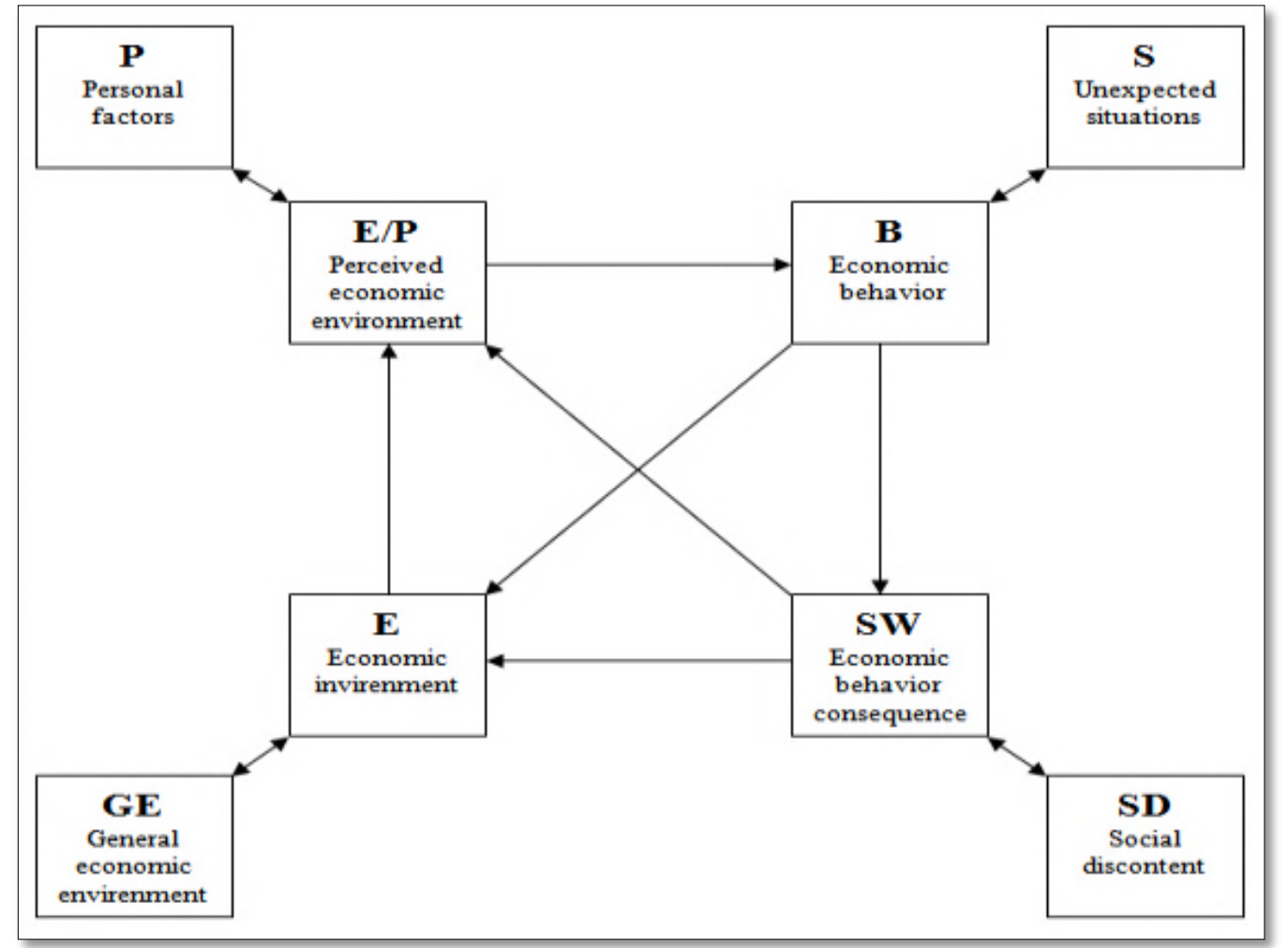

Source: Van Raaij 1980

Wilson et al. (1993) employed Van Raaij's model to explore decision making procedures in large-scale Arizona dairy farms as a case study. They used the relationship $\mathrm{P} \rightarrow \mathrm{E} / \mathrm{P} \rightarrow \mathrm{B}$ to investigate further explanations about risk management responses. In fact, Wilson's relationship had been already suggested by Van Raaij himself in 1980. He esteemed the value of perceived environment $\mathrm{E} / \mathrm{P}$ in order to influence the economic behavior $\mathrm{B}$. Ondersteijn et al. (2006) illustrated that it is important to examine the relationship between perceived external farm environment and applied management strategies to gain insight into the effect of this environment on decision-making. The relationship of $\mathrm{P} \rightarrow \mathrm{E} / \mathrm{P} \rightarrow \mathrm{B}$ was investigated by Meuwissen et al. (1999), Ejigie (2005), Flaten et al. (2005) and Størdal et al. (2007). The relationship $\mathrm{E} / \mathrm{P} \rightarrow \mathrm{B}$ that reflects the impact of farmers' risk attitudes and perceptions of risk source on selected risk management strategies is very necessary for 
devising risk reducing strategies. It helps developers of risk management strategies to get, to some extent, a systematic guideline to select the suitable management tools based on risk perceptions. Perhaps, farmers under a specific business environment with high perceptions of price risks tend to have a high desire for corresponding forward contracts with traders or food producers as price risk's management strategy. Similarly, risk-averse farmers, with specific socio-economic characteristics, may prefer risk avoidance strategies to manage risks.

As this study has an exploratory character, it suggests the investigation of the determinants of farmers' attitudes and perceptions' by examining the relations between the variables' groups in different directions. These multidirectional relationships could add further information that interprets farmers' risk attitudes and perceptions. Based on Van Raaij's argument about his model, perceptions and attitudes E/P evaluated by the information perceived from the environment, are translated on the ground by behavioral intentions $\mathrm{B}$ to improve or change part or all of the current activities. Thus, risk management tools used by farmers are a result of their risk attitudes and their perceptions of these risks. However, this does not mean that the mentioned sequence follows this one direction only. After experiencing the performance of applied economic behavior, individuals may reconfigure their personal belief structure and revise their opinions and attitudes. Therefore, after the economic behavior takes place, further acquisition of knowledge may arise; consequently further attitudes and perceptions' changes may take place. Koundouri et al. (2009) confirmed this causality when they demonstrated that the farmers' degree of risk aversion has changed considerably over the study period correspondingly to EU agricultural policy changes. Furthermore, Van Raaij (1980, p. 12) illustrated that "the four groups of variables E, E/P, B and SW are independent variables in one research design and dependent variable in another research design'’. Consequently, attitudes, perceptions, and management instruments interact with each other by multidirectional relationships $\mathrm{E} / \mathrm{P} \leftrightarrow \mathrm{B}$.

Van Raaij's argument about his model supports our study idea that the determinants of farmers' risk attitudes and their perceptions of risk sources and risk management strategies are not necessarily limited to the personal factors. As well, risk management strategies applied by farmers are not the final step of the decision-making procedure, further attitudes and perceptions may follow. Consequently, our research design (Figure 4.2) summarizes the possible relationships which could create wider vistas to explore more information about farmers' risk attitudes and perceptions. Based on this design, the second study's objective can be achieved by the following approaches: 
- The conventional approaches $P \rightarrow E / P$ and $P \rightarrow B$, to investigate the impact of the socioeconomic characteristics (S-E) on farmers' risk attitudes (RA) and their perceptions of risk sources (RS) and risk management strategies (RMS).

- The multidirectional approach $P \rightarrow E / P \leftrightarrow B$, to explore whether the subjective beliefs related to farmers' risk attitudes (RA), perceptions of risk sources (RS) and perceptions of risk management strategies (RMS) could influence attitudes and perceptions themselves.

Figure 4.2: Conceptual framework of the study

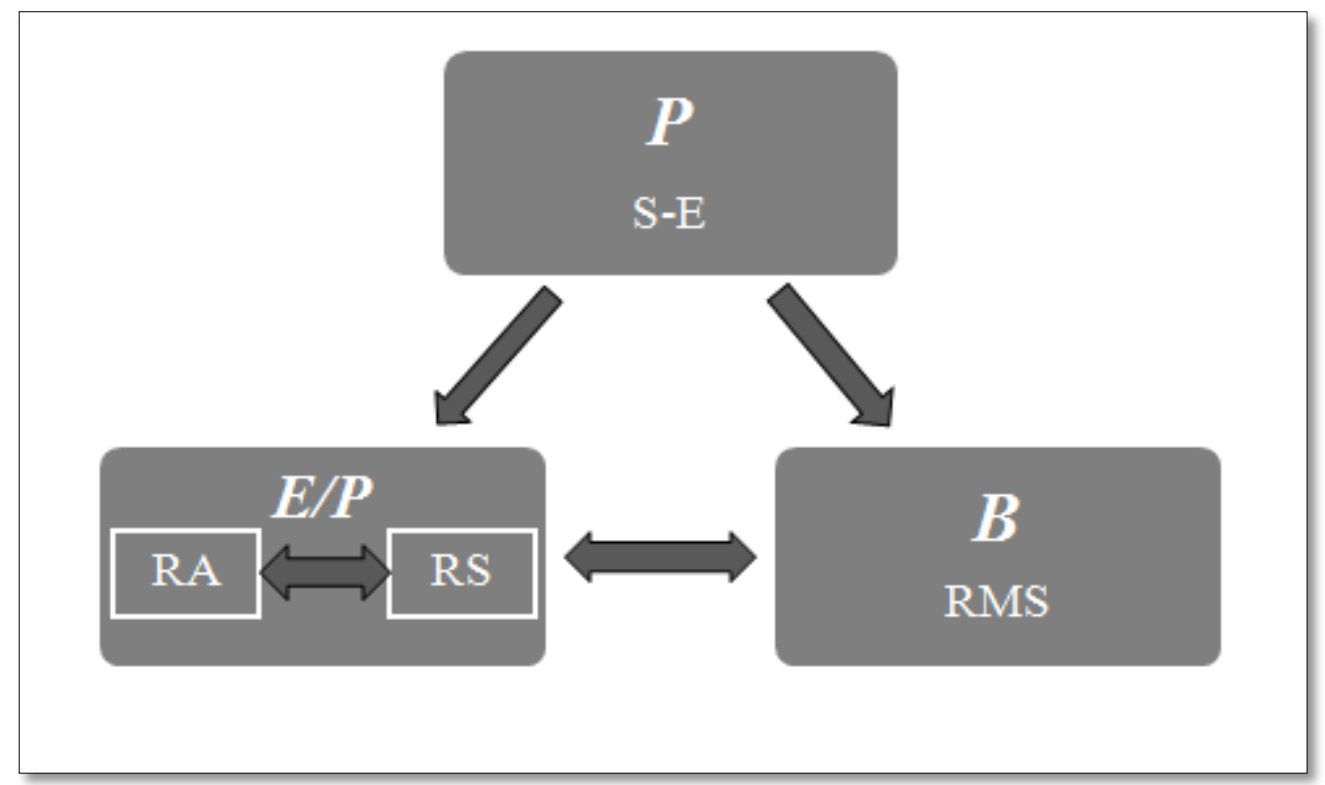

Source: Adapted from Van Raaij 1980

\subsection{Research methodology}

\subsubsection{Questionnaire design}

In order to fulfill research objectives, a structured interview questionnaire method was employed to elicit information from the wheat-cotton and pistachio farmers. The farm survey questionnaire (see appendix A) was structured into five major sections. The first section of the questionnaire asked about the characteristics of the farm enterprise such as farm size, owner status, farm's activities and crops and the family labour size. Irrigation methods and farm finance were elicited in this section. In the second section, ten-point Likert-scales (1 to 10) were submitted to evaluate farmers' perceptions of 31 sources of risk. In most of the previous studies, such questionnaires asked farmers to mark the risk sources scale regarding their consideration of the given risks' importance. However, Botterill and Mazur (2004) and 
Wideman (1992) as cited in Baccarini and Archer (2001), suggested that developers of risk management strategies have to deal with risks in terms of their probability of occurrences and the magnitude of the consequences. Murray-Webster and Hillson (2008, p. 5) demonstrated that "risk has two sides: uncertainty, which can be expressed as 'probability' or 'likelihood'; and how much it matters, expressed as 'impact' or 'consequence'. Both of these dimensions need to be understood so that good decisions can be made”. For this reason, these two aspects were addressed in the questionnaire separately for each source of risk as illustrated in Figure 4.3.

Figure 4.3: Example of risk source item and choice options in the questionnaire

What do you think, how likely is the occurrence of each of the following risks?

\begin{tabular}{|l|c|c|c|c|c|c|c|c|c|c|}
\hline Risk source & Low probability & 2 & 3 & 4 & 5 & 6 & 7 & 8 & 9 & High probability \\
\hline Precipitation shortage & $\square$ & $\square$ & $\square$ & $\square$ & $\square$ & $\square$ & $\square$ & $\square$ & $\square$ & $\square$ \\
\hline
\end{tabular}

How do you estimate the impact of these mentioned risks on your farm business?

\begin{tabular}{|l|c|c|c|c|c|c|c|c|c|c|}
\hline Risk source & No impact & 2 & 3 & 4 & 5 & 6 & 7 & 8 & 9 & Existence endangerment \\
\hline Precipitation shortage & $\square$ & $\square$ & $\square$ & $\square$ & $\square$ & $\square$ & $\square$ & $\square$ & $\square$ & $\square$ \\
\hline
\end{tabular}

Source: own elaboration

Part three inspects farmers' preferences of risk management strategies which are commonly employed in the region to mitigate farm risks. Five-point Likert-scales for 15 and 12 risk management strategies for wheat-cotton and pistachio respectively, were given in this section allowed 5 responses (mapped to integers -2 through +2 , respectively) as shown in Figure 4.4.

Figure 4.4: Example of risk management statement and choice potions in the questionnaire

How do you estimate the importance of the following risk management strategies for your farm business?

\begin{tabular}{|l|c|c|c|c|c||}
\hline Risk management strategy & $\begin{array}{c}\text { Strongly } \\
\text { disagree }\end{array}$ & Disagree & Unsure & Agree & $\begin{array}{c}\text { Strongly } \\
\text { agree }\end{array}$ \\
\hline I will diversify my farm activities. & $\square$ & $\square$ & $\square$ & $\square$ & $\square$ \\
\hline
\end{tabular}

Source: own elaboration

It is worth mentioning that risk sources and risk management strategies inspection scales were similarly designed as a five-point Likert-scales, but wheat-cotton farmers found difficulties to evaluate their risk probability and impact by this scale. For this reason, the scales were replaced by ten-point Likert-scales which were easily perceived as a number out of ten. The letter scale has been already used by Schaper et al. (2010). Such problem was not found with five-point Likert-scales of risk management strategies' evaluation because farmers 
found it easier to answer by agreement degrees. Given this research topic is unexampled aspect in Syria, there are no previous patterns which were concerned with Syrian agricultural risk sources and risk management strategies to improve them. Therefore, the second and third sections are drawn by discussion with farm experts of extension services, academic members in Aleppo University, expert members of NAPC and selected farmers in the study area. Additionally, previous studies were taken into account to adapt risk sources and risk management strategies questions such as Wilson et al. (1993), Martin and McLeay (1998), Meuwissen et al. (2001), Lien et al. (2006) and Schaper et al. (2010).

In order to obtain an impression about farmers' willingness to take risk, ten statements belonging to a self-assessment scale were designed as five-point Likert-scales in the fourth section of the questionnaire. Self-assessment scale enables the researcher to avoid the constraints which arise using gambling related method (ELCE method) particularly in Syrian case where people firmly believes that gambling is prohibited by Islamic doctrines. Farmers' risk attitudes are influenced by multiple factors' interactions, thus true risk attitudes are not always apparent (Bard and Barry 2000). In order to lessen this foible, it could be useful to increase the statement numbers in the scale, and then optimize them by a refinement procedure. For this reason, 10 statements were used in this study compared to 1-5 statements which were described by Schurle and Tierney (1990), Kastens and Featherstone (1996), Patrick and Ullerich (1996), Xu et al. (2005) and Meuwissen et al. (2001). Furthermore, using self-assessment scale with multi-items is better than that of single-item which is insufficient due to its validity, accuracy, reliability and measurement properties (McIver and Carmines, 1981). Farmers have been asked to answer each scale statement by one of the choices illustrated in Figure 4.5. The statements of self-assessment scale used in this study were improved previously by Kastens and Featherstone (1996), Meuwissen et al. (2001) and Schaper et al. (2010), with slight modifications.

Figure 4.5: Example of self-assessment scale's statement and choice options in the questionnaire

\begin{tabular}{|l|c|c|c|c|c|}
\hline Self-assessment scale's statement & $\begin{array}{c}\text { Strongly } \\
\text { disagree }\end{array}$ & Disagree & Unsure & Agree & $\begin{array}{c}\text { Strongly } \\
\text { agree }\end{array}$ \\
\hline $\begin{array}{l}\text { To implement my farm plan goals, I am willing to } \\
\text { take risks more than others. }\end{array}$ & $\square$ & $\square$ & $\square$ & $\square$ & $\square$ \\
\hline
\end{tabular}

Source: own elaboration

The last section summarizes some personal factors such as age, level of formal education, off-farm work and leadership possession. 
For further suggestions, a draft of the designed questionnaire was sent for consultation to wheat-cotton academic farmer who was in Rostock University as a Ph.D. student. Another draft was sent to a professor in Aleppo University who is also a pistachio farmer. Constructive suggestions and comments have been recommended to improve the questionnaire content.

\subsubsection{Study location}

Wheat-cotton data survey was conducted in the Al Hasakah governorate for several reasons: (1) The cultivated area in this governorate represents about $27.40 \%$ of the total Syrian cultivated area. (2) Al Hasakah has the superiority for wheat-cotton cultivated area and production (Figure 4.6).

Figure 4.6: Development of cultivated area (ha) and production (tons) for wheat and cotton in Al Hasakah compared to the other Syrian governorates, 2005-2011

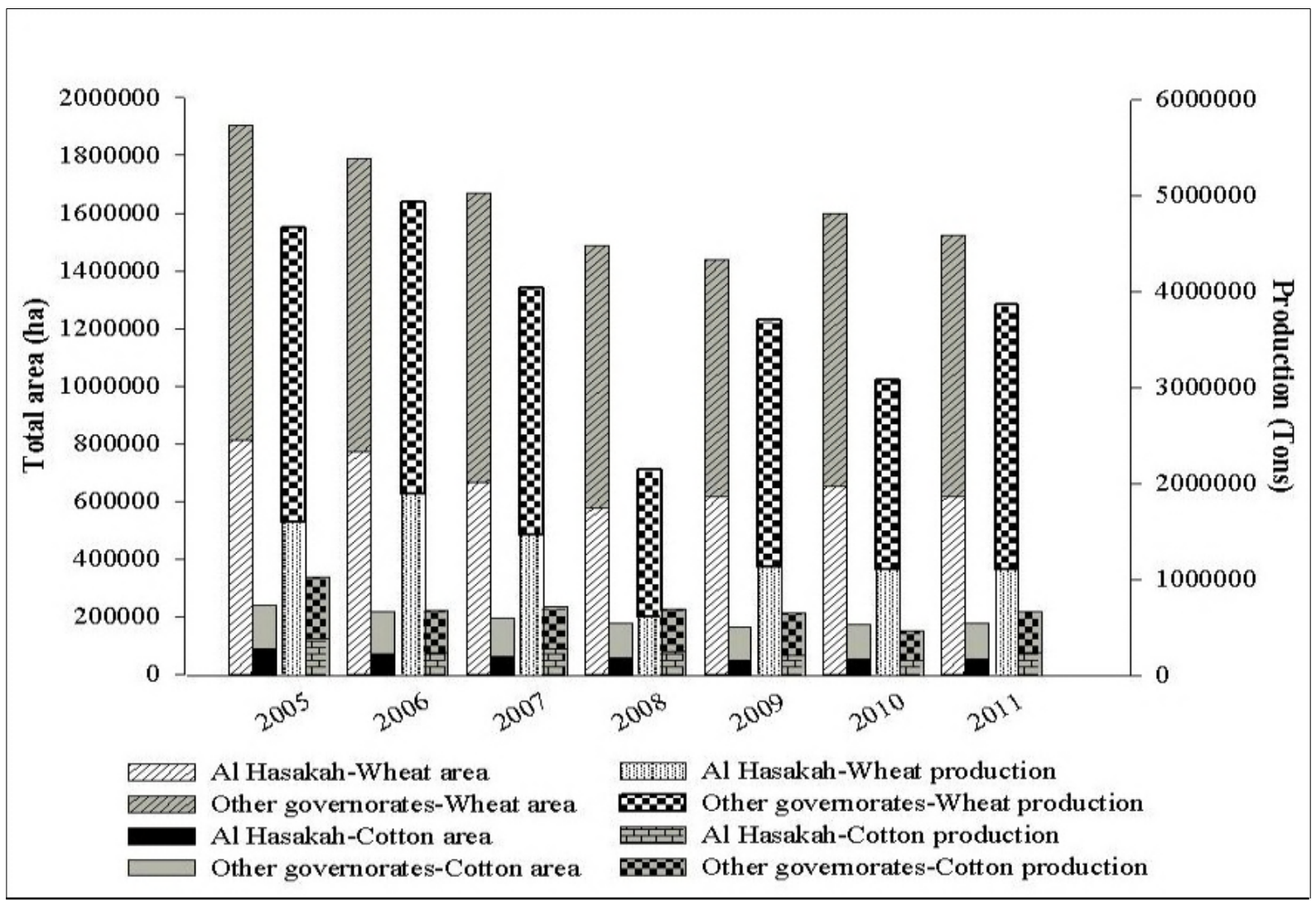

Source: Adapted from SADB 2013

On average, it contributed to $41 \%$ and $32 \%$ of the national land cultivated by wheat and cotton, respectively, during 2005-2011. These land shares produced on average 33\% and36\% of the national wheat and cotton production respectively in the same period (SADB 2013). (3) As Al Hasakah spreads over all agro-ecological zones, it was possible to collect information throughout wheat-cotton related zones (1, 2 and 3) within one governorate. 
Hamah and Idlib governorates were chosen to inspect the required pistachio data. As shown in Figure 4.7, about half of the pistachio land is concentrated in these two areas, furthermore Hamah and Idlib produced on average about $60 \%$ of the total Syrian pistachio production between 2005 and 2011 (SADB 2013). They also spread over zones 1 and 2, where pistachio cultivation is appropriate.

Figure 4.7: Development of Pistachio cultivated area (ha) and production (tons) for in Hamah and Idlib compared to the other Syrian governorates, 2005-2011

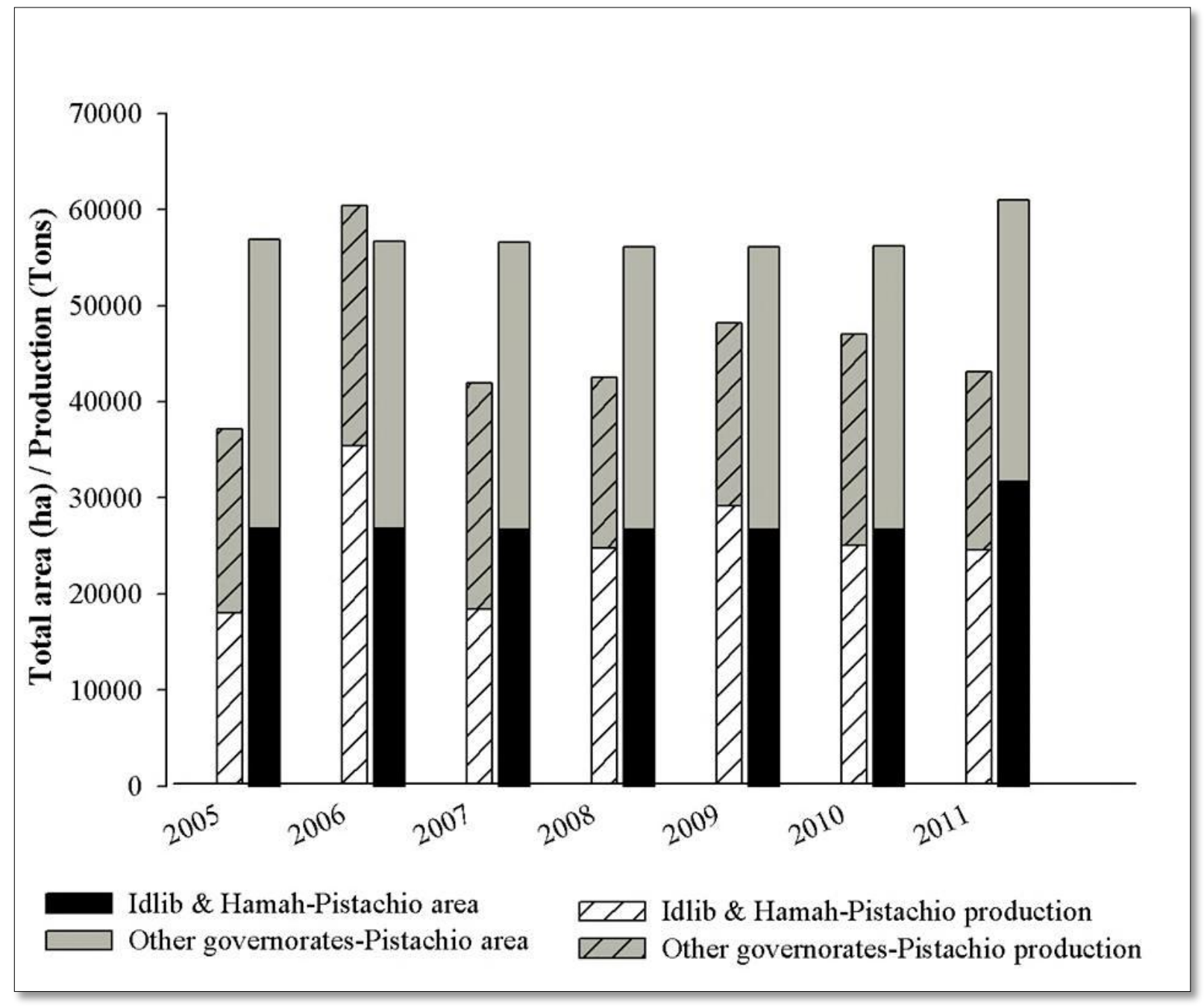

Source: Adapted from SADB 2013

\subsubsection{Sampling}

The sampling procedure focused on farms where the objective crop (wheat-cotton combination or pistachio) is the main occupation. Wheat-cotton samples were randomly selected throughout related agro-ecological zones from 32 villages along four axes shown in Figure 4.8. The same random selection was done for pistachio samples from 21 villages along Hamah-Idlib axis. Face-to-face interviews with 103 and 105 wheat-cotton and pistachio 
farmers, respectively, were conducted between November 2009 and January 2011 to gather required information from the respondents. Only the data related to agro-ecological zone where the farms are located was collected from the agricultural advisory centers in the study regions. The two academic farmers mentioned before suggested a local guide for each study area (wheat-cotton and pistachio).

Figure 4.8: Map of Syria and the selected study areas

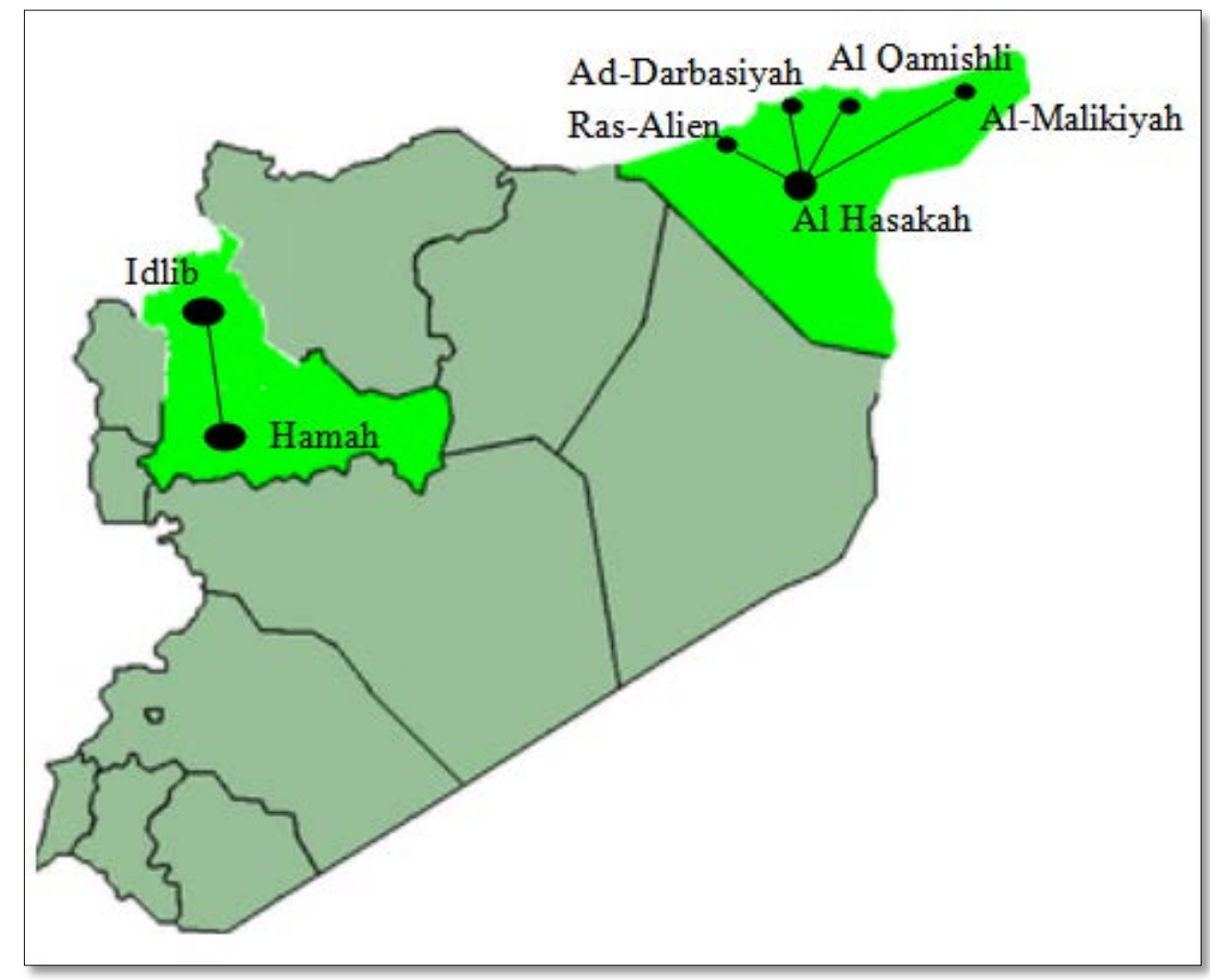

Source: Own modification

\subsubsection{Data limitation}

The main problem which occurred during the field survey was farmers' fear to provide information to someone who may be a member of the Intelligence Service. This behavior looks like 'authority phobia' that is considered a justified behavior given the bad reputation of Syrian Intelligence Service. The local guide played an essential role to deal with this problem since he wore traditional dress and talks the local dialect. Start with general talk in addition to share coffee drinking was important to create a goodwill atmosphere before starting the interview. This procedure was time-consuming; since most interviews were completed in 60120 minutes. Another important point that hinders data interviewing procedure was the widespread dissatisfaction among Syrian people (particularly rural population) against the state policy before the 2011 revolution. Some cotton farmers rebuffed me and said: 'You are 
the main risk source in my farm, you shared authority the decision of fuel price rising, and then you come to ask us about the impacts?' These mentioned difficulties and obstructions led to limit sample size.

\subsection{Data analysis}

Descriptive statistics (frequency distribution, arithmetic mean and standard deviation) were employed to describe farm and farmer characteristics. One way ANOVA and t-test were used to determine the differences between the farmers' socio-economic characteristics in different zones.

Farmers' risk attitudes were determined by the sum score of the self-assessment scale’s statements. In order to optimize the self-assessment scale, reliability test was employed. Reliability test evaluates contribution of the individual scale items in the common underlying construct. A measurement that frequently used to evaluate the reliability is Cronbach's coefficient alpha (Peter 1979; DeVellis 1991; Nunnally and Bernstein 1994; Bard and Barry 2000; Lagerkvist 2005; Bardhan et al. 2006; Hair et al. 2010). Coefficient alpha measures the proportion of communal variation due to true differences in farmers' attitudes toward the risk. It is measured as:

$$
\alpha=\frac{k}{k-1}\left(1-\frac{\sum \sigma_{i}^{2}}{\sigma_{y}^{2}}\right)
$$

where $\alpha$ is Cronbach's coefficient alpha, $k$ is the number of statements in the scale, $\sigma_{i}^{2}$ is the variance of the $i$ th statement, and $\sigma_{y}^{2}$ is the variance of the $k$-statement scale. The coefficient alpha ranges between 0 and 1 . The minimally acceptable coefficient alpha is subjective and varies based on the developer's objectives (Bard and Barry 2000). DeVellis (1991) suggested the range of aggregated coefficient alpha between 0.65 and 0.7 is minimally acceptable, while 0.7 and above is the minimum acceptable value by Nunnally and Bernstein (1994). In the exploratory factor analysis, Cronbach’s coefficient alpha value of 0.6 meets the lower limit accepted by Cox and Flin (1998), Harvey et al. (2002) and Hair et al. (2010).

The reliability test objective is to generate alpha as high as possible. Scale optimization can be established by the statement refinement procedure. The statements which have negative or very low Corrected Item-Scale Correlation (CISC) values were excluded to generate an improved Cronbach's coefficient alpha. CISC relates individual statements to the remaining items in the scale and it is represented as: 


$$
r_{1(y-1)}=\frac{r_{y 1} \sigma_{y}-\sigma_{1}}{\sqrt{\sigma_{1}^{2}+\sigma_{y}^{2}+2 \sigma_{1} \sigma_{y} r_{y 1}}}
$$

where $r_{y 1}$ is the correlation of item $x 1$ with a total score $y, \sigma_{y}$ is the standard deviation of the total score $y, \sigma_{1}$ is the standard deviation of item $x 1$, and $r_{1(y-1)}$ is the correlation of item $x 1$ with the sum of scores of all the items, $y$, exclusive of item $x 1$.

Rules of thumb suggest that the critical threshold of 0.5 is acceptable for CISC (Hair et al. 2010).

The aggregated score of the refined statement for each farmer refers to his attitude toward risk. This score will be used in the subsequent multiple regressions under the name of risk attitude scale.

Farmers’ perceptions of risk sources and risk management strategies were studied by descriptive analysis. Additionally, risk maps were used to differentiate between less relevant risks and relevant risks.

To investigate the determinants of resultant attitudes and perceptions, numbers of multivariate regressions were applied. Before that, factor analysis was used to reduce the number of variables belonging to risk sources and risk management strategies.

\subsubsection{Factor analysis}

Exploratory factor analysis (EFA) is an essential empirical tool used in various subjects such as economics, social, psychology, and political science. In agricultural risk studies, factor analysis facilitates to summarize the information about risk perceptions and risk management strategies obtained from a large set of variables in a reduced number of latent variables (factors), which explain the variance of original variables (Kim and Mueller 1978; Hair et al. 2010; Pallant 2007). Factor analysis gathers variables in combinations which are uncorrelated. The combinations obtained measure different dimensions in the data as they are uncorrelated (Manly 2004).

Factors with latent root criterion (eigenvalues) greater than 1 were considered in this study, which mean that each factor contributes for a greater variance than had been possible by any one of its variables.

About factor loadings, a minimum threshold of 0.3 is generally accepted in the literature, even though other authors suggest the minimal range between 0.4-0.5 in practical 
purposes (Von Pock 2007). In this study, values of greater or equal to 0.4 were employed to determine the inter-correlation among the original variables (Stevens 1992).

The Kaiser-Meyer-Olkin (KMO) method measures sampling adequacy and varies from 0 to 1 . KMO with 1 value means that each variable is perfectly predicted without error by the other variables. KMO result of 0.6 or greater is recommended (Hair et al. 2010). Von Pock (2007) has illustrated that KMO value of greater or equal to 0.50 is already considered to meet the minimum level in the literature.

In addition, orthogonal (varimax) rotation was implemented in order to minimize the number of variables that have high loadings on each factor, thus to obtain factor solutions that were easier to interpret.

To evaluate the internal consistency of each factor, Cronbach's coefficient alpha was employed as one of the most prevailing reliability tests. Cronbach's coefficient alpha of 0.6 was accepted in this study as a minimum level of factor reliability as suggested by Hair et al. (2010) for such exploratory factor analysis. Similarly, Harvey et al. (2002) accepted 0.61 to 0.88 in a study about safety culture attitudes, as well; Aditto (2011) accepted risk sources' factors with Cronbach coefficient alpha values, 0.43 and 0.51 .

Factor analysis' technique generates respondent's scores for each factor which can be used for the subsequent multiple regressions (Hair et al. 2010). Basically, the generated factor scores measure the deviation of an individual's score from the sample mean (Kim and Mueller, 1978; Kline and Wichelns, 1998).

\subsubsection{Multiple regression analysis}

To investigate the determinants of resultant attitudes and perceptions, based on the study’s approaches (see Figure 4.9), multiple regressions were employed as following:

1- Multiple regression analysis using Enter method to explain the conventional approaches $P \rightarrow E / P$ and $P \rightarrow B$. Enter method offers us information about size of the overall relationship between the socio-economic characteristics (S-E) (independent) and each of farmers' risk attitudes (RA) and their perceptions of risk sources (RS) and risk management strategies (RMS). Furthermore, it evaluates the unique contribution of each of socio-economic variable to that relationship. As shown in Figure 4.9, the aggregated scores of risk attitude scale, and standardized factor scores for risk sources and risk management strategies, obtained from the factor analysis, were separately 
regressed against socio-economic variables at the $5 \%$ as a maximum level of significance.

Figure 4.9: The assumed regressions related to the conventional approaches

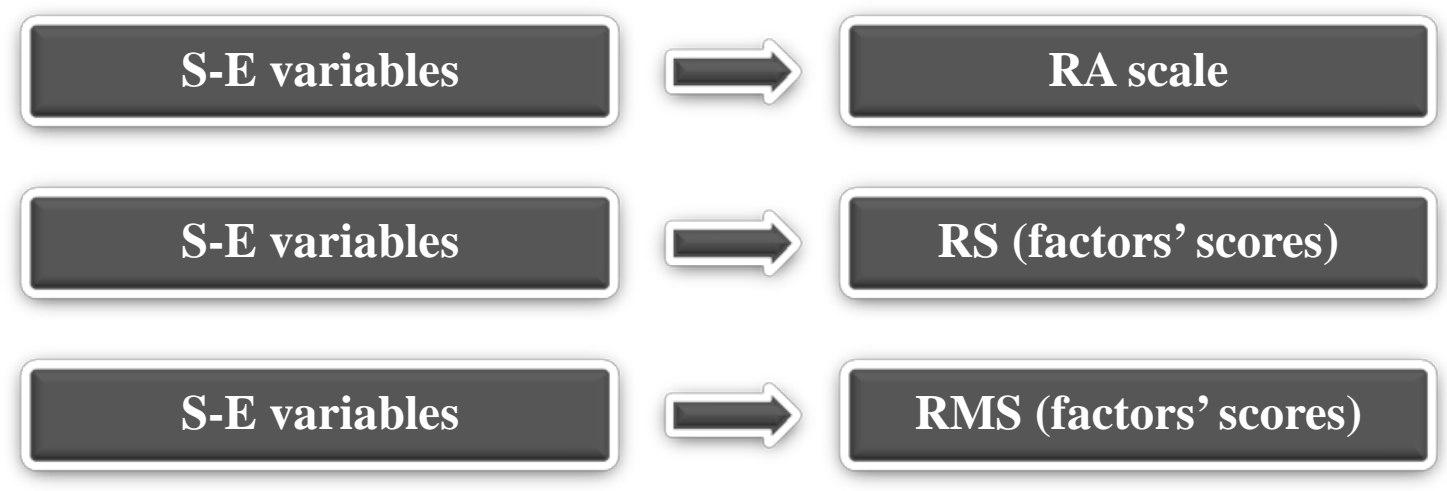

Source: Own modification

2- Multiple regression analysis using Stepwise method to explain the multidirectional approach $P \rightarrow E / P \leftrightarrow B$. Stepwise method provides the best combination of independent variables (objective and subjective information) to interpret the dependent one (Figure 4.10). Thus, the method provides the ability to evaluate the extent of contribution of the objective and subjective variables within the best combination. Regressions were performed at the $5 \%$ as a maximum level of significance.

Figure 4.10: The assumed regressions related to the multidirectional approaches

\section{S-E variables, RS factors and RMS factors}

S-E variables, RA scale and RMS factors

S-E variables, RA scaleand RA factors

\section{RA scale}

\section{RS factors}

RMS factors

Source: Own modification

All statistical analyses were done through SPSS Statistics for Windows, Version 20.0. The abbreviations for socio-economic characteristics (S-E), farmers' risk attitudes (RA), perceptions of risk sources (RS) and risk management strategies (RMS), will be used only in the following section to have simple following without repetition in long sentences. 


\section{RESULTS AND DISCUSSION}

\subsection{Socio-economic characteristics of the interviewed farmers}

\subsubsection{Wheat-Cotton farmers}

The aggregated statistics regarding to the socio-economic characteristics of the wheatcotton farmers are represented in Table 5.1. One way ANOVA was employed to test the differences between farmers' socio-economic characteristics in the three zones included in the study. The Levene-Test shows that the homoscedasticity cannot be assumed; hence the T2 test (Tamhane) was chosen for a post-hoc multiple group comparisons. This test offers the same results as the conservative Bonferroni-Test if the variances are homogeneous and enable pairwise comparisons on the grounds of a t-test (SPSS 2003; Backhaus et al. 2008).

Almost $62 \%$ of the farms were under a private ownership type. Land reform reached the highest share of land ownership in zone $3(\rho<0.001)$. This suggests more restrictions in zone 3 regarding land assignment procedure as submitted by Laws of 1958 (see section 2.3.4).

The average farm land of the farms was 26.54 ha. Due to family collective operation, two farms which had over-size (1000 and 700 ha) were excluded from overall calculated averages. The minimum farm size included in the questionnaire was 3 ha, thus the study survey sample met the threshold size ( $1 \mathrm{ha}$ ) needed to include the farm into the state annual plan (see section 2.3.3). The result showed that farm land increase by the movement from zone 3 to 1 . The same trend was observed for following items as well: Diversification of farm activities, crops’ diversification, wheat yield, cotton yield, and bank loans.

Poultry and animal husbandry were the most diversified activities noticed in the study area. Watermelon, maize and legume varieties such as lentils, broad bean and chickpea were observed in zones 1 and 2, while barley was preferred in the third one. Corresponding to average rainfall differentiation, the lowest percentage of farmers who cultivated rain-fed wheat (in addition to irrigated one) was found in the zone $3(\rho<0.05)$. Obtaining bank loans varies among wheat-cotton producers based on many aspects, particularly the commitment to Islamic doctrines which prohibit loans’ interest rates.

As discussed in section (2.3.3), cotton license's percentage is changeable by the annual agricultural plans. During study years (2009-2011), cotton licenses were governmentally submitted as $20 \%$ of total farm land in zone 1 and $17 \%$ in zone 2 and 3 . The result showed 
that the farmers at the study sites were not committed with state licenses. The highest share of offenders was observed in zone 3 (85.2\%) with significant differences in comparison with other zones $(\rho<0.001)$. This suggests that farmers in zone 3 tend to support their farm income by over-cultivation of cotton more than by reliance on farm business diversification.

Usage of Modern irrigation techniques (sprinkler and drip) was out of the ordinary mechanism in wheat-cotton area. Only six farmers adopted such a technique. Actually, modern irrigation is a new instrument in $\mathrm{Al}$ Hasakah region, thus its consequences are unclear so far. Wheat-cotton producers imagine it as a charged matter due to its construction and maintenance cost.

Around $79 \%$ of overall farmers had graduated with a primary education, while about $4 \%$ were illiterate. The highest share of higher educated farmers was revealed among those in zone 3. In that context, farmers' personal experience was the most important knowledge resource to make their farm-decisions. However, $19.4 \%$ of them relied on scientific materials such as agricultural textbooks and magazines, universities and scientific centers.

The age group distribution indicates that $31 \%$ of the farmers of the whole studied area were 40-49 years old. The largest group of youngest farmers (30-39 years old) was noticed in zone 3 (40.7\%), while the largest group of old farmers (50-59 years old) was located in zone 2 (37.5\%). Regarding the farmers' leadership, the interviewed operators were distributed as farm managers (58.3\%), farm successors (36.9\%), and farm partners (4.8\%). Almost 18\% of the farmers earned income by non-farm jobs. Family labour was observed as the main labour force in the wheat-cotton farms. 92\% of the farmers said that "our family' members very frequently participate in farm activities”. This corresponds with Ondersteijn et al. (2006) who reported that in many cases farm business looks like a family business. 
Table 5.1: Socio-economic characteristics of the Syrian wheat-cotton farmers, $(n=103)$

\begin{tabular}{|c|c|c|c|c|c|}
\hline \multirow[b]{2}{*}{ Item } & \multirow[b]{2}{*}{$\begin{array}{l}\text { Overall } \\
(n=103)\end{array}$} & \multicolumn{3}{|c|}{ Agro-ecological zone } & \multirow[b]{2}{*}{ Sig. } \\
\hline & & $\begin{array}{c}1 \\
(\mathrm{n}=44)\end{array}$ & $\begin{array}{c}2 \\
(\mathrm{n}=32)\end{array}$ & $\begin{array}{c}3 \\
(n=27)\end{array}$ & \\
\hline Ownership (\%) & & $\mathrm{a}$ & $\mathrm{a}$ & $\mathrm{b}$ & \\
\hline Private & 62.2 & 68.2 & 81.3 & 22.2 & \\
\hline Land reform & 32 & 22.7 & 12.5 & 70.4 & \\
\hline Rental & 7.8 & 9.1 & 6.3 & 7.4 & \\
\hline Farm land (ha) & 26.54 & 32.38 & 28.8 & 14.79 & ns \\
\hline Farm activity diversification (\%) & 30.1 & 38.6a & $34.4 \mathrm{ab}$ & $11.1 \mathrm{~b}$ & * \\
\hline Crop diversification (\%) & 52.4 & 75 a & $59.4 \mathrm{a}$ & $7.4 \mathrm{~b}$ & ${ }^{* * *}$ \\
\hline Wheat yield (ton/ha) & 4.73 & 5.5 a & $4.28 \mathrm{~b}$ & $4.03 \mathrm{~b}$ & ${ }^{* * *}$ \\
\hline Cotton yield (ton/ha) & 4.12 & 4.86 a & $3.66 \mathrm{~b}$ & $3.44 \mathrm{~b}$ & *** \\
\hline Rain-fed wheat (\%) & 18.2 & $31.1 \mathrm{a}$ & 40.6 a & $7.4 \mathrm{~b}$ & ${ }^{*}$ \\
\hline Cotton license (\%) & & a & a & $\mathrm{b}$ & ${ }^{* * *}$ \\
\hline Committed & 56.3 & 72.7 & 68.8 & 14.8 & \\
\hline Offender & 43.7 & 27.3 & 31.3 & 85.2 & \\
\hline Bank loan (\%) & 68.9 & $77.3 \mathrm{a}$ & $78.1 \mathrm{a}$ & $44.4 \mathrm{~b}$ & ** \\
\hline Modern irrigation (\%) & 5.8 & 6.8 & 3.1 & 7.4 & ns \\
\hline Scientific materials (\%) & 19.4 & $20.5 \mathrm{ab}$ & 6.3 a & $33.3 \mathrm{~b}$ & * \\
\hline Education (\%) & & & & & ns \\
\hline Illiterate & 3.9 & 9.1 & 0 & 0 & \\
\hline Primary & 78.6 & 70.5 & 90.6 & 77.8 & \\
\hline Secondary & 5.8 & 9.1 & 3.1 & 3.7 & \\
\hline Higher education & 11.7 & 11.4 & 6.3 & 18.5 & \\
\hline \multicolumn{6}{|l|}{ Farmer age (\%) } \\
\hline 20-29 years old & 7.8 & 6.8 & 9.4 & 7.4 & \\
\hline 30-39 years old & 23.3 & 22.7 & 9.4 & 40.7 & \\
\hline 40-49 years old & 31.1 & 34.1 & 25.0 & 33.3 & \\
\hline 50-59 years old & 25.2 & 25.0 & 37.5 & 11.1 & \\
\hline More than 60 & 12.6 & 11.4 & 18.8 & 7.4 & \\
\hline Leadership (\%) & & & & & ns \\
\hline Manager & 58.3 & 65.9 & 50 & 55.6 & \\
\hline Successor & 36.9 & 29.5 & 46.9 & 37 & \\
\hline Partner & 4.8 & 4.5 & 3.1 & 7.4 & \\
\hline Off-farm work (\%) & 18.4 & 11.4 & 15.6 & 33.3 & ns \\
\hline Family labour (\%) & & $\mathrm{a}$ & $\mathrm{a}$ & $\mathrm{b}$ & *** \\
\hline Vary infrequently & 2.9 & 0 & 3.1 & 7.4 & \\
\hline Infrequently & 1.9 & 0 & 0 & 7.4 & \\
\hline Sometimes & 2.9 & 4.5 & 0 & 3.7 & \\
\hline Frequently & 25.2 & 13.6 & 21.9 & 48.1 & \\
\hline Very frequently & 67 & 81.1 & 75 & 33.3 & \\
\hline
\end{tabular}

a,b,c: Different letters in a row indicate significant differences between different zones

Variables significant at $\mathrm{P}^{*} \leq 0.05, \mathrm{P}^{* *} \leq 0.01$ and $\mathrm{P}^{* * *} \leq 0.001$

ns: not significant

Source: Own elaboration using survey data

\subsubsection{Pistachio farm}

Table 5.2 offers a general overview of the different socio-economic characteristics of pistachio producers. In order to offer some comparison insights of the farmers' characteristics between the two related agro-ecological zones, $t$-test was employed. 
The results show that all interviewed pistachio operators fulfilled the land assignment procedure. Thus, all studied farms were under private ownership. Modern irrigation, particularly sprinkler irrigation, was the prevailing irrigation method in the all studied farms. Pistachio farmers were more committed to Islamic doctrines which prohibit loans with interest rates than those in the wheat-cotton sample. Therefore, none of the interviewed farmers relied on bank loans.

The average farm land of the overall farms was 8.5 ha. Farm activity diversification showed a low percentage (16.2\%) in comparison to that for crop diversification (73.3\%) of the total sample farms. The highest share of crop diversification was noticed in zone 1 (88.5\%). The distribution of crop diversification between the operators in both zones was significantly different $(\rho<0.001)$. Poultry and animal husbandry were the most frequently implemented diversification activities adopted in the study area, while olive, grape, fig and almond were commonly noticed in pistachio farms together with intercropping potato, vegetables and sugar beet. All pistachio trees in the studied farms were under the fruition stage; average trees age was 25.8 years with average yield 1.37 tons/ha.

Syrian pistachio is classified as a supplementally irrigated crop which requires one irrigation operation during the summer season. However, due to severe dry winters the need of multi-irrigation has increased. $19 \%$ of the farmers still run their pistachio as a supplementally irrigated crop; most of them were concentrated in zone 1 . Wells were the main water resource that the farmers relied on. However, the results show that only $45.7 \%$ of the total observed operators had their own wells. This indicates that a high share of cooperation regarding the irrigation operation.

Pistachio farmers were more educated than those of the wheat-cotton sample, about $57 \%$ of overall producers had achieved higher education. Furthermore, illiterate farmers were not present in the sample. Similarly, reliance on scientific materials in order to build a farm decision was recorded at a considerable percentage of $32.4 \%$.

The age group distribution indicates that most of the farmers (31\%) were 30-39 years old. A notable share of old producers (>60 years; 19\%) was also found. Leadership distribution was quite similar to the wheat-cotton farmers, including farm managers (58.1\%), farm successors (37.1\%), and farm partners (4.8\%). As well, family labour was detected as the main labour force in pistachio farm business. Differently to the wheat-cotton operators, a high percentage of pistachio farmers had non-farm job. This may be attributable to their high education level which enables them to easily find another job. 
Table 5.2: Socio-economic characteristics of the Syrian pistachio farmers, $(n=105)$

\begin{tabular}{|c|c|c|c|c|}
\hline \multirow[b]{2}{*}{ Item } & \multirow[b]{2}{*}{$\begin{array}{c}\text { Overall } \\
(\mathrm{n}=105)\end{array}$} & \multicolumn{2}{|c|}{ Agro-ecological zone } & \multirow[b]{2}{*}{ Sig } \\
\hline & & $\begin{array}{c}1 \\
(n=52)\end{array}$ & $\begin{array}{c}2 \\
(n=53)\end{array}$ & \\
\hline Farm land (ha) & 5.8 & 5.3 & 6.29 & ns \\
\hline Farm activity diversification (\%) & 16.2 & 13.5 & 18.9 & ns \\
\hline Crop diversification (\%) & 73.3 & 88.5 & 58.5 & ${ }^{* * * *}$ \\
\hline Trees age (year) & 25.8 & 23.37 & 28.19 & ${ }^{* * *}$ \\
\hline Yield (tons/ha) & 1.37 & 1.4 & 1.34 & ns \\
\hline Well (\%) & 45.7 & 53.8 & 37.7 & ns \\
\hline Supplemental irrigated pistachio (\%) & 19 & 26.9 & 11.3 & * \\
\hline Scientific materials (\%) & 32.4 & 25 & 39.6 & ns \\
\hline Education (\%) & & & & ns \\
\hline Illiterate & 0 & 0 & 0 & \\
\hline Primary & 30.5 & 30.8 & 30.2 & \\
\hline Secondary & 12.4 & 7.7 & 17 & \\
\hline Higher education & 57.1 & 61.5 & 52.8 & \\
\hline Age (\%) & & & & * \\
\hline $20-29$ years old & 17.1 & 25 & 9.4 & \\
\hline 30-39 years old & 34.3 & 40.4 & 28.3 & \\
\hline 40-49 years old & 19 & 9.6 & 28.3 & \\
\hline 50-59 years old & 10.5 & 5.8 & 15.1 & \\
\hline More than 60 & 19 & 19.2 & 18.9 & \\
\hline Leadership (\%) & & & & * \\
\hline Manager & 58.1 & 40.4 & 75.5 & \\
\hline Successor & 37.1 & 57.7 & 17 & \\
\hline Partner & 4.8 & 1.9 & 7.5 & \\
\hline Off-farm work (\%) & 58.1 & 46.2 & 69.8 & * \\
\hline Family labour (\%) & & & & ns \\
\hline Vary infrequently & 3.8 & 7.7 & 0 & \\
\hline Infrequently & 5.7 & 7.7 & 3.8 & \\
\hline Sometimes & 8.6 & 3.8 & 13.2 & \\
\hline Frequently & 51.4 & 42.3 & 60.4 & \\
\hline Very frequently & 50.5 & 38.5 & 22.6 & \\
\hline
\end{tabular}

Source: Own elaboration using survey data

Variables significant at $\mathrm{P}^{*} \leq 0.05, \mathrm{P}^{* *} \leq 0.01$ and $\mathrm{P}^{* * *} \leq 0.001$

ns: not significant

\subsection{Risk Attitude}

Wheat-cotton and pistachio farmers were asked to declare their degree of agreement with ten primary self-assessment statements (Table 5.3) on a 5-point scale where -2 is strongly disagree, 0 is neutral and +2 is strongly agree. The statements were constructed in such a way that a score of higher than 0 would represent risk-seeking attitudes, while less than 0 would be risk-averse. Six statements were worded so that the high disagreement implies that the farmer will accept more risk than if he agrees, therefore to avoid bias responses, these statements were reversed during analysis. 
Table 5.3 presents each statement's Corrected Item-Scale Correlation (CISC), the coefficient alpha calculated by a particular statement excluded from the scale of the remaining nine statements, and the overall coefficient alpha for all 10 statements. The overall coefficient alpha of 0.802 and 0.668 for wheat-cotton and pistachio sample respectively, indicates the 10 statements account for 80 and $67 \%$ of the total variation. Based on most of investigators' appraisal (DeVellis 1991; Cox and Flin 1998; Harvey et al. 2002; Hair et al. 2010), these levels are acceptable. However, for a more representative scale, it is useful to look for a chance to improve the reliability.

Table 5.3: Statements of risk attitude scale, and related CISC and coefficient alpha for the Syrian wheat-cotton and pistachio farmers, ( $\mathrm{n}=103$ and 105, respectively)

\begin{tabular}{|c|c|c|c|c|}
\hline \multirow{2}{*}{ Self-assessment scale’s primary statements } & \multicolumn{2}{|c|}{ Wheat-cotton } & \multicolumn{2}{|c|}{ Pistachio } \\
\hline & CISC & $\alpha$ & CISC & $\alpha$ \\
\hline $\begin{array}{l}\text { 1- I avoid decisions which bring forth either severe losses } \\
\text { or high profits (Reversed) }\end{array}$ & 0.732 & 0.751 & 0.584 & 0.598 \\
\hline $\begin{array}{l}\text { 2- To implement my farm plan goals, I am willing to take } \\
\text { more risks than others }\end{array}$ & 0.764 & 0.743 & 0.581 & 0.590 \\
\hline $\begin{array}{l}\text { 3- I am concerned with an existing profit more than } \\
\text { several predicted and non-guaranteed profit, (bird on hand } \\
\text { is bitter than ten on tree) (Reversed) }\end{array}$ & 0.664 & 0.760 & 0.572 & 0.588 \\
\hline $\begin{array}{l}\text { 4- I am more willing to adopt agricultural innovations } \\
\text { (new ways of doing things) than others }\end{array}$ & 0.794 & 0.739 & 0.514 & 0.604 \\
\hline $\begin{array}{l}\text { 5- I am reluctant to adopt agricultural innovations, until I } \\
\text { see their advantages and disadvantages from farmers } \\
\text { around me (Reversed) }\end{array}$ & 0.192 & 0.810 & -0.246 & 0.733 \\
\hline $\begin{array}{l}\text { 6- I take my decisions without hesitation regardless their } \\
\text { probable risks }\end{array}$ & 0.305 & 0.802 & 0.105 & 0.682 \\
\hline $\begin{array}{l}\text { 7- Before I take high risk probability decisions, I prefer to } \\
\text { discuss them with my family (Reversed) }\end{array}$ & 0.159 & 0.812 & 0.195 & 0.670 \\
\hline 8- I am at the mercy of policy risk (Reversed) & 0.405 & 0.792 & 0.426 & 0.624 \\
\hline 9- I am at the mercy of market risk (Reversed) & 0.324 & 0.801 & 0.505 & 0.604 \\
\hline 10 - I completely have production risk under control & 0.317 & 0.803 & 0.018 & 0.692 \\
\hline Cronbach's coefficient alpha for 10 statements & & 0.802 & & 0.668 \\
\hline
\end{tabular}

The highest Cronbach's coefficient alpha is the best scale which contains the optimal amount of information about farmers' RA. Refinement procedures by exclusion of statements which have negative or very low CISC are necessary to improve Cronbach's coefficient alpha. The procedure of statement exclusion continues to increase the coefficient alpha for the remaining statements. If further statement exclusion reduces the overall coefficient alpha, the 
reliability scale cannot be improved to any further extent and, thus the self-assessment scale has been optimized in explaining the farmers' RA.

Refinement procedure for wheat-cotton sample can be shown in Table 5.4. At first, the following five statements were excluded: 5, 6, 7, 9 and 10 which have low CISC values. The overall coefficient alpha for the new five statements scale is increased up to $88 \%$. The removal of statement 8 produced the highest possible alpha value of 0.944 . While continued eliminating for statement 3 to yield a 3-item scale, the corresponding overall alpha decreased to 0.94 . The corresponding overall alpha for three refined-item scale (0.94) is lower than the corresponding overall alpha of the four statements (0.944). The self-assessment scale with four statements offers the best explanation of the variance with the overall coefficient alpha of 0.944; it indicates that the communal variation of $94 \%$ is caused by RA. Thus, the resultant four refined statements scale was the developed scale for assessing RA among wheat-cotton farmers. 
Table 5.4: Refinement procedure of self-assessment scale’s statements, the Syrian wheat-cotton farmers' responses ( $\mathrm{n}=103$ )

\begin{tabular}{|c|c|c|c|c|c|c|c|c|}
\hline \multirow{2}{*}{ Self-assessment scale’s primary statements } & \multicolumn{2}{|c|}{10 Item-scale } & \multicolumn{2}{|c|}{5 Item-scale } & \multicolumn{2}{|c|}{4 Item-scale } & \multicolumn{2}{|c|}{3 Item-scale } \\
\hline & CISC & $\alpha$ & CISC & $\alpha$ & CISC & $\alpha$ & CISC & $\alpha$ \\
\hline $\begin{array}{l}\text { 1- I avoid decisions which bring forth either severe losses or high } \\
\text { profits (Reversed) }\end{array}$ & 0.732 & 0.751 & 0.851 & 0.819 & 0.873 & 0.925 & 0.831 & 0.946 \\
\hline $\begin{array}{l}\text { 2- To implement my farm plan goals, I am willing to take more risks } \\
\text { than others }\end{array}$ & 0.764 & 0.743 & 0.864 & 0.813 & 0.872 & 0.925 & 0.893 & 0.898 \\
\hline $\begin{array}{l}\text { 3- I am concerned with an existing profit more than several predicted } \\
\text { and non-guaranteed profit, (bird on hand is bitter than ten on tree) } \\
\text { (Reversed) }\end{array}$ & 0.664 & 0.760 & 0.789 & 0.835 & 0.823 & 0.940 & - & - \\
\hline $\begin{array}{l}\text { 4- I am more willing to adopt agricultural innovations (new ways of } \\
\text { doing things) than others }\end{array}$ & 0.794 & 0.739 & 0.886 & 0.807 & 0.899 & 0.916 & 0.906 & 0.887 \\
\hline $\begin{array}{l}\text { 5- I am reluctant to adopt agricultural innovations, until I see their } \\
\text { advantages and disadvantages from farmers around me (Reversed) }\end{array}$ & 0.192 & 0.810 & - & - & - & - & - & - \\
\hline $\begin{array}{l}\text { 6- I take my decisions without hesitation regardless their probable } \\
\text { risks }\end{array}$ & 0.305 & 0.802 & - & - & - & - & - & - \\
\hline $\begin{array}{l}\text { 7- Before I take high risk probability decisions, I prefer to discuss } \\
\text { them with my family (Reversed) }\end{array}$ & 0.159 & 0.812 & - & - & - & - & - & - \\
\hline 8- I am at the mercy of policy risk (Reversed) & 0.405 & 0.792 & 0.175 & 0.944 & - & - & - & - \\
\hline 9- I am at the mercy of market risk (Reversed) & 0.324 & 0.801 & - & - & - & - & - & - \\
\hline 10 - I completely have production risk under control & 0.317 & 0.803 & - & - & - & - & - & - \\
\hline Aggregate Cronbach’s coefficient alpha & & 0.802 & & 0.879 & & 0.944 & & 0.94 \\
\hline
\end{tabular}

Source: Own elaboration using survey data 
Similarly, the refinement procedure for pistachio operators was done as shown in Table 5.5. The statements with negative and low CISC values (5, 6, 7and 10) were kept away consequently, and the overall coefficient alpha increased from 0.668 to 0.817. Removal of statements 8 and 9 produced the highest possible alpha value of 0.844 . While continued exclusion of statement 4 lessened the overall reliability to 0.813. Therefore, the 4 self-assessment scale offers the best explanation of the variance with the overall coefficient alpha of 0.844 , indicating that the communal variation of $84 \%$ is caused by RA. The resultant 4 refined statements scale was the developed scale for assessing RA among pistachio farmers. 
Table 5.5: Refinement procedure of self-assessment scale’s statements, the Syrian pistachio farmers’ responses, (n=105)

\begin{tabular}{|c|c|c|c|c|c|c|c|c|}
\hline \multirow{2}{*}{ Self-assessment scale’s primary statements } & \multicolumn{2}{|c|}{10 Item-scale } & \multicolumn{2}{|c|}{6 Item-scale } & \multicolumn{2}{|c|}{4 Item-scale } & \multicolumn{2}{|c|}{3 Item-scale } \\
\hline & CISC & $\alpha$ & CISC & $\alpha$ & CISC & $\alpha$ & CISC & $\alpha$ \\
\hline $\begin{array}{l}\text { 1- I avoid decisions which bring forth either severe losses or high } \\
\text { profits (Reversed) }\end{array}$ & 0,584 & 0,598 & 0,701 & 0,767 & 0,677 & 0,808 & 0,708 & 0,715 \\
\hline $\begin{array}{l}\text { 2- To implement my farm plan goals, I am willing to take more risks } \\
\text { than others }\end{array}$ & 0,581 & 0,590 & 0,612 & 0,781 & 0,717 & 0,786 & 0,544 & 0,864 \\
\hline $\begin{array}{l}\text { 3- I am concerned with an existing profit more than several predicted } \\
\text { and non-guaranteed profit, (bird on hand is bitter than ten on tree) } \\
\text { (Reversed) }\end{array}$ & 0,572 & 0,588 & 0,698 & 0,760 & 0,686 & 0,802 & 0,774 & 0,623 \\
\hline $\begin{array}{l}\text { 4- I am more willing to adopt agricultural innovations (new ways of } \\
\text { doing things) than others }\end{array}$ & 0,514 & 0,604 & 0,525 & 0,800 & 0,655 & 0,813 & - & - \\
\hline $\begin{array}{l}\text { 5- I am reluctant to adopt agricultural innovations, until I see their } \\
\text { advantages and disadvantages from farmers around me (Reversed) }\end{array}$ & $-0,246$ & 0,733 & - & - & - & - & - & - \\
\hline $\begin{array}{l}\text { 6- I take my decisions without hesitation regardless their probable } \\
\text { risks }\end{array}$ & 0,105 & 0,682 & - & - & - & - & - & - \\
\hline $\begin{array}{l}\text { 7- Before I take high risk probability decisions, I prefer to discuss } \\
\text { them with my family (Reversed) }\end{array}$ & 0,195 & 0,670 & - & - & - & - & - & - \\
\hline 8- I am at the mercy of policy risk (Reversed) & 0,426 & 0,624 & 0,424 & 0,821 & - & - & - & - \\
\hline 9- I am at the mercy of market risk (Reversed) & 0,505 & 0,604 & 0,554 & 0,794 & - & - & - & - \\
\hline 10 - I completely have production risk under control & 0,018 & 0,692 & - & - & - & - & - & - \\
\hline Aggregate Cronbach's coefficient alpha & & 0.668 & & 0.817 & & 0.844 & & 0.813 \\
\hline
\end{tabular}


It can be concluded that the set of 4-refined statements (Table 5.6) measures the same underlying construct, wheat-cotton and pistachio farmers' attitudes toward risk, for the following reasons:

- High Cronbach's alpha values of 0.94 and 0.84 for wheat-cotton and pistachio respectively (Peter 1979; DeVellis 1991; Nunnally and Bernstein 1994; Hair et al. 2010).

- Significant positive correlation $(\rho \leq 0.001)$ among the answers given on the four statements (correlation ranging from 0.74 to 0.9 and from 0.48 to 0.78 for wheat-cotton and pistachio respectively).

- High loadings of the statements on a single factor model (ranging from 0.9 to 0.94 and from 0.81 to 0.84 for wheat-cotton and pistachio respectively) (with eigenvalues of 3.43 and 2.74 for the same samples cascade).

Table 5.6: Responses of the Syrian wheat-cotton and pistachio farmers about refined statements of self-assessment scale, ( $\mathrm{n}=103$ and 105, respectively)

\begin{tabular}{|c|c|c|c|c|}
\hline \multirow{2}{*}{ Self-assessment scale’s refined statements } & \multicolumn{2}{|c|}{ Wheat-cotton } & \multicolumn{2}{|c|}{ Pistachio } \\
\hline & Average & SD. & Average & SD. \\
\hline $\begin{array}{l}\text { 1- I avoid decisions which bring forth either severe losses } \\
\text { or high profits (Reversed) }\end{array}$ & -0.77 & 1.29 & -0.63 & 0.89 \\
\hline $\begin{array}{l}\text { 2- To implement my farm plan goals, I am willing to take } \\
\text { more risks than others }\end{array}$ & -0.25 & 1.41 & 0.39 & 1.03 \\
\hline $\begin{array}{l}\text { 3- I concerned with an existing profit more than several } \\
\text { predicted and non-guaranteed profit, (bird on hand is bitter } \\
\text { than ten on tree) (Reversed) }\end{array}$ & -0.61 & 1.29 & -0.64 & 1.12 \\
\hline $\begin{array}{l}\text { 4- I am more willing to adopt agricultural innovations } \\
\text { (new ways of doing things) than others }\end{array}$ & -0.25 & 1.42 & 0.43 & 1.06 \\
\hline
\end{tabular}

Table 5.6 shows statistics for respondents’ answers about each statement. Generally, the findings show the lower of average score for wheat-cotton producers assessing risk statements; indicates that those farmers are more towards risk aversion attitude. Our findings verify previous research suggesting that agricultural producers are risk-averse (Dillon and Scandizzo 1978; Binswanger 1980; Ramatnam et al. 1986; Jiménez 2003; Menapace et al. 2013). The average score of pistachio operators' responses, which varies from -1 to +1 , refers to a generally risk neutral trend. As a primary implication, this could indicate that pistachio farming is less risky due to Arrow (1971) and Rabin (2000) who asserted that people are, generally, risk neutral when the risk exposure is small. 
In order to create attitude scale which can be used for the subsequent multiple regressions, the refined four statements for each of wheat-cotton and pistachio producer were separately summed up to yield an aggregate RA score from -8 to +8 which will be used in a multiple regression analysis. Based on the summed score, the 16 interval scale $(-8$ to +8$)$ was divided by 3 to result in three categories of respondents, risk-averse, risk-neutral and riskseeking (Figure 5.1).

Figure 5.1: Distribution the Syrian wheat-cotton and pistachio farmers' by risk attitude categories, ( $\mathrm{n}=103$ and 105, respectively)

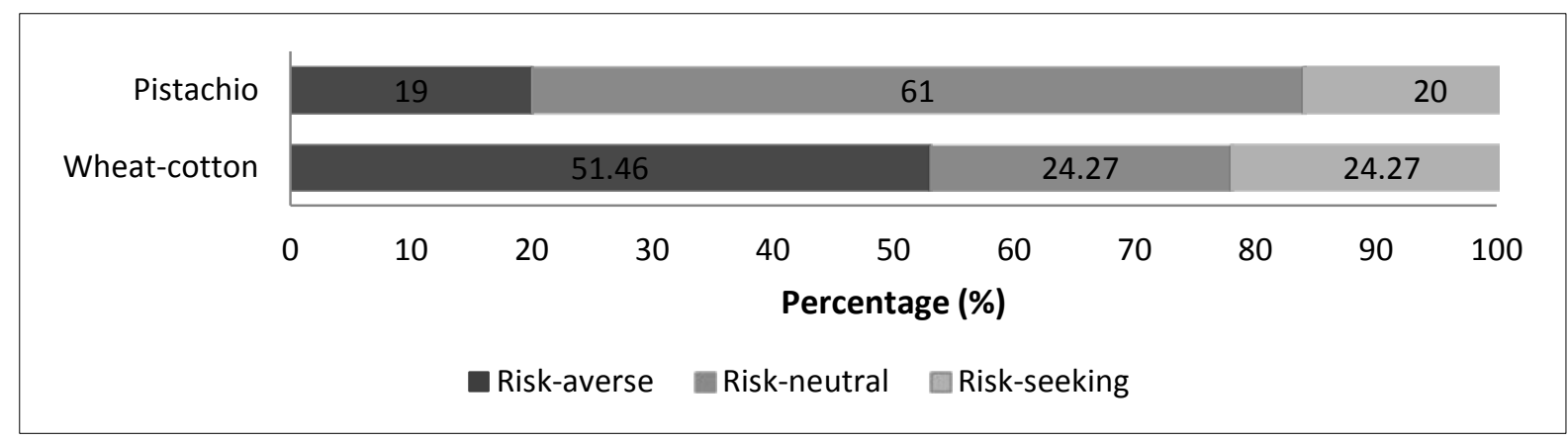

Source: Own elaboration using survey data

\subsection{Perceptions of risk sources}

\subsubsection{Wheat-cotton farmers}

Thirty-one sources of risk were considered in the questionnaire taking into account the perceived incident rate and the expected damage for each risk. Wheat-cotton producers were asked to answer these two aspects on ten-point Likert-scales. In order to display the results of farmers' answers for given RS in a simple way, the answers were classified depending on the average score ' 5 ' as follows: (1) Sources of risk that recorded average score below 5 for both incident rate and expected damage. (2) Sources of risk that recorded average score below 5 for incident rate and over 5 for expected damage. (3) Sources of risk that recorded average score over 5 for incident rate and below 5 for expected damage. (4) Sources of risk that recorded average score over 5 for both incident rate and expected damage.

Figure 5.2 shows RS which were perceived relatively low for both, incident rate and predicted loss. Machinery problems and labour failure due to city exodus, sickness and death were preserved as less important risks by wheat-cotton farmers in Syria. Within this risk group, risks of 'other climate factors' and 'land availability' revealed the highest average scores for incident rate ( $\mu=4.35$ and 4.61) and expected damage ( $\mu=3.52$ and 4.24). Other climate factors refer to the phenomena of weather disturbances such as frost, overheating and 
dust storm. These phenomena have negatively impacted the agricultural land availability by desert expansion, soil salinity and erosion. Our results show a high standard deviation $(\sigma=3.42)$ for the perceived incident rate of land availability risk indicating that farmers' perceptions of this aspect is varied. This variation could be attributed to zones, since significant differences were found between farmers' perceptions of land availability as RS and their location represented by zone $(\rho<0.001)$. Similarly, a high standard deviation was noticed for the expected damage of 'property rights rules' and 'farm inheritance rules'. This indicates a low level of unanimity among operators for land assignment restrictions. Given that wheat and cotton are strategic crops, and state agencies buy all the harvested quantities, it is logical for wheat-cotton producers to quantify risks of 'quality requirements' and 'competition from neighboring countries' as less important. It is worth to notice that 'plant pests and diseases' were located in this risk group ( $\mu=2.75$ and 2.74) for an incident rate and expected damage, respectively. This suggests the peerless protection system which characterizes wheat-cotton crops in Syria due to their importance as strategic crops.

Figure 5.2: Risk sources with low incident rates and low expected damages for Syrian wheatcotton farmers, $(n=103)$

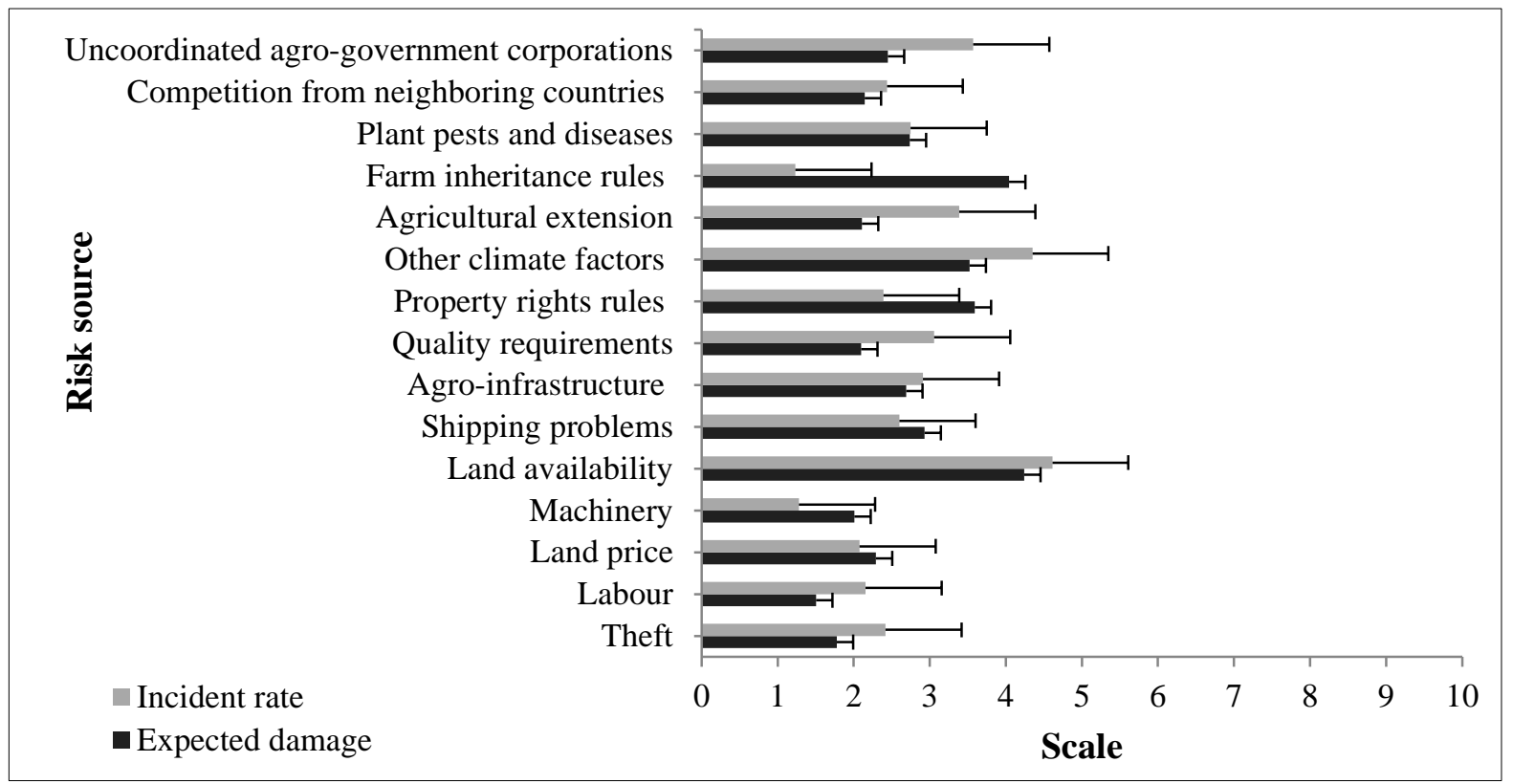

Bar value represents mean \pm standard deviation Source: Own elaboration using survey data

The second group of RS with perceived low incident rates and high expected damages is shown in Figure 5.3. Due to the governmental support for their crops, farmers do not expect to face the threat of 'price decrease', 'special compensation program elimination' and 'governmental support elimination'. However, this perception is not a unanimous issue amongst all studied farmers. High standard deviations ( $\sigma=3.29$ and 3.02) can be noticed for 
the elimination of 'special compensation program' and 'governmental support', respectively. Therefore, some farmers predicted impending subsidy elimination. The 'special compensation program' supports wheat-cotton producers with direct payments depending on cropped acres of cotton (SYP 8,000/ha plus 3000/season).

Regarding the preferences of cultivation, farmers expected high losses if the agricultural activities particularly wheat-cotton cultivation would not become the most preferred business in their region. This reflects difficulties to persuade farmers to replace their wheat-cotton combination by another crop if this is suggested by developers of RMS.

Irrigation modernization policy is aimed to preserve water resources by raising the efficiency of water use in agriculture. The governmental insistence for modern irrigation techniques' adoption is considered a new technology that may cause high losses. However, not all farmers perceived supplemental irrigation as a definitely risky aspect. They showed high standard deviations ( $\sigma=2.53$ and 3.30) for incident rate and potential damage, respectively. This suggests that farmers are in the process of modern irrigation technique persuasion.

Farmers' responses about 'insolvency of my farm' revealed a considerable expectation of income injury $(\mu=9.40)$ and middle incident rate $(\mu=4.75, \sigma=3.48)$. This indicates that some operators were really afraid of farm insolvency particularly in zone 3 , since significant differences were found between farmers' regarding expectation of insolvency between different agro-ecological zones $(\rho<0.001)$.

Figure 5.3: Risk sources with low incident rates and high expected damages for Syrian wheat-cotton farmers, $(n=103)$

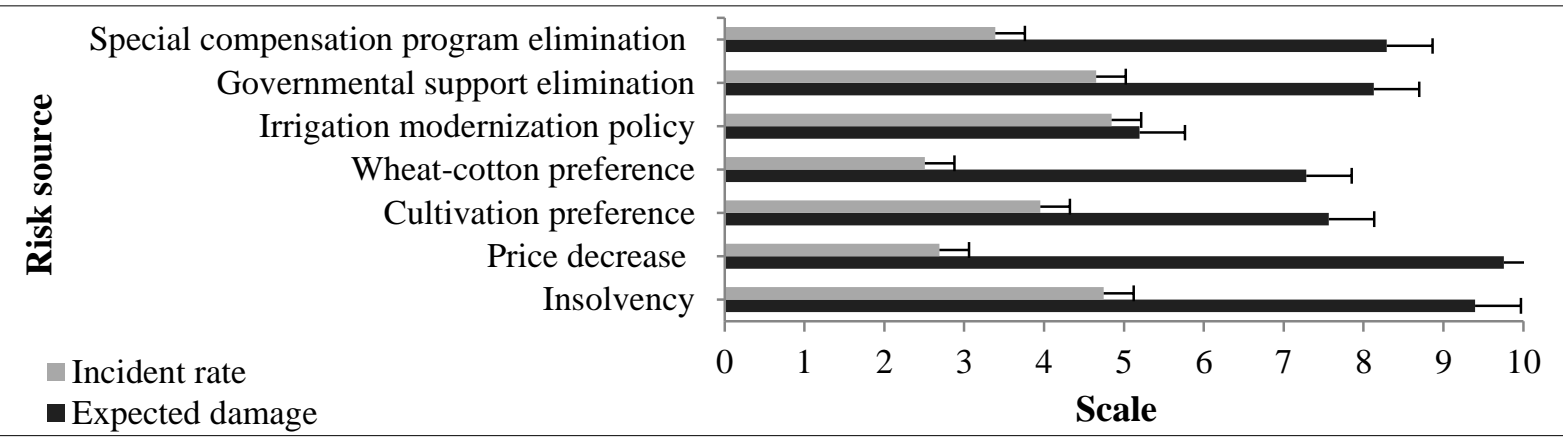

Bar value represents mean \pm standard deviation Source: Own elaboration using survey data

Two RS showed a high incident rate and low expected damage (Figure 5.4). Land tenure fragmentation by inheritance is a fait accompli in the Syrian agriculture, but farmers seem to operate their tenures collectively. Thus they did not involve this matter as a high risk consequence. Except fuel price, farmers regarded the increase of input prices as very likely 
because of the phase-out of subsidized inputs, but they did not expect significant negative consequences for their farm businesses.

Figure 5.4: Risk sources with high incident rates and low expected damages for Syrian wheat-cotton farmers, $(n=103)$

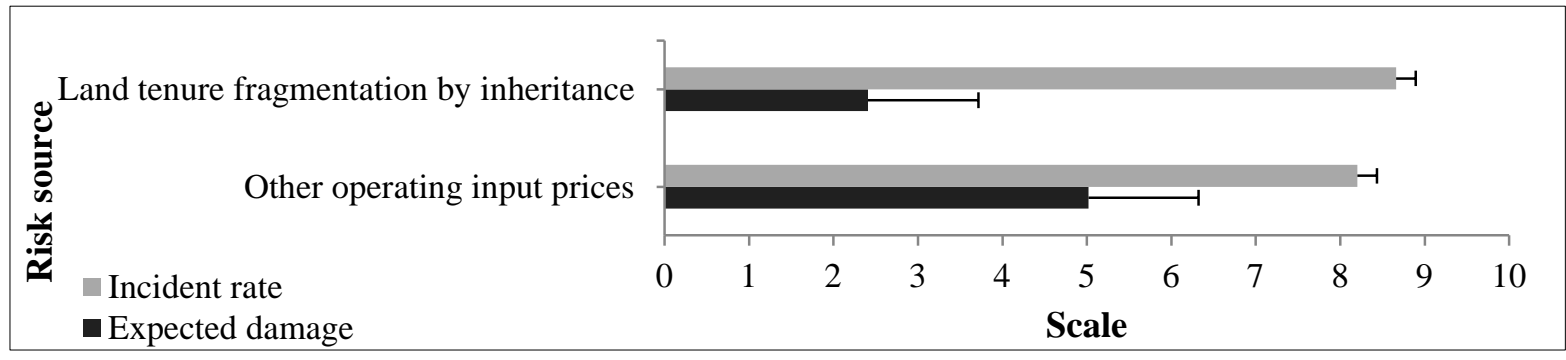

Bar value represents mean \pm standard deviation

Source: Own elaboration using survey data

Farmers were more concerned about risks represented in Figure 5.5, because of their high incident rates combined with high loss potentials. Precipitation shortage was perceived as the most important risk that threatens the wheat-cotton cultivation in Syria. It indicated a high average score for both the incident rate and the expected damage ( $\mu=9.82$ and 9.58), respectively, with low standard deviations $(\sigma=0.72$ and 1.12). The low annual rain-fall average has multiple negative effects represented by: (1) Rain-fed wheat failure. (2) More fuel consumption due to the increase of irrigation operations for irrigated wheat during the winter season. (3) More drying for the underground water needed to irrigate cotton in the summer. Fuel price increase was the second most important risk. The positive relationship between the precipitation shortage and repetition of irrigation operations, to compensate this shortage, means much more fuel consumption to run irrigation pumps. Therefore, the increase of fuel price seemed to be in the same risk combination with the rainfall deficit. A high average score for its incident rate $(\mu=9.70)$ and expected loss $(\mu=8.62)$ can be noticed.

Cotton licence policy is also a concerned aspect that the developers of RMS must consider in order to build fit strategies. Limitations of cotton licence by $20 \%$ of the total farm area in zone 1 and 17\% of the total farm land in zone 2 and 3 were perceived as an actual risk with high loss consequences ( $\mu=8.27)$. The high state price of harvested cotton (42 SYP/Kg) compared to wheat (20 SYP/Kg) raises farmers willingness to increase the cotton occupation in order to increase their net income.

Drying of rivers and underground water was of concern to wheat-cotton producers, with a high loss potential ( $\mu=8.53$ ), while its probability of occurrences showed a medium average score $(\mu=5.24)$ and a high standard deviation $(\sigma=3.79)$. This means that the farmers were not equally concerned about incident rate of ground water drying due to the abundance 
of ground water that operators in the first zone enjoy. A significant deference was found between farmers' expectation of drying of rivers and underground water, and their farm's zone $(\rho<0.001)$.

Decrease of farm business effectiveness and productivity compared with the past was perceived as a considerable threat since the farmers have to look for another non-farm income source to supplement their farm income. Actually, this is not easy to realise given scarceness of non-agricultural business in $\mathrm{Al}$ Hasakah governorate. Over the last decade, the highest unemployment rate in Syria was found in Al Hasakah with 26.5\% (NAPC 2010a).

Brokers' dominance rose due to the support elimination policy for inputs. Given that public sector agencies buy all cotton and wheat produced by farmers, there is no room for interventions of brokers' dominance in the marketing process. However, brokers' dominance arises in the case of marketing unauthorized cotton quantities cultivated behind state's back. For this reason a high standard deviation $(\sigma=3.23)$ of brokers' dominance probability was observed among farmers.

Figure 5.5: Risk source with high incident rates and high expected damages for Syrian wheatcotton farmers, $(n=103)$

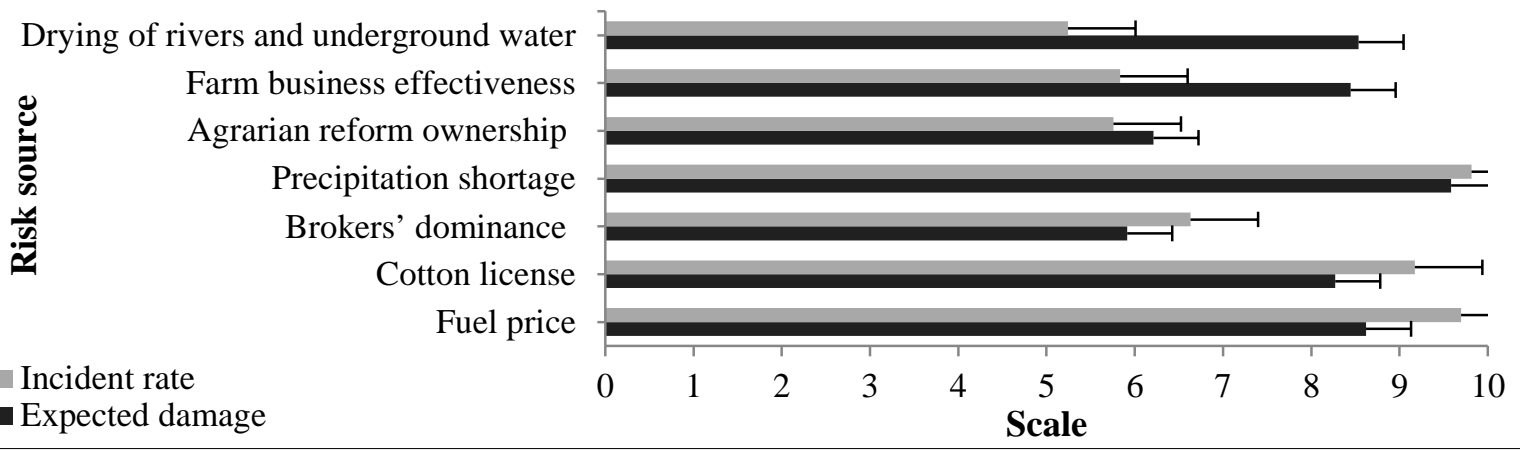

Bar value represents mean \pm standard deviation Source: Own elaboration using survey data

In conclusion, the rainfall deficiency as a production risk, the fuel price and the cotton license as political risks are the most critical risks that threaten the production of wheat and cotton in Syria. The strong effect of the precipitation shortage on harvested quantities of wheat-cotton, particularly in deserted year 2008, is highlighted in Figure 5.6. 
Figure 5.6: Development of rainfall average and production of wheat and cotton in Syria, 2005-2011

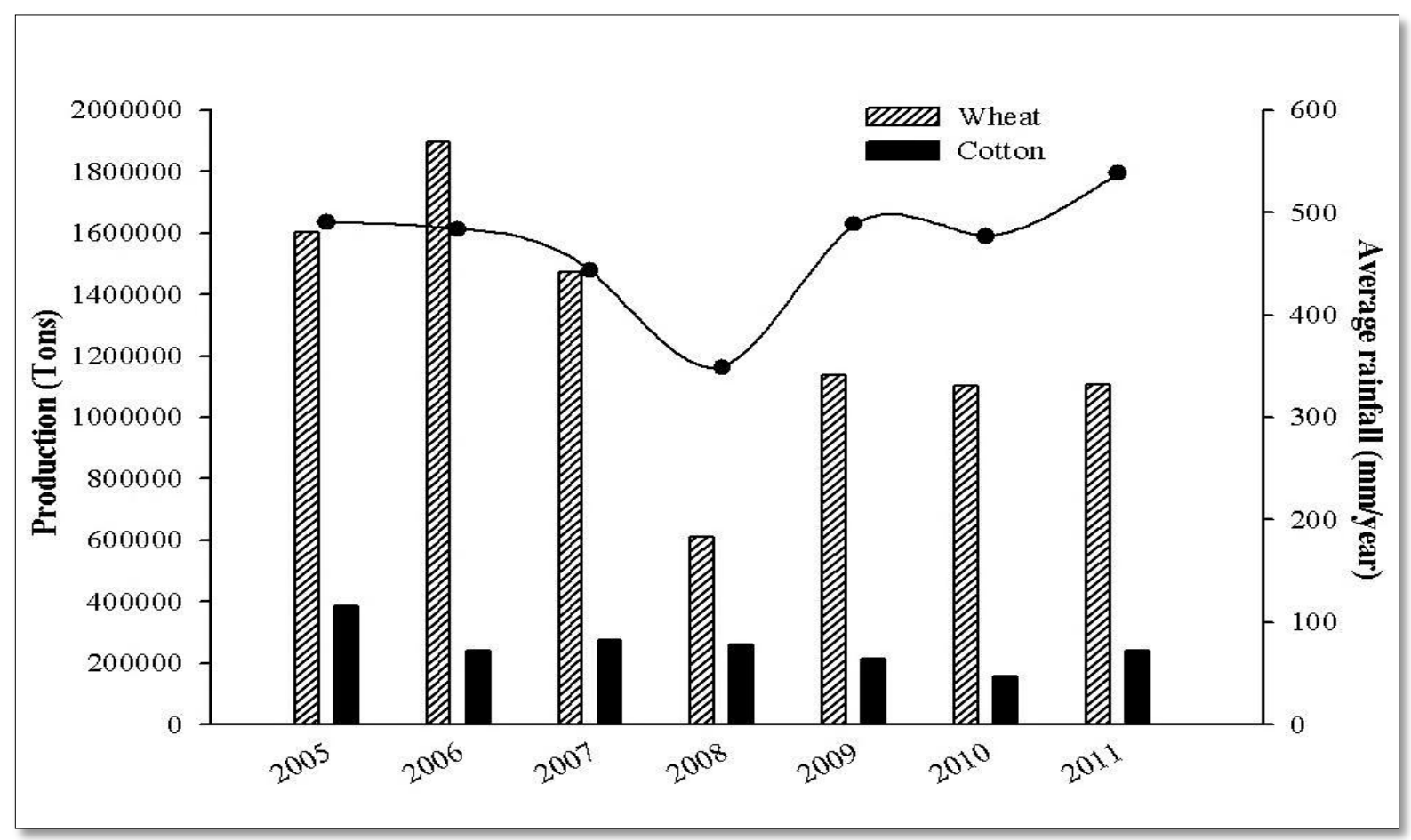

Source: (SADB 2013)

Finally, in order to acquire a better overview and ranking of the relevant risks in wheat-cotton farms, a risk map was drawn to distinguish between relevant risks and less relevant risks. As revealed in Figure 5.7, relevant risks are characterized by high average scores for the incident rate or the potential damage. The expectation values were calculated only for relevant risks by multiplying incident rate value and expected damage. These expectation values will be used in the further factor and regression analysis to get more explanations about the determinants of farmers’ perceptions of these relevant risks. 
Figure 5.7: Risk map of wheat-cotton farming in Syria

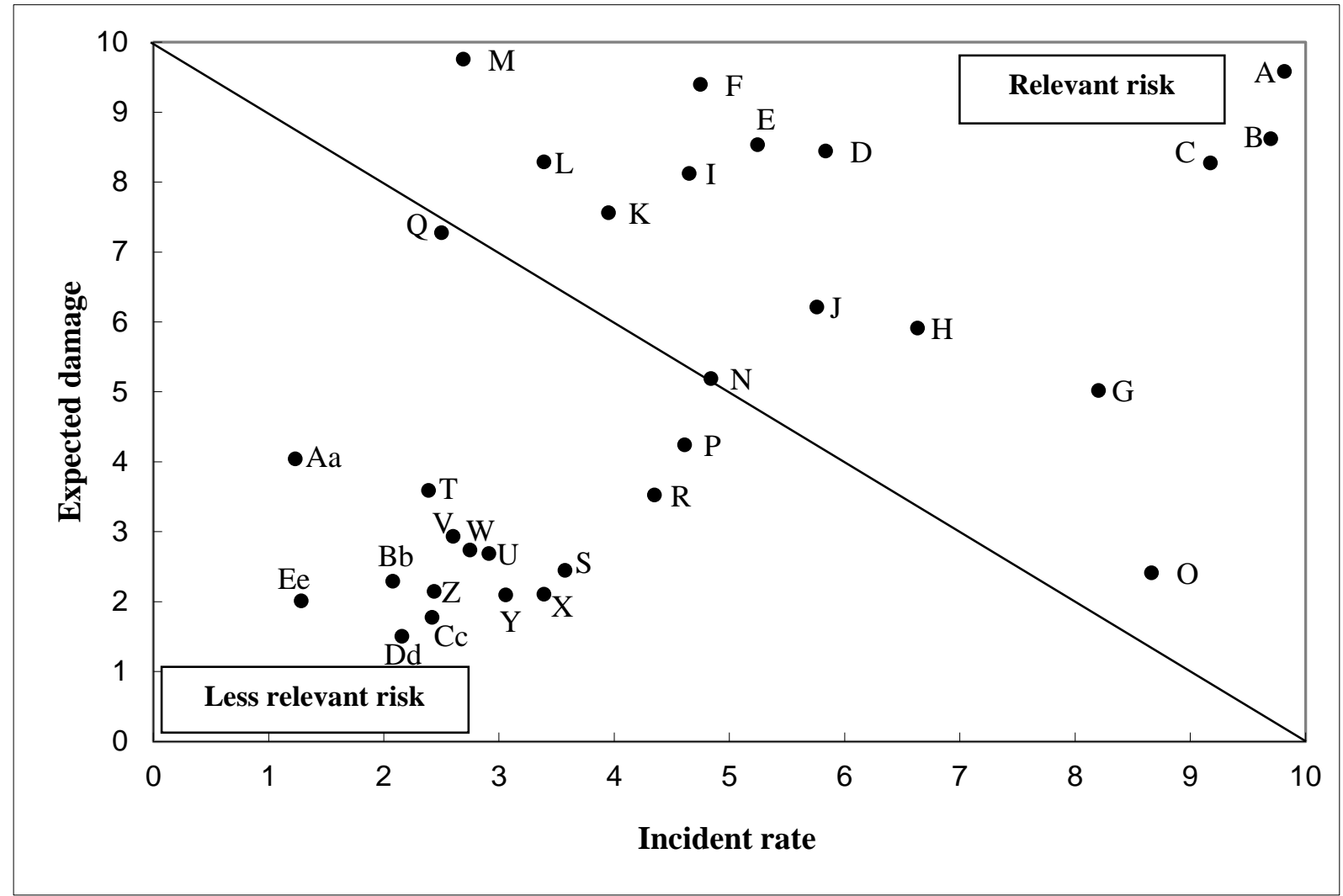

A: Precipitation shortage, B: Fuel price, C: Cotton license, D: Farm business effectiveness, E: Drying of rivers and underground water, F: Insolvency, G: Other operating input prices, H: Brokers' dominance, I: Governmental support elimination, J: Land reform, K: Cultivation preference, L: Special compensation program elimination, M: Price decrease, N: Irrigation modernization policy, O: Land tenure fragmentation by inheritance, $\mathbf{P}$ : Land availability, Q: Wheat-cotton preference, $\mathbf{R}$ : Other climate factors (frost, overheating, dust storm), S: Uncoordinated agro-government corporations, T: Property rights rules, U: Agro-infrastructure, V: Shipping problems, W: Plant pests and diseases, X: Agricultural extension, Y: Quality requirements, Z: Competition from neighboring countries, Aa: Farm inheritance rules, Bb: Land price, Cc: Theft of farm equipment etc., Dd: Labour, Ee: Machinery

Source: Own elaboration using survey data

\subsubsection{Pistachio farmers}

Figure 5.8 represents the less important risks faced by the pistachio operators in the study sites due to low incident rates combined with low expected damages. Farmers did not perceive the change of pistachio cultivation priority as a crucial risk. The lowest average score was noticed for the change of pistachio preference $(\mu=1.76$ and 1.97 for incident rate and predicted loss, respectively). This result suggests that pistachio cultivation is a prospering business in that region. Furthermore, in case of pistachio priority may change in the future, there will be no problem with farmers to shift to another crop business. This aspect is totally different from the wheat-cotton producers who showed a high fondness with wheat-cotton combination. The same comparison criteria can be detected regarding the farm business 
effectiveness as RS. Pistachio farmers were hardly perceived this risk, while wheat-cotton ones considered it with a high incident rate and potential damage.

It is worth mentioning that, in contrast to the wheat-cotton farmers, pistachio farmers did not comprehend the adoption of supplemental irrigation as a risk by itself. Low expected loss $(\mu=1.44, \sigma=1.62)$ was attributed to irrigation modernization policy compared to $(\mu=5.19$, $\sigma=3.30$ ) for the wheat-cotton producers. Farmers do not consider labour, machinery, quality requirements and shipping problems as important RS.

Figure 5.8: Risk sources with low incident rates and low expected damages for Syrian pistachio farmers, $(n=105)$

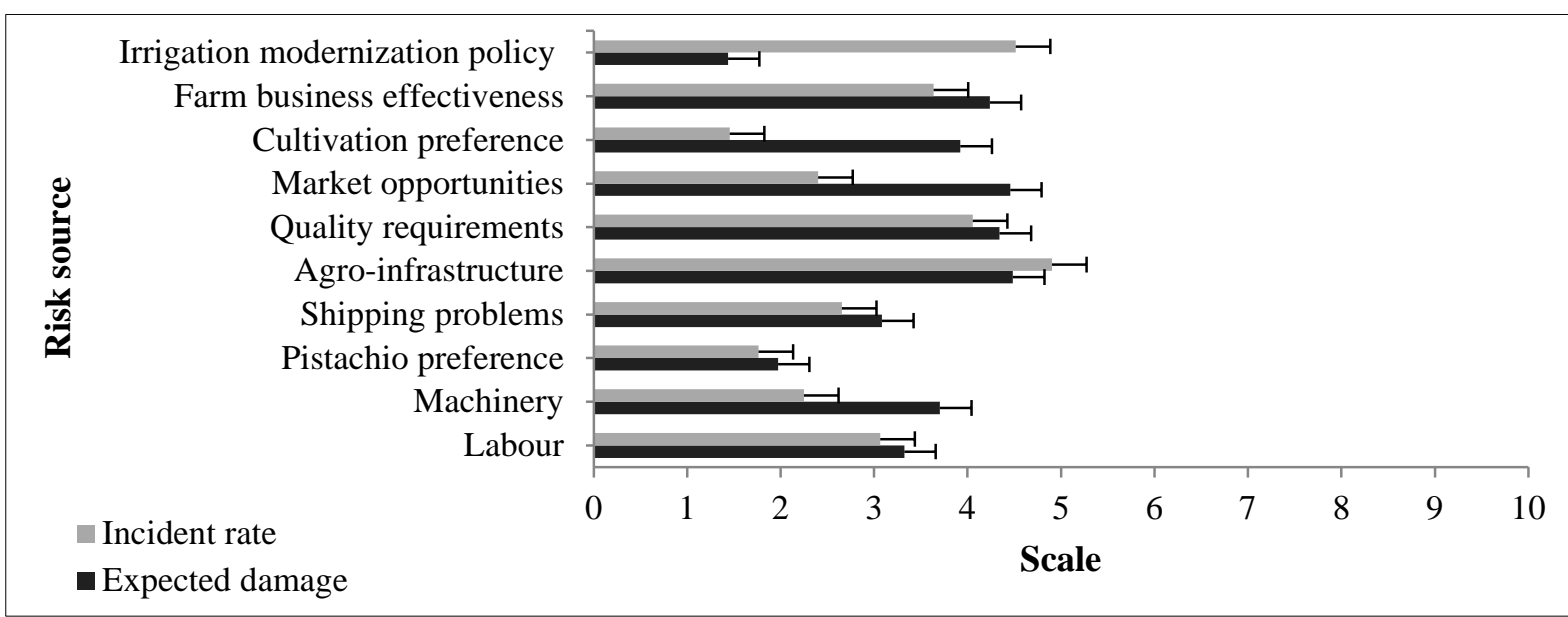

Bar value represents mean \pm standard deviation

Source: Own elaboration using survey data

Four RSs were attributed low occurrence probabilities and high potential damages as shown in Figure 5.9. Farm insolvency was a farfetched matter in pistachio farms $(\mu=2.81)$. Pistachio farmers were more concerned about predicted losses raised by market prices decrease $(\mu=8.11, \sigma=2.14)$. Risks of farm inheritance rules and land availability showed a medium perception of incident rate as well as expected income injury.

Figure 5.9: Risk sources with low incident rates and high expected damages for Syrian pistachio farmers, $(\mathrm{n}=105)$

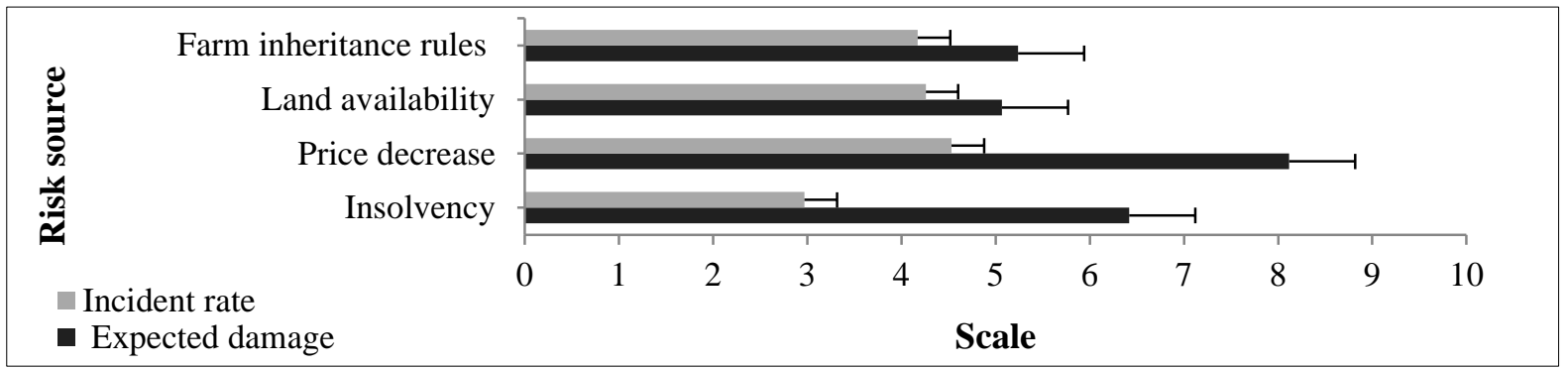

Bar value represents mean \pm standard deviation

Source: Own elaboration using survey data 
The third group includes risks that are characterized by high incident rates and low expected damages; they are shown in Figure 5.10. Uncoordinated agro-government corporations refer to the fragmentation of agricultural related institutions and bureaucratic procedures. Farmers' responses about this risk inscribed average scores near mid-point for the probability $(\mu=5.31)$, but less for loss consequence $(\mu=5.58)$. This bureaucracy seems negatively to affect the land assignment procedures since operators perceived a high occurrence probability for property rights rules risks $(\mu=7.10)$.

Similar to the wheat-cotton, pistachio producers evaluated land tenure fragmentation by inheritance as a quite probable $(\mu=6.20)$, but not as a challenging problem $(\mu=3.50)$.

Farmers expected further increase of land price $(\mu=6.97)$ compared to $(\mu=2.08)$ for wheat-cotton sample. This may indicate that the pistachio farm business environment is better than the external conditions for wheat-cotton cultivation which stimulates pistachio farmers to expand their cultivation, and consequently their demand for farm land.

Figure 5.10: Risk sources with high incident rates and low expected damages for Syrian pistachio farmers, $(\mathrm{n}=105)$

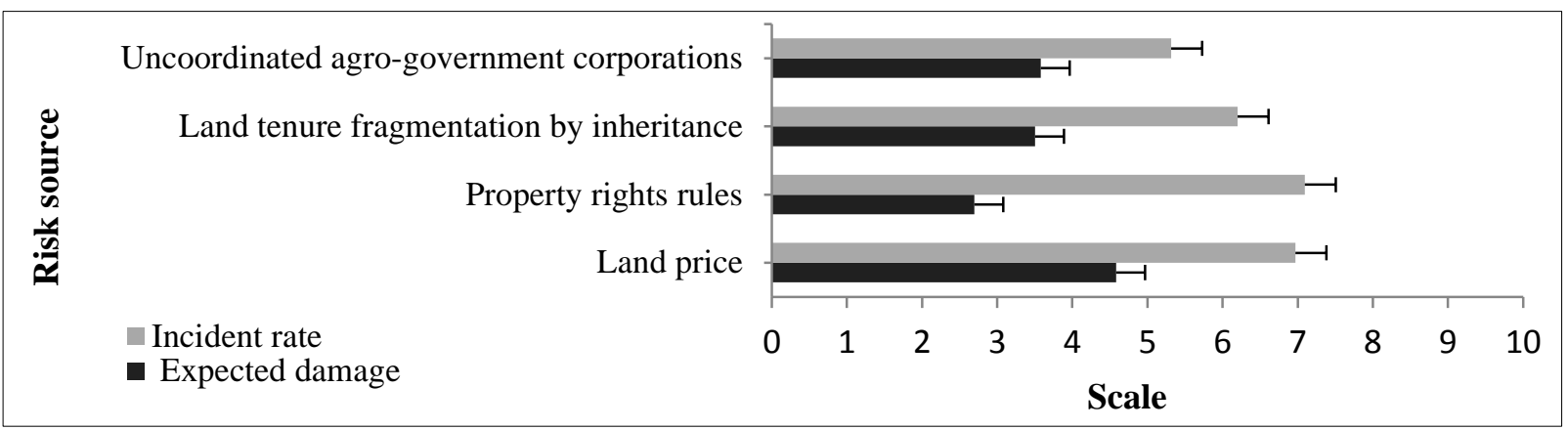

Bar value represents mean \pm standard deviation

Source: Own elaboration using survey data

Risks inscribed in Figure 5.11, represent the most important risks which were perceived relatively high by farmers. Dualism of rain-fall and fuel risk that had the priority in wheat-cotton farms comes again into sight in pistachio farms. Fuel price risk was ranked first for both incident rate $(\mu=9.24, \sigma=1.57)$ and potential damage $(\mu=9.18, \sigma=1.42)$. A similar result was found regarding the precipitation shortage, with $(\mu=9.40, \sigma=1.39)$ for incident rate and $(\mu=8.87, \sigma=1.34)$ for expected loss. Syrian pistachio was classified as a rain-fed crop for long decades. However, the recent frequent droughts forced farmers to manage supplemental irrigation during summer in case of insufficient rainfall in winter. This burdens additional operating cost that highly correlates with fuel price. Farmers also revealed a high concern about other input prices such as pesticides and fertilizers. Therefore, it can be concluded that rainfall paucity and price risks in input markets have the priority for pistachio farmers. 
On the contrary to the wheat-cotton sample, market risks seem to be more worthwhile aspects. Market competition comes from Turkish and Iranian pistachio varieties; it was suffered as a definite threat of farmers with high probability $(\mu=8.35)$ and effectiveness $(\mu=8.17)$. This unfavourable competition was translated by considerable fluctuation waves for pistachio market price $(\mu=6.29)$, which means farmers' uncertainty about farm income. Brokers' dominance that was highly worried regarding its probability and consequences exacerbate price risks of input and output markets.

Production risks such as underground water drought, climate factors and plant pests and diseases were seriously involved. High concerns of farmers about plant pests and diseases in comparison with those farmers in wheat-cotton area could be described in two directions. (1) Injury of plant pests and diseases is not limited to pistachio crop, but it extends to pistachio trees which are considered a farm capital item, contrarily to that of wheat-cotton crops. (2) Insufficiency of agricultural extension service in pistachio farm region, which is perceived a high important risk, may be unable to provide effective solutions in epidemic disease cases.

Figure 5.11: Risk sources with high incident rates and high expected damages, for Syrian pistachio farmers, $(n=105)$

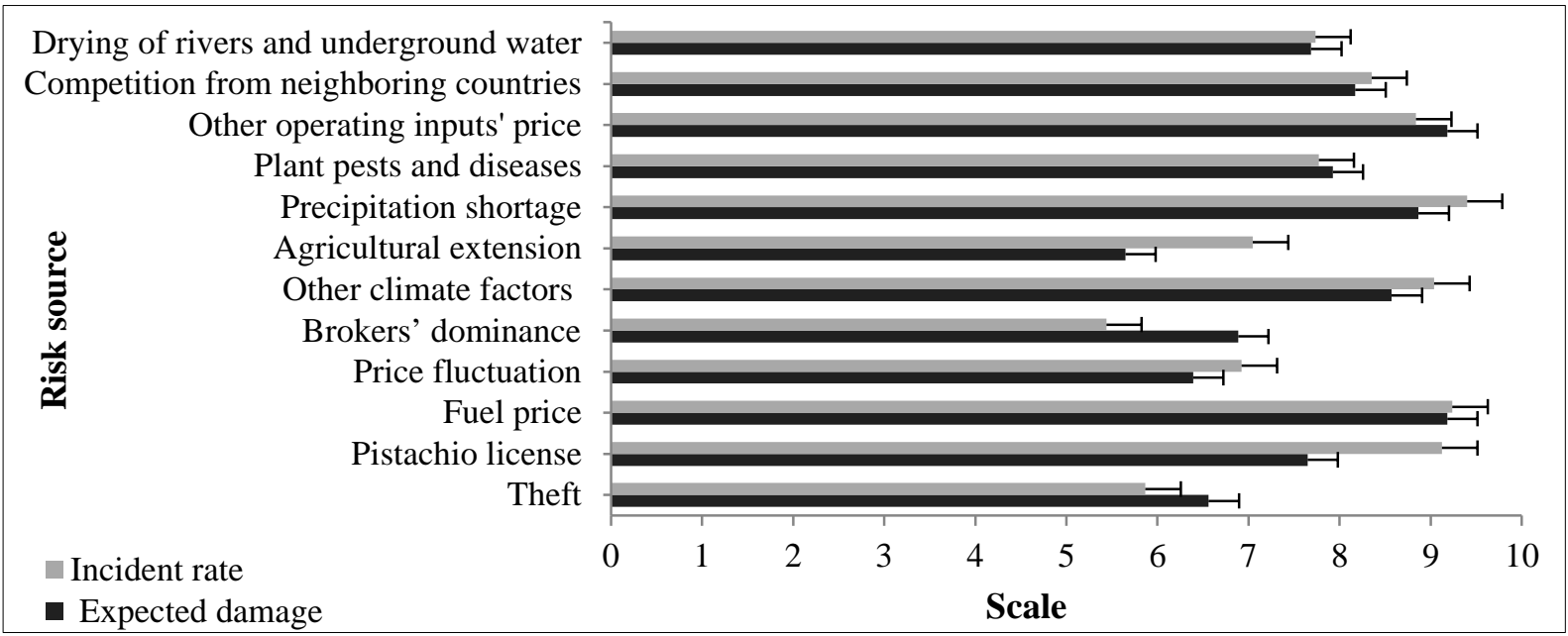

Bar value represents mean \pm standard deviation

Source: Own elaboration using survey data

Similar to cotton, state prohibition of pistachio land expansion is regarded as quite probable $(\mu=9.12)$ with considerable income injury $(\mu=7.65)$. The farmers' willingness to improve and expand their farms reflects the former evidence about the flourishing environment characterising pistachio farm businesses. As mentioned in section (2.3.3), pistachio area is controlled by the state plan purposes. For example, due to the project of hilly areas' reclamation planned by the $8^{\text {th }}$ FYP $(1996-2000)$, rapid growth rate in pistachio area 
was recorded. The following FYPs prohibit any further pistachio licenced area (Westlake 2001).

Technical separation between less relevant risks and relevant risks was carried out by developing a risk map. As revealed in Figure 5.12, the expectation values were calculated for relevant risks to continue with further statistical analysis.

Figure 5.12: Risk map of pistachio farming in Syria

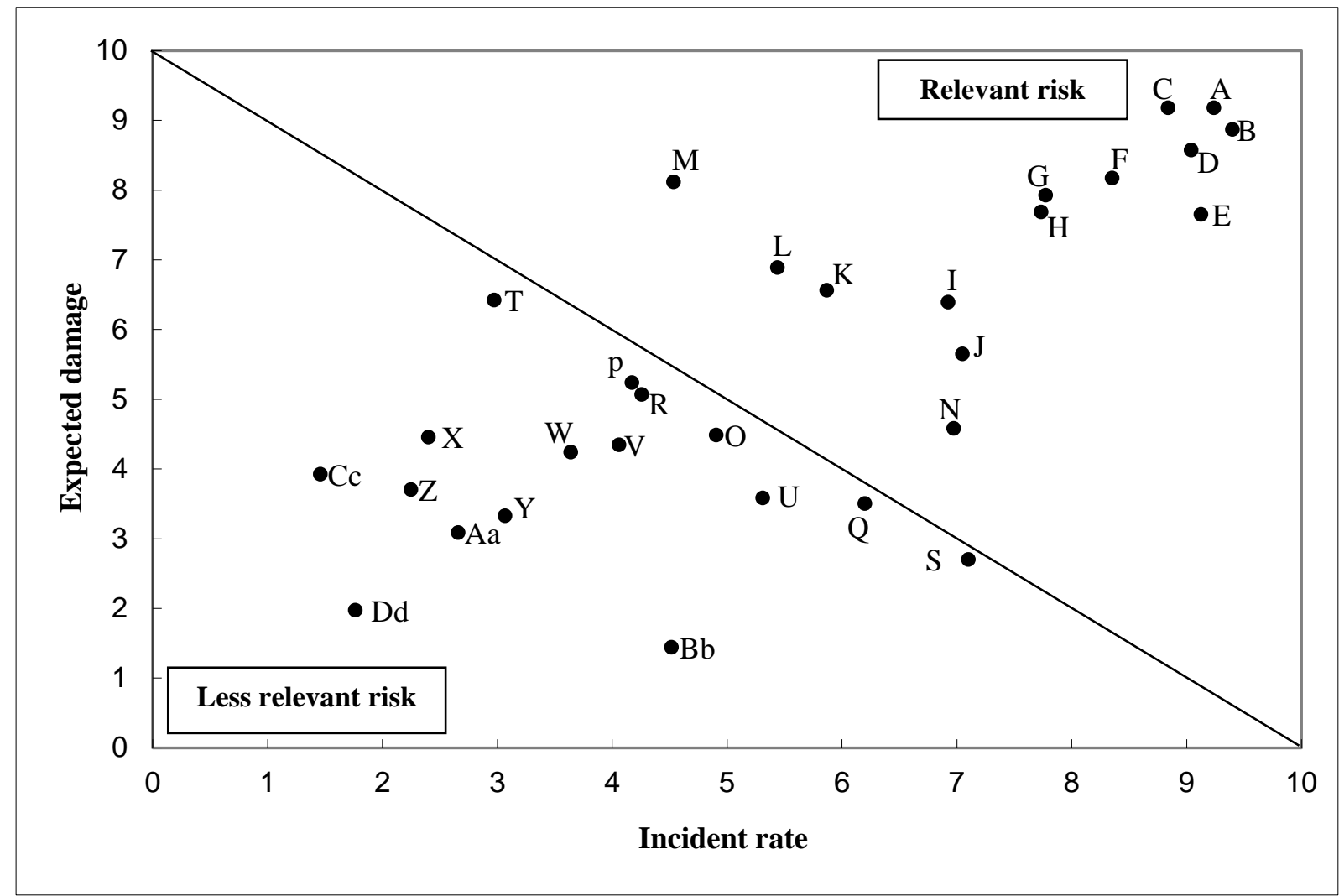

A: Fuel price, B: Precipitation shortage, C: Other operating input prices, D: Other climate factors (frost, overheating, dust storm), E: Pistachio license, F: Competition from neighboring countries, G: Plant pests and diseases, H: Drying of rivers and underground water, I: Price fluctuation, J: Property rights rules, K: Theft of farm equipment, etc., L: Brokers’ dominance, M: Price decrease, N: Land price, O: Agro-infrastructure, P: Farm inheritance rules, $\mathbf{Q}$ : Land tenure fragmentation by inheritance, $\mathbf{R}$ : Land availability, S: Agricultural extension, T: Insolvency, U: Uncoordinated agro-government corporations, V: Quality requirements, W: Farm business effectiveness, X: Market opportunities, Y: Labour, Z: Machinery, Aa: Shipping problems, Bb: Irrigation modernization policy, Cc: Cultivation preference, Dd: Pistachio preference

Source: Own elaboration using survey data

\subsection{Perceptions of risk management strategies}

\subsubsection{Wheat-Cotton farmers}

This section discusses how wheat-cotton farmers perceived the importance of 15 RMS in their farm business. The interviewed farmers were asked about their agreement with each RMS by five-point Likert scales from -2 (strongly disagree) to +2 (strongly agree). The 
agreement distribution for each RMS (Figure 5.13) reflects wide variations of farmers' preferences of given RMSs. Obviously, diversification of farm activities and crops were the most preferred strategies to cope with risk. Farmers who did not accept diversification justified their attitude by a lack of capital needed for such activities. Furthermore, farmers in the study area were accustomed to produce some cottage food for household consumption, particularly wheat-food products. However, $42 \%$ of them did not receive cottage food expansion as farm activity diversification. In this context, $42 \%$ of interviewed farmers showed ability to employ more hired labour in cases of need, while 30\% preferred an intensive use of family labour in such cases.

Given that the wheat-cotton market is restricted by state agencies, 93\% of farmers did not accept spread sales across traders and food manufacturers. As well, only $6.8 \%$ relied on forward contracts with traders or food manufacturers in order to finance their farm business. Farmers' willingness to collect information about futures and market options (41.75\%) may be due to the need to sell their farm diversification outputs to insure brokers for their unlicensed cotton.

Despite the risky environment of their farm business, 88\% were inconsistent with a strategy that suggests a limitation with one crop (wheat or cotton) and insertion of other crops (e.g. lentils). Farmers at the study sites highly refused wheat-cotton combination substitution with new crops; $50 \%$ strongly rejected the statement 'neither cotton nor wheat', and 33\% disagreed. Actually, the combination of wheat-cotton cultivation in the study area was perceived as a consecrated inherited tradition. Many of interviewed farmers in that area said: "I cannot imagine how our farms will be without the wheat-cotton combination". This aspect has to be carefully considered by RMS' developers when they design appropriate strategies for such a region.

To cope with water scarcity in the wheat-cotton region, the study suggested two related strategies, adoption of modern irrigation technique and cooperation with neighboring farmers for irrigation equipment supply. Half of the interviewed farmers rejected the modern irrigation employment, of which $16 \%$ strongly refused, while $15 \%$ did not confirm their final decision, yet. These various cognitions may be attributed to the recentness of such techniques in the region, thus consequences of adoption are still obscure. Farmers did not perceive irrigation cooperation mechanisms such as shared water reservoirs or shared irrigation nets as a favorable strategy. This could be attributed to farmers' negative impression toward cooperation strategies which are often controlled by customs and personal relationships. In 
addition, farmers did not reveal a considerable desire to enjoy cooperation items that were given in the questionnaire. Only 10.68 and 6.85\% accepted cooperation related to shipment and cottage food products respectively.

Figure 5.13: Attitudes toward risk management strategies of Syrian wheat-cotton farmers, $(n=103)$

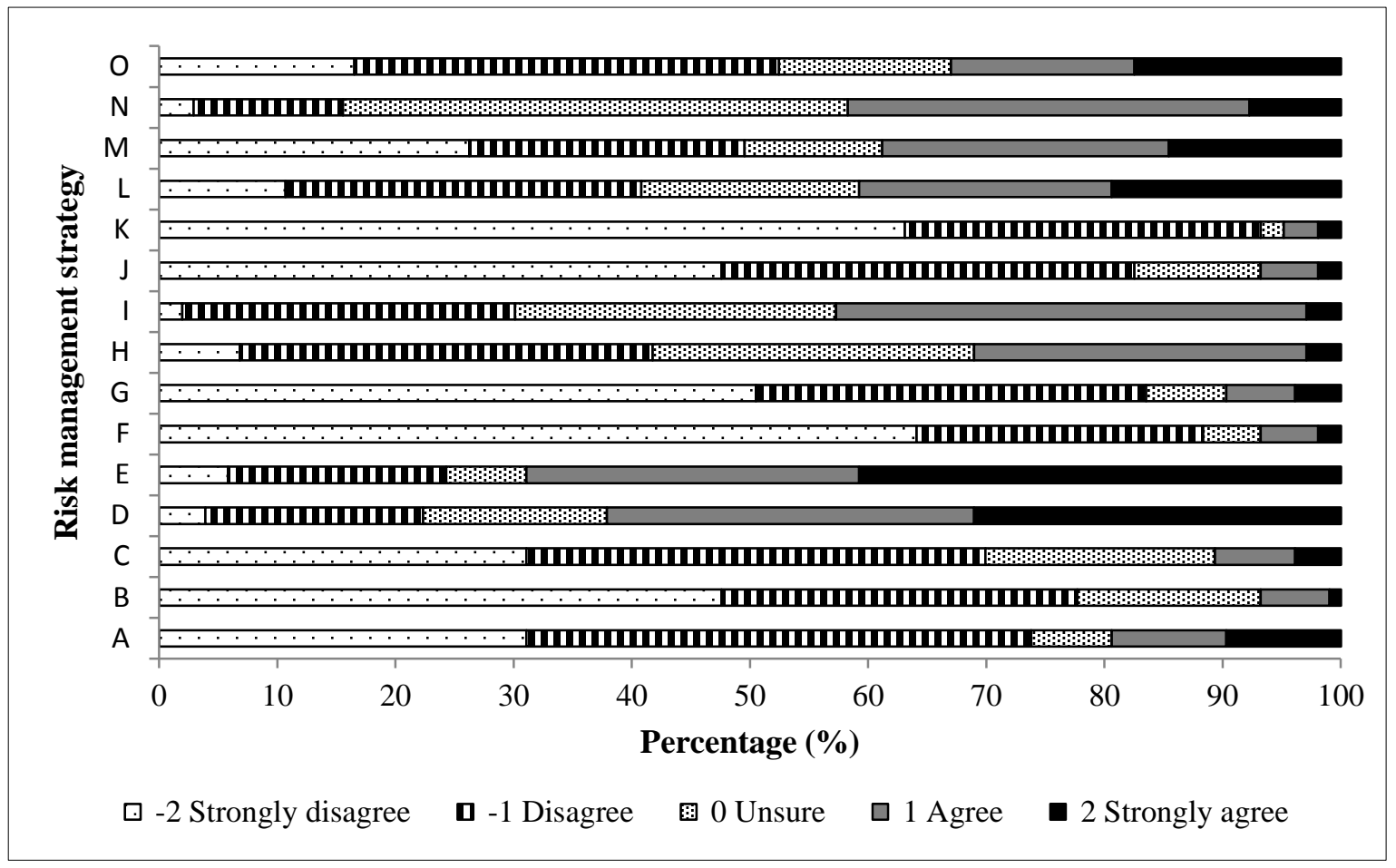

A: Irrigation cooperation, B: Shipment cooperation, C: Cooperation of cottage food products, D: Farm activities diversification (apiculture, poultry and animal husbandry), E: Farm crops diversification, F: One crop: either cotton or wheat, G: Other crops: neither cotton nor wheat, H: Cottage food products, I: Hired labour, in case of need, J: Forward contract with traders or food manufacturers, K: Spread sales across traders and food manufacturers, L: Farming as a secondary occupation, M: Farming forsaking, N: Inquiry for futures and market options. O: Modern irrigation techniques

Source: Own elaboration using survey data

To survive their livelihood, $41 \%$ of the respondents exhibited willingness to look for non-farm sustenance, and kept farm business as a supplemental occupation. Surprisingly, a high share of the interviewed farmers (38.83\%) does not mind giving up the farm business in case of getting a better job opportunity; while $12 \%$ were thinking about. These findings provide the adverse environment which choke farm business in the studied wheat-cotton region.

\subsubsection{Pistachio farmers}

Pistachio farmers were asked to evaluate their preferences for 12 RMSs. As shown in Figure 5.14, farm crops diversification inscribed a priority for the interviewed farmers. About $76 \%$ of the farmers agreed with crop diversification, of which around $73 \%$ are already have it. 
Similarly, diversification of farm activities and production of pistachio related cottage food (sweets and nut) showed a considerable percentage of agreement (63\% and 50\% respectively). In order to meet labour needed for new activities and crops, about $72 \%$ of the farmers relied on hired labour while almost 15\% preferred a dependence on family labour.

Given the high trees and field crops diversification noticed in the studied farms, approximately $90 \%$ of the interviewed farmers did not agree with the statement 'gradual substitution of pistachio trees with another crop', of which $71 \%$ strongly refused. This suggests that the pistachio business is more profitable than that of other crops. In that direction, 81\% cannot imagine pistachio farming forsaking, while 52.38\% did not accept to operate their farm as a secondary occupation. These percentages reveal a good farm business environment in pistachio region compared to wheat-cotton.

Figure 5.14: Attitudes toward risk management strategies of Syrian pistachio farmers, $(n=105)$

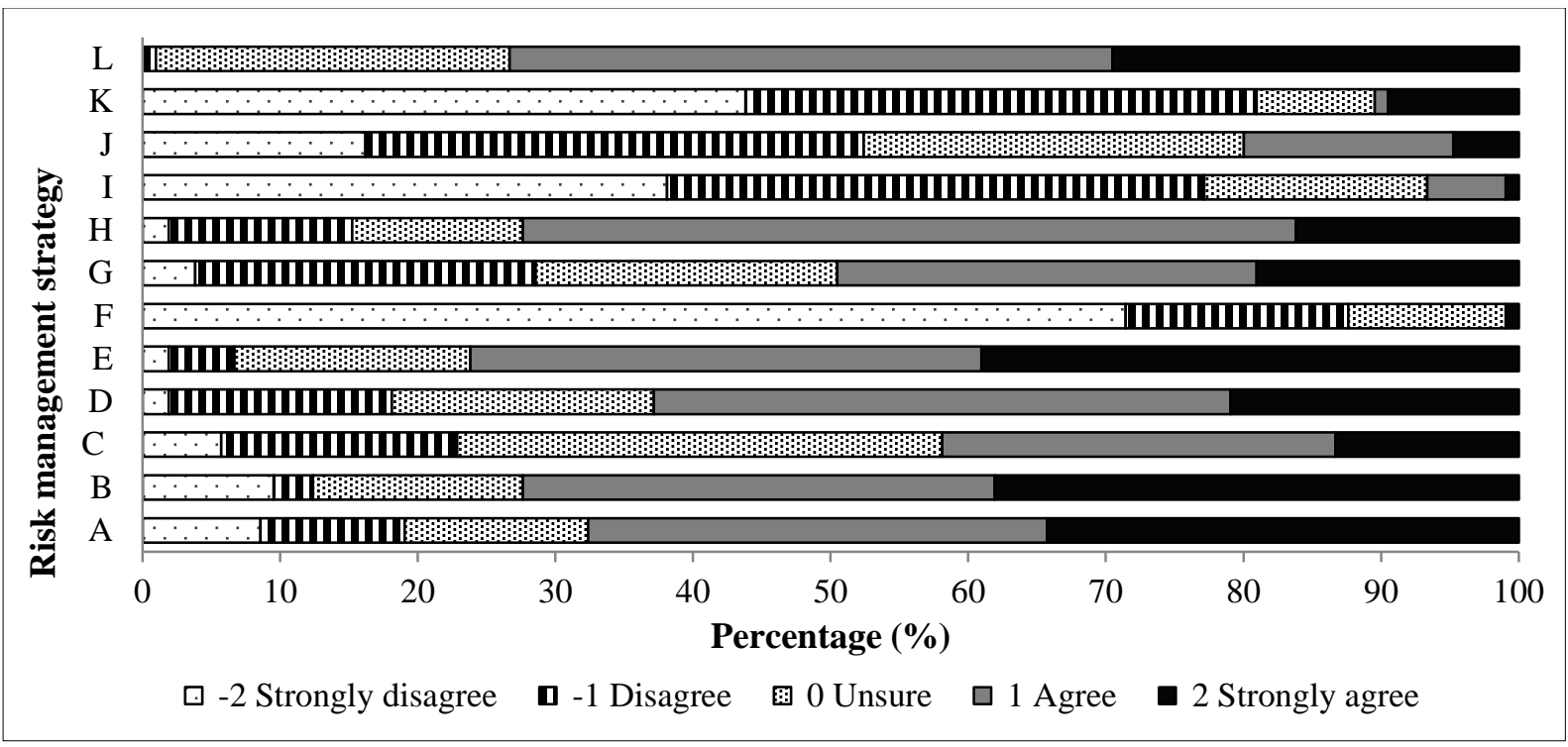

A: Irrigation cooperation, B: Shipment cooperation, C: Cooperation of cottage food products, D: Farm activities diversification (apiculture, poultry and animal husbandry), E: Farm crops diversification, F: Gradual substitution of pistachio trees with another crop, G: Cottage food products, H: Hired labour, in case of need, I: Forward contract with traders or food manufacturers, J: Farming as a secondary occupation, K: Farming forsaking, L: Inquiry for futures and market options

Source: Own elaboration using survey data

In order to cope with market risks, farmers unanimously agreed with the importance of 'inquiry for futures and options market', however a quarter of the farmers did not answer. This indicates that up-to-date information instruments are really scanty, and farmers often make their market-decision based on incomplete knowledge. As shown in Figure 5.14, the level of importance attached to 'forward contract with traders or food manufacturers' as an RMS is relatively small (6\%) indicating that farmers have less interest or trust in such 
contracts. To reduce production market cost, pistachio producers used to cooperate with each other to ship the harvested pistachio.

Cooperation status quo in pistachio farm business is better than in wheat-cotton farming. Cooperation for pistachio sweets and nut production was perceived as a favorable strategy by half of the interviewed farmers. Similar results were observed regarding irrigation cooperation. Almost 68\% of the operators share irrigation equipment, particularly wells and water reservoirs, since around 50\% of the farmers do not have own wells.

\subsection{Factor analysis}

\subsubsection{Risk sources}

\subsubsection{Wheat-cotton farmers}

Applying exploratory factor analysis on the 15 expectation values of the relevant RS for wheat-cotton farms resulted in four factors with a total variance explained of $65.53 \%$, which is considered as satisfactory in social sciences (Hair et al. 2010). The KMO value was 0.713, and the Cronbach’s alpha values for factors ranged from 0.61 to 0.79 .

Two RS (Land tenure fragmentation by inheritance and loss by land reform ownership), which are conditional on farm ownership type, were not included in the factor analysis, because they have many missing values.

The factors are described in Table 5.7. Based on the concentration of factor loadings, the four interpretable and feasible factors can be labelled as follows:

Factor 1 was named 'agriculture shrinkage' because of the relatively high loadings of RS variables that influence the besetting threats affecting wheat-cotton cultivation in Syria. It involves high loadings associated with a decrease of farm business effectiveness, decline of cultivation preference in the region, insolvency due to drying and decline of annual average rainfall. Factor 1 explains about 21\% of the total variation in the observed risk perceptions across the farmers in the sample.

Factor 2 incorporates a number of RSs related to the 'subsidy policy' for strategic crops' inputs and outputs. It includes high loadings for elimination of governmental support as well as the special compensation payment program. The high loading for the decrease of cotton and wheat prices which are considered as state supported prices can be noticed on this factor. Factor 2 explains almost 18\% of the total variance. 
Factor 3 was labelled 'cotton related policy' with high loadings for three political aspects: Cotton license rules, irrigation modernization policy, and fuel price. Cotton cultivation operations seem to be more affected these risks than wheat cultivation. Cotton operators were actually more worried about decline of cotton licences. Furthermore, cotton irrigation is more affected by fuel price rising than wheat, since cotton requires about 15 irrigation operations during its growing season compared with about 5 for wheat, which means more fuel consumption to run irrigation pumps. The forenamed high water requirements for cotton mean that cotton cultivation is more targeted by irrigation modernization rules than wheat.

Factor 4 refers to 'input prices'. It includes high loadings of other operating input prices, and brokers' dominance. Risks related to operating input costs are unprecedented aspects in wheat-cotton farms. These related risks occurred recently due to lifting of input subsidies for strategic crops which to an increase in brokers' dominance. The last two factors interpret nearly 14 and $12 \%$ of the total variation respectively.

Table 5.7: Varimax rotated factor loadings of relevant risk sources for Syrian wheat-cotton farmers, $(n=103)$

\begin{tabular}{|c|c|c|c|c|}
\hline \multirow{2}{*}{ Relevant risk sources } & \multicolumn{4}{|c|}{ Factors $^{\mathrm{a}}$} \\
\hline & 1 & 2 & 3 & 4 \\
\hline Precipitation shortage & 0.51 & -0.36 & -0.09 & 0.20 \\
\hline Drying of rivers and underground water & 0.70 & 0.48 & -0.07 & -0.08 \\
\hline Cultivation preference & 0.62 & 0.31 & -0.02 & 0.36 \\
\hline Land tenure fragmentation by inheritance ${ }^{b}$ & ---- & ---- & ---- & ---- \\
\hline Fuel price & 0.12 & -0.28 & 0.64 & 0.13 \\
\hline Other operating input prices & 0.18 & 0.01 & 0.11 & 0.83 \\
\hline Price decrease & 0.01 & 0.80 & -0.21 & 0.15 \\
\hline Brokers' dominance & 0.05 & 0.00 & 0.20 & 0.81 \\
\hline Farm business effectiveness & 0.81 & 0.04 & 0.38 & 0.11 \\
\hline Insolvency & 0.83 & 0.17 & 0.19 & 0.05 \\
\hline Irrigation modernization policy & 0.17 & 0.06 & 0.73 & 0.04 \\
\hline Governmental support elimination & 0.34 & 0.67 & 0.09 & 0.08 \\
\hline Special compensation program elimination & 0.12 & 0.81 & 0.08 & -0.12 \\
\hline Loss by land reform ownership ${ }^{\text {b }}$ & ---- & ---- & ---- & ---- \\
\hline Cotton license & -0.10 & 0.10 & 0.78 & 0.18 \\
\hline Eigenvalues & 3.70 & 2.29 & 1.33 & 1.20 \\
\hline Per cent of total variance explained & 20.96 & 17.79 & 14.33 & 12.46 \\
\hline Cumulative per cent of the variance explained & 20.95 & 38.75 & 53.07 & 65.53 \\
\hline Cronbach’s alpha & 0.79 & 0.76 & 0.61 & 0.66 \\
\hline Number of variables & 5 & 4 & 3 & 2 \\
\hline
\end{tabular}

${ }^{\mathrm{a}}$ Factors 1 to 4 are agriculture shrinkage, subsidy policy, cotton related policy and input prices respectively. Factor loadings $>|0.40|$ are in bold

${ }^{\mathrm{b}}$ Risk sources conditional on farm ownership type

Source: Survey data 


\subsubsection{Pistachio farmers}

The number of variables of expectation values for the relevant pistachio RS data was reduced from 14 to 5 by applying the exploratory factor analysis (Table 5.8). Five factors explain $74 \%$ of the total variance. The KMO value was 0.603 , and with regard to the reliability test Cronbach's alpha values for resultant factors range from 0.61 to 0.73 . Factors of pistachio operators were extremely different from those of wheat-cotton.

Referring to the results presented in Table 5.8, the five factors can be explained as follows:

Factor 1 was related to 'production' because of the high loadings of risks that affect directly the pistachio productivity. These risks are represented by the precipitation shortage, drying, plant pests and diseases, and insufficiency of agricultural extension system in the target region.

Factor 2 can be described as 'farm business environment' due to the high loadings associated with rainfall shortage accompanied by other climate factors such as frost, overheating, moisture fluctuation, etc. Furthermore, high loading for pistachio price decrease can be noticed in this factor. Given that pistachio trees are fairly resistant to drought, trees' yield is affected by other unfavourable climate factors more than the precipitation shortage, particularly when such factors coincide with flowering stage. Losses caused by the affected yield are exacerbated when they are combined with low market prices due to increasing supply of Turkish and Iranian pistachio in Syrian markets. Indeed, high loading of theft of farm equipment was noticed on this factor, indicating a bad situation grips the general farm environment.

Factor 3 is strongly associated with 'market risks' and involves large loadings of pistachio price' decrease and variability, brokers' dominance of inputs and outputs, and competition from neighboring countries. Each of the three previous factors interprets about $16 \%$ of the total variation.

Factor 4 is called 'input prices' because of the highest factor loading of the fuel price, and other operating input prices on this factor.

Factor 5 reflects 'pistachio expansibility'. It includes risks that constrict farmers' willing to horizontally expand their pistachio farm business. High loadings resulted from increasing farm land price and prohibition of additional pistachio farm licence. Close to $13 \%$ of the total variation can be explained by each of the two last factors. 
Table 5.8: Varimax rotated factor loadings of relevant risk sources for Syrian pistachio farmers, $(n=105)$

\begin{tabular}{|c|c|c|c|c|c|}
\hline \multirow{2}{*}{ Relevant risk sources } & \multicolumn{5}{|c|}{ Factors $^{\mathrm{a}}$} \\
\hline & 1 & 2 & 3 & 4 & 5 \\
\hline Precipitation shortage & 0.53 & 0.43 & -0.19 & 0.45 & -0.12 \\
\hline Drying of rivers and underground water & 0.86 & -0.02 & 0.02 & -0.07 & 0.23 \\
\hline Other climate factors (frost, overheating, dust storm) & 0.37 & 0.83 & -0.19 & 0.02 & -0.04 \\
\hline Plant pests and diseases & 0.83 & 0.18 & 0.18 & 0.15 & -0.05 \\
\hline Theft of farm equipment, etc. & 0.17 & 0.60 & 0.29 & 0.09 & 0.30 \\
\hline Fuel price & -0.17 & 0.11 & -0.03 & 0.87 & 0.07 \\
\hline Other operating input prices & 0.34 & -0.05 & 0.17 & 0.82 & 0.01 \\
\hline Farm land price & 0.14 & -0.35 & -0.04 & 0.09 & 0.79 \\
\hline Price fluctuation & -0.05 & 0.18 & 0.77 & 0.17 & 0.05 \\
\hline Price decrease & -0.18 & 0.74 & 0.42 & 0.05 & -0.09 \\
\hline Brokers' dominance & 0.14 & 0.32 & 0.74 & -0.27 & -0.02 \\
\hline Competition from neighbour countries & 0.12 & -0.17 & 0.78 & 0.07 & 0.09 \\
\hline Agricultural extension’ insufficiency & 0.43 & 0.32 & 0.31 & -0.17 & 0.51 \\
\hline Pistachio license & -0.05 & 0.21 & 0.06 & 0.03 & 0.83 \\
\hline Eigenvalues & 3.59 & 2.06 & 1.86 & 1.60 & 1.25 \\
\hline Per cent of total variance explained & 16.38 & 16.13 & 15.97 & 12.90 & 12.58 \\
\hline Cumulative per cent of the variance explained & 16.38 & 32.50 & 48.47 & 61.37 & 73.95 \\
\hline Cronbach’s alpha & 0.70 & 0.69 & 0.73 & 0.67 & 0.61 \\
\hline Number of variables & 4 & 4 & 4 & 3 & 2 \\
\hline
\end{tabular}

\subsubsection{Risk management strategies}

\subsubsection{Wheat-cotton farmers}

Results of the exploratory factor analysis of the Syrian wheat-cotton farmers' responses to RMS are summarized in Table 5.9. Factor analysis grouped the 15 RMS into 5 interpretable and feasible factors with a total variance explained of nearly $68 \%$. The KMO measure of data sufficiency was 0.586. In addition, the Cronbach's alpha values for factors ranged from 0.62 to 0.78 . Based on the concentration of factor loadings, the five factors can be described as 'diversification', 'cooperation', 'wheat-cotton combination substitution', ‘secure income’ and 'alternative markets', respectively.

On the factor 'diversification', relatively high loadings of diversification of farm activities and crops were accompanied with high loadings of strategies that are required by diversification. Using hired labour, cooperation for cottage food products, and forward contract with traders or food manufacturers, all of these instruments are needed in case of diversification of activities and crops, and food products processing. Factor one explains about $16 \%$ of the total variation of farmers' risk management preferences. 
Factor 2 is described as 'cooperation' because of the significant loadings of RMS related to cooperation for irrigation equipment, crop shipment and cottage food products. The loading for modern irrigation techniques' adoption on this factor is considered as cooperation mechanism. Actually, most of the modern irrigation equipments for strategic crops, which are subsidized by irrigation modernization program, are supplied by agricultural cooperatives. Approximately $13 \%$ of the total variation can be explained by this factor.

Factor 3 is associated with strategies adopted to avoid crop rotation risks. This can be done by either expulsion of the high risk crop or by starting a new crop rotation without cotton and wheat. Therefore, factor 3 is called 'wheat-cotton combination substitution'. The proportion of the total variance interpreted by this factor was about $13 \%$.

Table 5.9: Varimax rotated factor loadings of risk management strategies for Syrian wheatcotton farmers, $(n=103)$

\begin{tabular}{lccccc}
\hline \multirow{2}{*}{ Risk management strategies } & \multicolumn{5}{c}{ Factors ${ }^{\mathrm{a}}$} \\
\cline { 2 - 6 } & 1 & 2 & 3 & 4 & 5 \\
\hline Irrigation cooperation & 0.17 & $\mathbf{0 . 8 3}$ & 0.22 & 0.02 & -0.16 \\
Shipment cooperation & -0.24 & $\mathbf{0 . 7 6}$ & 0.12 & 0.02 & 0.00 \\
Cooperation of cottage food products & $\mathbf{0 . 5 2}$ & $\mathbf{0 . 5 6}$ & 0.30 & 0.03 & -0.21 \\
Modern irrigation techniques & 0.08 & $\mathbf{0 . 5 3}$ & -0.20 & -0.31 & 0.35 \\
Diversification of farm activities & $\mathbf{0 . 7 1}$ & 0.20 & 0.10 & 0.00 & 0.30 \\
Diversification of farm crops & $\mathbf{0 . 6 6}$ & -0.08 & -0.13 & -0.02 & 0.09 \\
Cottage food products & $\mathbf{0 . 8 1}$ & -0.01 & 0.10 & -0.22 & -0.03 \\
Hired labour, in case of need & $\mathbf{0 . 4 3}$ & -0.18 & -0.32 & -0.39 & -0.16 \\
Forward contract with traders or food manufacturers & $\mathbf{0 . 4 3}$ & 0.02 & -0.10 & -0.10 & $\mathbf{0 . 6 0}$ \\
Spread sales across traders and food manufacturers & 0.06 & -0.05 & -0.06 & 0.09 & $\mathbf{0 . 8 6}$ \\
Inquiry for futures and market options & -0.07 & -0.09 & 0.32 & -0.21 & $\mathbf{0 . 6 7}$ \\
One crop: either cotton or wheat & 0.00 & 0.29 & $\mathbf{0 . 8 4}$ & -0.01 & -0.03 \\
Other crops: neither cotton nor wheat & 0.01 & 0.02 & $\mathbf{0 . 8 9}$ & 0.10 & 0.07 \\
Farming as a secondary occupation & -0.08 & -0.11 & -0.06 & $\mathbf{0 . 8 8}$ & -0.01 \\
Farming forsaking & -0.11 & 0.04 & 0.12 & $\mathbf{0 . 8 8}$ & -0.14 \\
& & & & & \\
\hline Eigenvalues & 3.01 & 2.68 & 1.76 & 1.52 & 1.19 \\
Per cent of total variance explained & 15.71 & 13.62 & 13.14 & 12.73 & 12.59 \\
Cumulative per cent of the variance explained & 15.71 & 29.33 & 42.48 & 55.20 & 67.79 \\
Cronbach's alpha & 0.69 & 0.64 & 0.78 & 0.65 & 0.62 \\
Number of variables & 6 & 4 & 2 & 2 & 3 \\
\hline
\end{tabular}

${ }^{a}$ Factors 1 to 5 are diversification, corporation, wheat-cotton combination substitution, secure income and alternative markets, respectively. Factor loadings $>|0.40|$ are in bold Source: Survey data

Factor 4 refers to the 'secure income' strategy due to the high loadings of 'farming as a secondary occupation' and 'farm business forsaking' in order to occupy a position with more certain income. Factor 4 accounts for nearly 13\% of the total variance.

The idea of naming factor 5 'alternative markets' comes from the high loadings of forward contract with traders or food manufacturers, spreading sales across traders and food 
manufacturers, and collecting information about futures and market options. The total variation that can be explained by factor 5 is close to $13 \%$.

\subsubsection{Pistachio farmers}

Table 5.10 presents the Varimax rotated factor loadings of RMS for the pistachio farmer group. The analysis has identified three factors that underlie farmers' perceptions of RMS in their farm businesses. By these three factors, nearly $64 \%$ of the total variance in farmers' preferences to assorted RMS was explained. With regard to reliability test, the Cronbach's alpha values for factors 1,2 and 3 were $0.84,0.80$ and 0.60 respectively. The Kaiser-Meyer-Olkin (KMO) value was 0.671.

Table 5.10: Varimax rotated factor loadings of risk management strategies for Syrian pistachio farmers, $(\mathrm{n}=103)$

\begin{tabular}{lccc}
\hline \multirow{2}{*}{ Risk management strategies } & \multicolumn{3}{c}{ Factors $^{\text {a }}$} \\
\cline { 2 - 4 } Irrigation cooperation & 1 & 2 & 3 \\
Shipment cooperation & $\mathbf{0 . 8 3}$ & 0.03 & -0.09 \\
Cooperation of cottage food products & $\mathbf{0 . 8 2}$ & 0.02 & -0.19 \\
Diversification of farm activities & $\mathbf{0 . 6 1}$ & $\mathbf{0 . 5 9}$ & 0.24 \\
Diversification of farm crops & $\mathbf{0 . 7 1}$ & $\mathbf{0 . 4 4}$ & -0.06 \\
Gradual substitution of pistachio trees & 0.33 & $\mathbf{0 . 8 1}$ & -0.14 \\
Cottage food products & -0.08 & -0.20 & $\mathbf{0 . 7 9}$ \\
Hired labour, in case of need & $\mathbf{0 . 6 0}$ & 0.36 & 0.09 \\
Forward contract with traders or food manufacturers & $\mathbf{0 . 6 5}$ & 0.04 & 0.23 \\
Farming as a secondary occupation & 0.19 & 0.28 & $\mathbf{0 . 4 7}$ \\
Farming forsaking & 0.17 & -0.08 & $\mathbf{0 . 7 4}$ \\
Inquiry for futures and market options & -0.35 & 0.13 & $\mathbf{0 . 7 6}$ \\
\hline Eigenvalues & -0.06 & $\mathbf{0 . 8 6}$ & 0.01 \\
Per cent of total variance explained & 4.05 & 2.17 & 1.44 \\
Cumulative per cent of the variance explained & 27.50 & 18.32 & 17.96 \\
Cronbach's alpha & 27.50 & 45.81 & 63.78 \\
Number of variables & 0.84 & 0.80 & 0.65 \\
\hline
\end{tabular}

${ }^{a}$ Factors 1 to 3 are on-farm management, diversification and secure income, respectively. Factor loadings $>|0.40|$ are in bold Source: Survey data

According to the results presented in Table 5.10, it can be observed that factor 1 is strongly relevant to risk impact reduction mechanisms represented by cooperation and diversification of farm activities. Factor 1 involves high loadings of multiple scopes of cooperation (irrigation, shipment, and food producing and marketing). In addition, high loadings of diversification, producing food products and using hired labour were noticed. Factor 1 is named 'on-farm management'. This factor accounts for nearly $28 \%$ of the total variation. 
Factor 2 is interpreted as ‘diversification’ due to relatively high loadings of inclusion of new activities and crops in farm business accompanied by inquiry for futures and market options. Loading of cooperation regarding cottage food products can be noticed. This is pertinent to food processing at farm level as a sort of diversification of farm activities.

Factor 3 obviously reflects 'secure income' due to its association with RMS which provide a certain livelihood. These strategies are farming as a secondary occupation, farming forsaking, forward contract with traders of food manufacturers and gradual pistachio substitution. Each of factors 2 and 3 explains about $17 \%$ of the total variation.

\subsection{Determinants of attitudes and perceptions based on socio-economic characteristics}

For all multiple regressions, preliminary analyses were carried out to verify that there was no violation of the multiple regression assumptions. Multicollinearity, homoscedasticity, independence of error, and linearity were examined to ensure the appropriateness of the equations. Some models did not meet the normal distribution assumption. However, since the sample size is more than 100 for each wheat-cotton and pistachio farms, the impact of this problem was limited, and did not lead to other assumption violations (e.g., heteroskedasticity) (Hair et al. 2010).

\subsubsection{Farmers’ risk attitudes}

Socio-economic characteristics were regressed against each of wheat-cotton and pistachio farmers' RA, separately, to determine the effect of farmers' circumstances on their attitudes toward risk.

The two models represented in Table 5.11 were statistically significant at one per mill (1\%) level of significance. This indicates that the models have significant explanatory power, and socio-economic variables included in these models offer useful insights on farmers' RA.

A closer look at the estimation results presented in Table 5.11 provides several insights as to the determinants of farmers' RA. Regression coefficients indicate that, for both, wheatcotton and pistachio samples, farmers' education level was positively related to their attitudes toward risk, with statistical significance at 5\% level. In addition, wheat-cotton producers' reliance on books and scientific centers as their main knowledge resources was related to their $\mathrm{RA}$, at $1 \%$ level, by direct manner. It is obvious that more educated farmers as well as those wheat-cotton operators who rely on books and scientific centers as their main knowledge resources tended to exhibit more risk-seeking behavior. This result is congruent with the 
conclusion that high educated individuals have been positively associated with risk acceptance (Moscardi and Janvry 1977; Binswanger 1980; Eidman 1983 as cited by Boggess et al. 1985; Anosike and Coughenour 1990; Binici 2001; Aditto 2011; Roslan et al. 2012).

Education and knowledge from scientific sources affect farmers' RA by multidirectional effects. Literacy and numeracy enhance farmers' ability to receive, decode and understand information (Knight et al. 2003). Perry and Johnson (2000) deduced that education in supplies skills increases farmers' ability to mitigate risk. Furthermore, education may facilitate openness to new ideas and modern practices (Knight et al. 2003). Jamison and Lau (1982) indicated that operators who achieved the fourth year of schooling were more willing to introduce chemical inputs. Similarly, Ethiopian literate farmers were more likely to adopt fertilizer than illiterate ones (Croppenstedt et al. 2003; Weir and Knight 2000). Just and Calvin (1994) illustrated that education level is directly correlated with Multiple Peril Crop Insurance participation. The empirical studies which were done by Knight et al. (2003) and Bakhshoodeh and Shajari (2006), found a strong direct relationship between schooling and farmers' willingness to adopt new technologies. Consequently, adoption of innovations is more likely to increase farm output and, therefore, farmers' willingness to take more risks. In that direction, education and knowledge from scientific sources are assumed to provide farmers a real image of many misconceptions which are commonly considered as risks, but actually are not. For example, most wheat-cotton producers consider adopting modern irrigation technique as a risky aspect itself. However, education and scientific knowledge help farmers to perceive such technique as risk management mechanism.

The contribution of family members to the total farm labour force was negatively related to wheat-cotton farmers' RA. Namely, when the household members contribute most of farm labour force, farm managers tend to reveal more risk-averse behavior. This probably refers to one or both of the following two aspects. First, the higher the family size the higher the subsistence consumption need, and therefore, the lower the willingness to accept risks (Sekar and Ramasamy 2001; Ayinde 2008). Second, none of the family members earn income from non-agricultural sources. Simply, the higher the family members who have off-farm work the higher the willingness to take risk due to their income which serves as a substitute in risk threat period (Perry and Johnson, 2000).

Farm land size was inversely related to pistachio operators' RA at 5\% level of significance. Risk accepting farmers operate small farms. This finding disagreed with Perry and Johnson (2000), Xu et al. (2005), Sckokai and Moro (2006) and Koundouri et al. (2009) 
who found that operators with medium and large farms are most willing to take risk. The pistachio producers with larger operations would behave more risk-averse. This will be possible if capital items of the total land tenure are taken as a measure of farmers' wealth, whereupon the logic of safety is ranked first. Furthermore, large producers are expected to avoid high risk decision due to the complexity of decision-making on larger farms. Boggess et al. (1985) illustrated that large farm owners are more worried about risks related to production, operating cost and business environment than small farmers. This rising worry may hedge their willingness to take more risks.

As shown in Table 5.11, the average of pistachio trees age was significantly related to farmers' RA, indicating that with young trees, farmers give more attention to their farming, implying risk aversion. The young trees age refers to the recency of the farm business or a huge renewal process. The simple argument of this finding is that farmers, as all investors, start with lower willingness to take risks at the beginning of farming; when the farm business consolidates, risk-taking behavior may arise.

Although older producers are expected to be more risk-averse than younger farmers, our results did not show a significant effect of farmers' age on their attitudes toward risk.

The goodness-of-fit of the multiple regression models represented by Adjusted $\mathrm{R}$ squared $\left(R_{a d j}^{2}\right)$ was equal to 0.26 and 0.24 for wheat-cotton and pistachio, respectively. These values for $R_{a d j}^{2}$ indicate the percentage of RA variance that can be explained by farm and farmer characteristics. Actually, the resultant $R_{a d j}^{2}$ values seem to be low, but they are in line with previous studies. $R_{a d j}^{2}$ values recorded by Aditto (2011) were 0.05 and 0.06 for studied farmers groups in Thailand. This value accounted to 0.12 in a study among organic and conventional dairy farming in Norway (Flaten et al. 2005). In 2011, Picazo-Tadeo and Wall demonstrated that socio-economic characteristics related to Spanish rice producers interpreted about $13 \%$ of their RA variance. Socio-economic variables employed by Pålsson (1996) contributed to only 1\% of the variance of households' RA in Sweden. This percentage was 20 for Malaysian paddy producers studied by Roslan et al. (2012).

In fact, the low $R_{a d j}^{2}$ values arise due to farmer-specificity of RA. As clearly concluded by Bond and Wonder (1980), King and Oamek (1983), Tauer (1986) and Bard and Barry (2000) it is difficult to build a methodological relationship between socio-economic characteristics and farmers' RA. Before the submission of this conclusion, however, further investigation about the contribution of subjective believes to farmers' RA will be hold later in section 5.7. 
Table 5.11: Results of multiple regressions for farmers’ risk attitude scale against socioeconomic variables of wheat-cotton farmers $(n=103)$ and pistachio farmers $(\mathrm{n}=105)^{\mathrm{a}}$

\begin{tabular}{|c|c|c|}
\hline \multirow{2}{*}{ Socio-economic variables } & \multicolumn{2}{|c|}{ Risk attitude scale } \\
\hline & Wheat-cotton & Pistachio \\
\hline Education $^{\text {b }}$ & $0.23^{*}$ & $0.35^{*}$ \\
\hline Farmer age ${ }^{\mathrm{b}}$ & -0.07 & -0.09 \\
\hline Leadership ${ }^{\mathrm{C}} \mathrm{M}-\mathrm{S}$ & -0.02 & 0.04 \\
\hline Leadership M-P & -0.04 & 0.03 \\
\hline Off-farm work ${ }^{\mathrm{d}}$ & 0.02 & 0.04 \\
\hline Family labour ${ }^{\mathrm{e}}$ & $-0.21^{*}$ & -0.11 \\
\hline Scientific materials ${ }^{\mathrm{f}}$ & $0.31^{* *}$ & 0.17 \\
\hline Zone $^{\mathrm{g}} 1-2$ & 0.05 & -0.04 \\
\hline Zone 1-3 & -0.09 & ni \\
\hline Ownership ${ }^{\mathrm{h}} \mathrm{P}-\mathrm{L}$ & -0.05 & ni \\
\hline Ownership P-R & 0.00 & ni \\
\hline Farm land ${ }^{\mathrm{b}}$ & 0.13 & $-0.26^{*}$ \\
\hline Activity diversification ${ }^{\mathrm{i}}$ & 0.20 & 0.16 \\
\hline Rain-fed wheat ${ }^{j}$ & -0.11 & ni \\
\hline Bank loan ${ }^{k}$ & -0.06 & ni \\
\hline Pistachio occupation ${ }^{\text {b }}$ & ni & -0.14 \\
\hline Trees age $^{b}$ & ni & $0.41^{* * *}$ \\
\hline Private well ${ }^{1}$ & ni & -0.01 \\
\hline$R_{a d j}^{2}$ & 0.26 & 0.24 \\
\hline F-statistic & $3.39^{* * *}$ & $3.53^{* * *}$ \\
\hline
\end{tabular}

${ }^{\mathrm{a}}$ Variables and models significant at $\mathrm{P}^{*} \leq 0.05, \mathrm{P}^{* *} \leq 0.01$ and $\mathrm{P}^{* * * *} \leq 0.001$

${ }^{\mathrm{b}}$ scale variables: education, farmer age and trees age measured by total years, farm land (ha) and pistachio occupation measured by percentage of the total farm land

${ }^{\mathrm{c}}$ Measured by two dummy variables 'M-S' and 'M-P' with 0 indicating manager (M) leadership and 1 indicating successor $(\mathrm{S})$ and partner (P) leadership respectively

${ }^{\mathrm{d}}$ Measured by a dummy variable with 0 indicating there is no off-farm work, and 1 indicating farmers has off-farm work

e measured by five-point Likert-scales, -2 vary infrequently, -1 infrequently, 0 sometimes, 1 frequently and 2 very frequently

${ }^{\mathrm{f}}$ Measured by a dummy variable with 0 indicating farmer does not rely on scientific material, and 1 indicating farmer rely on scientific material as knowledge resource

${ }^{g}$ Measured by two dummy variables '1-2' and '1-3' with 0 indicating zone (1) and 1 indicating zone (2) and zone (3) respectively

${ }^{\mathrm{h}}$ Measured by two dummy variables 'P-L' and 'P-R' with 0 indicating private $(\mathrm{P})$ ownership, and 1 indicating land reform (L) and rental (R) ownership respectively

${ }^{\mathrm{i}}$ Measured by a dummy variable with 0 indicating farm without activity diversification, and 1 indicating farm with activity diversification

${ }^{\mathrm{j}}$ Measured by a dummy variable with 0 indicating farm without rain-fed wheat area, and 1 indicating farm with rain-fed wheat area

${ }^{\mathrm{k}}$ Measured by a dummy variable with 0 indicating farm without bank loans as financial resource, and 1 indicating farm with bank loans as financial resource

${ }^{1}$ Measured by a dummy variable with 0 indicating farm without private well, and 1 indicating farm with private well.

Source: Survey data 


\subsubsection{Farmers' perceptions of risk sources}

\subsubsection{Wheat-cotton farmers}

Multiple regressions were carried out for each of the four RS factors identified with factor analysis to investigate the classification possibility of wheat-cotton farmers' perceptions of RSs depending on their socio-economic status. As shown in Table 5.12, models 1 to 3 were statistically significant at 1\%o level of significance, while model 4 was statistically significant at 5\% level. Except the fourth model, the goodness-of-fit of the multiple regression models was fairly high compared to previous studies. Consequently, the set of socio-economic variables used in this study plays a considerable role in investigating farmers' perceptions of RSs. The low $R_{a d j}^{2}$ in the studies of Flaten et al. (2005), Størdal et al. (2007) and Aditto (2011) suggested a low explanatory power of socio-economic variables in terms of farmers' cognitions of RS. Therefore, they deduced an individualistic nature of these perceptions. In our study, the following variables did not show any significant relationship with any of RS factors: farmer age, family labour, farm land, activity diversification, bank loans as financial resource, manager against partner leadership and private against rental ownership. It appears that none of the mentioned variables contributes to interpret RS factors. On the contrary, agro-ecological zones play an essential role in explaining the variance of all factors related to wheat-cotton farmers' perceptions of RS. This result is expected since there are noticeable climate differences across zones leading to variations in the farming environment, and thereby in farmers' risk preferences. This is consistent with Bickerstaff and Walker (2001, p. 139), who illustrated that "perception could be viewed as the rational outcome of logical human cognitive processes based upon the source, physical environment and spatial attributes of the local area”. Consequently, the geographical location affects the farms’ operating environment which in turn influences farmers’ perceptions of RS.

Unsurprisingly, the relationship between farm location represented by agro-ecological zones and 'agriculture shrinkage' perception score was positive at $1 \%$ level of significance. Farmers in zone 3 and, to a lesser extent, in the second zone identified shrinkage of agriculture as fait accompli compared to those in zone 1. Given the differentiation of precipitations and ground water abundance between zones, the last severe droughts played a conclusive role to enhance differentiated perceptions of agricultural environments throughout zones. The result evidences that zone 1 is not totally proof against agriculture shrinkage, particularly the spread of drought that threatens all zones. Since, regardless the agro- 
ecological zones, Farmers who cultivate rain-fed wheat gave more importance of 'agriculture shrinkage' as an RS. A positive relationship can be noticed between the existence of rain-fed wheat and farmers’ perceptions of agriculture shrinkage, at 1\%o of significance level.

'Subsidy policy' was recognized as the most important risk by farmers in zone 3. This result shows the importance of state subsidy for strategic crops in order to foster agribusiness sustainability in such regions. Furthermore, operators with successor leadership were less likely concerned with subsidy policy as an important risk.

Farmers in zone 1 perceived 'cotton related policy' which restricts the expansion of cotton cultivation expansibility as more important as those in zones 2 and 3 (by the negative signs of the zone dummies ' $1-2$ ' and ' $1-3$ '). Farmers in zone 1 claim that ground water abundance in their region gives them the eligibility to cultivate cotton more than the state imposed percentage (20\%).

Scientific material (books, scientific centers) as knowledge resources were negatively correlated with perceptions of the risk of 'cotton related policy' at $1 \%$ o level. This suggests that farmers who rely on scientific material to obtain required information were relatively less concerned with risks of 'cotton related policy'. This implies the former explanation about the role of scientific knowledge to provide farmers a real image about misconceptions (e.g., the necessity of modern irrigation adoption, and the water consumption rationalization). The direct relation at 5\% level, between 'cotton related policy' and total years of formal education, could mean that books and scientific resources are more valuable than formal education to provide farmers with direct solutions for their problematic agricultural aspects. Land reform beneficiaries, who were more concerned with losses raised by agrarian reform laws, tended to classify 'cotton related policy’ as highly relevant.

Four variables were significantly associated with 'input prices'. Obviously, losses associated with input prices were perceived as more important among educated farmers as well as those in zone 2. However, farmers with successor leadership and those who earn nonagricultural income had less concern about input prices since such income could enhance farmers' ability to bear operating input cost. The low $R_{a d j}^{2}$ related to the 'input prices' risk factor reveals the personal sensibility of its latent variables, or farmers' RA and their perceptions of RMS could add further information to interpret farmers' estimations of input price risks. Thus, to match with the investigation further regressions will be performed throughout section 5-7. 
Table 5.12: Results of multiple regressions for risk source factors against socio-economic variables of wheat-cotton farmers $(n=103)^{a}$

\begin{tabular}{|c|c|c|c|c|}
\hline \multirow[b]{2}{*}{ Socio-economic variables } & \multicolumn{4}{|c|}{ Risk source factors } \\
\hline & $\begin{array}{l}\text { Agriculture } \\
\text { shrinkage }\end{array}$ & Subsidy policy & $\begin{array}{c}\text { Cotton related } \\
\text { policy }\end{array}$ & $\begin{array}{l}\text { Input } \\
\text { prices }\end{array}$ \\
\hline Education $^{\mathrm{b}}$ & 0.04 & -0.01 & $0.27^{*}$ & $0.27^{*}$ \\
\hline Farmer age $^{\mathrm{b}}$ & -0.13 & -0.13 & 0.08 & -0.11 \\
\hline Leadership ${ }^{\mathrm{c}} \mathrm{M}-\mathrm{S}$ & -0.11 & $-0.24^{*}$ & -0.16 & $-0.38^{* *}$ \\
\hline Leadership M-P & -0.02 & 0.01 & -0.07 & 0.01 \\
\hline Off-farm work $^{\mathrm{d}}$ & -0.08 & 0.12 & -0.22 & $-0.29^{*}$ \\
\hline Family labour ${ }^{\mathrm{e}}$ & 0.15 & -0.17 & -0.19 & 0.21 \\
\hline Scientific materials ${ }^{\mathrm{f}}$ & -0.06 & 0.03 & $-0.45^{* * *}$ & 0.19 \\
\hline Zone $^{\mathrm{g}} 1-2$ & $0.34^{* * *}$ & 0.10 & $-0.37^{* * *}$ & $0.34^{* *}$ \\
\hline Zone 1-3 & $0.60^{* * *}$ & $0.46^{* * *}$ & $-0.43^{* * *}$ & 0.04 \\
\hline Ownership ${ }^{\mathrm{h}} \mathrm{P}-\mathrm{L}$ & 0.15 & 0.06 & $0.31^{* *}$ & 0.02 \\
\hline Ownership P-R & -0.15 & 0.05 & -0.05 & -0.10 \\
\hline Farm land ${ }^{\mathrm{b}}$ & 0.06 & -0.04 & 0.01 & -0.06 \\
\hline Farm activity diversification ${ }^{\mathrm{i}}$ & -0.13 & 0.07 & 0.08 & -0.06 \\
\hline Rain-fed wheat ${ }^{\mathrm{j}}$ & $0.33^{* * *}$ & -0.17 & -0.02 & 0.09 \\
\hline Bank loan ${ }^{\mathrm{k}}$ & 0.02 & 0.00 & 0.10 & -0.02 \\
\hline$R_{a d j}^{2}$ & 0.33 & 0.41 & 0.36 & 0.14 \\
\hline F-statistic & $4.37^{* * *}$ & $4.76^{* * *}$ & $4.81^{* * *}$ & $2.12^{*}$ \\
\hline
\end{tabular}

${ }^{a}$ Variables and models significant at $\mathrm{P}^{*} \leq 0.05, \mathrm{P}^{* *} \leq 0.01$ and $\mathrm{P}^{* * *} \leq 0.001$

${ }^{\mathrm{b}}$ scale variables: education and farmer age measured by total years, farm land (ha)

' Measured by two dummy variables 'M-S' and 'M-P' with 0 indicating manager (M) leadership and 1 indicating successor (S) and partner (P) leadership respectively

${ }^{\mathrm{d}}$ Measured by a dummy variable with 0 indicating there is no off-farm work, and 1 indicating farmers has off-farm work

${ }^{\mathrm{e}}$ measured by five-point Likert-scales, -2 vary infrequently, -1 infrequently, 0 sometimes, 1 frequently and 2 very frequently

${ }^{\mathrm{f}}$ Measured by a dummy variable with 0 indicating farmer does not rely on scientific material, and 1 indicating farmer rely on scientific material as knowledge resource

${ }^{g}$ Measured by two dummy variables ' $1-2$ ' and ' $1-3$ ' with 0 indicating zone (1) and 1 indicating zone (2) and zone (3) respectively

${ }^{\mathrm{h}}$ Measured by two dummy variables 'P-L' and 'P-R' with 0 indicating private (P) ownership, and 1 indicating land reform (L) and rental (R) ownership respectively

${ }^{\mathrm{i}}$ Measured by a dummy variable with 0 indicating farm without activity diversification, and 1 indicating farm with activity diversification

${ }^{\mathrm{j}}$ Measured by a dummy variable with 0 indicating farm without rain-fed wheat area, and 1 indicating farm with rain-fed wheat area

${ }^{\mathrm{k}}$ Measured by a dummy variable with 0 indicating farm without bank loans as financial resource, and 1 indicating farm with bank loans as financial resource

Source: Survey data

\subsubsection{Pistachio farmers}

Multiple regressions were undertaken for each of the five RS factors recognized by factor analysis to determine socio-economic variables which influence pistachio farmers' perceptions of RSs. The results represented in Table 5.13 showed the five models which were statistically significant at $1 \%$ level. The goodness-of-fit coefficients of the multiple regression models are higher than those found in previous studies. Therefore, a considerable explanatory power can be detected by socio-economic predictors. The following variables did not reveal 
any significant relationship with any of RS factors: family labour, diversification of farm activity, trees age and manager against partner leadership.

Pistachio occupation was directly related, at $1 \%$ level of significance, to 'production risk' as an important RS. Production risk was sensed relatively more important as farmers become more specialized in pistachio production. This could suggest that pistachio is more affected by production risks, e.g. plant diseases, than other crops including in farm business. In addition, due to the recent precipitation shortage, the establishment of irrigation techniques became an urgent need to compensate this shortage. Thus, high pistachio proportion in rainfed farms requires much more money to cover irrigation cost. Unexpectedly, operators who have their private well gave production risk more concern. This shows that those farmers were seriously concerned with water reduction, particularly if the state prohibits to deepen the existing wells.

Private well ownership and off-farm work existence were inversely associated with 'farm business environment' perceptions, at 1\%o level. Farmers who have their own well and those who earn income from non-agricultural sources were less worried about risks associated with an unfavorable farm business environment. This influences the importance of owned wells as main irrigation water sources to mitigate the potential damage caused by this environment. Income-diversifying is supposed to provide farmers for basic necessities to maintain their farm operations, particularly in the absence of credit desire. It is also implied that off-farm earning enables farmers to be more flexible for coping with changes in the farming environment (Legesse and Drake 2005).

The results also demonstrate that geographic location and farm land were statistically significant, at 5\% level of significance, in explaining variations of farmers' perceptions of farm business environment. Regarding the given environment differentiation between the agro-ecological zones, it is axiomatic to find that farmers in zone 2 were more concerned about the risks associated with such environment. Similarly, risks integrated with farm business environment were perceived at higher importance in the larger farms. This may be attributed to the recent severe climatic effects which resulted in extensive losses of all farms. This finding is similar to the results of Boggess et al. (1985) and Størdal et al. (2007) who concluded that property size makes owners more concerned about factors that influence future economic performance at the property.

Relatively, larger producers were more concerned about market risk factor. Positive relationships were found between market risk and farm size and percentage of pistachio 
occupation. Conversely, Boggess et al. (1985) illustrated that larger farmers were less concerned with market prices since economies of size enable them to survive price variability by making them low-cost producers. In our case study, however, the considerable assessment of market risk among specialized and large producers could reflect the negative impacts of absence of specialist market in pistachio region, in addition to the unexpected state prohibition of pistachio export in some years (Aliqtisadi 2011). Market risk perception has an inverse relationship with scientific materials as knowledge resource. This reflects the turmoil of the pistachio market which makes it impossible for the related agencies to predict pistachio market development.

Table 5.13: Results of multiple regressions for risk source factors against socio-economic variables of pistachio farmers $(n=105)^{a}$

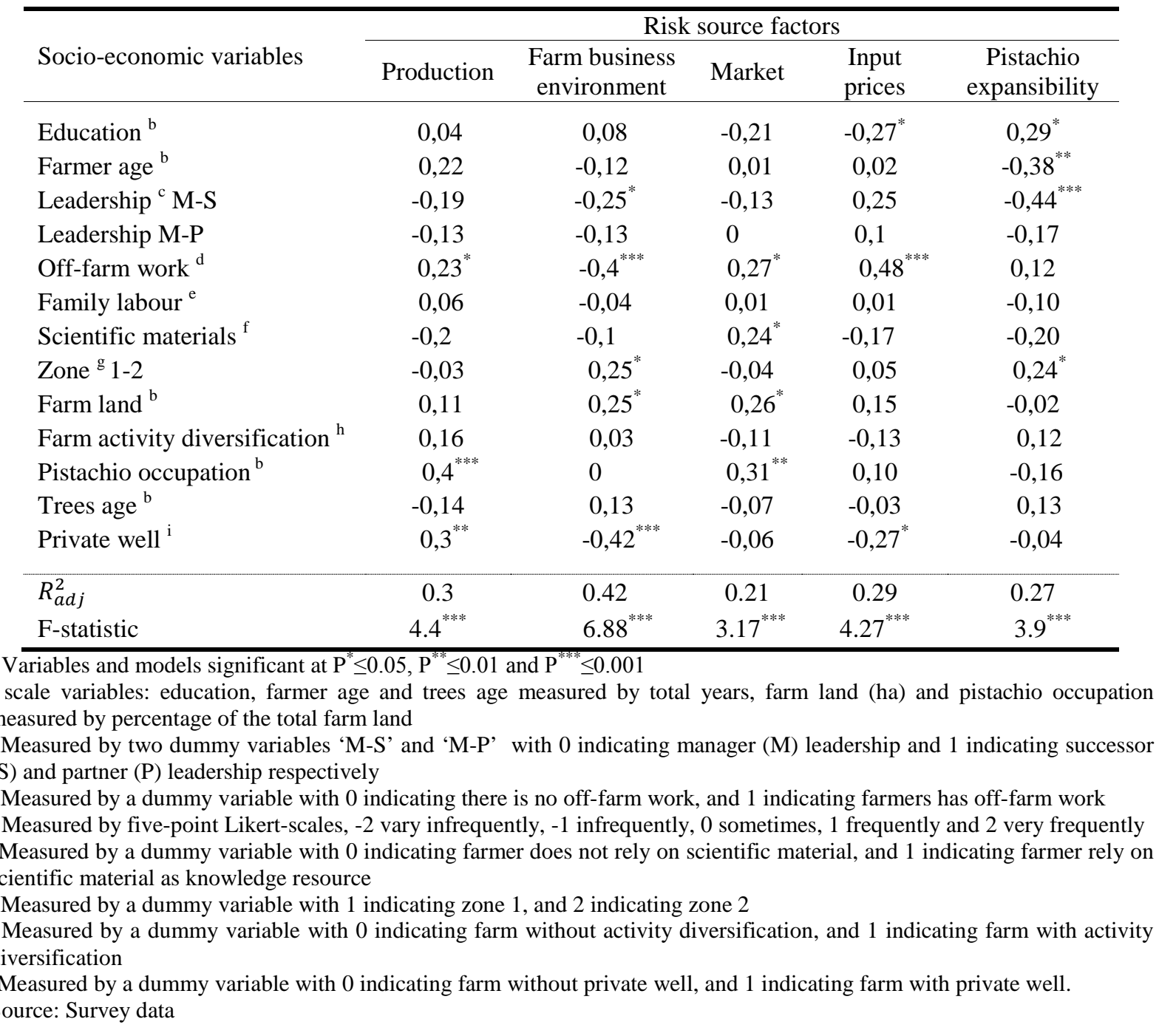

Similar to their concern with market risks, farmers who have off-farm work were also concerned with input prices. Off-farm work coefficient shows a direct significant association with these RSs at $1 \%$ level. This signifies that operators who have additional job have more 
anxiety about the risks that negatively affect the overall household income. Educated farmers and those who have private wells seemed to be less concerned about input costs.

Regarding the perceptions of 'pistachio expansibility', the results show that farmers in zone 2 were more concerned about such an RS. This may suggest that the legalisations of pistachio licences are more stringent in this region. Similarly, educated and young producers as well as farm managers were more willing to expand their farm business. For this reason, they perceived the prohibition of pistachio farm licence as highly relevant.

\subsubsection{Farmers' perceptions of risk management strategies}

\subsubsection{Wheat-cotton farmers}

Socio-economic blend was regressed against each factor of wheat-cotton farmers' perceptions of RMS. By referring to results presented in Table 5.14, several points can be detected. The estimated regression models 3, 4 and 5 have considerable levels of explanatory power compared with results in similar prior studies. Socio-economic variables included in these models interpret 32,36 , and $23 \%$ of the total variance of related risk management factors respectively with statistically significant relationship at $1 \%$ level. Again, agroecological zones played a notable role in the interpretation of farmers' perceptions of risk management strategies. Conversely, farmer age, off-farm work, ownership, activity diversification and bank loans as financial resource do not contribute to the explanation of any of the RMS factors.

Goodness-of-fit of the multiple regression models related to 'diversification' and 'secure income' factors showed low $R_{a d j}^{2}$ values and significant relation with socio-economic variables at $5 \%$ and $1 \%$ levels respectively. This implies the low explanatory power of the selected set of socio-economic variables to elucidate farmers' perceptions of diversification and secure income as favorable RMS. Furthermore, none of socio-economic variables used in this study was able to interpret farmers' perceptions of 'diversification' as RMS; since none of these variables was significant at the $\rho<0.05$ level. This may be attributed to one of two reasons: (1) Farmers' interest of diversification varies according to their personality. (2) Farmers' RA and their perceptions of RS could add the valuable information that reflects their concern about diversification as an RMS.

By a closer look to farmers' perceptions of 'wheat-cotton combination substitution, eight socio-economic variables were strongly associated with it. Results showed that highly educated farmers accepted risks mitigation using replacement of wheat-cotton combination. 
The direct relationship at 5\%, between farmers' education level and their perceptions of 'wheat-cotton combination replacement' suggests that education is able to change the consecrated inherited tradition characterized of this combination in order to mitigate risks.

A negative relationship at 1\%o of significance level can be shown between successor leadership and 'wheat-cotton combination substitution'. This implies that the farm successor was less likely to employ the aforementioned strategy. The same direction of the relationship can be found between this RMS and partner leadership at 5\%. This suggests, corresponding to the former argument about the consecrated belief of wheat-cotton, that successors and/or partners are not accredited to decide the replacement of the wheat-cotton without the managers; agreement.

Furthermore, farmers’ perceptions of ‘wheat-cotton combination substitution’ as RMS varied by farm location. Zones 2 and 3 were found to positively affect the farmers' contentment with wheat-cotton combination replacement at $1 \%$ level. This indicates that the terrible agricultural status quo in zones 2 and 3 imposed operators to accept the abandoning of wheat-cotton combination in order to survive their farm business. The result's table also shows an increased desire to adopt cooperation strategy among farmers in zones 2 and 3 compared to those in zone 1.

Three variables are still significantly related to farmers' perceptions of wheat-cotton combination replacement at 5\% level, family labour and farm land (direct relationship), and rain-fed wheat (inverse relationship). This infers the higher willingness of large producers as well as those who rely on their family as a labour force to replace wheat-cotton combination compared with those who already cultivate wheat as rain-fed crop.

Farm land and location play a considerable role to elucidate the variance of farmers' interest in 'cooperation' as RMS. Cooperative agreements were of greater concern for farmers in zones 2 and 3, at 1\% and 1\%o of significance level respectively, compared to zone 1 . This finding could be attributed to the severe drought that spread over all wheat-cotton producers, particularly large farms in zone 3. This also prompted farmers to intensify their efforts to reduce risks and costs using cheap mechanisms such as cooperation. Managers of larger farms were more likely to rank cooperation as an important response to the complexities that could correspond with the large-scale farms. The inverse relationship between the education level and farmers' perceptions of 'cooperation' strategy at $1 \%$ level, points out that educated farmers were less willing to adopt cooperation mechanisms. This can be interpreted by the absence of well-advised frame needed to control cooperation mechanisms. 
Table 5.14: Results of multiple regressions for risk management strategy factors against socio-economic variables of wheat-cotton farmers $(n=103)^{a}$

\begin{tabular}{|c|c|c|c|c|c|}
\hline \multirow[b]{2}{*}{$\begin{array}{l}\text { Socio-economic } \\
\text { variables }\end{array}$} & \multicolumn{5}{|c|}{ Risk management strategy factors } \\
\hline & Diversification & Cooperation & $\begin{array}{l}\text { Wheat-cotton } \\
\text { combination } \\
\text { substitution }\end{array}$ & $\begin{array}{l}\text { Secure } \\
\text { income }\end{array}$ & $\begin{array}{l}\text { Alternative } \\
\text { markets }\end{array}$ \\
\hline Education ${ }^{\mathrm{b}}$ & -0.20 & $-0.30^{* *}$ & $0.26^{*}$ & 0.13 & 0.23 \\
\hline Farmer age $^{\mathrm{b}}$ & 0.06 & -0.06 & -0.15 & -0.21 & 0.00 \\
\hline Leadership ${ }^{\mathrm{c}} \mathrm{M}-\mathrm{S}$ & 0.21 & 0.21 & $-0.34^{* * *}$ & $-0.29^{*}$ & -0.05 \\
\hline Leadership M-P & 0.19 & 0.08 & $-0.19^{*}$ & 0.02 & -0.15 \\
\hline Off-farm work ${ }^{\mathrm{d}}$ & 0.07 & 0.24 & -0.20 & 0.20 & 0.13 \\
\hline Family labour ${ }^{\mathrm{e}}$ & 0.13 & -0.09 & $0.24^{*}$ & -0.01 & -0.11 \\
\hline Scientific materials ${ }^{\mathrm{f}}$ & -0.11 & 0.18 & 0.14 & $-0.22^{*}$ & -0.02 \\
\hline Zone $^{\mathrm{g}} 1-2$ & -0.14 & $0.31^{* *}$ & $0.55^{* * *}$ & 0.02 & $-0.21^{*}$ \\
\hline Zone 1-3 & -0.08 & $0.44^{* * *}$ & $0.53^{* * *}$ & 0.01 & -0.01 \\
\hline Ownership ${ }^{\mathrm{h}} \mathrm{P}-\mathrm{L}$ & 0.08 & -0.07 & 0.04 & 0.23 & -0.04 \\
\hline Ownership P-R & 0.15 & 0.15 & -0.07 & 0.01 & -0.09 \\
\hline Farm land ${ }^{\mathrm{b}}$ & 0.23 & $0.23^{*}$ & $0.22^{*}$ & 0.06 & 0.17 \\
\hline Activity diversification ${ }^{\mathrm{i}}$ & 0.21 & -0.01 & -0.08 & -0.12 & 0.14 \\
\hline Rain-fed wheat ${ }^{\mathrm{j}}$ & 0.02 & -0.02 & $-0.18^{*}$ & $0.24^{*}$ & $-0.22^{*}$ \\
\hline Bank loan ${ }^{\mathrm{k}}$ & 0.02 & 0.14 & -0.07 & -0.01 & 0.00 \\
\hline$R_{a d j}^{2}$ & 0.13 & 0.32 & 0.36 & 0.18 & 0.21 \\
\hline F-statistic & $2^{*}$ & $4.14^{* * *}$ & $4.83^{* * *}$ & $2.44^{* *}$ & $2.79^{* * *}$ \\
\hline
\end{tabular}

${ }^{a}$ Variables and models significant at $\mathrm{P}^{*} \leq 0.05, \mathrm{P}^{* *} \leq 0.01$ and $\mathrm{P}^{* * * *} \leq 0.001$

${ }^{\mathrm{b}}$ scale variables: education and farmer age measured by total years, farm land (ha)

' Measured by two dummy variables 'M-S' and 'M-P' with 0 indicating manager (M) leadership and 1 indicating successor (S) and partner (P) leadership respectively

${ }^{\mathrm{d}}$ Measured by a dummy variable with 0 indicating there is no off-farm work, and 1 indicating farmers has off-farm work e measured by five-point Likert-scales, -2 vary infrequently, -1 infrequently, 0 sometimes, 1 frequently and 2 very frequently

${ }^{\mathrm{f}}$ Measured by a dummy variable with 0 indicating farmer does not rely on scientific material, and 1 indicating farmer rely on scientific material as knowledge resource

${ }^{g}$ Measured by two dummy variables ' $1-2$ ' and ' $1-3$ ' with 0 indicating zone (1) and 1 indicating zone (2) and zone (3) respectively

${ }^{\mathrm{h}}$ Measured by two dummy variables 'P-L' and 'P-R' with 0 indicating private (P) ownership, and 1 indicating land reform $(\mathrm{L})$ and rental (R) ownership respectively

${ }^{\mathrm{i}}$ Measured by a dummy variable with 0 indicating farm without activity diversification, and 1 indicating farm with activity diversification

${ }^{\mathrm{j}}$ Measured by a dummy variable with 0 indicating farm without rain-fed wheat area, and 1 indicating farm with rain-fed wheat area

${ }^{\mathrm{k}}$ Measured by a dummy variable with 0 indicating farm without bank loans as financial resource, and 1 indicating farm with bank loans as financial resource

Source: Survey data

A direct relationship between rain-fed existence and 'secure income' strategy in comparison to an inverse one related to 'alternative markets' strategy can be noticed. Operators who cultivate parts of their farms by rain-fed wheat were concerned with securing their income by non-agricultural sources more than 'market management'. This is normal given that the last noteworthy rain-fed yield was in 2005. Conversely, market management was accepted as a highly favorable strategy by farmers in zone 1 as opposed to those in zones 2 and 3 (as indicated by negative signs of the zone dummies ' $1-2$ ' and ' $1-3$ '). This seems that farmers in the zone1 exploited water resources abundance in their region to cultivate over the authorized cotton license. Therefore, they looked for markets and brokers to sell illegal 
production behind the state's back. Similarly, farmers in the zone 1 frequently sell part of their wheat production to food industry manufacturers which widely spread in this region.

The successor farmers as well as those who obtained required information from the scientific resources did not reveal an interest with secure income as a relevant RMS.

\subsubsection{Pistachio farmers}

Table 5.15 summarizes three models influencing pistachio farmers' risk management preferences based on socio-economic characteristics. These models that were figured by multiple regressions were carried out for each of the three RMS factors revealed by factor analysis against the farmers' socio-economic profile. Goodness-of-fit of the three multiple regression models was rather high. They record $0.44,0.38$ and 0.31 for 'on-farm management, 'diversification' and 'secure income’ factors, respectively, with statistical significance at 1\%o level for all models. In contrast to its role in the wheat-cotton sample, geographical location represented by agro-ecological zones did not play any significant role in explaining the variance of farmers’ perceptions of RMS. Similarly; farmer age, leadership, knowledge, and the percentage of pistachio occupation did not show any significant relationship with any of the risk management factors (at any considered levels of significance).

Usually, farmers with higher general level of education tend to prefer off-farm activities more than on-farm ones because of their higher qualifications which enable them to enter other economic sectors. Surprisingly, a strong direct relationship was found between farmers' level of formal education and 'on-farm management' strategy at 1\%o level, versus an inverse relationship with secure income strategy at $1 \%$ level. It appears that educated farmers were more willing to mitigate risk impacts through on-farm mechanisms than to look for nonfarm resources to support farm income. This willingness arises from their ability to perfectly employ farm resources capacity to manage their risks.

Operators who already had off-farm work tended to be less concerned with on-farm management strategy (inverse relationship at 1\%o level of significance). This is due to their reliance on off-farm income to supplement their net income in addition to their lacking of required time needed to adopt such on-farm instruments. Vice versa, farms with a high level of farm activity diversification appeared to impress farmers to be less concerned with procurement of off-farm income. Diversification levels were negatively correlated to secure income strategy at $1 \%$ level. 
The contribution of family members to the total farm labour force was positively correlated to farmers' adoption of 'on-farm management' and 'secure income' strategies at $1 \%$ and $5 \%$ levels of significance, respectively. Namely, when the household members contribute most of farm labour force, farms tend to show a high level of diversification. This suggests that family labour force is a catalyst for on-farm activity diversification in wheatcotton farms. The significant and positive relationship between the size of family labour and certain income as RMS could reflect the households desire to diversify their income sources.

Table 5.15: Results of multiple regressions for risk management strategy factors against socio-economic variables of pistachio farmers $(n=105)^{a}$

\begin{tabular}{|c|c|c|c|}
\hline \multirow{2}{*}{ Socio-economic variables } & \multicolumn{3}{|c|}{ Risk management strategy factors } \\
\hline & On-farm management & Diversification & Secure income \\
\hline Education $^{\mathrm{b}}$ & $0,75^{* * *}$ & 0,18 & $-0,39^{* *}$ \\
\hline Farmer age ${ }^{b}$ & $-0,21$ & 0,17 & 0,07 \\
\hline Leadership ${ }^{\mathrm{c}} \mathrm{M}-\mathrm{S}$ & $-0,20$ & 0,15 & $-0,09$ \\
\hline Leadership M-P & $-0,08$ & $-0,06$ & $-0,07$ \\
\hline Off-farm work ${ }^{d}$ & $-0,34^{* * *}$ & $-0,11$ & 0,16 \\
\hline Family labour ${ }^{\mathrm{e}}$ & $0,18^{*}$ & 0,13 & $0,26^{* *}$ \\
\hline Scientific materials ${ }^{\mathrm{f}}$ & $-0,06$ & $-0,04$ & 0,15 \\
\hline Zone $^{\mathrm{g}} 1-2$ & 0,11 & $-0,01$ & 0,09 \\
\hline Farm land ${ }^{\mathrm{b}}$ & 0,05 & $0,28^{* *}$ & $-0,10$ \\
\hline Farm activity diversification ${ }^{\mathrm{h}}$ & 0,12 & 0,08 & $-0,34^{* * *}$ \\
\hline Pistachio occupation ${ }^{\text {b }}$ & 0,03 & $-0,16$ & $-0,13$ \\
\hline Trees age $^{b}$ & 0,11 & $0,38^{* * *}$ & 0,15 \\
\hline Private well ${ }^{\mathrm{i}}$ & $-0,34^{* * *}$ & 0,06 & $-0,15$ \\
\hline$R_{a d j}^{2}$ & 0.44 & 0.38 & 0.31 \\
\hline F-statistic & $7.53^{* * *}$ & $5.9^{* * *}$ & $4.7^{* * *}$ \\
\hline
\end{tabular}

${ }^{a}$ Variables and models significant at $\mathrm{P}^{*} \leq 0.05, \mathrm{P}^{* *} \leq 0.01$ and $\mathrm{P}^{* * *} \leq 0.001$

${ }^{\mathrm{b}}$ scale variables: education, farmer age and trees age measured by total years, farm land (ha) and pistachio occupation measured by percentage of the total farm land

' Measured by two dummy variables 'M-S' and 'M-P' with 0 indicating manager (M) leadership and 1 indicating successor (S) and partner (P) leadership respectively

${ }^{\mathrm{d}}$ Measured by a dummy variable with 0 indicating there is no off-farm work, and 1 indicating farmers has off-farm work

e measured by five-point Likert-scales, -2 vary infrequently, -1 infrequently, 0 sometimes, 1 frequently and 2 very frequently

${ }^{\mathrm{f}}$ Measured by a dummy variable with 0 indicating farmer does not rely on scientific material, and 1 indicating farmer rely on scientific material as knowledge resource

${ }^{\mathrm{g}}$ Measured by a dummy variable with 1 indicating zone 1, and 2 indicating zone 2

${ }^{\mathrm{h}}$ Measured by a dummy variable with 0 indicating farm without activity diversification, and 1 indicating farm with activity diversification

${ }^{\mathrm{i}}$ Measured by a dummy variable with 0 indicating farm without private well, and 1 indicating farm with private well Source: Survey data

The use of diversification as RMS was positively related to the size of the farm. The limited resource base of small farms and corresponding diminishing returns to farm activity is probably the principle cause of farm activities’ limitation (Boggess et al. 1985). Farmers preferred diversification as RMS by increasing the age of the trees. This could refer to farmers’ willingness to replace the aged pistachio trees by other crops. 
Again, a surprise resulted about private well ownership was found in the pistachio farms. Farmers, who own their private wells, tended to classify on-farm management strategy as less relevant. This implies that wells, due to drought effects on the water table, are no longer considered as a critical factor to support the expansion of on-farm activities.

\subsection{Contribution of subjective information to resultant attitudes and perceptions}

After obtaining insights into the role of socio-economic characteristics to interpret farmers' RA, RS, and RMS, the relationships between farmers' subjective beliefs and their attitudes and perceptions were discovered by the multidirectional approach $\mathrm{P} \rightarrow \mathrm{E} / \mathrm{P} \leftrightarrow \mathrm{B}$. The subjective information represented by farmers' RA and their perceptions of RA and RMS were used in the regressions as independent variables in order to optimize the understanding of farmers' attitudes and perceptions themselves.

\subsubsection{Wheat-cotton farmers}

The results of the multidirectional relationship were presented in Table 5.16 under three regressions: (1): RAs as dependent variables were regressed against S-E variables, perceptions of RS and perceptions of RMS as independent variables. (2) Perceptions of RS as dependent variables were regressed against S-E variables, RA and perceptions of RMS as independent variables. (3) Perceptions of RMS as dependent variables were regressed against S-E variables, RA and perceptions and perceptions of RS as independent variables.

Regarding the wheat-cotton farmers' RA, the subjective information contributes to a considerable extent in explaining farmers' RA. Various relationships which provide interesting explanations about farmers' RA were discovered by employing the subjective beliefs in the regressions. As can be seen in Table 5.16, the regression analysis supported the former importance of education and scientific material to interpret farmers' attitudes toward risk. Furthermore, the regression output signified a negative relationship between farmers' RA and their subjective perception of agriculture shrinkage as an RS factor. This presumes that farmers who suffered agricultural degradation as fait accompli, are more risk-averse, conversely operators who believed in the goodness of agriculture are more risk-seeking. This result provides a number of implications. First, it might explain farmers' reluctance to adopt innovations, such as modern irrigation techniques even despite their high subsidization, can be attributed to their desperation of farming effectiveness. Second, since the type of risk itself drives farmers' motivations for accepting risks (Rohrmann 2005), the presence of this 
negative relationship might indicate that farmers’ perceptions of agricultural development was critically determined their attitudes toward risks.

A positive relationship was found between alternative markets as a relevant RMS and farmers' RA. This result confirms the belief that the brokers' existence as an alternative wheat-cotton market could encourage operators to breach the state agricultural plan by overlicensed cotton production. This is itself considered as risky behavior in wheat-cotton farm business.

Subsidy policy was noticed as a critical aspect that affects farmers' willingness to take risk. A positive relationship between farmers' RA and their concern about subsidize lifting, at 1\%o level, was detected. This suggests that farmers' expectations of government support lifting create risk-aversion tendencies among them. The elimination of governmental support burdens farmers more costs which reduce their desire to take more risks.

A positive relationship was observed between farmers' RA and their interest with 'cooperation' as RMS factor. This pointed out that farmers' adoption of cooperation, as important mechanisms to manage risks could enhance their willingness to take risks. Cooperatives in wheat-cotton farming support more stable input prices, particularly after the elimination of governmental support of inputs. Cooperatives have an ability to store large quantities of seeds, fertilizers and pesticides, and supply farmers during the different farm operations at a stable price. Therefore, cooperation as RMS played a considerable role to constitute farmers' willingness to take risk.

Furthermore, cooperation contributed to shaping farmers' perceptions of 'cotton related policy' as a relevant source of risk since a negative relationship was found between the cooperation as RMS and risk of cotton cultivation policy. This assumes that operators who coped with risk using cooperation mechanisms incorporated with others in order to manage cotton irrigation operations such as the establishment of public water reservoir or shared modern irrigation networks; thus they are less likely to expect high losses by cotton cultivation policy.

The subjective beliefs provide very crucial evidences about farmers' preferences of secure income as RMS. Goodness-of-fit of the multiple regression models related to secure income factor increased from 0.18 by limitation with socio-economic variables, to 0.36 by adding the subjective variables of RA and RS perceptions. The regression results revealed a positive relationship between farmers' estimation of secure income strategy and their perceptions of agricultural shrinkage, subsidy policy, cotton related policy and input prices as 
relevant sources of risk. Except agricultural shrinkage, these sources of risk summarize the political risk in wheat-cotton farm business. This exhibits that political risks in wheat-cotton farming significantly threatened the net farm income and, consequently forced farmers to supplement their income either by running the farm as a secondary occupation or by full abandonment. Actually, the risk of frequent and unexpected changes of policies (e.g., cotton license and subsidy policies) poses a high risk of income stability. In addition, farmers are not able to plan for the future and develop strategies suitable for their production under these unpredictable changes. Therefore, off-farm work is a considerable solution to secure income. The positive relationship between subsidy policy and wheat-cotton combination substitution as an appropriate RMS suggests that some farmers change their crop preferences as a final strategy to cope with such a political risk before looking for off-farm alternatives. In this context, it worth mentioning that although subsidy policy played a notable role to explain farmers' inducement of wheat-cotton replacement, socio-economic variables contributed to a large extent in constituting such inducement.

A negative relationship was detected between farmers' recognition of agricultural shrinkage as an RS, and alternative markets as RMS. This indicates that the geographic location was not the only factor that distinguishes farmers' perceptions of agriculture shrinkage. However, marketing restriction by the governmental agencies also enhanced farmers’ assessment of agricultural degradation as an important RS.

Regarding the indicators of Goodness-of-fit of the multiple regression models, 'diversification' and 'alternative market' factors showed low $R_{a d j}^{2}$ values (0.18 and 0.26, respectively). This assumes the low explanatory power of socio-economic variables as well as subjective beliefs of RA and RS in explaining these two RMS factors. This suggests that farmers' contentment with diversification and alternative market varied according to the operators' personality. Similarly, a low $R_{a d j}^{2}$ value was observed for input prices as a risk factor. This result might refer to two aspects, the individualistic nature of farmers' perceptions of such risks and/or the immaturity of farmers' comprehension of input prices risks since such risks are new in strategic crop marketing. 
Table 5.16: Results of multiple regressions for farmers' risk attitude scale, risk source factors and risk management strategy factors of wheatcotton farmers $(\mathrm{n}=103)^{\mathrm{a}}$

\begin{tabular}{|c|c|c|c|c|c|c|c|c|c|c|}
\hline \multirow[b]{2}{*}{ Independent variables ${ }^{\mathrm{b}}$} & \multirow{2}{*}{$\begin{array}{c}\text { Risk } \\
\text { attitude } \\
\text { scale }\end{array}$} & \multicolumn{4}{|c|}{ Risk source factors } & \multicolumn{5}{|c|}{ Risk management strategy factors } \\
\hline & & $\begin{array}{l}\text { Agriculture } \\
\text { shrinkage }\end{array}$ & $\begin{array}{l}\text { Subsidy } \\
\text { policy }\end{array}$ & $\begin{array}{c}\text { Cotton related } \\
\text { policy }\end{array}$ & $\begin{array}{l}\text { Input } \\
\text { prices }\end{array}$ & Diversification & Cooperation & $\begin{array}{c}\text { Wheat-cotton } \\
\text { substitution }\end{array}$ & $\begin{array}{l}\text { Secure } \\
\text { income }\end{array}$ & $\begin{array}{c}\text { Alternative } \\
\text { markets }\end{array}$ \\
\hline 1. Education ${ }^{\mathrm{c}}$ & $0,25^{* *}$ & & & & & & & & & \\
\hline 1. Farmer age ${ }^{c}$ & & & & & & & & & & \\
\hline 1. Leadership ${ }^{\mathrm{d}} \mathrm{M}-\mathrm{S}$ & & & $-0,18^{*-}$ & & $-0,19^{*}$ & & & & & \\
\hline 1. Leadership M-P & & & & & & & & & & \\
\hline 1. Off-farm work ${ }^{\mathrm{e}}$ & & & & & $-0,24^{*}$ & & & & $0,29^{\text {**** }}$ & $0,27^{* *-}$ \\
\hline 1. Family labour ${ }^{\mathrm{f}}$ & & & & & $0,26^{* *}$ & $0,25^{* *}$ & & $0,32^{* * *}$ & & \\
\hline 1. Scientific materials ${ }^{g}$ & $0,26^{* *}$ & & & $-0,27^{* *}$ & $0,23^{*}$ & & & $0,26^{* *}$ & $-0,24^{* *-1}$ & \\
\hline 1. Zone ${ }^{\mathrm{h}} 1-2$ & & $0,26^{* *}$ & & $-0,22^{* *}$ & $0,29^{* * *}$ & & $0,20^{*-}$ & $0,44^{* * *}$ & $-0,32^{\text {**** }}$ & $-0,23^{\text {**- }}$ \\
\hline 1. Zone 1-3 & & $0,56^{* * *}$ & $0,52^{* * *}$ & & & & $0,36^{* * * *}$ & $0,39^{* * *}$ & $-0,43^{* *}$ & \\
\hline 1. Ownership ${ }^{\mathrm{i}} \mathrm{P}-\mathrm{L}$ & & & & & & & & & & \\
\hline 1. Ownership P-R & & & $-0,17^{*}$ & & & $0,23^{*}$ & $0,30^{* * *}$ & & & \\
\hline 1. Farm land ${ }^{\mathrm{c}}$ & & & & & & & & & & \\
\hline 1. Activity diversification ${ }^{j}$ & & & & & & & & & & \\
\hline 1. Rain-fed wheat ${ }^{\mathrm{k}}$ & & $0,20^{*}$ & & & & & & & & \\
\hline 1. Bank loan ${ }^{I}$ & & & & $0,21^{* *}$ & & & & & & \\
\hline 2. Risk attitude scale & & $-0,22^{* *}$ & $0,24^{* * *}$ & & & & & & & $0,32^{* * *}$ \\
\hline 3. Agriculture shrinkage & $-0,29^{* * *}$ & & & & & & & & $0,54^{* * *}$ & \\
\hline 3. Subsidy policy & & & & & & & & $0,31^{* *}$ & $0,39^{* * *-1}$ & \\
\hline 3. Cotton related policy & & & & & & & $-0,38^{* * *-1}$ & & & \\
\hline 3. Input prices & & & & & & $-0,30^{* * *}$ & & & $0,26^{* *-1}$ & \\
\hline 4. Diversification & & & & & $-0,29^{* *}$ & & & & & \\
\hline 4. Cooperation & $0,28^{* * *}$ & & & $-0,44^{* * *}$ & & & & & & \\
\hline 4. wheat-cotton substitution & & & $0,17^{*-}$ & & & & & & & \\
\hline 4. Secure income & & $0,24^{* *}$ & $0,17^{*}$ & $0,16^{*}$ & $0,29^{* *}$ & & & & & \\
\hline 4. Alternative markets & $0,18^{*}$ & $-0,17^{*}$ & & & & & & & & \\
\hline$R_{a d j}^{2}$ & $0.43^{* * *}$ & $0.49^{* * *}$ & $0.49^{* * *}$ & $0.43^{* * *}$ & $0.28^{* * *}$ & $0.18^{* * *}$ & $0.40^{* * *}$ & $0.35^{* * *}$ & $0.36^{* * *}$ & $0.26^{* * *}$ \\
\hline
\end{tabular}

${ }^{\mathrm{a}}$ Variables and models significant at $\mathrm{P}^{*} \leq 0.05, \mathrm{P}^{* *} \leq 0.01$ and $\mathrm{P}^{* * * *} \leq 0.001$

b ' 1 ' refers to socio-economic variables, ' 2 ' refers to risk attitude scale, ' 3 ' refers to risk source factors, ' 4 ' refers to risk management strategy factors

${ }^{\mathrm{c}}$ Scale variables: education and farmer age measured by total years, farm land (ha)

${ }^{\mathrm{d}}$ Measured by two dummy variables 'M-S' and 'M-P' with 0 indicating manager (M) leadership and 1 indicating successor (S) and partner (P) leadership respectively

e, g, , , k, ' Measured by a dummy variable with 0 indicating "NO", and 1 indicating "YES"

${ }_{\mathrm{f}}^{\mathrm{f}}$ Measured by five-point Likert-scales, -2 vary infrequently, -1 infrequently, 0 sometimes, 1 frequently and 2 very frequently

${ }^{\mathrm{h}}$ Measured by two dummy variables ' $1-2$ ' and ' $1-3$ ' with 0 indicating zone (1) and 1 indicating zone (2) and zone (3) respectively

${ }^{i}$ Measured by two dummy variables 'P-L' and 'P-R' with 0 indicating private (P) ownership, and 1 indicating land reform (L) and rental (R) ownership respectively. Source: Survey data 


\subsubsection{Pistachio farmers}

The results of multidirectional relationships in pistachio sample are shown in Table 5.17. In contrary to the wheat-cotton sample, the subjective information related to pistachio farmers' RA and their perceptions of RS and RMS did not reveal a high magnitude to influence the attitudes and the perceptions themselves.

As can be seen in Table 5.17, the regression analysis did not reveal any significant relationship between farmers' RA and their perceptions of RS and RMS. This denotes that farm and farmer characteristics included in this study were more valuable to determine the pistachio farmers' attitudes toward risk. These characteristics explained $26 \%$ of the total variance of farmers' RA, which indicates the complex and individualistic nature of such attitudes. This finding is parallel to those of other studies, for instance, Pennings and Garcia (2001), Gómez-Limón et al. (2003), Serra et al. (2008) and Koundouri et al. (2009). They concluded that farmers' attitudes toward risks seem to be the result of intrinsic causes such as intentions, personal and psychological characteristics rather than socio-economic factors.

A similar observation was noticed for 'farm business environment' and 'input prices' as RS factors, and 'secure income' as RMS factor. For the other RA and RMS factors, the models revealed the superiority of objective data (socio-economic variables) compared to the subjective information to form farmers’ perceptions.

A positive relationship was observed between 'on-farm management' adoption and 'production' and 'pistachio expansibility' as RMS. This result could be interpreted by two different dimensions. First, on-farm instruments were valuated higher by producers who perceived the production risk as a significant concern. Second, farmers' inventiveness in such on-farm implementations enhanced their willingness to expand their pistachio business; consequently they were more concerned with restrictions of pistachio expansion. Furthermore, subjective beliefs of farmers' RA significantly contributed to build their comprehensions of dealing with risks by on-farm management. A positive relationship was revealed between RA scale and on-farm management factor.

Surprisingly, farmers who perceive a high pistachio market risk appeared to consider the diversification strategy as less important. In fact, farm diversification is considered as a crucial strategy to mitigate market risks. Conversely, market risk negatively affected the farmers’ desire to run a more diversified pistachio enterprise. 
Table 5.17: Results of multiple regressions for farmers' risk attitude scale, risk source factors and risk management strategy factors of pistachio farmers $(n=105)^{\text {a }}$

\begin{tabular}{|c|c|c|c|c|c|c|c|c|c|}
\hline \multirow[b]{2}{*}{ Independent variables ${ }^{\mathrm{b}}$} & \multirow{2}{*}{$\begin{array}{c}\text { Risk } \\
\text { attitude } \\
\text { scale }\end{array}$} & \multicolumn{4}{|c|}{ Risk source factors } & \multicolumn{4}{|c|}{ Risk management strategy factors } \\
\hline & & Production & $\begin{array}{c}\text { Farm business } \\
\text { environment }\end{array}$ & Market & $\begin{array}{c}\text { Input } \\
\text { prices }\end{array}$ & $\begin{array}{c}\text { Pistachio } \\
\text { expansibility }\end{array}$ & On-farm management & Diversification & $\begin{array}{l}\text { Secure } \\
\text { income }\end{array}$ \\
\hline 1. Education ${ }^{\mathrm{c}}$ & $0,46^{* * *}$ & & & & & & $0,62^{* * *}$ & & $-0,22^{*}$ \\
\hline 1. Farmer age ${ }^{c}$ & & $0.39^{* * *}$ & & & & & & & \\
\hline 1. Leadership ${ }^{\mathrm{d}} \mathrm{M}-\mathrm{S}$ & & & $-0,19^{*}$ & & & $-0,35^{* * *}$ & & & \\
\hline \multicolumn{10}{|l|}{ 1. Leadership M-P } \\
\hline 1. Off-farm work ${ }^{\mathrm{e}}$ & & $0.21^{*}$ & $-0,42^{* * *}$ & $0,2^{*}$ & $0,38^{* * *}$ & $0,25^{* *}$ & $-0,43^{* * *}$ & & \\
\hline 1. Family labour ${ }^{f}$ & & & & & & & $0,25^{* * *}$ & $0,15^{*}$ & $0,27^{* *}$ \\
\hline 1. Scientific materials ${ }^{\mathrm{g}}$ & & & & & $-0,21^{*-}$ & & & & \\
\hline 1. Zone ${ }^{\mathrm{h}} 1-2$ & & & $0.27^{* *}$ & & & & & & \\
\hline 1. Farm land ${ }^{\mathrm{C}}$ & $-0,18^{*}$ & & $0.25^{* *}$ & $0,4^{* * *}$ & & & & $0,44^{* *}$ & \\
\hline 1. Activity diversification ${ }^{\mathrm{i}}$ & $0,23^{*}$ & & & & & & & & $-0,3^{* * *}$ \\
\hline 1. Pistachio occupation & & $0,36^{* * *}$ & & $0,37^{* * *}$ & & $-0,17^{*-}$ & & & \\
\hline 1. Trees age $^{\mathrm{c}}$ & $0,36^{* * *}$ & & & & & & & $0,37^{* * *}$ & $0,23 *$ \\
\hline 1. Private well ${ }^{\mathrm{j}}$ & & $0,41^{* *}$ & $-0,42^{* * *}$ & & $-0,34^{* * *}$ & & $-0,37^{* * *}$ & & $-0.21^{*-}$ \\
\hline 2. Risk attitude scale & & & & & & & $0,15^{*}$ & & \\
\hline 3. Production & & & & & & & $0,25^{* * *}$ & & \\
\hline \multicolumn{10}{|c|}{ 3. Farm business environment } \\
\hline 3. Market & & & & & & & & $-0,28^{* * *}$ & \\
\hline \multicolumn{10}{|l|}{ 3. Input prices } \\
\hline 3. Pistachio expansibility & & & & & & & $0,35^{* * *}$ & & \\
\hline 4. On-farm management & & $0.19^{*}$ & & & & $0,37^{* * *}$ & & & \\
\hline 4. Diversification & & & & $-0.23^{*}$ & & & & & \\
\hline \multicolumn{10}{|l|}{ 4. Secure income } \\
\hline$R_{a d j}^{2}$ & $0.26^{* * *}$ & $0.32^{* * *}$ & $0.43^{* * *}$ & $0.29^{* * *}$ & $0.27^{* * *}$ & $0.23^{* * *}$ & $0.57^{* * *}$ & $0.41^{* * *}$ & $0.32^{* * *}$ \\
\hline
\end{tabular}

${ }^{a}$ Variables and models significant at $\mathrm{P}^{*} \leq 0.05, \mathrm{P}^{* * *} \leq 0.01$ and $\mathrm{P}^{* * * *} \leq 0.001$

b ' 1 ' refers to socio-economic variables, ' 2 ' refers to risk attitude scale, ' 3 ' refers to risk source factors, ' 4 ' refers to risk management strategy factors

' scale variables: education, farmer age and trees age measured by total years, farm land (ha) and pistachio occupation measured by percentage of the total farm land

${ }^{\mathrm{d}}$ Measured by two dummy variables 'M-S' and 'M-P' with 0 indicating manager (M) leadership and 1 indicating successor (S) and partner (P) leadership respectively

e , g, i , j Measured by a dummy variable with 0 indicating there is no off-farm work, and 1 indicating farmers has off-farm work

${ }^{\mathrm{f}}$ measured by five-point Likert-scales, -2 vary infrequently, -1 infrequently, 0 sometimes, 1 frequently and 2 very frequently

${ }^{\mathrm{h}}$ Measured by a dummy variable with 1 indicating zone 1 , and 2 indicating zone 2

Source: Survey data 


\section{CONCLUSIONS AND IMPLICATIONS}

The agricultural sector plays an important role in the Syrian economy. In general, the agricultural business environment is fundamentally changing due to the natural disasters caused by the climate change phenomena, and agricultural liberalization. This changeable environment confronts the Syrian agriculture, as many of developing and emerging countries, with high risks which negatively impact the farmers' income as well as the national economy. Therefore, new risk management strategies are needed to stabilize the agricultural sector as well as farm households. These strategies are now more and more being developed. In order to support policy makers, advisors, and developers of risk management strategies to improve appropriate management tools, our study sought to provide empirical insights using Syrian wheat-cotton and pistachio farmers as an example. The analysis was done under two objectives: (1) Identification of farmers' attitudes toward risks, perceptions of risk sources and preferences of risk management strategies. (2) Investigation of factors that cause such attitudes and perceptions. This chapter summarizes the most important findings generated throughout the research process and concludes with their implications for researchers and policy-makers.

Wheat-cotton farmers, whose income is entirely dependent on the cash flow from farm production, were more likely risk-averse than in pistachio farmers which could be better described as risk-neutral farmers.

Regarding the result of risk sources’ perceptions, it seems that it is generally accepted for both wheat-cotton and pistachio, that rainfall shortage and fuel price increase were the most important risk sources that threaten the Syrian agriculture. This was despite that pistachio is only partly irrigated compared to cotton which is a totally irrigated crop. This finding reflects that precipitation and fuel price seemed to be perceived as widespread challenges which curb the agricultural development in Syria regardless to production system and geographical location. This general consensus about the two most important RS, however, does not mean that the agricultural status quo is equal in wheat-cotton and pistachio regions. Risks of 'farm business effectiveness decline' and 'farm insolvency' were ranked at the fourth and fifth level of importance among wheat-cotton farmers, whereas, pistachio producers did not expect these two scenarios in their farms. This lets us simply conclude that the risk environment surrounding wheat-cotton regions reaches a critical hump since agriculture is the main source of livelihood in such regions. 
Regarding wheat-cotton area, it is characterized by frequent droughts which adversely affect the yield and increase the operating costs and thus lead to devastating consequences for net farm income. With such a downturn, some bankruptcies are likely to occur, and farmers who are highly leveraged and have no off-farm income, such as the majority of wheat-cotton farmers, would be most vulnerable

In addition to decreasing rainfall average and increasing fuel price, restriction of cotton license is perceived the third important source of risk in case of wheat-cotton farmers. Nevertheless, large numbers of interviewed wheat-cotton farmers exceeded the legal cotton license. This implies that the dry winter forces wheat-cotton farmers to irrigate their wheat in this season, thus, increasing wheat production costs close to the level of cotton. Given that state cotton price is higher than the wheat price, consequently, under the same production costs, cotton is more profitability than wheat.

Large scope of previous literatures such as Dillon and Scandizzo (1978), Binswanger (1980) and Anderson and Hazell (1997) suggested that risk-averse farmers are more willing to seek various risk management alternatives in order to avoid risk exposure. Surprisingly, despite their risk-averse nature, wheat-cotton farmers were less desired toward the adoption of management tools. Out of 15 risk management strategies, only the diversification was totally preferred by wheat-cotton operators. Moreover, ‘farming as a secondary occupation' and 'faming forsaking' were acceptable by almost half of interviewed farmers. The employment of modern irrigation techniques was highly refused. These indicators reflect the prevailing despair toward risk treatment in which cause to constrict the agriculture in wheat-cotton sites.

Some general recommendations may be drawn to wheat-cotton farmers' terrible condition. Theses farmers need to be supported by a specific policy which takes into account the specificity of the risks the farms are exposed to and wheat-cotton farmers' nature. The policy makers have carefully to consider the three following aspects in their policy planning, the high share of rural poverty and unemployment, natural resource limitation and insufficient human resource qualification. Additionally, it could be better for policy makers to deal with risks of drought, fuel price and cotton license, as one combination. It is common knowledge that the modern irrigation practices play a crucial role in saving the groundwater, particularly ongoing water scarcity along with growing intensity of agriculture and water use. It seems logical, therefore, to apply such techniques for Syrian agriculture. In order to encourage the farmers to use them, the agricultural policies in wheat-cotton regions may precondition the adoption of modern irrigation tools to supply farms with fuel at the full subsidised price. 
Furthermore, modern irrigation equipment could be governmentally introduced as tax-exempt loans. Thereby, the net farm income will become higher as the irrigation cost becomes lower. Consequently, by these suggested procedures, farmers may be satisfying in cultivation the cotton as the cotton license. The government may offer insurance or similar schemes as financially sustainable. Additionally, further researches in breeding programs should be directed toward the improvement of drought resistant varieties.

The results of our research revealed that wheat-cotton farmers were less concerned about plant pests and diseases. They believe that all wheat-cotton diseases and insects are under control, particularly Earias insulana boisd. They achieve the management of such problem by using Turkish varieties of cotton seeds which are more resistant to pests than the Syrian varieties, and by applying the biological control which is governmentally supported in cotton fields. However, due to stem rust Ug99, Al Hasakah governorate lost about $70 \%$ of the wheat production in 2010, the year after the questionnaire time (Damaspost 2010). This indicated the importance of improvement of technology package with drought as well as rustresistant varieties

Contrary to wheat-cotton, pistachio producers seem to be more satisfied with their farm income, thus they did not find a necessity to supplemented it or replace it by non-farm income. This displays the reasons for the lowest level of agreement of 'gradual substitution of pistachio trees with another crop', 'farming as a secondary occupation' and 'faming forsaking'.

Although the 'input prices' and 'variability and decrease of pistachio market prices' were perceived as relevant risks by pistachio producers, the 'forward contract with traders or food manufacturers' is not perceived as a preferred option. This reveals the negative impact of the absence of market instruments' in Syria. The country, thus, is characterized by incomplete markets (Cafiero 2007). Furthermore, most of the pistachio farmers preferred to inquire for futures and market options in order to mitigate price risk. This reminds policy makers that information access, for finance and marketing decision-making, is important to the success for many pistachio producers.

The relationships between socio-economic characteristics of farmers and their risk attitudes and perceptions of risk sources and risk management strategies, revealed some significant insights. The geographical location represented by agro-ecological zones was significantly related to wheat-cotton farmers' perceptions of risk sources and risk management strategies. This indicates that policy makers and advisors should consider the 
substantial differences between zones when developing policies and recommendations. For instance, farmers in zone 3 perceived the shrinkage of agriculture as a strong threat in their region. Furthermore, they have less ability to apply risk management practices in their farms compared to those in zones 1 and 2. This reality may encourage policy developers to supply wheat-cotton farmers in zone 3 with higher levels of subsidies than farmers in zones 1 and 2. Level of formal education and farmers' reliance on scientific materials as information resource were positively stimulated wheat-cotton farmers to take risks. Moreover, farmers who used to consult the scientific stuff of the accessible research centers or follow the scientific references to answer their questions were more able to cope with risks. For instance, they perceived the factor of cotton related policy as less important risk source. Since irrigation modernization policy was an important item in cotton related policy, this means that they agreed to adopt modern irrigation practices in their farms. This conclusion confirms that despite their low education level, scientific materials are very important to persuade farmers with urgent skills which are necessary to save their farm business. Thereby, MAAR could establish widespread scientific centers along with scientific books and journals libraries in wheat-cotton regions.

On the contrary, scientific materials did not play a significant role in order to explain farmers' attitudes and perceptions in pistachio sites. Education level of pistachio farmers was more critical to determine their attitudes and perceptions than scientific information. Farmers' attitudes toward risks were positively related to the age of pistachio trees. Pistachio farmers' perceptions of risk sources and risk management strategies were not affected in any way by agro-climatic zones. Variables such off-farm work, farm land and wells ownership had considerable relationships with such perceptions. Furthermore, the availability of family labour enhanced the willingness of pistachio farmers to try risk management alternatives.

Our findings also provide new evidences on the relationships between subjective beliefs and both risk attitudes and perceptions for wheat-cotton samples. These evidences provide policy makers a wide prospect in order to optimize risk management strategies. For instance, wheat-cotton farmers' subjective beliefs about the shrinkage of agriculture as an important risk source factor were negatively related to their attitudes toward risks. Conversely, wheat-cotton farmers' perceptions of cooperation as a preferred risk management strategy were positively affected their willingness to take risks. Furthermore, wheatcotton farmers who were more (less) interested in cooperation tended to perceive greater (smaller) importance of 'cotton related policy' as a relevant source of risk. 
In the contrast, the subjective information did not significantly contribute to pistachio farmers' attitudes and perceptions. None of the subjective variables was able to explain their attitudes toward risk. The only insights that turned out to be useful for risk management developers were the significant positive relationships between on-farm management, as risk management strategy, and production, environment and pistachio expansibility as risk sources.

In general, for both wheat-cotton and pistachio farmers, the classification of the resultant attitudes and perceptions based on their socio-economic characteristics was not possible. The reasons for that were the low $R_{a d j}^{2}$ values associated with the multiple regression models. Therefore, the conclusion of previous researches, that risk attitudes and perceptions are highly farmer-specific, cannot be rejected. The highly complex and individualistic nature of risk attitudes and perceptions, however, is not the final discovery. The investigation in subjective beliefs in multidirectional relationships leads to a new room of explanations. Thus, more employment of such beliefs and relationships could be recommended for further studies in order to gain more in depth insights.

Regarding the farmer-specific nature of the resultant attitudes and perceptions, further farm and farmer-specific variables could by suggested for further researches. For instance, farmers' goals, aspirations, expectations, cognitive bias, emotions and feelings could be useful. Hardaker et al. (1997, p. 15) illustrated that "farmers in developing countries may be very averse to risk". Conceivably, wealth indicators (farm and off-farm income, and asset endowment) may add more clarification about farmers' attitudes and perceptions. A number of indicators related to agro-ecological zones such as rainfall time and frequency, soil fertility and depth of underground water could be useful since zones notably reflected risk attitudes and perceptions.

Given individuals’ attitudes and perceptions are functions of the time (Van Raaij 1881; Gómez-Limón et al. 2003; Xu et al. 2005) the continuous researches are essential in such field study.

Finally, Pidgeon (1998, p. 5) confirmed that "careful assessments of risk are necessary conditions for guiding policy decisions”. If successful, this research is valuable for researchers, advisors, policy makers and risk management developers in Syria as well as similar conditions countries to understand the details about of farmers' risk attitudes perceptions. 


\section{BIBLIOGRAPHY}

Acton, Q. A. (2012). Agrochemicals-Advances in Research and Application: 2012 Edition. Scholarly Editions.

Ada, T., Malcolm, B., and Williams, J. (2006). A survey of price risk management in the Australian cotton industry. Australasian Agribusiness Review, 14.

Aditto, S. (2011). Risk analysis of smallholder farmers in central and north-east Thailand. PhD thesis. Lincoln University, New Zealand.

Aditto, S., Gan, C. and Nartea, G. V. (2012). Sources of Risk and Risk Management Strategies: The Case of Smallholder Farmers in a Developing Economy. Edited by Nerija Banaitiene, 449 .

Aimin, H. (2010). Uncertainty, risk aversion and risk management in agriculture. Agriculture and Agricultural Science .Procedia, 1, 152-156.

Akanda, A., Freeman, S. and Placht, M. (2007). The Tigris-Euphrates River Basin: Mediating a Path Towards Regional Water Stability. The Fletcher School Journal for issues related to Southwest Asia and Islamic Civilization. Tufts University. Medford. United States. URL: http://fletcher.tufts.edu/AlNakhlah/Archives/ /media/Fletcher/Microsites/ al\%20Nakhlah/archives/pdfs/placht-2.pdf. Accessed: 14.07.2013.

Akcaoz, H. and Ozkan, B. (2005). Determining risk sources and strategies among farmers of contrasting risk awareness: A case study for Cukurova region of Turkey. Journal of arid environments, 62(4), 661-675.

Alhasan, H. and Alnoaimi, Q. (2004). Land tenure CBS. Central Bureau of Statistics. Syria. URL: http://cbssyr.sy/studies/st19.pdf. Accessed: 17.09 2013. (Arabic).

Ali, J. and Kapoor, S. (2008). Farmers' perception on risks in fruits and vegetables Production: An empirical study of Uttar Pradesh. Agricultural economics research review, 21.

Aliqtisadi. (2011). Arabic elcetronic magazine. http://aliqtisadi.com/ Accessed: 14.01.2014.

Al-Shareef, M. (2007). Comparative advantages of pistachio. National Agricultural Policy Center. Damascus. Working paper, 30.

Altinbilek, D. (2004). Development and management of the Euphrates-Tigris Basin. International Journal of Water Resources Development. 20 (1). 15-33. URL: $\quad$ http://www.tandfonline.com/doi/pdf/10.1080/07900620310001635584. Accessed: 15.08.2013. 
Anderson, J. R., Dillon, J. L. and Hardaker, B. (1977). Agricultural decision analysis. Ames: The Iowa State University Press.

Anderson, J. R. (1997). An 'ABC' of risk management in agriculture: overview of procedures and perspectives. In: Huirne, R. B. M., Hardaker, J. B. and Dijkhuizen, A. A. (Eds.). Risk management strategies in agriculture: state of the art and future perspectives. Backhuys Publishers, Mansholt Institute, Wageningen, The Netherlands, pp. 1-13.

Anderson, J. R. and Hazell, P. B. R. (1997). Risk considerations in agricultural policymaking. In: Huirne, R. B. M., Hardaker, J. B. and Dijkhuizen, A. A. (Eds.). Risk management strategies in agriculture: state of the art and future perspectives. Backhuys Publishers, Mansholt Institute, Wageningen, The Netherlands, pp. 273-284.

Anosike, N. and Coughenour, C. M. (1990). The Socioeconomic basis of farm enterprise diversification decisions1. Rural sociology, 55(1), 1-24.

AOAD. Arab Organization for Agricultural Development. (2011). Annual report on Arab food security. URL: http://www.aoad.org/Arab_food_security_report_\%202011.pdf. Acessed: 12.07.2013.

Arrow, K. E. (1971). Essays in the theory of risk-bearing, Markham Publishing company.

Atiya, B. (2007). Comparative advantages of live sheep meat. NAPC. National Agricultural Policy Center. Working paper. 29. FAO project GCP/SYR/006/ITA - Phase II. URL: http://napcsyr.net/dwnldfiles/working_papers/en/29_sheep_comp_adv_ba_en.pdf. Accessed: 09.10.2010.

Australian/New Zealand Standards (2004). Risk management guidelines companion to AS/NZS 4360. Standards Australia International Ltd, GPO Box 5420, Sydney, NSW 2001 and Standards New Zealand, Private Bag 2439, Wellington 6020.

Ayinde, O. E. (2008). Effect of socio-economic factors on risk behaviour of farming households: an empirical evidence of small-scale crop producers in Kwara State, Nigeria. Agricultural Journal, 3(6), 447-453.

Baccarini, D. and Archer, R. (2001). The risk ranking of projects: a methodology. International Journal of Project Management, 19(3), 139-145.

Backhaus, K., Erichson, B., Plinke, W., and Weiber, R. (2008). Multivariate Analysemethoden - eine anwendungsorientierte Einfuehrung. Berlin/Heidelberg: Springer. 
Bakhshoodeh, M. and Shajari, S. (2006). Adoption of new seed varieties under production risk: an application to rice in Iran. Poster prepared for presentation at the International Association of Agricultural Economists, Gold Coast, Australia.

Bard, S. K. and Barry, P. J. (2000). Developing a scale for assessing risk attitudes of agricultural decision makers. The International Food and Agribusiness Management Review, 3(1), 9-25.

Bardhan, D., Dabas, Y. P. S., Tewari, S. K. and Kumar, A. (2006). An assessment of risk attitude of dairy farmers in Uttaranchal (India). In Agricultural Economists Conference, pp. 12-18.

Bardsley, P. and Harris, M. (1987). An Approach to the economic estimation of attitudes to risk in agriculture. Australian Journal of Agricultural and Resource Economics, 31(2), 112-126.

Barry P. J. (Ed). (1984). Risk Management in Agriculture. Iowa State University Press, Ames, Iowa.

Barry, P. J. and Fraser, D. R. (1976). Risk management in primary agricultural production: methods, distribution, rewards, and structural implications. American Journal of Agricultural Economics, 58(2), 286-295.

Baquet, A. E., Hambleton, R. and Jose, D. (1997). Introduction to risk management: understanding agricultural risks: production, marketing, financial, legal, human resources. US Department. of Agriculture, Risk Management Agency.

Beaumont, P. (1996). Agricultural and environmental changes in the upper Euphrates catchment of Turkey and Syria and their political and economic Implications. Applied Geography. 16(2). 137-157.

Belitz, H. D., Grosch. W. And Schieberle, P. (Eds.). (2009). Food chemistry. 4th edition. Springer-Verlag Berlin, Germany.

Bell, D. E. and Raiffa, H. (1988). Risky choice revisited, In: Bell, D. E., Raiffa, H. and Tversky, A. (Eds.). Decision making, descriptive, normative and prescriptive interactions. Cambridge University Press, Cambridge, UK, pp. 99112.

Bennett, A. and Marston, D. (2008). Syrian Arab Repuplic: staff report for the 2008 article IV consultation. IMF. International Monetary Fund. Washington. D.C.. $\begin{array}{llll}\text { Country } & \text { Report } & \text { No. } & 09 / 55 .\end{array}$ URL: http://www.imf.org/external/pubs/ft/scr/2009/cr0955.pdf. Accessed: 17.07.2013.

Berg, E. and Kramer, J. (2008). Policy options for risk management. In: Meuwissen, M. P., Van Asseldonk, M. A., and Huirne, R. B. (Eds.). Income stabilisation in European agriculture: design and economic impact of risk management tools. Wageningen Academic Pub. 
Bickerstaff, K. and Walker, G. (2001). Public understandings of air pollution: the localisation'of environmental risk. Global Environmental Change, 11(2), 133145.

Binici, T. (2001). The risk anitudes of farmers and the socioeconomic factors reflecting them: a Case study for Lower Seyhan Plain farmers in Adana Province, Turkey.

Binswanger, H. P. (1980). Attitudes toward risk: experimental measurement in rural India. American Journal of Agricultural Economics, 62(3), 395-407.

Boggess, W. G., Anaman, K. A. and Hanson, G. D. (1985). Importance, causes and management responses to farm risks: evidence from Florida and Alabama. Southern .Journal of Agricultural Economics, 17(2), 105-16.

Bond, G. E. and Wonder, B. (1980). Risk attitudes amongst Australian farmers. Australian Journal of Agricultural and Resource Economics, 24(1), 16-34.

Botterill, L. and Mazur, N. (2004). Risk and risk perception: a literature review. Project No. BRR-8A, Rural Industries Research and Development Corporation, Barton.

Breisinger, C. and Diao, X. (2008). Economic transformation in theory and practice: what are the message for Africa? IFPRI. International Food Policy Research Institute. Discussion Paper 00797. Washington. DC. URL: $\quad$ http://www.ifpri.org/sites/default/files/publications/ifpridp00797.pdf. Accessed 17.07.2013.

Breisinger, C., van Rheenen, T., Ringler, C., Nin Pratt, A., Minot, N., Aragon, C., Yu, B., Ecker, O. and Zhu, T. (2010). Food security and economic development in the Middle East and North Africa: current state and future north prespective. IFPRI. International Food Policy Research Institute. Discussion paper 00985. Washington. URL: $\quad$ http://www.ifpri.org/sites/default/files/publications/ifpridp00985.pdf. Accessed 17.07.2013.

Breisinger, C., Zhu, T., Al Riffai, P., Nelson, G., Robertson, R. and Funes, J. (2011). Glopal and local economic impacts of climate change in Syria and options for adaptation. IFPRI. International Food Policy Research Institute. Discussion paper $\quad 01091 . \quad$ Washington. DC. URL: $\quad$ http://www.ifpri.org/sites/default/files/publications/ifpridp01091.pdf. Accessed: 01.03.2013.

Brorsen, B. W . (1995). Optimal hedge ratios with risk-neutral producers and nonlinear borrowing costs. American Journal of Agricultural Economics, 77(1), 174-181.

Cafiero, C. (2003). Agricultural Policies in developing countries. NAPC. National Agricultural Policy Center. Training materials. FAO project GCP/SYR/006/ITA - Phase II. URL: http://napcsyr.net/dwnld- 
files/training_materials/en/tm_ag_pol_developing_countries_en.pdf. Accessed: 31.05.2013.

Cafiero, C. (2007). Agricultural risk management in market oriented economy: the challenges for Syrian agricultural policy. An agricultural policy forum. National Agricultural Policy Center, (NAPD). Damascus. proceeding No 23. URL: $\quad$ http://www.napcsyr.net/dwnldfiles/proceedings/en/23_ag_risk_mang_en.pdf. Accessed: 02.05.2008.

CBS. Central Bureau of Statistics. Syria. (2009). Statistical abstract. 2010. URL: http://cbssyr.sy/index-EN.htm. Accessed: 12.052013.

CBS. Central Bureau of Statistics. Syria. (2010). Statistical abstract. 2010. URL: http://cbssyr.sy/index-EN.htm. Accessed: 12.052013.

CBS. Central Bureau of Statistics. Syria. (2011). Statistical abstract. 2011. URL: http://cbssyr.sy/index-EN.htm. Accessed: 12.052013.

CEDARE. Centre for Environment and Development for Arab Region and Europe. (2009). Report: country specific social and economic conditions for farming systems in Mediterranean partner countries. Presented to European commission. URL: http://www.swup-med.dk/Deliverables/ /media/SwupMed/Docs/pdf/D51.ashx. Accessed: Accessed 17.07.2013.

Chavas, J. P. and Holt, M. T. (1990). Acreage decisions under risk: the case of corn and soybeans. American Journal of Agricultural Economics, 72(3), 529-538.

Chavas, J. P. and Holt, M. T. (1996). Economic behavior under uncertainty: A joint analysis of risk preferences and technology. The review of economics and statistics, 78(2), 329-35.

Cowell, F. A. and Schokkaert, E. (2001). Risk perceptions and distributional judgments. European Economic Review, 45(4), 941-952.

Cox, S., and Flin, R. (1998). Safety culture: philosopher's stone or man of straw?. Work and Stress, 12(3), 189-201.

CRED. Center for Research on the Epidemiology of Disaster. (2009). The International Disaster Database. Result for Country Profile: Syrian Arab Republic. URL: www.emdat.be/result-country-profile. Accessed: 23.07.2013.

Croppenstedt, A., Demeke, M. and Meschi, M. M. (2003). Technology adoption in the presence of constraints: the case of fertilizer demand in Ethiopia. Review of Development Economics, 7(1), 58-70.

Crouhy, M., Galai, D. and Mark, R. (2006). The essentials of risk management. New York: McGraw-Hill.

Curtis, B. C., Rajaram, S., and Macpherson, H. G. (2002). Bread wheat: improvement and production. 
Dallas, M. (2006). Value and risk management a guide to best practice. Malden, MA: Blackwell Pub.

Damaspost.

URL: http://www.damaspost.com/\%D8\%A7\%D9\%82\%D8\%AA\%D8\%B5\%D8\%A7 \%D8\%AF/ug99-\%D8\%AA\%D9\%81\%D8\%AA\%D9\%83-

\%D8\%A8\%D9\%85\%D8\%AD\%D8\%B5\%D9\%88\%D9\%84-

\%D8\%A7\%D9\%84\%D9\%82\%D9\%85\%D8\%AD-

\%D8\%A7\%D9\%84\%D8\%B3\%D9\%88\%D8\%B1\%D9\%8A.htm.

14.10.2012. (Arabic).

Accessed:

Dencic, S., Mladenov, N. and Kobiljski, B. (2011). Effects of genotype and environment on breadmaking quality in wheat. International Journal of Plant Production, 5(1), 71-82.

DeVellis, R. F. (1991). Scale development: theory and applications. (Vol. 26). Newbury Park, CA: Sage Publications, Social Research Methods Series.

Dillon, J. L. and Scandizzo, P. (1978). Risk attitudes of subsistence farmers in NorthEast Brazil: a sampling approach. American Journal of Agricultural Economics 60 (3), 425-435.

Dillon, J. L. (1979). Bernoullian decision theory: outline and problems. In: Roumasset, J. A., Boussard, J. M. and Singh, I. (Eds.). Risk, uncertainty, and agricultural development. Agricultural Development Council, New York, USA, pp. 23-38.

Eckman, D. T., Patrick, G. F. and Musser, W. N. (1996). Factors affecting written marketing plan adoption by large-scale grain producers. Review of Agricultural Economics, 565-574.

Edelman, M. A., Schmiesing, B. H. and Olsen, D. R. (1990). Use of selected marketing alternatives by Iowa farmers. Agribusiness 6(2), 121-132.

Edwards-Jones, G. (2001). Agricultural policy and the environment in Syria: an examination of impacts and suggestions for policy reform. Policy study. FAO Project GCP/SYR/006/ITA - Phase I http://napcsyr.net/dwnldfiles/policy_studies/en/14_environment_en.pdf. Accessed: 04.07.2013.

Edwards-Jones, G. (2003). Agricultural policy and environment in Syria: the case of rangeland grazing and soil management. In: Fiorillo. C. and Vercueil. J. (Eds.). Syrian agriculture at the crossroads. Agricultural Policy and Economic Development Series. FAO Project GCP/SYR/006/ITA. 115-138. URL: $\quad$ http://www.napcsyr.net/dwnldfiles/fao_publications/sac/syrian_agriculture_at_the_cross_roads_en.pdf. Accessed: 15.02.2011.

Ejigie, D. A. (2005). The economics of smallholder coffee farming risk and its influence on household use of forests in Southwest Ethiopia. PhD thesis, University of Bonn. Cuvillier Verlag. 
El-Fadel, M., El Sayegh, Y., Abou Ibrahim, A., Jamali, D. and El-Fadl, K. (2002). The Euphrates-Tigris Basin: a case study in surface water conflict resolution. Journal of Natural Resources and Life Sciences Education. 31. 99-110.

Erian, W., Ouldbedy, B., Awad, H., Zaghtit, E. and Ibrahim. S. (2013) UNISDR. Background paper prepared for the global assessment report on disaster risk reduction. Agriculture drought in Africa Mediterranean and Middle East. Geneva, Switzerland, 2013. URL: http://www.preventionweb.net/english/hyogo/gar/2013/en/bgdocs/Erian\% 20et.al,\%202012.pdf. Accessed: 02.04.2014.

European Commission. (2001). Risk management tools for EU agriculture with a special focus on insurance. European Commission. Working document, $\quad$ http://ec.europa.eu/agriculture/publi/insurance/text_en.pdf. Accessed: 14.01.2014.

FAO. Food and Agriculture Organization of the United Nations (2001). Food Balance Sheets. A hand book. URL: $\quad$ ftp://ftp.fao.org/docrep/fao/011/x9892e/x9892e00.pdf. Accessed: 17.07.2013.

FAO. Food and Agriculture Organization of the United Nations (2003a). Trade Reforms and Food Security - Conceptualizing the Linkage. Commodity Policy and Projections Service. Commodities and Trade Division. FAO. Rome. 2003. URL: $\quad$ ftp://ftp.fao.org/docrep/fao/005/y4671e/y4671e00.pdf. Accessed: 17.07.2013.

FAO. Food and Agriculture Organization of the United Nations (2003b). Fertilizer use by crop in the Syrian Arab Republic. Land and Plant Nutrition Management Service. Land and Water Development Division. FAO. Rome. 2003. URL: $\quad$ http://www.fao.org/docrep/012/i0936e/i0936e00.htm. Accessed: 08.05.2013.

FAO. Food and Agricultural Organization of the United Nations. (2005). Collective groundwater management in the North-East region of Syria. Extended Concept Note for Project Proposal. URL: ftp://ftp.fao.org/agl/iptrid/SyriaGWM.pdf. Accessed: 26.07.2013.

FAO. Food and Agriculture Organization of the United Nations. (2011). AQUASTAT.

Database. URL: http://www.fao.org/nr/water/aquastat/data/query/results.html. Accessed: 10.05.2013.

FAO. Food and Agriculture Organization of the United Nations. (2013). Drought. FAO land and water. URL: http://www.fao.org/docrep/017/aq191e/aq191e.pdf. Accessed: 01.04.2014.

FAS. Foreign Agricultural Service of the United States Department of Agriculture USDA. (2002). Syria's 2001/02 wheat production breaks record. 
URL: $\quad$ http://www.fas.usda.gov/pecad2/highlights/2002/04/syria/index.htm. Accessed: 01.08.2013.

FDR. Federal Research Division. Library of Congress (2005). Country profile: Syria. URL: http://lcweb2.loc.gov/frd/cs/profiles/Syria.pdf. Accessed: 02.05.2012.

Fiorillo, C. and Vercueil, J. (Eds.). (2003). Syrian agriculture at the crossroads Vol. 8. Agricultural Policy and Economic Development Series. FAO Project GCP/SYR/006/ITA. URL: http://www.napcsyr.net/dwnldfiles/fao_publications/sac/syrian_agriculture_at_the_cross_roads_en.pdf.

Accessed: 15.02.2011.

Flaten, O., Lien, G., Koesling, M., Valle, P. S. and Ebbesvik, M. (2005). Comparing risk perceptions and risk management in organic and conventional dairy farming: empirical results from Norway. Livestock Production Science, 95(1), $11-25$.

Forni, N. (2003). Land tenure and labour relations. In: Fiorillo, C. and Vercueil, J. (Eds.). Syrian agriculture at the crossroads. Agricultural Policy and Economic Development Series. FAO Project GCP/SYR/006/ITA. 309-334. URL: $\quad$ http://www.napcsyr.net/dwnldfiles/fao_publications/sac/syrian_agriculture_at_the_cross_roads_en.pdf.

Accessed: 15.02.2011.

Francisco, E. M. and Anderson, J. R. (1972). Chance and choice west of the darling. Australian Journal of Agricultural and Resource Economics, 16(2), 82-93.

Frenken, K. (2009). Irrigation in the Middle East region in figures. AQUASTAT Survey - 2008. FAO Water Reports 2009. No. 34. FAO Land and Water Division URL: ftp://ftp.fao.org/docrep/fao/012/i0936e/i0936e00.pdf. Accessed: 29.07.2013.

Gallego, J., Conte, C. G., Dittmann, C., Stroblmair, J. and Bielza, M. (2007). Mapping climatic risks in the EU agriculture. In 101st Seminar, July 5-6, 2007, Berlin Germany, No. 9260. European Association of Agricultural Economists.

Galli, D., Morini, Ch. and Terlizzi, B. D. (2010). Sustainable crop management model in Syrian strategic crops: the experience of the cooperation project Rationalization of Ras Al-Ain irrigation system. ISDA- Innovation and Sustainable Development in Agriculture and food. Montpelier. France. URL: http://hal.archivesouvertes.fr/docs/00/52/20/55/PDF/Galli_Sustainable.pdf. Accessed: 26.07.2013.

Garzouzi, E. (1963). Land reform in Syria. Middle East Journal. 17:1/2. 83-90.

Gómez-Limón, J. A., Arriaza, M. and Riesgo, L. (2003). An MCDM analysis of agricultural risk aversion. European Journal of Operational Research, 151(3), 569-585. 
Goodwin, B. K. and Schroeder, T. C. (1994). Human capital, producer education programs, and the adoption of forward-pricing methods. American Journal of Agricultural Economics, 76(4), 936-947.

Craven, A., Garratt, J. and Padovani, L. (2011). Regulatory aspects of pesticide risk assessment. In: Capri, E. and Karpouzas, D. (Eds.). Pesticide Risk Assessment in Rice Paddies: Theory and Practice: Theory and Practice. Elsevier. 25-43.

Guehlstorf, N. P. (2004). The political theories of risk analysis (Vol. 4). Springer.

Gunjal, K. and Legault, B. (1995). Risk preferences of dairy and hog producer in Quebec. Canadian Journal of Agricultural Economics/Revue canadienne d'agroeconomie, 43(1), 23-35.

Gustafsson, J. (2000). Risk management in finnish biopharmaceutical companies. Master thesis. Helsinki University of Technology. Helsinki.

Hair, Jr. F., Black, W. C., Babin, B. J. and Anderson, R. E. (2010). Multivariate data analysis. $7^{\text {th }}$ Edition. Pearson Prentice Hall.

Hall, D. C., Knight, T. O., Coble, K. H., Baquet, A. E. and Patrick, G. F. (2003). Analysis of beef producers' risk management perceptions and desire for further risk management education. Review of Agricultural Economics, 25(2), 430-448.

Hamal, K. B. and Anderson, J. R. (1982). A note on decreasing absolute risk aversion among farmers in Nepal. Australian Journal of Agricultural and Resource Economics, 26(3), 220-225.

Hanson, J., Dismukes, R., Chambers, W., Greene, C. and Kremen, A. (2004). Risk and risk management in organic agriculture: views of organic farmers. Renewable agriculture and food systems, 19(04), 218-227.

Hardaker. J. B., Huirne. R. B. M. and Anderson. J. R. (1997). Coping with risk in agriculture. CAB International. Wallingford. U.K.

Harvey, J., Erdos, G., Bolam, H., Cox, M. A., Kennedy, J. N. and Gregory, D. T. (2002). An analysis of safety culture attitudes in a highly regulated environment. Work and Stress, 16(1), 18-36.

Harwood, Y., Heifner, R., Coble, K., Perry, J. and Somwaru, A. (1999). Managing risk in farming: concepts. research. and analysis. Market and trade economics division and resource economics division. economic research service. U.S. Department of Agriculture. Agricultural Economic Report No. 774.

Heidelbach, O. (2007). Efficiency of selected risk management instruments: An empirical analysis of risk reduction in Kazakhstani crop production. Institut für Agrarentwicklung in Mittel-und Osteuropa (IAMO).

Hillson, D. and Murray-Webster, R. (2004). Understanding and managing risk attitude. In Proceedings of 7th Annual Risk Conference, London, UK. 
URL: $\quad$ http://www.risk-attitude.com/riskattitude_paper.pdf. Accessed: 26.04.2013.

Hillson, D. and Murray-Webster, R. (2007). Understanding and managing risk attitude. Gower Publishing, Ltd.

Höhendinger, K. (2006). Water politics in the Middle East: the Euphrates Tigris Basin. Seminar Paper. Marmara University. Istanbul.

Huirne, R. B. M., Hardaker, J. B. and Dijkhuizen, A. A. (Eds.). (1997). Risk management strategies in agriculture: state of the art and future perspectives, Mansholt Institute, Wageningen, Netherlands, pp.151-162.

Huirne, R. B., Meuwissen, M. P., Hardaker, J. B. and Anderson, J. R. (2000). Risk and risk management in agriculture: an overview and empirical results. International Journal of Risk Assessment and Management, 1(1), 125-136.

ICARDA. International Center for Agricultural Research in the Dry Areas. (2008). Annual report. URL: $\quad$ http://r4d.dfid.gov.uk/PDF/Outputs/ICARDA/ICARDA_AR2008.pdf. Accessed: 06.05.2013.

ICARDA. International Center for Agricultural Research in the Dry Areas. (2009). Annual report. URL: $\quad$ http://r4d.dfid.gov.uk/PDF/Outputs/ICARDA/ICARDA_AR2009.pdf. Accessed: 13.05.2013.

ICARDA. International Center for Agricultural Research in the Dry Areas. (2011). Annual report. URL: http://www.icarda.org/publications-resources/annualreport. Accessed: 13.05.2013.

IFAD. International Fund for Agricultural Development. (2001). The Syrian Arab Republic: Country Programme Evaluation. Report No. 1178-SY. URL: http://www.ifad.org/evaluation/public_html/eksyst/doc/country/pn/syria/s yria.pdf. Accessed: 02.05.2013.

IFAD. International Fund for Agricultural Development. (2009). Syrian Arab Republic: Country strategic opportunities programme. Executive Board Ninety-eighth Session Rome. 15-17 December 2009. URL: http://www.ifad.org/gbdocs/eb/98/e/EB-2009-98-R-22.pdf. Accessed: 23.06.2013.

IFAD. International Fund for Agricultural Development. (2012). Syrian Arab Republic: Thematic study on participatory rangeland management in The Badia. Badia Rangelands Development Project. Near East. North Africa and Europe Division Programme Management Department. URL: http://www.ifad.org/pub/pn/badia.pdf. Accessed: 02.05.2013.

Ilaiwi, M. (2001) Soils of the Syrian Arab Republic. In : Zdruli, P., Steduto, P., Lacirignola, C., and Montanarella, L. (Eds.). Soil resources of Southern and 
Eastern Mediterranean countries. Bari : CIHEAM. 2001. 227 -242 (Options Méditerranéennes: Série B. Etudes et Recherches. 34). URL: http://om.ciheam.org/om/pdf/b34/01002096.pdf. Accessed: 21.07.2013.

Jamal, M., Arslan, A. and Dayoub, K. (2007). Harnessing salty water to enhance sustainable livelihoods of the rural poor in four countries in West Asia and North Africa: Syria. GCSAR -MAAR. Syrian Arab Republic. URL: http://www.iwmi.cgiar.org/Assessment/files_new/research_projects/ICB A\%20NationalReport_Syria\%20Part\%201.pdf. Accessed: 22.03.2013.

Jamison, D. T. and Lau, L. J. (1982). Farmer education and farm efficiency. Johns Hopkins University Press.

Jiménez, F. J. (2003). Risk attitudes and the family environment: application to the firm-households in the olive-oil sector. Cuadernos de Economía, vol. 27, 2004, pp. 217-240.

Just, R. E. and Calvin, L. (1994). An empirical analysis of US participation in crop insurance. In Economics of Agricultural Crop Insurance: Theory and Evidence (pp. 205-252). Springer Netherlands.

Kahneman, D. and Tversky, A. (1979). Prospect theory: an analysis of decision under risk. Econometrica: Journal of the Econometric Society, 263-291.

Kahneman, D. and Tversky, A. (2009). Choices, values, and frames. In: Kahneman, D. and Tversky, A. (Eds.). Choices, Values, and Frames. Cambridge University Press, pp. 1-16.

Kaniewski, D., Van Campo, E. and Weiss, H. (2012). Drought is a recurring challenge in the Middle East. Proceedings of the National Academy of Sciences, 109(10), 3862-3867.

Kaplinsky, R. (2000). Globalisation and unequalisation: What can be learned from value chain analysis? Journal of development studies, 37(2), 117-146.

Kashaninejas, M. (2011). Pistachio (Pistachio vera L.). In: Yahia, E. (Ed.). Postharvest biology and technology of tropical and subtropical fruit. pp 218244.

Kastens, T. L. and Featherstone, A. M. (1996). Feedforward backpropagation neural networks in prediction of farmer risk preferences. American Journal of Agricultural Economics, 78(2), 400-415.

Kaya, I. (1998). The Euphrates-Tigris basin: an overview and opportunities for cooperation under international law. Arid Lands Newsletter. 44. Conflict Resolution and Transboundary Water Resources. URL: $\quad$ https://ag.arizona.edu/OALS/ALN/aln44/kaya.html. Accessed: 14.07.2013. 
Kay, R. D. and Edwards, W. M. (1999). Farm management: instructor's manual (No. 1373).

Keilany, Z. (1980). Land Reform in Syria. Middle Eastern Studies. 16. No. 3. 209224.

Kim, J. O. and Mueller, C. W. (Eds.). (1978). Factor analysis: statistical methods and practical issues ,Vol. 14. Sage.

King, R. P. and Oamek, G. E. (1983). Risk management by Colorado dryland wheat farmers and the elimination of the disaster assistance program. American Journal of Agricultural Economics, 65(2), 247-255.

Kline, J. and Wichelns, D. (1998). Measuring heterogeneous preferences for preserving farmland and open space. Ecological Economics, 26(2), 211-224.

Knight, J., Weir, S. and Woldehanna, T. (2003). The role of education in facilitating risk-taking and innovation in agriculture. The Journal of Development Studies, 39(6), 1-22.

Knutson, R. D., Smith, E. G., Anderson, D. P. and Richardson, J. W. (1998). Southern farmers' exposure to income risk under the 1996 farm bill. Journal of Agricultural and applied economics, 30(01).

Kobzar, O. A. (2006). Whole-farm risk management in arable farming: portfolio methods for farm-specific business analysis and planning. $\mathrm{PhD}$ thesis. Wageningen University.

Koundouri, P., Laukkanen, M., Myyrä, S. and Nauges, C. (2009). The effects of EU agricultural policy changes on farmers' risk attitudes. European Review of Agricultural Economics, 36(1), 53-77.

Lagerkvist, C. J. (2005). Assessing farmers' risk attitudes based on economic, social, personal, and environmental sources of risk: evidence from Sweden. In AAEA Annual Meeting, July, pp. 24-25.

La Rovere, R. (1997). Risk, Income and land Use in the Atlantic zone of Costa Rica: an assessment with a linear programming model No. 166. Bib. Orton IICA/CATIE.

Lence, S. H. (2000). Using consumption and asset return data to estimate farmers' time preferences and risk attitudes. American Journal of Agricultural Economics, 82(4), 934-947.

Legesse, B. and Drake, L. (2005). Determinants of smallholder farmers' perceptions of risk in the Eastern highlands of Ethiopia. Journal of Risk Research, 8(5), 383-416. 
Lien, G., Flaten, O., Jervell, A. M., Ebbesvik, M., Koesling, M. and Valle, P. S. (2006). Management and risk characteristics of part-time and full-time farmers in Norway. Applied Economic Perspectives and Policy, 28(1), 111-131.

MAAR. Ministry of Agriculture and Agrarian Reform. Syria. (2007). The annual Statistical groups.URL: http://moaar.gov.sy/main/archives/590. Accessed: 09.05.2013. (Arabic).

MAAR. Ministry of Agriculture and Agrarian Reform. Syria. (2009). The annual Statistical groups.URL: http://moaar.gov.sy/main/archives/590. Accessed: 09.05.2013. (Arabic).

MAAR. Ministry of Agriculture and Agrarian Reform. Syria. (2011). The annual Statistical groups 2011.URL: http://www.moaar.gov.sy/site_ar/agristat/2011/1.pdf. Accessed: 09.05.2013. (Arabic).

MAAR. Ministry of Agriculture and Agrarian Reform. Syria. (2013). Official Website. Ministry's news and activities. URL: http://moaar.gov.sy/main/archives/category/news. Accessed: 15.06.2013. (Arabic).

Machina, M. (1987). Choice under uncertainty: problems solved and unsolved. Economic Perspectives, 1, 121-154.

Madani, A. (2005). Syrian agricultural trade. In: NAPC. (National Agricultural Policy Center ). Agriculture and Trade Liberalization in Syria in the Context of Bilateral Trade Agreements. the Arab Free Trade Area and the WTO. working paper. 5. 3-28. FAO Project GCP/SYR/006/ITA - Phase II. URL: $\quad$ http://napcsyr.net/dwnldfiles/working_papers/en/05_agr_trade_libera_en.pdf. Accessed: 25.09.2010.

Maldonado, J. (2009). Syria cotton and products annual. USDA, Foreign Agricultural Service.

Maletta, H. (2003). Private investmant in Syrian agriculture and agribusiness. In: Fiorillo, C. and Vercueil, J. (Eds.). Syrian agriculture at the crossroads. Agricultural Policy and Economic Development Series. FAO Project GCP/SYR/006/ITA. 54-86. URL: http://www.napcsyr.net/dwnldfiles/fao_publications/sac/syrian_agriculture_at_the_cross_roads_en.pdf.

Accessed: 15.02.2011.

Makus, L. D., Lin, B. H., Carlson, J. and Krebill-Prather, R. (1990). Factors influencing farm level use of futures and options in commodity marketing. Agribusiness, 6(6), 621-631.

Manly, B. F. (2004). Multivariate statistical methods: a primer. Third edition. CRC Press. 
Martin, S. (1996). Risk management strategies in New Zealand agriculture and horticulture. Review of Marketing and Agricultural Economics, 64, 31-44.

Martin, S. and McLeay, F. (1998). The diversity of farmers' risk management strategies in a deregulated New Zealand environment. Journal of Agricultural Economics, 49(2), 218-233.

Masri, A. (2006). Country pasture/forage resource profiles. Surian Arab Republic. FAO. $\quad$ Rome. URL: http://www.fao.org/ag/AGP/AGPC/doc/counprof/PDF\%20files/Syria.pdf. Accessed: 17.09.2010.

McIver, J. P. and Carmines, E. G. (1981). Unidimensional scaling (No. 24). Sage Publication; Quantitative Applications in the Social Sciences Series.

McIntyre, B. D., Herren, H. R., Wakhungu, J. and Watson, R. T. (2009). Agriculture at a Crossroads. International Assessment of Agricultural Science and Technology for Development Global Report. Washington, DC: IAASTD.

McLeay, F., Martin, S. and Zwart, T. (1996). Farm business marketing behavior and strategic groups in agriculture. Agribusiness, 12(4), 339-351.

MEDSTAT II. (2009). Syria Arab Republic: country statistical situation report. Version.2.

URL: http://epp.eurostat.ec.europa.eu/portal/page/portal/european_neighbourho od_policy/documents/CSSR_Syria___\%20EN_0509.pdf. Accessed: 09.02.2013.

Merna, T. and Al-Thani, F. F. (2008). Corporate risk management. John Wiley and Sons.

Menapace, L., Colson, G. and Raffaelli, R. (2013). Risk aversion, subjective beliefs, and farmer risk management strategies. American Journal of Agricultural Economics, 95(2), 384-389.

Meuwissen, M. P., Huirne, R. B. M. and Hardaker, J. B. (1999). Perceptions of risks and risk management strategies: an analysis of Dutch livestock farmers. AAEA Annual Meeting, August ,pp. 8-11.

Meuwissen, M. P. M., Huirne, R. B. M. and Hardaker, J. B. (2001). Risk and risk management: an empirical analysis of Dutch livestock farmers. Livestock Production Science, 69(1), 43-53.

Miller, A., Dobbins, C., Pritchett, J., Boehlje, M. and Ehmke, C. (2004). Risk management for farmers. Staff paper, 04-11.

Moscardi, E. and de Janvry, A. (1977). Attitudes toward risk among peasants: An econometric approach. American Journal of Agricultural Economics, 59(4), 710-716. 
MSEA. Ministry of State for Environmental Affairs. Syria. (2003). Strategy and national environmental action plan for the Syrian Arab Republic. URL: http://smap.ew.eea.europa.eu/fol112686/fol886672/copy_of_fol522871/fo 1202182/Environmental_Strategy_and_Action_Plan_E_doc/. Accessed: 09.06.2013.

Munlahasan, A. (2007). Water use efficiency in Syrian agriculture. NAPC. National Agricultural Policy Center. Working paper. 26. FAO project GCP/SYR/006/ITA - Phase II. URL: http://napcsyr.net/dwnldfiles/working_papers/en/26_water_eff_am_en.pdf. Accessed: 09.10.2010.

Murray-Webster, R. and Hillson, D. (2008). Managing group risk attitude. Gower Publishing, Ltd.

Musser, W. N. and Musser, L. M. (1984). Psychological perspective on risk analysis. In: Barry P. J. (Ed). Risk Management in Agriculture. Iowa State University Press, Ames, Iowa, pp. 82-92.

Musser, W. N. (1998). Risk management overview. In Mid-Atlantic Risk Management Regional Conference, Williamsburg, VA, pp. 6-7.

NAPC. National Agricultural Policy Center. (2002). The state of food and agriculture in Syrian Arab Republic. periodical reports. URL: http://napcsyr.net/dwnldfiles/periodical_reports/en/sofas_2002_en.pdf. Accessed: 24.05.2013.

NAPC. National Agricultural Policy Center. (2007). The state of food and agriculture in Syria. periodical reports. URL: http://napcsyr.net/dwnldfiles/periodical_reports/en/sofas_2007_en.pdf.

NAPC. National Agricultural Policy Center. (2008). Database. URL: http://www.napcsyr.org/caf/form?collection=Production.NationalAggrega tes.LandandDomain=Production-

$\underline{\text { NationalAggregatesandservlet }=1 \text { andlanguage }=E N a n d v e r s i o n=s y r d b}$. Accessed: 15.01.2010.

NAPC. National Agricultural Policy Center. (2009). Syria agricultural trade 20082009 periodical reports. URL: http://napcsyr.net/dwnldfiles/periodical_reports/en/sat_08-09_en.pdf. Accessed: 24.05.2013.

NAPC. National Agricultural Policy Center. (2010a). The state of food and agriculture in Syria. periodical reports. URL: http://napcsyr.net/dwnldfiles/periodical_reports/ar/sofas_2010_en.pdf. Accessed: 24.05.2013.

NAPC. National Agricultural Policy Center. (2010b). Syria agricultural trade 2010. URL: $\quad$ http://napcsyr.net/dwnld-files/periodical_reports/ar/sat_2010_ar.pdf. Accessed: 24.05.2013. (Arabic).

Nguyen, N. C. (2007). Risk management strategies and decision support tools for dry land farmers in southwest Queensland. Australia. PhD Thesis. University of Queensland. Gatton. Queensland. Australia. 
Nicol, R. M., Ortmann, G. F. and Ferrer, S. R. (2007). Perceptions of key business and financial risks by large-scale sugarcane farmers in KwaZulu-Natal in a dynamic socio-political environment. Agrekon, 46(3), 351-370.

Noell, C. and Odening, M. (1997). Changes in risk management over time - the impact of learning and changing risk preference. In: Huirne, R. B. M., Hardaker, J. B. and Dijkhuizen, A. A. (Eds.). Risk management strategies in agriculture: state of the art and future perspectives, Mansholt Institute, Wageningen, Netherlands, pp.151-162.

Nunnally, J. C. and Bernstein, I. H. (Eds.). (1994). Psychometric theory (3rd Ed.), New York: McGraw-Hill.

Olarinde, L. O., Manyong, V. M. and Akintola, J. O. (2010). Factors influencing risk aversion among maize farmers in the Northern Guinea Savanna of Nigeria: implications for sustainable crop development programmes. International Journal of Food, Agriculture and Environment, 8(1), 128-134.

Ondersteijn, C. J. M., Giesen, G. W. J. and Huirne, R. B. M. (2006). Perceived environmental uncertainty in Dutch dairy farming: the effect of external farm context on strategic choice. Agricultural Systems, 88(2), 205-226.

Pallant, J. (Ed.). (2007). SPSS survival manual: a step by step guide to data analysis using SPSS for Windows (3rd Ed.). McGraw Hill/Open University Press. New York.

Pålsson, A. M. (1996). Does the degree of relative risk aversion vary with household characteristics?. Journal of economic psychology, 17(6), 771-787.

Pannell, D. R. and Nordblom, T. L. (1998). Impacts of risk aversion on whole-farm management in Syria. The Australian Journal of Agricultural and Resource Economics. 42:3, pp. 227-247.

Parthasarathy, S. N. (2003a). Agricultural inputs and market liberalization. In: Fiorillo, C. and Vercueil, J. (Eds.). Syrian agriculture at the crossroads. Agricultural Policy and Economic Development Series. FAO project GCP/SYR/006/ITA. 363-380. http://www.napcsyr.net/dwnldfiles/fao_publications/sac/syrian_agriculture_at the_cross_roads_en.pdf.

Accessed: 15.02.2011.

Parthasarathy, S. N. (2003b). Agricultural credit system: institutions and policies. In: Fiorillo, C. and Vercueil, J. (Eds.). Syrian agriculture at the crossroads. Agricultural Policy and Economic Development Series. FAO Project GCP/SYR/006/ITA. 381-404. URL: http://www.napcsyr.net/dwnldfiles/fao_publications/sac/syrian_agriculture_at_the_cross_roads_en.pdf. Accessed: 15.02.2011.

Patrick, G. F. and Ullerich, S. (1996). Information sources and risk attitudes of largescale farmers, farm managers, and agricultural bankers. Agribusiness, 12(5), 461-471. 
Patrick, G. F. and Musser, W. N. (1997). Sources of and responses to risk: factor analyses of large-scale US cornbelt farmers. In: Huirne, R. B. M., Hardaker, J. B. and Dijkhuizen, A. A. (Eds.). Risk management strategies in agriculture: State of the art and future perspectives, Mansholt Institute, Wageningen, Netherlands, pp. 45-54.

Patrick, G. R., Wilson, P. N., Barry, P. J., Boggess, W. G. and Young, D. L. (1985). Risk perceptions and management responses: producer-generated hypotheses for risk modeling. Southern Journal of Agricultural Economics, 17(2), 231-238.

Pellegrino, J. M. (1999). Risk management in agriculture: argentine evidence of perceived sources of risk, risk management strategies and risk efficiency in rice farming. Master thesis, Lincoln University, Lincoln, New Zealand.

Pennings, J. M. and Garcia, P. (2001). Measuring producers' risk preferences: A global risk-attitude construct. American Journal of Agricultural Economics, 83(4), 993-1009.

Perry, J. and Johnson, J. (2000). Influences of human capital and farm characteristics on farmer's risk attitudes. Economic Research Service, USDA.

Personal communication with Agricultural advisory center in Al Hasakah 28.11.2009.

Personal communication with wheat-cotton farmers in Al Hasakah 02.01.2010.

Persons, H. K. (1959). Land reform in the United Arab Republic. Land economics. 35 No 4. 319-326.

Peter, J. P. (1979). Reliability: a review of psychometric basics and recent marketing practices. Journal of Marketing Research (JMR), 16(1).

Picazo-Tadeo, A. J. and Wall, A. (2011). Production risk, risk aversion and the determination of risk attitudes among Spanish rice producers. Agricultural Economics, 42(4), 451-464.

Pidgeon, N. (1998). Risk assessment, risk values and the social science programme: why we do need risk perception research. Reliability Engineering \& System Safety, 59(1), 5-15.

Pingali, P. L. (2001). Environmental consequences of agricultural commercialization in Asia. Environment and Development Economics, 6(4), 483-502.

Pope, R. D. and Just, R. E. (1991). On testing the structure of risk preferences in agricultural supply analysis. American Journal of Agricultural Economics, 73(3), 743-748.

Rabin, M. (2000). Risk aversion and expected-utility theory: a calibration theorem. Econometrica, 68(5), 1281-1292. 
Ramatnam, S., Rister, M. E., Bessler, D. A. and Novak, J. (1986). Risk attitudes and farm/producer attributes: a case study of Texas Coastal Bend grain sorghum producers. Southern Journal of Agricultural Economics December, 85-95.

Ramaratnam, S. S., Rister, M. E., Bessler, D. A. and Novak, J. (1986). Risk attitudes and farm/producer attributes: a case study of Texas coastal bend grain sorghum producers. Southern Journal of Agricultural Economics, 18(02).

Renn, O. (1992). Concepts of risk: A classification. In: Krimsky S. and Golding D. (Eds.). Social theories of risk. Westport, CT, Praeger, pp. 53-79.

Ritchie, J. W., Abawi, G. Y., Dutta, S. C., Harris, T. R. and Bange, M. (2004). Risk management strategies using seasonal climate forecasting in irrigated cotton production: a tale of stochastic dominance. Australian Journal of Agricultural and Resource Economics, 48(1), 65-93.

Robison, L. J. (1982). An appraisal of expected utility hypothesis tests constructed from responses to hypothetical questions and experimental choices. American journal of Agricultural Economics, 64(2), 367-375.

Rohrmann, B. (2005). Risk attitude scales: concepts, questionnaires, utilizations. Project report. http://www.rohrmannresearch.net/pdfs/rohrmann-racreport.pdf. Accessed: 13.06.2013.

Roslan, N. A., Abdullah, A. M., Ismail, M. M., and Radam, A. (2012). Influence of socio-economic factors on farmer's behaviours toward risks. $11^{\text {th }}$ International Annual Symposium on Sustainability Science and Management. e-ISBN 978967-5366-93-2.

Roumasset, J. A., Boussard, J. M. and Singh, I. (Eds.). (1979). Risk, uncertainty, and agricultural development. Agricultural Development Council, New York, USA.

SADB. Syrian Agricultural Database. (2013). URL: http://napcsyr.net/sadb.htm. Accessed: 08.07.2013.

Sadiddin, A. and Atiya, B. (2009). Analysis of agricultural production for selected crops: wheat. cotton and barley. NAPC. National Agricultural Policy Center. working paper 44. URL: http://napcsyr.net/dwnldfiles/working_papers/en/44_analysis_production_ab_en.pdf. Accessed: 24.10.2009.

Salman, M. and Mualla, W. (2003). The utilization of water resources for agriculture in Syria: analysis of current situation and future challenges. Eric International Seminars on Planetary Emergencies. Sicily. Italy. URL: ftp://ftp.fao.org/agl/iptrid/conf_italy_03.pdf. Accessed: 26.07.2013.

SANA. Syrian Arab News Agency. (2012). URL: http://sana.sy/ara/4/2012/02/01/397576.htm. Accessed: 29.05.2013. (Arabic). 
Sarris, A. (2001). Final report on agricultural development strategy for Syria. FAO project GCP/SYR/006/ITA URL: $\quad$ http://www.fao.org/world/syria/gcpita/pubs/policystudies/16bAgrDevStrategyforSyria-En_1-48.pdf. Accessed: 23.05.2013.

Sarris, A. (2003). Agricultural in the Syrian macroeconomic context. In: Fiorillo, C. and Vercueil, J. (Eds.). Syrian agriculture at the crossroads. Agricultural Policy and Economic Development Series. FAO project GCP/SYR/006/ITA. 3-28. URL: $\quad$ http://www.napcsyr.net/dwnldfiles/fao_publications/sac/syrian_agriculture_at_the_cross_roads_en.pdf.

Accessed: 15.02.2011

Sarris., A. and Corsi, A. (2003). The Syrian agricultural producers: structural and distributional features. In: Fiorillo, C. and Vercueil, J. (Eds.). Syrian agriculture at the crossroads. Agricultural Policy and Economic Development Series. FAO project GCP/SYR/006/ITA. 279-308. URL: http://www.napcsyr.net/dwnldfiles/fao_publications/sac/syrian_agriculture_at_the_cross_roads_en.pdf. Accessed: 15.02.2011.

Schaper, C., Lassen, B. and Theuvsen, L. (2010). Risk management in milk production: a study in five European countries. Food Economics-Acta Agricult Scand C, 7(2-4), 56-68.

Schoemaker, P. J. (1991). Choices involving uncertain probabilities: Tests of generalized utility models. Journal of Economic Behavior and Organization, 16(3), 295-317.

Schurle, B. and Tierney Jr., W. I. (1990). A comparison of risk preference measurements with implications for extension programming. Department of Agricultural Economics, Kansas State University, Manhattan. No.91-6.

Sckokai, P. and Moro, D. (2006). Modeling the reforms of the common agricultural policy for arable crops under uncertainty. American Journal of Agricultural Economics, 88(1), 43-56.

Sekar, I. and Ramasamy, C. (2001). Risk and resource analysis of rainfed tanks in South India. Journal of Social and Economic Development, 3(2), 208-215.

Sepulcre-Canto, G., Horion, S., Singleton, A., Carrao, H. and Vogt, J. (2012). Development of a combined drought indicator to detect agricultural drought in Europe. Natural Hazards and Earth System Sciences, 12(11).

Serra, T., Zilberman, D. and Gil, J. M. (2008). Differential uncertainties and risk attitudes between conventional and organic producers: the case of Spanish arable crop farmers. Agricultural Economics, 39(2), 219-229.

Shapiro, B. I. and Brorsen, B. W. (1988). Factors affecting farmers' hedging decisions. North Central Journal of Agricultural Economics, 10(2), 145-153. 
SIA. SYRIAN INVERSTMENT AGENCY. (2007). The second annual investment report. Syria. URL: http://moaar.gov.sy/main/archives/4392. Accessed: 01.05.2013.

SIA. Syrian Investment Agency. (2011). Investment opportunities guide in Syria. URL: http://www.syriainvestmentmap.org/FCKBIH/file/reports/Investment\%20 Opportunities\%20Guide\%20IN\%20Syria\%202011.pdf. Accessed: 01.05.2013.

Singh, R. K., Vishwakarma, A. and Singh, P. K. (2005). Managing risk in agriculture under drought situation in Uttar Pradesh: A case study. Agricultural Economics Research Review, 18.

Sjöberg, L. (1998). Why do people demand risk reduction? In: Lydersen, S., Hansen, G. K., and Sandtorv, H. A. (Eds.). ESREL-98: Safety and reliability. Trondheim: A. A. Balkema, pp. 751-758.

Slovic, P. (1992). Perception of risk: reflections on the psychometric paradigm. In: Krimsky S. and Golding D. (Eds.). Social Theories of Risk. Westport, CT: Praeger. 117-152.

Slovic, P. (2001). The risk game. Journal of Hazardous Materials, 86(1), 17-24.

Sonka, S. T. and Patrick, G. F. (1984). Risk management and decision making in agricultural firms. In: Barry P. J. (Ed). Risk Management in Agriculture. Iowa State University Press, Ames, Iowa. 82-92.

SPSS. (2003). SPSS Advanced $\quad$ Models 12.0. URL: http://support.spss.com/ProductsExt/SPSS/Documention/SPSSforWindo ws/German/SPSS\%20Advanced\%20Models\%2012.0.pdf. $\quad$ Accessed: 16.10.2011.

Stevens, J. (Ed.). (1992). Applied multivariate statistics for the social sciences. 2nd Ed. Hillsdale (NJ): Lawrence Erlbaum Associates.

Størdal, S., Lien, G. and Hardaker, J. B. (2007). Perceived risk sources and strategies to cope with risk among forest owners with and without off-property work in eastern Norway. Scandinavian journal of forest research, 22(5), 443-453.

Syrian customs. (2013). Official website. value guide. URL: http://www.customs.gov.sy/books/Value\%20Guide.pdf. Accessed: 12.06.2013. (Arabic).

Tauer, L. W. (1986). Risk preferences of dairy farmers. North Central Journal of Agricultural Economics, 7-15.

TID. Technology Integration Division. (2011). Syria in perspective. an orientation guide. Defense Language Institute. Foreign Language Center. URL: http://famdliflc.lingnet.org/products/cip/Syria/default.html. Accessed: 05.05.2013. 
Tversky, A. and Kahneman, D. (1992). Advances in prospect theory: Cumulative representation of uncertainty. Journal of Risk and uncertainty, 5(4), 297-323.

Tversky, A. and Fox, C. R. (1995). Weighing risk and uncertainty. Psychological review, 102(2), 269.

UNISDR. United Nations International Strategy for Disaster Reduction (2011). Global Assessment Report on Disaster Risk Reduction. Geneva, Switzerland. URL: http://www.preventionweb.net/english/hyogo/gar/2011/en/home/downloa d.html.Accessed: 05.08.2012.

USDA. United States Department of Agriculture (2011). World agricultural production.

Van Raaij, W. F. (1981). Economic psychology. Journal of Economic Psychology, $1(1), 1-24$.

Varela-ortega, C. and Sagardoy, J. A. (2001). Final report on agricultural water use. FAO project GCP/SYR/006/ITA - Phase I. URL: http://napcsyr.net/dwnldfiles/policy_studies/en/11_water_en.pdf. Accessed: 29.10.2010.

Varela-Ortega, C. and Sagardoy, J. A. (2003). Irrigation water policies in Syria: current developments and future options. In: Fiorillo, C. and Vercueil, J. (Eds.). Syrian agriculture at the crossroads. Agricultural Policy and Economic Development Series. FAO Project GCP/SYR/006/ITA. 334-360. URL: $\quad$ http://www.napcsyr.net/dwnldfiles/fao_publications/sac/syrian_agriculture_at_the_cross_roads_en.pdf.

Accessed: 15.02.2011.

Von Pock, A. (2007). Strategic management in Islamic finance. Deutscher Universitäts-Verlag.

Waters, D. (2011). Supply chain risk management: vulnerability and resilience in logistics. Kogan Page Publishers.

Wattenbach, H. (2006). Farming system of the Syrian Arab Republic. NAPC. National Agricultural Policy Center. Technical Report. FAO project GCP/SYR/006/ITA URL: $\quad$ ftp://ftp.fao.org/docrep/fao/009/ag418e/ag418e00.pdf. Accessed: 13.05.2013.

Wegener, M. K. (1994). Modelling studies in the Australian sugar industry, PhD thesis, The University of Queensland, St Lucia, Queensland, Australia.

Wehrheim, P. (2003). Agricultural and food policy in Syria: financial transfers and fiscal flows. In: Fiorillo, C. and Vercueil, J. (Eds.). Syrian agriculture at the crossroads. Agricultural Policy and Economic Development Series. FAO Project GCP/SYR/006/ITA. 87-114. URL: http://www.napcsyr.net/dwnldfiles/fao_publications/sac/syrian_agriculture_at_the_cross_roads_en.pdf.

Accessed: 15.02.2011. 
Weir, S. and Knight, J. (2000). Adoption and diffusion of agricultural innovations in Ethiopia: the role of education. University of Oxford, Institute of Economics and Statistics, Centre for the Study of African Economies.

Westlake, M. (2001). Final report on strategic crops' sub-sector. FAO project GCP/SYR/006/ITA $\quad-\quad$ Phase I. URL: http://www.fao.org/world/syria/gcpita/pubs/policystudies/StrategicCropsEn_1-70.pdf. Accessed: 29.10.2010.

Westlake, M. (2003). The economics of strategic crops. In: Fiorillo, C. and Vercueil, J. (Eds.). Syrian agriculture at the crossroads. Agricultural Policy and Economic Development Series. FAO Project GCP/SYR/006/ITA. 137-165. URL: $\quad$ http://www.napcsyr.net/dwnldfiles/fao_publications/sac/syrian_agriculture_at_the_cross_roads_en.pdf. Accessed: 15.02.2011.

Williams, J. and Schroder, W. (1999). Agricultural price risk management: the principles of commodity trading. Oxford University Press. Melbourne, Australia.

Wilson, P. N., Luginsland, T. R. and Armstrong, D. V. (1988). Risk perceptions and management responses of Arizona dairy producers. Journal of Dairy Science, 71(2), 545-551.

Wilson, P. N., Dahlgran, R. D., Conklin, N. C., Armstrong, D., and Luginsland, T. (1993). Perceptions as reality on large-scale dairy farms. Review of Agricultural Economics, 15(1), 89-101.

Xu, P., Alexander, C., Patrick, G. and Musser, W. (2005). Effects of farmers' risk attitudes and personality types on production and marketing decisions. Staff Paper, pp. 05-10.

Yigezu, A. Y., Aw-Hassan, A., Shideed, K. and El-Shater, T. (2011). Economic and environmental impact of supplementary irrigation in rain-fed agriculture: the case of wheat in Syria. ICARDA. International Center for Agricultural Research in the Dry Areas. Aleppo. Syria. URL: http://impact.cgiar.org/sites/default/files/images/ICARDA.pdf. Accessed: 15.01.2013

Young, D. L. (1979). Risk preferences of agricultural producers: their use in extension and research. American Journal of Agricultural Economics, 1063-1070.

Yu, B., You, L. and Fan, S. (2010). Toward a typology of food security in Developing countries. IFPRI. International Food Policy Research Institute. Discussion paper $00945 . \quad$ Washington. DC. URL: $\quad$ http://www.ifpri.org/sites/default/files/publications/ifpridp00945.pdf. Accessed 17.07.2013. 


\section{APPENDIX}

\section{Questionnaire}

\section{Georg-August Universität Göttingen Department für Agrarökonomie und Rurale Entwicklung

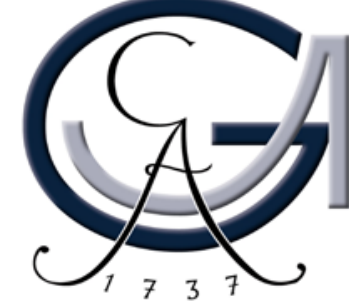

\section{Questionnaire:}

\section{Risk management on Syrian wheat-cotton and pistachio farms}

By:

Mohamad Isam Almadani

Department für Agrarökonomie und Rurale Entwicklung

Platz der Göttinger Sieben 5

37073 Göttingen

E-Mail:malmada@gwdg.de

Under supervision of:

Prof. Dr. Ludwig Theuvsen

Prof. Dr. Jörg Michael Greef 
Dear Ladies and Gentlemen,

Mohamad Isam Almadani, PhD student in Goettingen University, Germany is doing a survey on risk management on Syrian wheat-cotton and pistachio farms. The collected data will be analyzed within a research project. All collected data will be kept anonymous, without any chance to trace back your person or your farm.

Thank you for your participation.

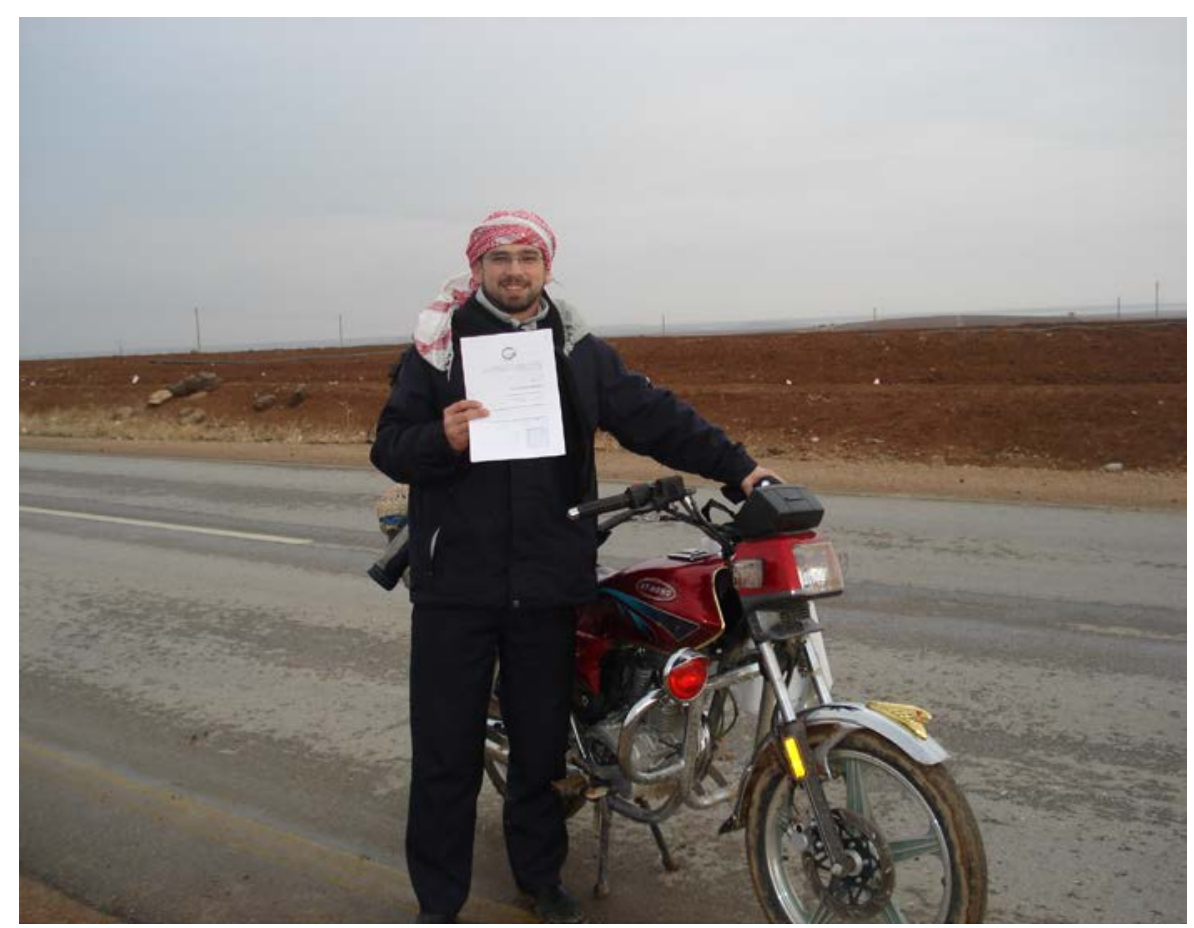

Structure of the questionnaire:

1. Preface and farm organization

2. Perceptions of risk sources

3. Perceptions of risk management strategies

4. Risk attitude

5. Farmer characteristics

Please cross in the middle of the boxes and write on the given lines.

\begin{tabular}{|l|l|}
\hline Name of the interviewer & \\
\hline Date (dd/mm/yyyy) & \\
\hline Time when starting the interview & \\
\hline
\end{tabular}




\section{Part 1: Preface and farm organization}

1.1. Please name the region where you are from

\subsection{Please state the ownership type of your farm (Ownership)}
$\square$ Private
$\square$ Rental
$\square$ Land reform
$\square$ Other: ...

1.3. Please state the main agricultural activities in your farm: (cultivation, animal husbandry, cottage food products)

1.4. What are the main crops in your farm crop rotation and its ratio in percentage or hectare per year?

\begin{tabular}{|l|c|c|}
\hline Crop & $\%$ & ha/year \\
\hline & & \\
\hline & & \\
\hline Total & $100 \%$ & ha \\
\hline
\end{tabular}

1.5. Please specify the production capacity of your farm in this year

\begin{tabular}{|l|l|}
\hline Total farm land (ha) & \\
\hline Share of irrigated land (ha) & \\
\hline Share of rain-fed land (ha) & \\
\hline Share of supplemental irrigated (Pistachio) (ha) & \\
\hline Average of yield of your agricultural production (ton/year) & \\
\hline Trees age (pistachio) & \\
\hline Cotton license (\%) & \\
\hline
\end{tabular}

1.6. What are the financial resources for your farm activities? You can cross more than one

$\square$ Own equity capital

$\square$ Loans from Agricultural Cooperative Bank

$\square$ Loans from mediator traders

$\square$ Other: 
1.7. Which option of irrigation do you follow in your farm? Please, mark only one possibility for each

$\begin{array}{lll}\square \text { Well } & \square \text { River } & \square \text { Public net } \\ \square \text { Flood irrigation } & \square \text { Sprinkler irrigation } & \square \text { Drip irrigation }\end{array}$

\subsection{Do you have private well?}

$\square$ No $\quad \square$ Yes

1.9. Which option of the future price governmental policy of the strategic crops do you prefer? Please mark only one possibility (only for wheat-cotton sample)

$\square$ Without any change

$\square$ Price rising as much as fuel price rising

$\square$ Market liberalization
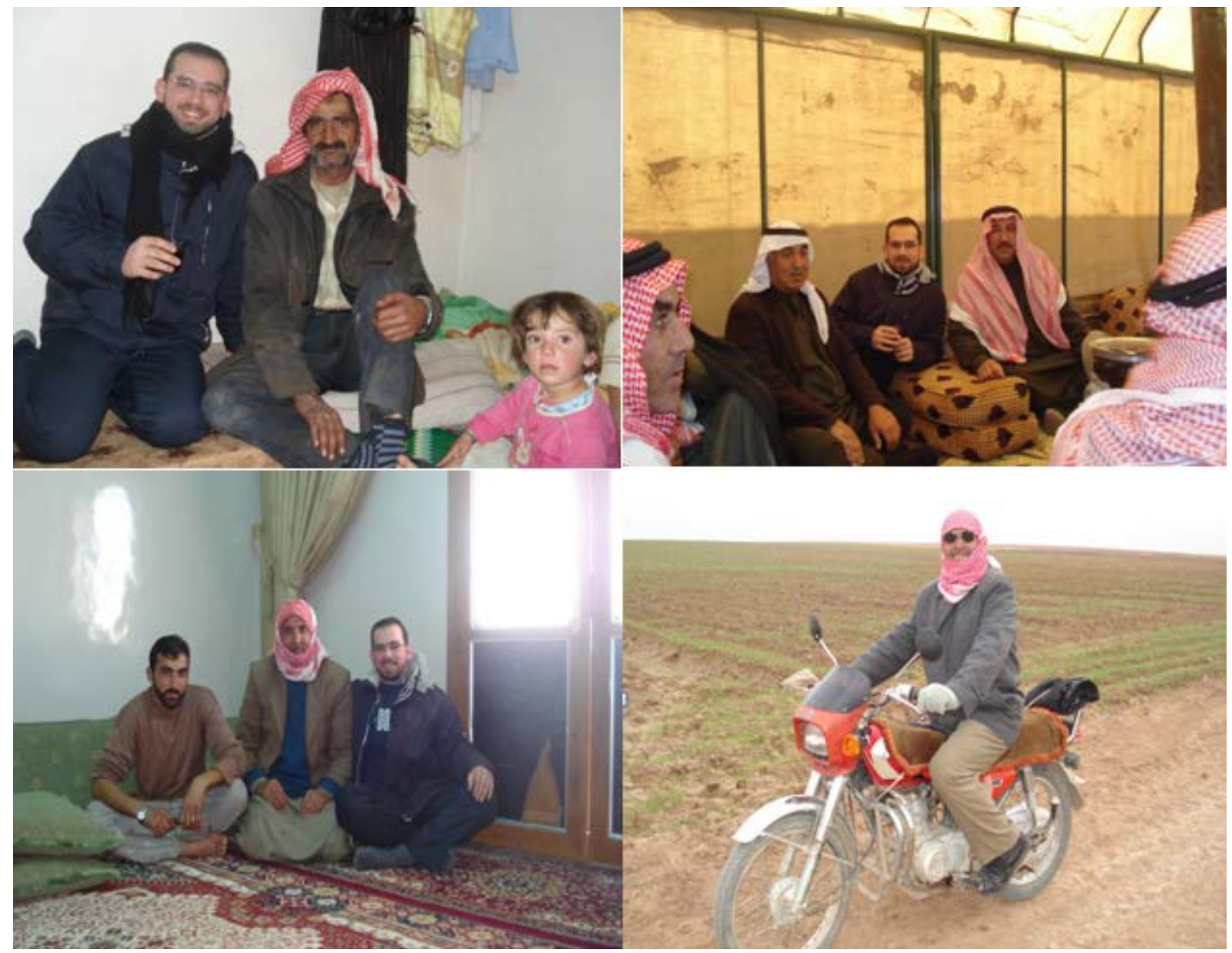


\section{Part 2: Perceptions of risk sources}

In this part we ask you to evaluate some ascertained risks. We classified them into three groups: production risks, market risks and policy risks

2.1. Concerning to the production risks, what do you think, how likely is the occurrence of each of the following risks?

Please mark on the 10 point scale (1: low probability to 10: high probability)

\begin{tabular}{|l|l|l|l|l|l|l|l|l|l|l|}
\hline Risk Items & $\mathbf{1}$ & $\mathbf{2}$ & $\mathbf{3}$ & $\mathbf{4}$ & $\mathbf{5}$ & $\mathbf{6}$ & $\mathbf{7}$ & $\mathbf{8}$ & $\mathbf{9}$ & $\mathbf{1 0}$ \\
\hline Precipitation shortage & $\square$ & $\square$ & $\square$ & $\square$ & $\square$ & $\square$ & $\square$ & $\square$ & $\square$ & $\square$ \\
\hline Drying of rivers and underground water & $\square$ & $\square$ & $\square$ & $\square$ & $\square$ & $\square$ & $\square$ & $\square$ & $\square$ & $\square$ \\
\hline Other climate factors (frost, overheating, dust storm) & $\square$ & $\square$ & $\square$ & $\square$ & $\square$ & $\square$ & $\square$ & $\square$ & $\square$ & $\square$ \\
\hline Plant pests and diseases & $\square$ & $\square$ & $\square$ & $\square$ & $\square$ & $\square$ & $\square$ & $\square$ & $\square$ & $\square$ \\
\hline Land availability & $\square$ & $\square$ & $\square$ & $\square$ & $\square$ & $\square$ & $\square$ & $\square$ & $\square$ \\
\hline Land tenure fragmentation by inheritance & $\square$ & $\square$ & $\square$ & $\square$ & $\square$ & $\square$ & $\square$ & $\square$ & $\square$ \\
\hline Labour & $\square$ & $\square$ & $\square$ & $\square$ & $\square$ & $\square$ & $\square$ & $\square$ & $\square$ \\
\hline Machinery & $\square$ & $\square$ & $\square$ & $\square$ & $\square$ & $\square$ & $\square$ & $\square$ & $\square$ & $\square$ \\
\hline Cultivation preference & $\square$ & $\square$ & $\square$ & $\square$ & $\square$ & $\square$ & $\square$ & $\square$ & $\square$ \\
\hline Wheat-cotton/pistachio preference & $\square$ & $\square$ & $\square$ & $\square$ & $\square$ & $\square$ & $\square$ & $\square$ & $\square$ \\
\hline Theft of farm equipment, etc. & $\square$ & $\square$ & $\square$ & $\square$ & $\square$ & $\square$ & $\square$ & $\square$ & $\square$ \\
\hline
\end{tabular}

2.2. How do you estimate the impacts of these production risks for your farm business? Please mark on the 10 point scale (1: no impact to 10: existence endangerment)

\begin{tabular}{|l|l|l|l|l|l|l|l|l|l|l|}
\hline Risk Items & $\mathbf{1}$ & $\mathbf{2}$ & $\mathbf{3}$ & $\mathbf{4}$ & $\mathbf{5}$ & $\mathbf{6}$ & $\mathbf{7}$ & $\mathbf{8}$ & $\mathbf{9}$ & $\mathbf{1 0}$ \\
\hline Precipitation shortage & $\square$ & $\square$ & $\square$ & $\square$ & $\square$ & $\square$ & $\square$ & $\square$ & $\square$ & $\square$ \\
\hline Drying of rivers and underground water & $\square$ & $\square$ & $\square$ & $\square$ & $\square$ & $\square$ & $\square$ & $\square$ & $\square$ & $\square$ \\
\hline Other climate factors (frost, overheating, dust storm) & $\square$ & $\square$ & $\square$ & $\square$ & $\square$ & $\square$ & $\square$ & $\square$ & $\square$ & $\square$ \\
\hline Plant pests and diseases & $\square$ & $\square$ & $\square$ & $\square$ & $\square$ & $\square$ & $\square$ & $\square$ & $\square$ & $\square$ \\
\hline Land availability & $\square$ & $\square$ & $\square$ & $\square$ & $\square$ & $\square$ & $\square$ & $\square$ & $\square$ \\
\hline Land tenure fragmentation by inheritance & $\square$ & $\square$ & $\square$ & $\square$ & $\square$ & $\square$ & $\square$ & $\square$ & $\square$ \\
\hline Labour & $\square$ & $\square$ & $\square$ & $\square$ & $\square$ & $\square$ & $\square$ & $\square$ & $\square$ \\
\hline Machinery & $\square$ & $\square$ & $\square$ & $\square$ & $\square$ & $\square$ & $\square$ & $\square$ & $\square$ \\
\hline Cultivation preference & $\square$ & $\square$ & $\square$ & $\square$ & $\square$ & $\square$ & $\square$ & $\square$ & $\square$ \\
\hline Wheat-cotton/pistachio preference & $\square$ & $\square$ & $\square$ & $\square$ & $\square$ & $\square$ & $\square$ & $\square$ & $\square$ \\
\hline Theft of farm equipment, etc. & $\square$ & $\square$ & $\square$ & $\square$ & $\square$ & $\square$ & $\square$ & $\square$ & $\square$ \\
\hline
\end{tabular}


2.3. Concerning to the market risks, what do you think, how likely is the occurrence of each of the following risks?

Please mark on the 10 point scale (1: low probability to 10: high probability)

\begin{tabular}{|l|c|c|c|c|c|c|c|c|c|c|}
\hline Risk Items & $\mathbf{1}$ & $\mathbf{2}$ & $\mathbf{3}$ & $\mathbf{4}$ & $\mathbf{5}$ & $\mathbf{6}$ & $\mathbf{7}$ & $\mathbf{8}$ & $\mathbf{9}$ & $\mathbf{1 0}$ \\
\hline Fuel price & $\square$ & $\square$ & $\square$ & $\square$ & $\square$ & $\square$ & $\square$ & $\square$ & $\square$ & $\square$ \\
\hline Other operating input prices & $\square$ & $\square$ & $\square$ & $\square$ & $\square$ & $\square$ & $\square$ & $\square$ & $\square$ & $\square$ \\
\hline Land price & $\square$ & $\square$ & $\square$ & $\square$ & $\square$ & $\square$ & $\square$ & $\square$ & $\square$ & $\square$ \\
\hline Price decrease & $\square$ & $\square$ & $\square$ & $\square$ & $\square$ & $\square$ & $\square$ & $\square$ & $\square$ & $\square$ \\
\hline Price fluctuation (Pistachio) & $\square$ & $\square$ & $\square$ & $\square$ & $\square$ & $\square$ & $\square$ & $\square$ & $\square$ & $\square$ \\
\hline Shipping problems & $\square$ & $\square$ & $\square$ & $\square$ & $\square$ & $\square$ & $\square$ & $\square$ & $\square$ & $\square$ \\
\hline Quality requirements & $\square$ & $\square$ & $\square$ & $\square$ & $\square$ & $\square$ & $\square$ & $\square$ & $\square$ & $\square$ \\
\hline Brokers' dominance & $\square$ & $\square$ & $\square$ & $\square$ & $\square$ & $\square$ & $\square$ & $\square$ & $\square$ & $\square$ \\
\hline Competition from neighboring countries & $\square$ & $\square$ & $\square$ & $\square$ & $\square$ & $\square$ & $\square$ & $\square$ & $\square$ & $\square$ \\
\hline Market opportunities (pistachio) & $\square$ & $\square$ & $\square$ & $\square$ & $\square$ & $\square$ & $\square$ & $\square$ & $\square$ & $\square$ \\
\hline Farm business effectiveness & $\square$ & $\square$ & $\square$ & $\square$ & $\square$ & $\square$ & $\square$ & $\square$ & $\square$ & $\square$ \\
\hline Insolvency & $\square$ & $\square$ & $\square$ & $\square$ & $\square$ & $\square$ & $\square$ & $\square$ & $\square$ & $\square$ \\
\hline
\end{tabular}

2.4. How do you estimate the impacts of these market risks for your farm business? Please mark on the 10 point scale (1: no impact to 10: existence endangerment)

\begin{tabular}{|l|l|l|l|l|l|l|l|l|l|l|}
\hline Risk Items & $\mathbf{1}$ & $\mathbf{2}$ & $\mathbf{3}$ & $\mathbf{4}$ & $\mathbf{5}$ & $\mathbf{6}$ & $\mathbf{7}$ & $\mathbf{8}$ & $\mathbf{9}$ & $\mathbf{1 0}$ \\
\hline Fuel price & $\square$ & $\square$ & $\square$ & $\square$ & $\square$ & $\square$ & $\square$ & $\square$ & $\square$ & $\square$ \\
\hline Other operating input prices & $\square$ & $\square$ & $\square$ & $\square$ & $\square$ & $\square$ & $\square$ & $\square$ & $\square$ \\
\hline Land price & $\square$ & $\square$ & $\square$ & $\square$ & $\square$ & $\square$ & $\square$ & $\square$ & $\square$ \\
\hline Price decrease & $\square$ & $\square$ & $\square$ & $\square$ & $\square$ & $\square$ & $\square$ & $\square$ & $\square$ \\
\hline Price fluctuation (Pistachio) & $\square$ & $\square$ & $\square$ & $\square$ & $\square$ & $\square$ & $\square$ & $\square$ & $\square$ \\
\hline Shipping problems & $\square$ & $\square$ & $\square$ & $\square$ & $\square$ & $\square$ & $\square$ & $\square$ & $\square$ \\
\hline Quality requirements & $\square$ & $\square$ & $\square$ & $\square$ & $\square$ & $\square$ & $\square$ & $\square$ & $\square$ \\
\hline Brokers' dominance & $\square$ & $\square$ & $\square$ & $\square$ & $\square$ & $\square$ & $\square$ & $\square$ & $\square$ \\
\hline Competition from neighboring countries & $\square$ & $\square$ & $\square$ & $\square$ & $\square$ & $\square$ & $\square$ & $\square$ & $\square$ \\
\hline Market opportunities (pistachio) & $\square$ & $\square$ & $\square$ & $\square$ & $\square$ & $\square$ & $\square$ & $\square$ & $\square$ \\
\hline Farm business effectiveness & $\square$ & $\square$ & $\square$ & $\square$ & $\square$ & $\square$ & $\square$ & $\square$ & $\square$ \\
\hline Insolvency & $\square$ & $\square$ & $\square$ & $\square$ & $\square$ & $\square$ & $\square$ & $\square$ & $\square$ \\
\hline
\end{tabular}


2.5. Concerning the political risks, what do you think, how likely is the occurrence of each of the following risks?

Please mark on the 10 point scale (1: low probability to 10: high probability)

\begin{tabular}{|l|c|c|c|c|c|c|c|c|c|c|}
\hline Risk Items & $\mathbf{1}$ & $\mathbf{2}$ & $\mathbf{3}$ & $\mathbf{4}$ & $\mathbf{5}$ & $\mathbf{6}$ & $\mathbf{7}$ & $\mathbf{8}$ & $\mathbf{9}$ & $\mathbf{1 0}$ \\
\hline Irrigation modernization policy & $\square$ & $\square$ & $\square$ & $\square$ & $\square$ & $\square$ & $\square$ & $\square$ & $\square$ & $\square$ \\
\hline Governmental support elimination & $\square$ & $\square$ & $\square$ & $\square$ & $\square$ & $\square$ & $\square$ & $\square$ & $\square$ \\
\hline Special compensation program elimination (wheat-cotton) & $\square$ & $\square$ & $\square$ & $\square$ & $\square$ & $\square$ & $\square$ & $\square$ & $\square$ & $\square$ \\
\hline Land reform & $\square$ & $\square$ & $\square$ & $\square$ & $\square$ & $\square$ & $\square$ & $\square$ & $\square$ & $\square$ \\
\hline Uncoordinated agro-government corporations & $\square$ & $\square$ & $\square$ & $\square$ & $\square$ & $\square$ & $\square$ & $\square$ & $\square$ \\
\hline Property rights rules & $\square$ & $\square$ & $\square$ & $\square$ & $\square$ & $\square$ & $\square$ & $\square$ & $\square$ \\
\hline Farm inheritance rules & $\square$ & $\square$ & $\square$ & $\square$ & $\square$ & $\square$ & $\square$ & $\square$ & $\square$ \\
\hline Agro-infrastructure & $\square$ & $\square$ & $\square$ & $\square$ & $\square$ & $\square$ & $\square$ & $\square$ & $\square$ \\
\hline Agricultural extension & $\square$ & $\square$ & $\square$ & $\square$ & $\square$ & $\square$ & $\square$ & $\square$ & $\square$ \\
\hline License & $\square$ & $\square$ & $\square$ & $\square$ & $\square$ & $\square$ & $\square$ & $\square$ & $\square$ \\
\hline
\end{tabular}

2.6. The impacts caused by risks are also important. How do you estimate the impacts of these political risks for your farm business? Please mark on the 10 point scale (1: no impact to 10: existence endangerment)

\begin{tabular}{|l|c|c|c|c|c|c|c|c|c|c|}
\hline Risk Items & $\mathbf{1}$ & $\mathbf{2}$ & $\mathbf{3}$ & $\mathbf{4}$ & $\mathbf{5}$ & $\mathbf{6}$ & $\mathbf{7}$ & $\mathbf{8}$ & $\mathbf{9}$ & $\mathbf{1 0}$ \\
\hline Irrigation modernization policy & $\square$ & $\square$ & $\square$ & $\square$ & $\square$ & $\square$ & $\square$ & $\square$ & $\square$ & $\square$ \\
\hline Governmental support elimination & $\square$ & $\square$ & $\square$ & $\square$ & $\square$ & $\square$ & $\square$ & $\square$ & $\square$ & $\square$ \\
\hline Special compensation program elimination (wheat-cotton) & $\square$ & $\square$ & $\square$ & $\square$ & $\square$ & $\square$ & $\square$ & $\square$ & $\square$ & $\square$ \\
\hline Land reform & $\square$ & $\square$ & $\square$ & $\square$ & $\square$ & $\square$ & $\square$ & $\square$ & $\square$ & $\square$ \\
\hline Uncoordinated agro-government corporations & $\square$ & $\square$ & $\square$ & $\square$ & $\square$ & $\square$ & $\square$ & $\square$ & $\square$ \\
\hline Property rights rules & $\square$ & $\square$ & $\square$ & $\square$ & $\square$ & $\square$ & $\square$ & $\square$ & $\square$ \\
\hline Farm inheritance rules & $\square$ & $\square$ & $\square$ & $\square$ & $\square$ & $\square$ & $\square$ & $\square$ & $\square$ \\
\hline Agro-infrastructure & $\square$ & $\square$ & $\square$ & $\square$ & $\square$ & $\square$ & $\square$ & $\square$ & $\square$ \\
\hline Agricultural extension & $\square$ & $\square$ & $\square$ & $\square$ & $\square$ & $\square$ & $\square$ & $\square$ & $\square$ \\
\hline License & $\square$ & $\square$ & $\square$ & $\square$ & $\square$ & $\square$ & $\square$ & $\square$ & $\square$ \\
\hline
\end{tabular}




\section{Part 3: Perceptions of risk management strategies}

To avoid risk or to minimize their impacts, there are many possible strategies. Which of the following strategies will you pursue in the future? Please mark it.

\begin{tabular}{|c|c|c|c|c|c|}
\hline Risk management Items & $\begin{array}{l}\text { Strongly } \\
\text { disagree }\end{array}$ & Disagree & Unsure & Agree & $\begin{array}{c}\text { Strongly } \\
\text { agree }\end{array}$ \\
\hline Irrigation cooperation & $\square$ & $\square$ & $\square$ & $\square$ & $\square$ \\
\hline Shipment cooperation & $\square$ & $\square$ & $\square$ & $\square$ & $\square$ \\
\hline Cooperation of cottage food products & $\square$ & $\square$ & $\square$ & $\square$ & $\square$ \\
\hline $\begin{array}{l}\text { Farm activities diversification (apiculture, } \\
\text { poultry and animal husbandry) }\end{array}$ & $\square$ & $\square$ & $\square$ & $\square$ & $\square$ \\
\hline Farm crops diversification & $\square$ & $\square$ & $\square$ & $\square$ & $\square$ \\
\hline Cottage food products & $\square$ & $\square$ & $\square$ & $\square$ & $\square$ \\
\hline One crop: either cotton or wheat & $\square$ & $\square$ & $\square$ & $\square$ & $\square$ \\
\hline Other crops: neither cotton nor wheat & $\square$ & $\square$ & $\square$ & $\square$ & $\square$ \\
\hline $\begin{array}{l}\text { Gradual substitution of pistachio trees with } \\
\text { another crop }\end{array}$ & $\square$ & $\square$ & $\square$ & $\square$ & $\square$ \\
\hline Hired labour, in case of need & $\square$ & $\square$ & $\square$ & $\square$ & $\square$ \\
\hline Modern irrigation techniques & $\square$ & $\square$ & $\square$ & $\square$ & $\square$ \\
\hline Inquiry for futures and market options & $\square$ & $\square$ & $\square$ & $\square$ & $\square$ \\
\hline $\begin{array}{l}\text { Spread sales across traders and food } \\
\text { manufacturers }\end{array}$ & $\square$ & $\square$ & $\square$ & $\square$ & $\square$ \\
\hline $\begin{array}{l}\text { Forward contract with traders or food } \\
\text { manufacturers }\end{array}$ & $\square$ & $\square$ & $\square$ & $\square$ & $\square$ \\
\hline Farming as a secondary occupation & $\square$ & $\square$ & $\square$ & $\square$ & $\square$ \\
\hline Farming forsaking & $\square$ & $\square$ & $\square$ & $\square$ & $\square$ \\
\hline
\end{tabular}




\section{Part 4: Risk attitude}

To evaluate the risk attitude, self-assessment scale is introduced in the following table. Pleas mark your agreement with each statement in the scale.

\begin{tabular}{|l|c|c|c|c|c|}
\hline Self-assessment scale's statements & $\begin{array}{c}\text { Strongly } \\
\text { disagree }\end{array}$ & Disagree & Unsure & Agree & $\begin{array}{c}\text { Strongly } \\
\text { agree }\end{array}$ \\
\hline $\begin{array}{l}\text { I avoid decisions which bring forth either severe losses } \\
\text { or high profits }\end{array}$ & $\square$ & $\square$ & $\square$ & $\square$ & $\square$ \\
\hline $\begin{array}{l}\text { To implement my farm plan goals, I am willing to take } \\
\text { more risks than others }\end{array}$ & $\square$ & $\square$ & $\square$ & $\square$ & $\square$ \\
\hline $\begin{array}{l}\text { I am concerned with an existing profit more than } \\
\text { several predicted and non-guaranteed profit, (bird on } \\
\text { hand is bitter than ten on tree) }\end{array}$ & $\square$ & $\square$ & $\square$ & $\square$ & $\square$ \\
\hline $\begin{array}{l}\text { I am more willing to adopt agricultural innovations } \\
\text { (new ways of doing things) than others }\end{array}$ & $\square$ & $\square$ & $\square$ & $\square$ & $\square$ \\
\hline $\begin{array}{l}\text { I am reluctant to adopt agricultural innovations, until I } \\
\text { see their advantages and disadvantages from farmers } \\
\text { around me }\end{array}$ & $\square$ & $\square$ & $\square$ & $\square$ & $\square$ \\
\hline $\begin{array}{l}\text { I take my decisions without hesitation regardless their } \\
\text { probable risks }\end{array}$ & $\square$ & $\square$ & $\square$ & $\square$ & $\square$ \\
\hline $\begin{array}{l}\text { Before I take high risk probability decisions, I prefer to } \\
\text { discuss them with my family }\end{array}$ & $\square$ & $\square$ & $\square$ & $\square$ & $\square$ \\
\hline I am at the mercy of policy risk & $\square$ & $\square$ & $\square$ & $\square$ & $\square$ \\
\hline I am at the mercy of market risk & $\square$ & $\square$ & $\square$ & $\square$ & $\square$ \\
\hline I completely have production risk under control & $\square$ & $\square$ & $\square$ & $\square$ & $\square$ \\
\hline
\end{tabular}




\section{Part 5: Farmer characteristics}

5.1. Which activity do you perform on your farm? (Leadership)

$\square$ Manager

$\square$ Successor

$\square$ Partner

5.2. Which job training did you finish? (Highest certificate)
Illiterate
$\square$ Primary School
$\square$ Secondary School
$\square$ Higher education

5.3. Do you rely on scientific centers, books and/or journals to get the information which are needed in your farm business?
$\square$ No
$\square$ Yes

5.4. Do you have off-farm job, if yes, what is it?

$\square$ No

$\square$ Yes

5.5. Do members of your family participate in the farm operations? If yes, how often do they participate?
$\square$ No
$\square$ Yes:

\begin{tabular}{|c|c|c|c|c|}
\hline Very infrequently & Infrequently & Sometimes & Frequently & Very frequently \\
\hline$\square$ & $\square$ & $\square$ & $\square$ & $\square$ \\
\hline
\end{tabular}

5.6. What is your date of birth?

5.7. Here you can comment on other factors that you consider important in such topic

Time when ending the interview................ 